UC-NRLF

||| | ||||||||||||||||||||||||||||||||.|||||| В 3 892 796 


\section{AGRIC. LIBRARY}

LIBRARY

OF THE

UNIVERSITY OF CALIFORNIA.

$$
n \text { a cobb }
$$

Class 



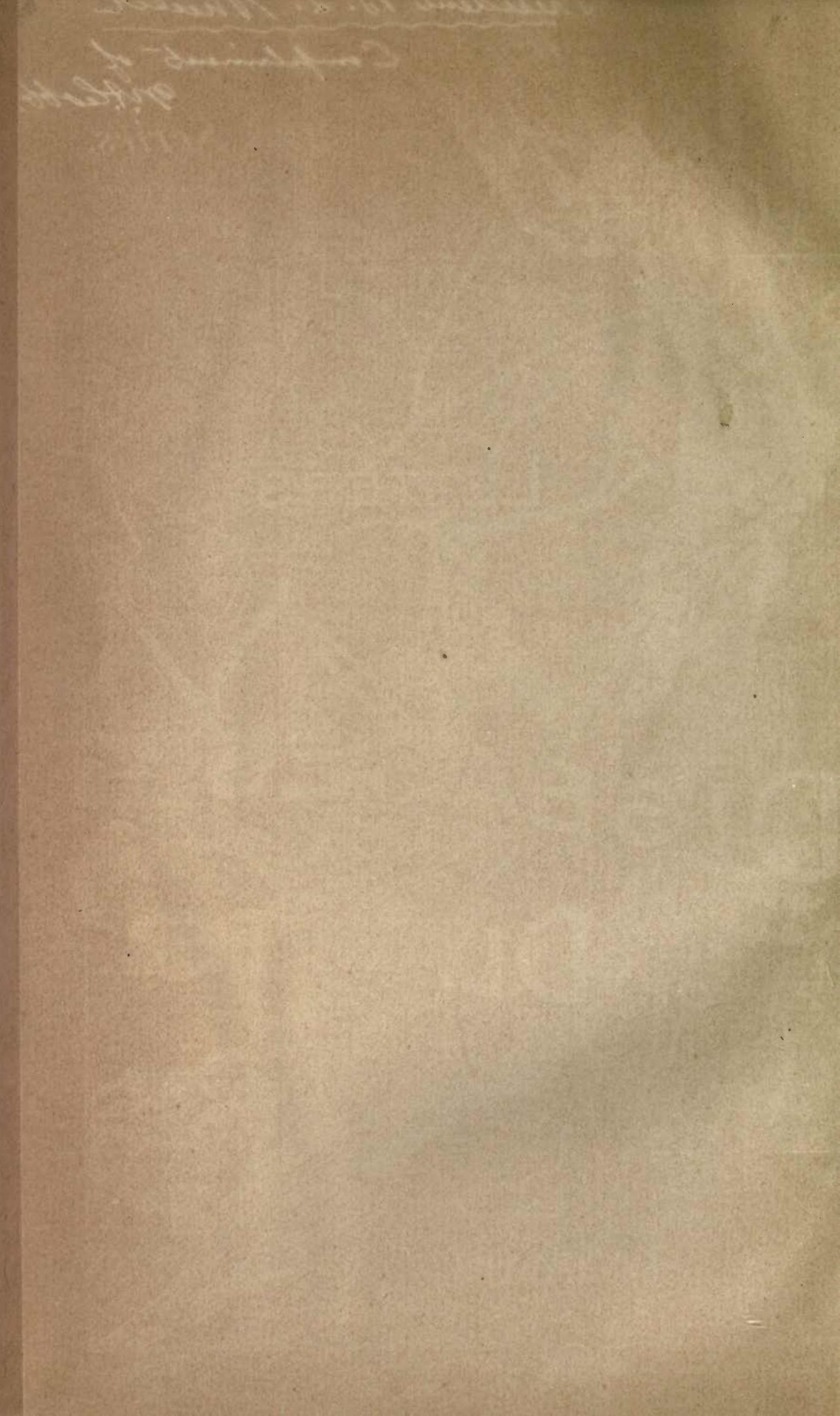


1. List of Plants found Growing Wild within 30 miles of Amherst.

51 pages-in Atlas of Hampshire County, Mass., 1887.

2. List of Plants.

Separate edition, S. E. Bridgeman \& Co., Northhampton, Mass., 1887.

3. Beitrage zur Anatomie und Ontogonie der Nematoden.

36 pages, with 32 original illustrations on 3 lithographic plates Jenaischen Zeitschrift fur Naturwissenschaft, XXIII Bd., N.F. XVI, 1888.

4 Inaugural-Dissertation zur Erlangen der Doktorw ürde.

Gustav Fischer, Jena, 1888. Same as the above.

5. The Differentiator.

Sydney, 1889. Reprint in American Naturalist, Philadelphia, 1889.

6. Report on Occupation of the Table of the British Association at the Naples Zoological Station.

Report of the British Association, London, 1889.

7. Neue parasitische Nematoden.

3 pages, with 9 original illustrations on one plate. Archiv für Naturgeschichte, Berlin, 1889.

8. Two new Instruments for Biologists.

11 pages, with 5 original figures on one lithographic plate. Proceedings of the Linnæan Society of New South Wales, Sydney, 1890.

9. Oxyuris larvae hatched in the human stomach under normal conditions.

18 pages, with 5 original figures on one lithographic plate. Proceedings of the Linnæan Society of New South Wales, Sydney, 1890.

10. A Nematode Formula.

5 pages, with description of Oncholaimus index. Agricultural Gazette, 1890.

11. Reprint of the above.

Department of Agriculture, Sydney, 1890.

12. Contributions to an Economic Knowledge of the Australian Rusts (Uredineæ).

In course of publication. So far issued, 154 pages, with 303 original illustrations in the text, and 1 plate. Agricultural Gazette, Sydney, 1890-94.

13. Arabian Nematodes.

20 pages. Proceedings of the Linnæan Society of New South Wales, Sydney, 1890.

14. Tylenchus and Root-gall.

30 pages, with 21 original illustrations in the text, and 1 plate with 9 illustrations after Neal. Agricultural Gazette, Sydney, 1890.

15. Anticoma : A genus of free-living nematodes.

10 pages, with 12 original illustrations in the text. Proceedings of the Linnæean Society of New South Wales, Sydney, 1890.

16 Notes on Diseases of Plants.

3 pages. Diseases of the vine, pear tree, strawberry plant, and hollyhock. Agricultural Gazette, Sydney, 1891.

17. Pathological Notes.

2 pages, with 4 original illustrations in the text. Disease of lueerne. Agricultural Gazette, Sydney, 1891.

18. Rust in Wheat: Report to Sydney Conference on. 7 pages. In "Rust in Wheat" (Report of Conference on), Legislative Assembly, New South Wales, 2nd Session, 1891.

19. Dialogue concerning the manner in which a poisonous spray does its work in preventing or checking blight.

8 pages, with 8 original illustrations in the text. Agricultural Gazette, Sydney, 1891.

20. Reprint of the same.

Department of Agriculture, Sydney, 1891.

21. Notes on the Diseases of Plants.

Diseases of apple, strawberry, and wheat. Agricultural Gazette, Sydney, 1891.

22. Onyx and Dipeltis: New nematode genera, with a note on Dorylaimus.

16 pages, with 17 original illustrations in the text. Proceedings of the Linnæan Society of New South Wales, Sydney, 1891.

23. Maize for the table

11 pages. Agricultural Gazette, Sydney, 1891.
24. Notes on the Diseases of Plants.

Diseases of the apple and vine. Agricultural Gazette, Sydney, 1891.

25. Smut.

6 pages, with 9 original illustrations in the text. Agricultural Gazette, Sydney, 1891.

26. Smuts.

Separate and enlarged with more illustrations. Department Agriculture, Sydney, 1891.

27. Hair-worm.

2 pages. Agricultural Gazette, 1891.

28. Notes on Diseases of Plants.

Diseases of horse-radish and apples. Agricultural Gazette, Sydney, 1891.

29. Insect-larva eating Rust on Wheat and Flax.

4 pages, with 4 original illustrations in the text. Conjoint paper. Agricultural Gazette, Sydney, 1891.

30. The same.

Reprint in The Annals and Magazine of Natural History, London, 1891.

31. Pathological Notes.

Diseases of maize and the apple. Agricultural Gazette, Sydney, 1891.

32. Notes on the Diseases of Plants.

Diseases of the apple, pear, peach, and flax. Agricultural Gazette, Sydney, 1891.

33. Strawberry Bunch.

11 pages, with 4 original illustrations in the text and 1 plate with 9 illustrations, after Rizema Bos. A disease of the strawberry plant. Agricultural Gazette, Sydney, 1891.

34. Reprint of the same.

Department of Agriculture, Sydney, 1891.

35. Parasites in the stomach of a cow.

2 pages, with 2 original illustrations in the text. Agricultural Gazette, Sydney, 1891.

36. Notes on the Diseases of Plants.

9 pages, with 8 illnstrations (mostly original) in the text, and one plate with 2 illustrations. Diseaser of the potato, onion, tobacco. Agricultural Gazette, Sydney, 1891.

37. Reprint of the above.

Department of Agriculture, Sydney, 1891.

38. Devastating Eel-worm.

5 pages, with 7 original illustrations in the text. Agricultural Gazette, Sydney, 1891.

39. Devastating Eel-worm.

The above with 2 additional illustrations. Department of Agriculture, Sydney, 1891.

40. Plant Diseases, and How to Prevent them.

28 pages, with 30 original figures in the text, and 7 figures on 4 plates. Diseases of the apple, pear, apricot, grape, rose, strawberry, pumpkin, cabbage, and turnip. Agricultural Gazette, Sydney, 1892.

41. Miscellaneous Publication, No. 12 ,

Department of Agriculture, Sydney, 1893, is a reprint of the above.

42. Notes on the Diseases of Plants.

2 pages. Disease of the orange. Agricultural Gazette, sydney, 1892.

43. Plant Diseases, and How to Prevent them.

14 pages, with 25 original illustrations in the text, and 2 original illustrations on one plate. The diseases "Take-all," and "Dry Blight." Agricultural Gazette, Sydney, 1892.

44. Reprint of the same.

Department of Agriculture, Sydney, 1893.

45. Cold storage of Apples, from the Vegetable Pathologist's point of view.

5 pages. Agricultural Gazette, Sydney, 1892.

46. Reprint of the above.

Department of Agriculture, Sydney, 1892.

47. Rust in Wheat: Report to Adelaide Conference on.

7 pages, with 21 original illustrations in the text. C. E. Bristow, Adelaide, 1892.

48. Plant Diseases, and How to Prevent them

4 pages, and 5 illustrations, mostly original, in the text. Diseases of the vine-root, bean, and appletree. Agricultural Gazette, Sydney, 1892.

49. Reprint of the above.

Department of Agriculture, Sydney, 1892. 


\section{DEPARTMENT OF AGRICULTURE, SYDNEY, NEW SUUTH WALES.}

Miscellaneous Publication, No. 666.

\section{LETTERS}

UN THE

\section{DISEASES OF PLANTS:}

BY

N. A. ÇOBB.

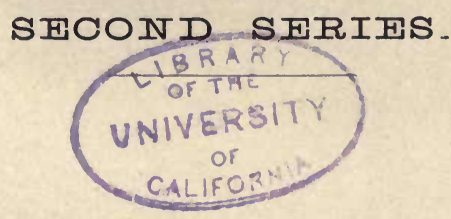

Published by Authority of

THE GOVERNMENT OF THE STATE OF NEW SOUTH WALES.

SYDNEY : WILLIAM APPLEGATE GULLICK, GOVERNMENT PRINTER 


$$
\begin{aligned}
& s^{\beta} c^{313)} \\
& a^{2} e^{a^{a}}
\end{aligned}
$$




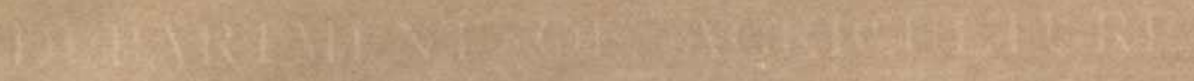
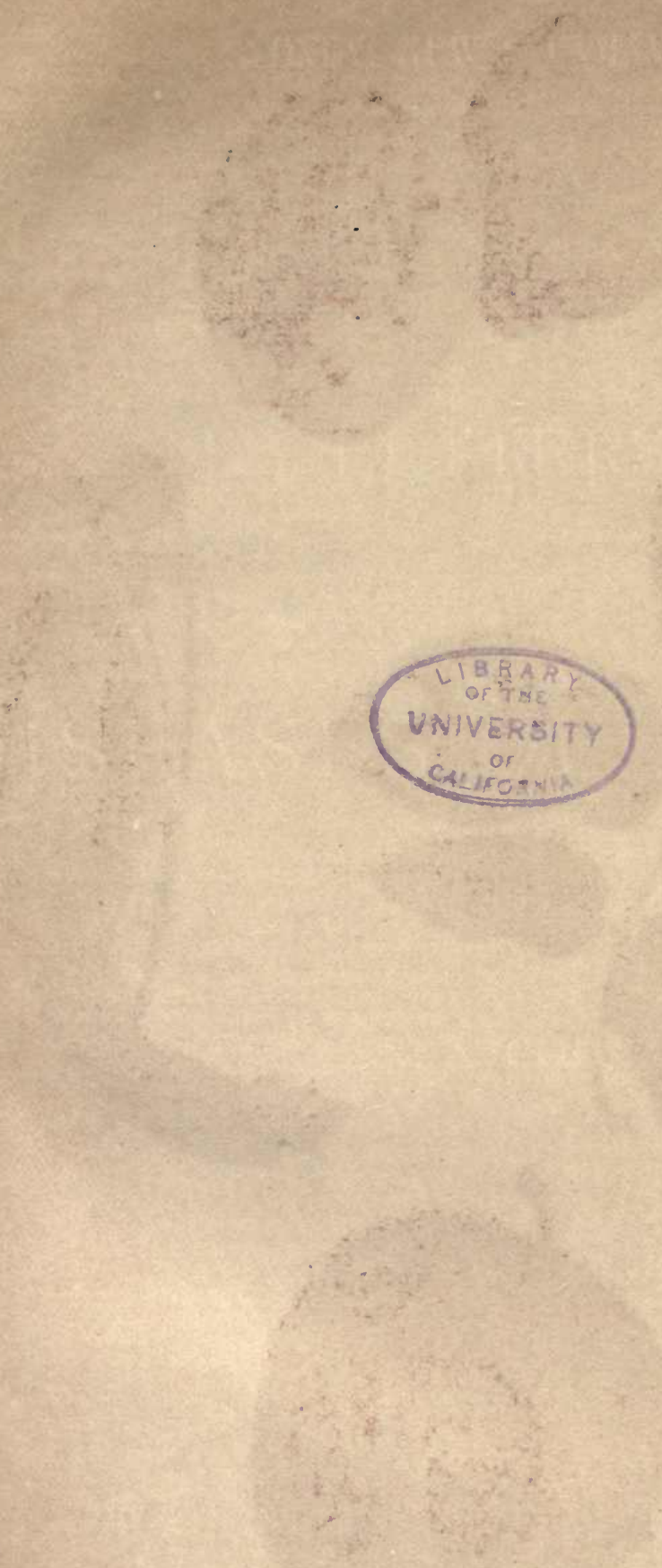


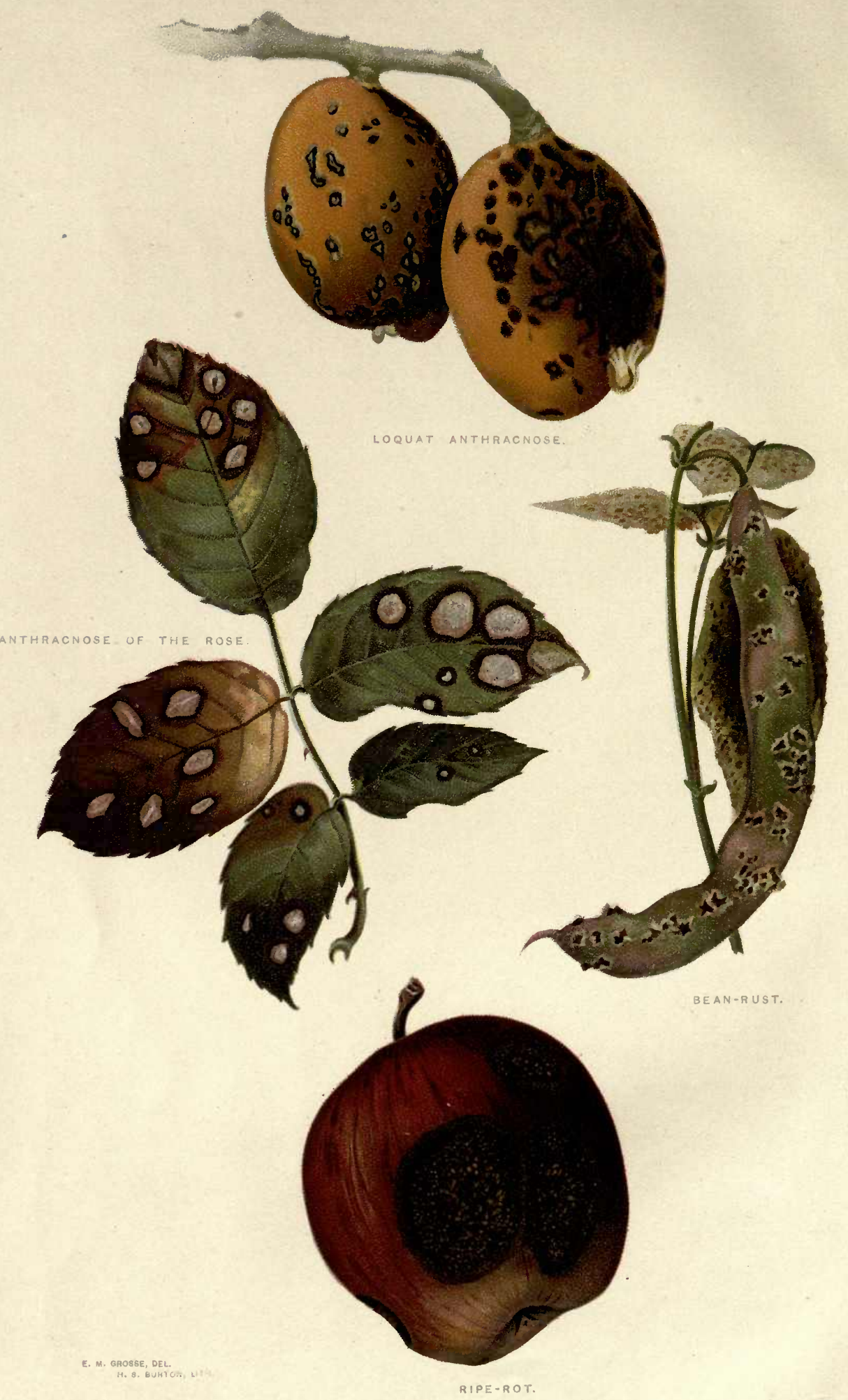




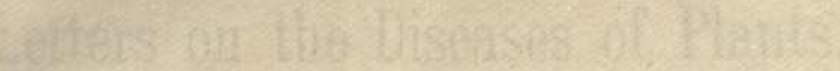

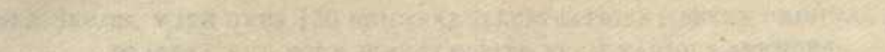

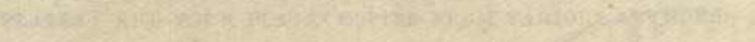

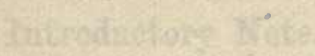

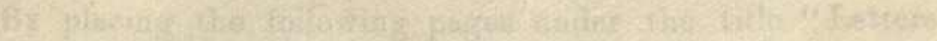

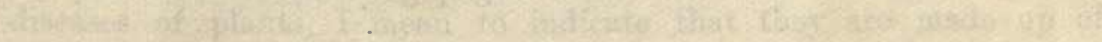

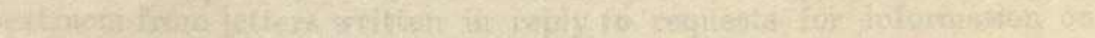

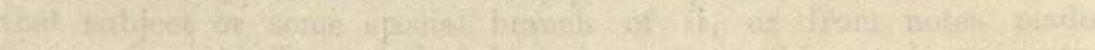

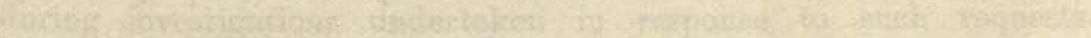

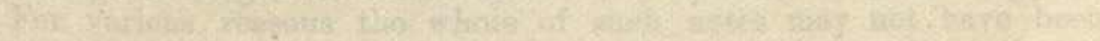

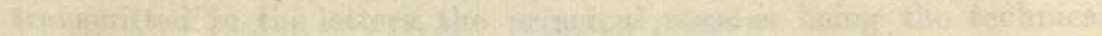
40.7. Was?

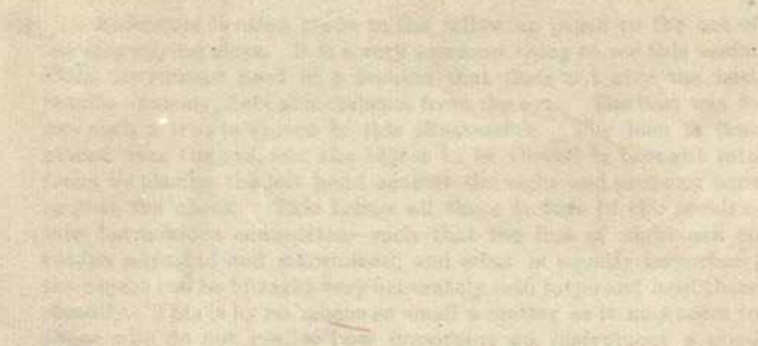

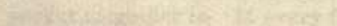

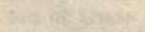

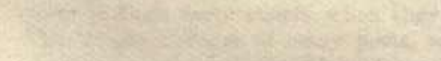

arias

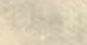

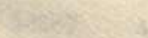

127564 



\section{Letters on the Diseases of Plants.}

SECOND SERIES, WITH OVER 150 ORIGINAL ILLUSTRATIONS ; SEVEN ORIGINAL COLOURKD PLATES ; AND FOUR PLATES COPIED FROM VARIOUS AUTHYRS.

\section{N. A. COBB. Introductory Note.}

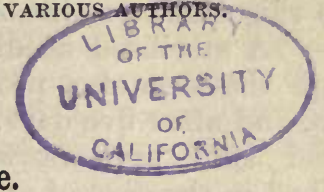

By placing the following pages under the title "Letters" on the diseases of plants, I mean to indicate that they are made up of extracts from letters written in reply to requests for information on that subject or some special branch of it, or from notes made during investigations undertaken in response to such requests. For various reasons the whole of such notes may not have been transmitted in the letters, the principal reasons being the technical nature of the information and the fact that it could not be well conveyed without the aid of drawings, and these could not be prepared in

Fig. 1.-Reference is often made in the following pages to the use of the magnifying glass. It is a very common thing to see this useful little instrument used in a fashion that does not give the best results-namely, held at a distance from the eye. The best way to use such a lens is shown in this illustration. The lens is first placed near the eye, and the object to be viewed is brought into focus by placing the left hand against the right and pressing both against the cheek. This brings all three factors in the problem into harmonious connection-such that the line of sight can be readily adjusted and maintained, and what is equally important, the object can be brought very accurately into focus and held there steadily. This is by no means so small a matter as it may seem to those who do not realise how important an instrument a good pocket magnifier is. If every farmer carried, and frequently used, one of these instruments, it would result in the discovery of many pests in their early stages, when they might be easily put down. The incipient stages of many pests, while quite invisible to the unaided eye, are easily visible under a good magnifying glass. The importance of discovering these pests at the earliest moment does

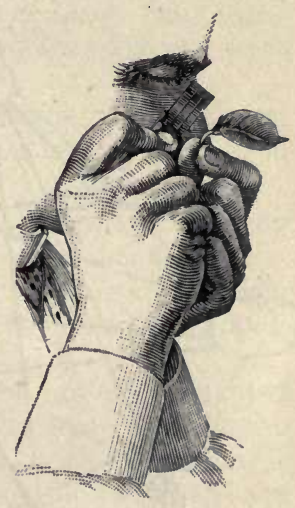
not need to be argued.

time to accompany letters calling for a prompt reply on account of. the money loss that might be involved in delay. Often the wording is taken verbatim from the correspondence, but more often it has been changed and incorporated with that of other letters on the same malady, and the two have been used to amplify and explain the subsequent notes and drawings. The drawings have been prepared with unusual care under my personal supervision, each drawing having passed through several critical revisions before appearing in its present form; they may therefore be relied upon as picturing with great fidelity the objects from which they were made.

It is a pleasure to note the highly intelligent care bestowed on our illustrations by Messrs. E. M. Grosse, H. S. Burton, and W. E. Chambers. The public probably do not realise how often one of their most insignificant looking drawings is the result of long and patient study. 


\section{RIPE Rot.}

[See Coloured Plate, Frontispiece.]

IN December, 1891, and January, 1892, I conducted a number of experiments with the common ripe rot of the apple, then generally known among mycologists as Gloeosporium fructigenum*. In commenting on this disease in the April number of this Gazette for that year, I said :- "A sterilised needle bearing a few bitter-rot spores is thrust through the skin of a peach, plum, nectarine, pear, cherry, grape, or mango, and after five days, from the invisible puncture thus made, a diseased spot appears which passes through all the stages just described in the case of apple. I have observed the disease occurring naturally on the peach, grape, pear, and mango."

In the same year Dr. Halsted, of New Jersey, U.S.A., carried out a similar set of experiments with the same general results. Dr. Halsted made a larger number of cross inoculations than $I$, and his results were even more suggestive than mine. I give some of his results in his own words:-

"The work, so far as it has gone, and it is far from being completed, may be represented graphically by a diagram (Fig. 2), in which the several fruits.

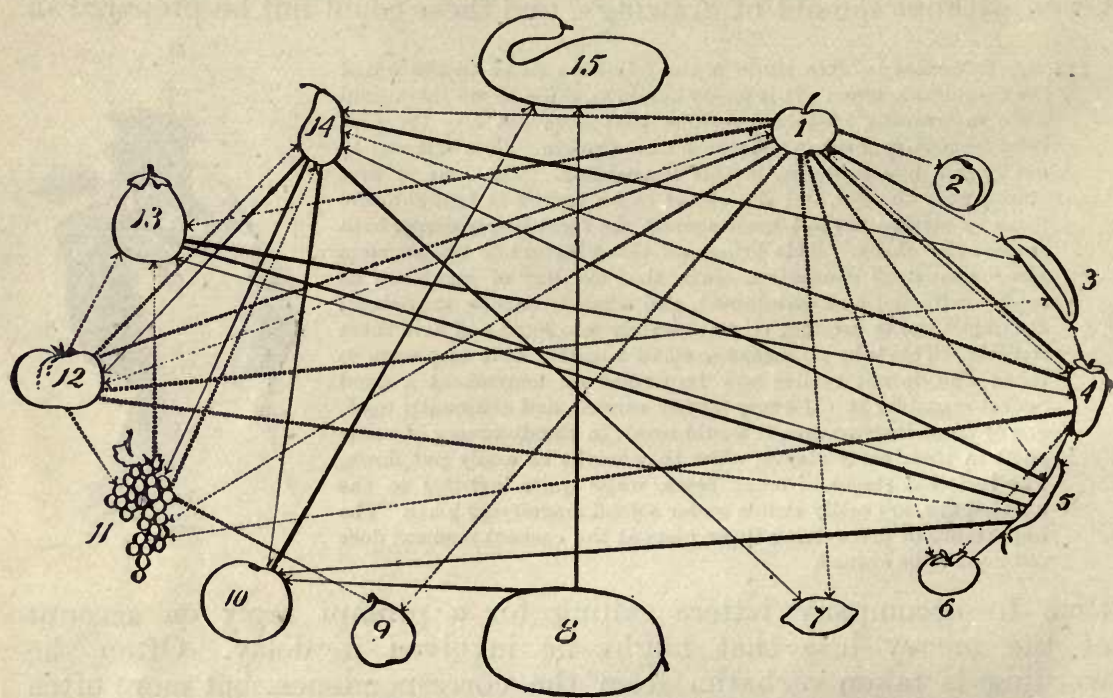

Fig. 2.-Diagram showing inoculations.

1, Apple : 2, Peach; 3, Banana ; 4, Pepper; 5, Bean; 6, Persimmon; 7, Lemon; 8, Watermelon : 9 Quince; 10, Citron; 11, Grapes; 12, Tomato; 13, Egg-plant; 14, Pear; 15, Squash.

treated are arranged in an uval, and the successful inoculations are shown by lines drawn from the fruit yielding the rot naturally to the ones which are susceptible under the conditions of inoculation.

"There are two sorts of lines,-the dotted ones, representing the Gloensporiums, or light-coloured fungi, and the solid ones, the Colletotrichums, which are usually dark, as above stated, because of the stiff, black bristles. The arrow shows the direction in which the inoculation has gone.

* Now more correctly called (Glomerella rufomaculans (Berk.), Spaulding and Von Schreuk. 
' It is quite natural to start with the apple in the consideration, and with the light-coloured anthracnose, known as the Ripe Rot (Gloeosporium fructigenum, Berk.). Up to this time the only other fruit upon which this fungus was known to grow is the grape, the Division of Pathology of the Department of Agriculture having recently established this fact. It was an easy matter to verify this work, but of more interest to find that when the virus was transferred to the flesh of the peach it quickly developed in a vigorous way, and produced a similar patch/of decay not identical in appearance because of a difference in texture of the host, but the spore masses and spores were the same.

"In like manner it was taken to the pear and the quince, so that the same ripe rot fungus produces its destructive work upon the three sorts of fruit of the apple class.

"Turning now to the tomato group, the chart shows that the dotted lines run to each of these-namely, the pepper, egg-plant, and the tomato. Noting the arrows in this connection, it will be seen that the native Gloeosporium of the pepper and of the tomato, supposed to be different species and distinct from the one upon the apple, were cultivated upon the latter fruit, where each produced the ripe rot of the apple. Following the oval around to the right, beginning with the apple, it will be seen that, besides those fruits already mentioned, the arrows point to the banana, bean, and lemon, all fruits representing widely different groups of plants.

" No attempts were made to cultivate any of the peach fungi upon the other fruits. The banana has received three besides the one from the apple, two of which are pink-namely, from pepper and tomato; and a black one, represented by the solid line, from the pear. Much work is now under way with the banana.

"The pepper has given its pink anthracnose to six-namely, the banana, pear, persimmon, apple, grape, and bean. The dark species has been received from the egg-plant and the bean.

"In connection with the bean, the dark lines are most abundant, showing that here the genus Colletotrichum is quite at home. It sends this to pepper, pear, egg-plant, citron, and persimmon, and receives the same from the egg, plant only-in this case an even exchange. The pink comes from pepper, apple, and tomato.

"The persimmon has only been used as a recipient, and not experimented with largely. The apple and pepper Gloeosporium thrives upon it, and the bean Colletotrichum. Only a little work has been finished with the lemon, it having received thus far from only apple and the pear, but the two fungi are not in the same genus.

"The watermelon has not been inoculated with anything, but its* anthracnose has been carried to the squash and the citron.

"Upon the quince the apple and grape Gloeosporium has been grown-in other words, the ripe-rot is doubly proved to thrive upon the quince. The citron has only dark lines coming from the bean, melon, and pear, and sends out its own to the squash.

"From the grape has given out light lines to quince and egg-plant, and similar lines run to it from apple, pepper, and tomato. One solid line runs to it-namely, from the pear.

"The tomato exchanges the pink-rot with the apple, sends it also to banana, bean, grape, egg-plant, and pear. It receives the dark lines from the pear.

"From the egg-plant goes out dark rot to pepper, and an exchange is made to the bean. It also receives the pink rot from apple, grape, and tomato.

* See Plate opposite p. 26. 
The pear sends its Colletotrichum to banana, lemon, citron, grape, and pepper, and receives the same group from the bean. The pink rot comes from the apple, pepper, and tomato. No attempt has been made to send anything out from the squash, and it has received the dark decay from the melon and citron. It is, perhaps, too early in the work to draw conclusions, and the facts in themselves may warrant their being stated without further remark."

\begin{tabular}{|c|c|c|c|}
\hline & 1. Pear & & \\
\hline & 2. Egg-plant & Ripe rot or & 2. Grape \\
\hline & 3. Toinato & Gloeosporium & 3. Citron \\
\hline Ripe rot or & 4. Pepper & of Pear & 4. Lemon \\
\hline Gloeosporium & 5. Grape & will grow on - & 5. Bean \\
\hline of Apple & 6. Quince & & (6. Banana. \\
\hline grow on- & 8. Persimmon & Ripe rot or & (1. Egg-plan \\
\hline & $\begin{array}{l}\text { 9. Bean } \\
\text { 10. Banana }\end{array}$ & $\begin{array}{l}\text { Gloeosporium } \\
\text { of Grape }\end{array}$ & 2. Pear \\
\hline & 11. Peach. & will grow on- & (3. Quince. \\
\hline & 1. Egg-plant & & 1. Apple \\
\hline & 2. Pear & Ripe rot or & 2. Pear \\
\hline & 3. Apple & Gloeosporium & 3. Bean \\
\hline of & 4. Quince & of Pepper & 4. Grape \\
\hline will grow on- & 5. Banana & will grow on- & 5. Banana \\
\hline & $\begin{array}{l}\text { Bean } \\
\text { Grape. }\end{array}$ & & \\
\hline
\end{tabular}

On glancing at the above table one is immediately struck with the great variety of orders represented by the possible hosts of any given form of Gloeosporium. In a similar manner the forms of Colletotrichum, a so-called genus related to Gloeosporium, were found to be more or less indifferent to the botanical order of their host plant.

Colletotrichum of Egg-plant $\left\{\begin{array}{l}\text { Pepper } \\ \text { Bean. }\end{array}\right.$

Colletotrichum of Citron Squash.

Colletotrichum of Melon* Squash.

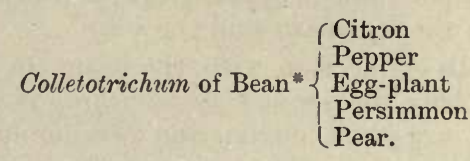

The following table may stand as a striking example of the great variety of fruits that a single species of this genus may infest. It is a compilation from various authoritative sources, those marked with an asterisk having been proved or verified by the author :-

LIST of fruits on which it has been experimentally proved that the ripe-rot fungus of the apple will thrive :-

\begin{tabular}{|c|c|c|}
\hline \multirow{8}{*}{$\begin{array}{l}\text { Gloeosporium of } \\
\text { the apple will } \\
\text { thrive on- }\end{array}$} & & \\
\hline & 1. "Quince & 10. Tomato \\
\hline & 3. * Peach & 12. Pepper \\
\hline & 4. *Plum & 13. Persimmon \\
\hline & 5. "Nectarine & 14. Bean \\
\hline & 7. "Grape & $\begin{array}{l}\text { 15. "Banana. } \\
\text { 16. "Hawthorne }\end{array}$ \\
\hline & 8. *Mango & 17. "Guava \\
\hline & (9. Lemon & \\
\hline
\end{tabular}

From time to time for a number of years past I have continued to experimentally test the powers of the ripe-rot fungi of a number of fruits to produce rot in other kinds of fruit and other kinds of vegetation. Before proceeding to examine some extracts from notes on these experiments, it may be well to pause a moment to consider certain general observations. 
Concentric Arrangement of the Pustules. (See Fig. 3.)

I am not aware that the concentric arrangement of the pustules of the Gloeosporium has received an explanation. I formerly ventured to propound the query whether this arrangement was not the result of diurnal variations in the growth. Observation in connection with the following series of inoculations has convinced me that there is nothing in that idea. I am more inclined to think that the concentric arrangement is due to successive waves of growth. In the formation of this theory the chief idea is that when a series of pustules has become ripe, i.e., arrived at the sporeproducing stage, perhaps some of the spores germinate, or some of the peripheral mycelia rejuvenate, and having perforce to grow outwards in search of food, create as it were a new spore bed, which in turn gives rise to a new set of pustules, and so on indefinitely. Under this theory each ring of pustules represents a new "generation" of spores, or a

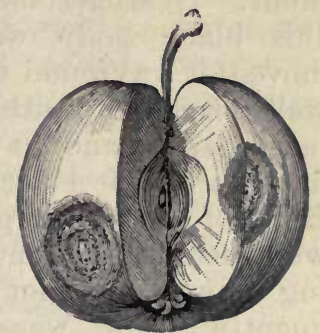

Fig. 3.-Apple attacked by ripe rot. A section has been removed so as to show how the rot penetrates. The concentric arrangement of the pustules is shown.

fresh wave of growth, and there will be as many rings of pustules as there are "generations" or waves. This theory seems to accord closely with the known facts.

Whenever in the course of these observations terms such as Guava Gloeosporium and Banana Gloeosporium are used, nothing more is meant than that the form mentioned was found growing naturally on the guava or on the banana as the case might be. It should not be inferred that the terms mean more than this unless there is a definite statement to that effect. Thus when the term Banana Gloeosporium is used it must not be thought this term is synonymous with Gloeosporium musarum. It may be or it may not. Some basic principle had to be adopted, and it seemed best to use the occurrence in nature as the foundation of the system of reference. At an early stage of the inoculations it seemed certain that the hitherto accepted nomenclature was inadequate, and I was forced to fall back upon the above plan as the next best thing.

It was most interesting to watch the progress of the diseased spot that arose from an inoculation. According to the fruit experi-

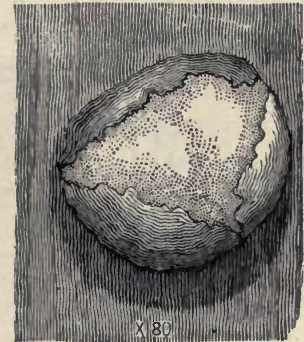

Fig. 4.-Ripe-rot pustule from an Apple, magnified. mented with, according even to the variety used, so would there arise certain peculiarities in the growth of the fungus. The growth on the pear was somewhat different from that on the apple, and on the latter again differed from that on the quince. The different varieties of apple presented their peculiarities in the inception and progress of the disease; nay, even the stage of ripeness at the time of inoculation exerted a marked influence. 
Sometimes, and this seemed especially true when the fruit experimented upon was a little unripe, the initial stages would be tardy, and for some time the diseased area would increase but slowly in size, assuming a darkish colour. On such occasions the pustules would be slow in appearing, and would be few and scattered, the first appearance of each being marked by a minute jet-black shiny point. If, after some days, this black body was removed, it was found to be a well-formed perithecium, lens-shaped, and having a dark wall. These particular fruits of the fungus growth were usually slow in ripening spores, and not infrequently they were outstripped by the sporeproducing portions more

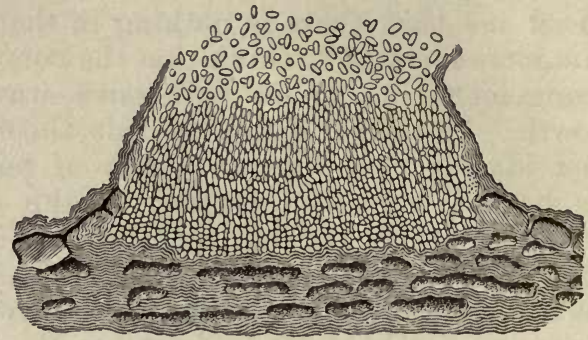

Fig. 5.-Section of a ripe-rot pustule of Apple. remote from the point of inoculation. Thus after a time the progress of the disease seemed to become swifter, the invaded tissue appearing to become more watery and the pustules larger and very much nearer

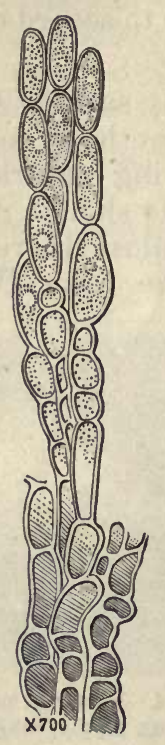

Fig. 6. - Ripe-rot spores on hyphae. together and lighter in colour. The black pustules were ofttimes wholly absent from these later stages.

As it has been the custom in the past to regard as separate forms worthy of distinct names-socalled specific names-Gloeosporia that varied from each other in certain features of form, size, and colour, it is well worth while, now that we $e^{\circ}$ know what a wide range of substratum is suitable for the growth of these fungi, to inquire to what extent the same form may vary when grown on a variety of hosts.

T'he discussion may best turn largely on the spores, because it is largely upon these that naturalists in the past have relied for data in the establishment of their species of Gloeosporium.

As to form, it has become very evident in the course of these experiments that it is quite variable, and that the variations are due to a considerable extent to the resistance the fungus meets in breaking through the epidermis of the host. In all cases where the skin of the host plant offered decided resistance to rupture, as evidenced, for instance, by tardiness in the appearance of loose spores, there was a marked irregularity of form. The spores would be bent instead of straight, clavate instead of uniform in diameter from end to end, or perhaps somewhat dumb-bell-shaped instead of cylindroid. In addition to this, the various spores would vary from each other in 
size more than was the case where they found an easy exit. In some instances I observed that pustules which at first showed these traits of irregularity would, after the rupture of the epidermis, assume greater regularity as a result of this release of pressure.

The colour and internal structure of the spores were less variable than the form, but even these were subject to decided variations. Thus in the case of the Gloeosporium of the guava, a form with large and loose internal granulation, it was evident that when grown on the pomaceous fruits its granulation became finer, and in the same connection the vacuole became more definite in form. The variations in colour, however, seemed comparatively slight.

I must add that it is not entirely to mechanical causes that I attribute the resistance of the skin in certain cases to the action of the fungus. I feel it all the more necessary to mention this because my conclusions in another somewhat similar case appear to me to have been misunderstood. It may be true, and I think probably is true, that fungi at the time of their outbreak exert a chemical effect upon the epidermal tissues

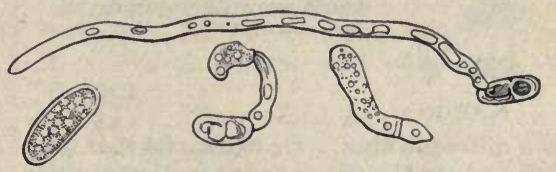

Fig. 7.-Ripe-rot spores germinating. of the host,- perhaps a solvent effect. But whatever means may be utilised by the fungus to effect its release, it seems to me the effect on the parasite of an enforced delay in the outbreak will be much the same. It will go on increasing in size, and this growth will result in the pressure which has been mentioned above.

It would not be unreasonable to suppose that there would be connected with a mechanical toughness of the cuticle an internal resistance to the attacks of the fungus due to a correlated toughness of parenchymatous tissues. There is evidence of such correlation in a number of fruits.

\section{Description of Various Inoculation Experiments.}

I have now to add to the cross inoculations already mentioned the following more recently made by me in connection with the occurrence of the ripe-rot on the passion-fruit and other fruits.

1. Passion-frutt inoculated from the Gloeosporium of the Banana.-The inoculation point became the centre of a discoloured area, which in the course of three weeks became nearly an inch in diameter. No pustules appeared. It remained undetermined whether the exciting cause was Gloeosporium or not; but I am inclined to think it was the Gloeosporium. There is a Glseosporium occurring in nature on the passion-fruit, the fnrm of whose spores it is impossible to distinguish from those of the species known as Gloeosporium fructigenum, although I failed on taking these spores and testing them by inocula. tion to prove that they would infect other fruit. Only one series of trials was made.
2. Passion-fruit inoculated from Guava Gloeosporium.-After eighteen days there was no tangible result.

3. LEMON inoculated frorn Gloeosporium of the Banana.-In a week there was definite proof of disease in the shape of a discoloured area concentric with the inoculation spot. This area continued to increase slowly in size for six weeks, the lemon meanwhile becoming dry and hard. It seemed as if the skin of the lemon became too tough to allow of the fungus forming pustules. It remained undetermined whether the fungus resulting from inoculation was really a Gloeosporium, but I am inclined to think it was, and that in all probaibility 
it would have fruited if the skin had not dried up.

Dr. Halsted reports having been successful in inoculating the lemon with $G$. fructigenum.

4. BaNana inoculated from Gloeosporium of the Banana.-The Gloeosporium began to fructify on the seventh day, before any of the other fruits that were inoculated at the same time with the same material had begun to show signs of growth. This may tend to show that a Gloeosporium which has been produced on a given fruit acts more promptly on that fruit than on others

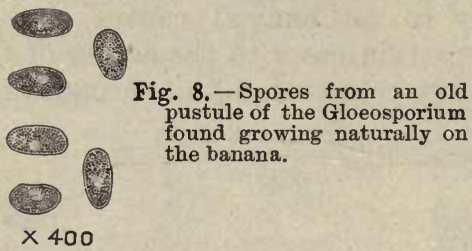

of a different kind. Or it may be that the difference in the time of germination in this case was due to the fact that the fungus having just completed a cycle in the banana found itself again on ground of precisely the same stage of ripeness. In other

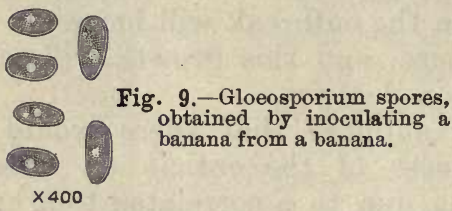

words, the slower growth on the other fruits soon to be mentioned may have been an effect not of the change in the host, but in the condition of the host.

On the twelfth day the banana was thoroughly infested. (Figs. 8 and 9.)

5. Banana inoculated with the Gloeosporium of the Banana after the fungus had been passed through the Quince. Several bananas were inoculated. All promptly showed signs of having taken, and all became infested.

6. GRAPE inoculated from Gloeosporium of the Banana.-At the end of thirteen days the grape showed traces of one or

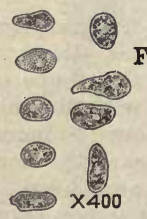

Fig. 10.-Spores of the Gloeosporium, obtained by inociating a grape with spore of the Gloeosporium found growing naturally on the banana.

two dark unruptured pustules of considerable size. The result on the grape, which was of the large white firm-fleshed long-keeping type, was in striking contrast with the considerable number of other inoculations made from the same source. The pustules were few and dark, and the growth was slow. There was a concentric and dark appearance reminiscent. of the Black Spot or Anthracnose of the Grape.

On the fourteenth day pustules were removed from under the skin of the grape and examined. The mycelium resembled that of a Gloeosporium, and spores measuring 5-7 $\times 7-14 \mu$ were found, coloured as in the banana. Thus it was shown that these spores were smaller and rounder than on the banana, though some of them reached the size $6 \times 14 \mu$. (See Fig 10.) The colour and structure were identical with those of the original spores. I never saw any of the pustules on the grape burst open promptly and emit spores freely as. was usually the case on other fruits. It was always necessary at this stage, in order to secure spores for examination, in the case at any rate of this particular variety of grape, to dig beneath the skin and remove the lenticular-shaped spore beds.

On the twenty-third day the pustules burst, and it was interesting to note that the spores were of a little brighter green colour than other spores resulting on other fruits in the same series of inoculations, and that they had, perhaps, a little coarser granulation. There were also some irregularities in the form, some spores being more pointed at one end than the other.

7. PEar inoculated from Gloeosporium of the Banana.-At the end of the twelfth day the pear gave slight evidence of infestation.

At the end of sixteen days great numbers of pustules were to be seen on the pear, but none of them had broken through the epidermis. Most of them were darkcoloured, a feature of these pustules in certain states and varieties of the pear.

On the twenty-first day it was found that the dark-coloured pustules which were still under theskin of the pear boreellipsoidal, but not yet mature, spores. The dark colour of the pustules was due for the most part to the colour of the fungus elements themselves, and not to the pigment of the skin of the pear. No doubt there was a discolouration of the skin of the pear through the action of the fungus, but this was not the main element in the dark colour of the pustules.

There is a most decided difference in the appearance of the fructification of Glocosporium in pears of different varieties. According as the pear has been evolved for earliness or lateness, for immediate consumption or for long keeping, for sweetness or for acidity, for mildness or for astringency, there have been produced in the fruit properties having, it appears, a decided influence on the history of its Gloeosporium parasite. 
8. Passion-froit inoculated from the Banana Gloeosporium.-The inoculation took, but after a month no pustules had formed. Concentric with the inoculation point was an area about an inch in diameter, which had taken on a reddish-purple colour. This was the evidence upon which the Gloeosporium was believed to have taken. It is known that a species of Gloeosporium occurs in nature on the passion-fruit, so similar in its spore characteristics to the Gloeosporium of the pomaceous fruits that it is difficult to point ont any difference. I have myself seen and carefully examined this Gloeosporium of the passion-fruit.

9. Date-plum inoculated from Banana (see Figs. 11 and 12).-After twelve days the date-plum showed slight evidences of being diseased at the point of inoculation. On the next day pustules were

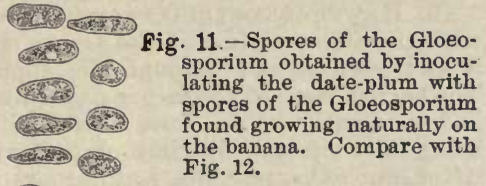

अक्षात $\times 400$

noted under the skin of the date-plum. They appeared to be finer and closer together than on the other fruits inoculated from the same source. It seemed as if the fructification met some resistance from the skin of the date-plum, which is known to be long resistant to decay. Probably the skin of this fruit, notwithstanding its thinness, is rather more resistant than that of other fruits. I think the keeping qualities of the date-plum bear out this theory. If they are not knocked about these fruits keep for a long time without decaying, although the pulp may meanwhile become remarkably soft and of such a nature that it would mest readily decay if once yeast fungi or bacteria should gain entrance. It may also be that the astringent property of the date-plum has

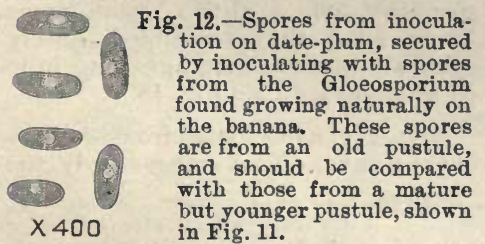

something to do with the difference in the appearance of the Gloeosporium pustules on this fruit. - On the fourteenth day pustules were removed from under the skin and spores were found to exist in them in abundance, and they were identical in form, size, and colour with those of the banana and quince of the same series of inoculations. The spores measured $5-6 \times 12-14 \mu$.
Still, for a long time afterwards the pustules remained sub-epidermal and the spores continued to show irregularities due to resistance of the skin to rupture.

From the somewhat exceptional action of the Banana Gloeosporium on the dateplum it might be thought that the conditions were uncongenial. Thus the pustules were smaller than usual in other members of this series of inoculations, and the spores were tardy in their outbreak, as has been already mentioned.

Nevertheless, when spores derived from this date-plum were used to inoculate the banana once more, they produced the characteristic disease with promptitude. In a week's time diseased areas had developed bearing scores of well-grown pustules, whose spores were of the form, size, and colour characteristic of the Banana Gloensporium, in spite of the fact that the "seed" taken from the date-plum were undersized and distorted.

10. Pear inoculated from Gloeosporium of the Banana.-After twenty-three days

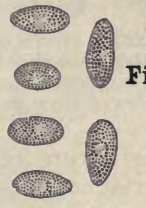

Fig. 13.-Spores of the Gloeosporium from inoculation on pear from spores found growing naturally on the banana.

\section{$\times 400$}

the rotten area on the pear was $1 \frac{1}{2}$ inches across, and bore hundreds of pustules, from some of which spores were being emitted in "tendrils."

11. QUINCE inoculated from Gloeosporium of the Banana.-Not successful. The inoculation seemed to take in a partial manner. After twenty-three days the spot was only $\frac{1}{8}$ inch across, and was but little sunken. It was mottled brown in colour and dry looking, with no indications of pustules. It seemed as if the quince was not in the right condition for receiving the fungus-perhaps too green.

12. QUINCE inoculated from Gloeosporium of the Banana.-At the end of twelve days the rotten area was upwards of half an inch across, and bore fruiting pustules, often dark coloured, from which salmoncoloured spores were oozing. There was an appearance of the concentric rings

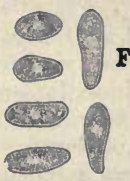

Fig. 14.-Spores of Gloeosporium, obtained by inoculating the quince with spores found growing naturally on the banana.

\section{$\times 400$}

characteristic of the ripe rot of the apple. This is the quince from which spores were used to reinoculate a banana (No. 5); the 
inoculation on the banana was entirely successful.

On the thirteenth day the spores from this quince were compared with those from a banana that had been inoculated from the same source, namely, a banana on which the Gloeosporium was found growing in nature. The spores on the quince were $12-18 \times 6 \mu$, and were of practically the same dimensions as those of the inoculated banana, 11-14 × 6-7 $\mu$, but they had a coarser internal granulation and more of a tendency to be pointed at one end. The colouration in the two sets of spores was identical.

13. APPLE inoculated from Gloeosporium of the Banana.-No resulting disease. The apple was a tough-looking Russet. This experiment was afterward repeated with the result of verifying the records of others that the disease can be easily trans-

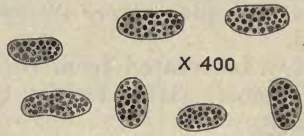

Fig. 15.-Spores of Gloeosporium, grown on the apple from an inoculation from hanana Gloeosporium. These spores are somewhat unripe, i.e., were taken from pustules of slow growth, and not yet burst.

ferred to the apple. The nature of the apple utilised in the first trial explains the failure of the inoculation, and emphasises the fact of specific resistance.

14. Peach inoculated from Gloeosporium of the Banana. - For a long time it appeared as if this inoculation was a failure, but ultimately a virulent outbreak of spores occurred. On the seventeenth day the peach was examined for the first time in

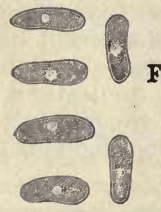

Fig. 16.-Gloeosporium spores, obtained by inoculating a peach with spores from the Gloeosporium found growing naturally on the bauana.

$\times 400$

several days, and it was found to be almost literally covered with deliquescent spore masses of a salmon colour (Fig. 16).

The skin of the peach is such that the early stages of the growth are not very apparent

The spores measured 6-7 x 20-25 $\mu$, these being the largest secured on any fruit in this particular series of inoculations (inoculations from banana on to nine different fruits belonging to various orders).

Spores taken from this peach reproduced the disease on the banana. It was found to be impossible to measure the size of the pustules on the peach. Clavate spores of somewhat greater length were seen, $-27 \mu$.
15. QUINCE inoculated from Gloeosporium of the Guava.-Took readily, the fungus coming into fruit after five days, and continuing to fruit abundantly thereafter. The spores (see Fig. 17) showed a variation from the original form as found on the guava, the variation being in the direction of the form found on the pomaceous fruits.

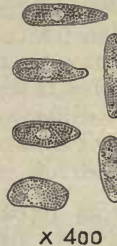

Fig. 17.-Gloeosporium spores, obtained from an inoculation on quince with spores from the Gloeosporium found growing naturally on the guava.

$\times 400$

Spores from this culture were used to inoculate a guava, and with success. (See Inoculation 19.)

16. HAWTHORNE BERRIES were inoculated with the Gloeosporium of the Guava after it had been passed through the apple.The berries were of Crataegus oxyacantha, and were gathered in June near Sydney, being fully ripe at the time of gathering. After nine days, pustules had formed and burst open, though the spores of the

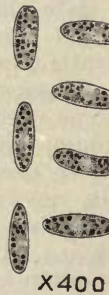

Gloeosporium had not yet formed. The spore beds of mycelium were fully formed, and, as usual, consisted of closely-packed septate threads, at the summits of which, however, there was, as yet, no indication of the formation of spores.

On the eleventh day well-formed spores were secured and drawn. In form and size $(4 \cdot 2-5 \cdot 6 \times 9-21 \mu$, and averaging $14 \times 4 \cdot 8 \mu$ ) they resembled closely the original spores as found growing in nature on the guava. (See Fig. 18.)

16a. APPLE inoculated from Gloeosporium of the Guava. - Tuok rather slowly, the first

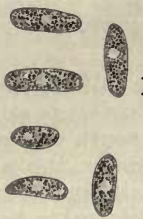

Fig. 19.--Spores of the Gloeosporium, produced on apple by inoculating it with Gloeosporium spores found growing

$\times 400$ naturally on he guava.

spores being obtained after ten days. There was a manifest difference between 
the spores obtained and those sown. The difference is shown in the illustrations. The spores as originally found on the guava were loosely granular and the vacuole was not very conspicuous. The generation on the apple was more finely granular, and the vacuole was more clearly to be seen. My notes, made at the time, say that the spores had varied in the direction of the form of the Gloeosporium spores as ordinarily found on the apple in nature. After sixteendays the rotten area was threefourths of an inch across, and some of the pustules had begun to emit "tendrils."

17. Pear inoculated from the Gloeosporium of the Guava. - In eleven days the pear was half rotten, but without any

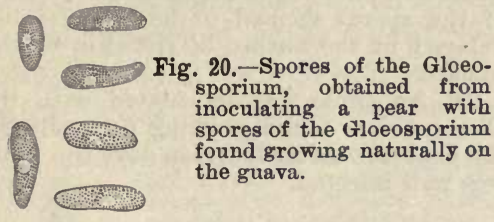

$\times 400$

definite outbreak of pustules. The rot seemed too soft for ripe rot. No pustules or spores could be found, but a coarse dark and very granular nycelium was seen. A repetition of the inoculation was successful.

18. Banana inoculated with Guava Gloeosporium.-Took rather slowly. On

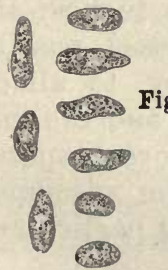

Fig. 21.-Gloeosporium spores, obtained by inoculating a banana with Gloeosporium spores found growing naturally on the guava.

$\times 400$

the eleventh day the spot was 4 millimetres across, and bore a single pustule, that the vacuole was more distinct. Two days later other pustules began to appear. On the sixteenth day there were some half dozen well-developed cushion-like pustules, and on the eighteenth day these had increased to a score. The spores were drawn, and appear at Fig. 21.

19. GUAva of the large yellow sort was inoculated from a quince that had received its seed from a Gloeosporium found growing naturally on the small red variety of guava. The object of the inoculation was to see if the change of form noted on the quince would be retained on the guava, or whether there would be a reversion to the form as it originally occurred on the guava.

The disease took slowly, but twenty-four days later there were well-developed pustules for a distance of five millimetres from the point of inoculation. The pustules were of rank growth, and were in all respects like those from which the seed had been taken on the original small red guava. The yellow guava was ultimately completely destroyed by Penicillium, and this may account for the somewhat slow growth of the Gloeosporium, but it is to be remarked that this yellow guava was a hard specimen and far from ripe to begin with. The spores, on being compared with the drawings made from the original "seed" as found growing in nature on the small red guava, proved to be identical in size, structure, and colour.

20. APPLE inoculated in two places with Gloeosporium growing naturally on quince. After twelve days this apple was com. pletely brown, soft and rotten, and numerous blackish pustules had appeared and were evidently concentric in arrangement with the two inoculated spots. The pustules were not, however, in rings. A few had already sent out "tendrils" of spores. These were mounted and examined, and were found to be rather more spindleshaped than is common in Gloeosporium, of a greenish colour, rather more finely and densely granular than is usual in the genus,

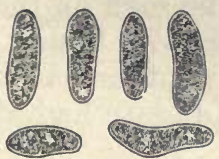

$\times 400$

Fig. 22.-Gloeosporium growing naturally on the quince. Compare these original spores with their progeny, shown in the two following illustra. tions. It will be seen that on the apple the spores have become more slender and more pointed. The difference is less marked than in similar cases on pages 16 and 17.

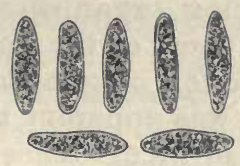

$\times 400$
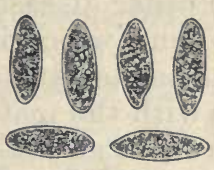

$\times 400$

Fig. 23.-Spores of the Fig. 24.-Spores of the GloeoGloeosporium, obtained from an inoculation on apple from the spores of a Gloeosporium found grow. ing naturally on the quince, and shown in Fig. 22.

which, on examination, proved to be an immature Gloeosporium pustule. The only spore seen was curved, but otherwise had the appearance of the spores sown except

and with no central clear space. Figs. 23 and 24.) sporium, obtained by inoculating an apple with spores of a Gloeosporium found growing naturally on the quince, and shown in Fig. 22. These spores are from the same inoculation as Fig. 23, but at an earlier stage. It will be noted that at a later stage the spores became much more elongated. 
These spores germinated readily ; usually from one end only, sometimes from both, seldom from the side.

When a coil of these spores is placed under a cover glass in water culture, only the outer spores of the coil germinate-as if the presence together of a large number of spores prevented germination.

21. Pear inoculated from Gloeosporium found growing naturally on the leaves of

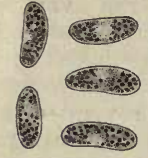

$\times 400$

Fig. 25.-Gloeosporium from the leaves of the passion-vine.

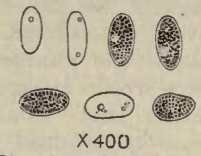
spores, obtained by in. oculating a pear with spores found growing naturally on the leaves of the passion-vine.
Fig. 26.-Gloeosporium

passion-vine. Twenty-four hours later there were no indications of the fungus having "taken" except that, the surrounding area was a trifle sunken.
Twenty-four days later a few pustules were found, having well-developed spores. These are shown in Fig. 26.

22. Plum inoculated with the Gloeosporium of the apple. After five days the plum was well infested.

23. Spores from the foregoing inoculation were used to inoculate a tomato of the yellow variety. After ten days the tomato was well infested. The pustules were

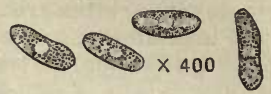

Fig, 27.-Spores of a Gloeosporium found growing naturally on the tomato.

small and close together, and the outbreak of the spores seemed to be considerably delayed by the nature of the skin of the tomato.

24. An apple was inoculated with the Gloeosporium found growing naturally on the pepper. After fourteen days the apple was well infested.

\section{Ripe-rot Fungi found growing naturally on various kinds of Vegetation.}

\section{Ripe-rot fungus on the Banana. (See Fig. 45.)}

The following facts were noted with reference to a specimen bunch of bananas sent from Byron Bay, and said to be failing to set and ripen. As soon as the fruits reached a length of about three inches, and sometimes earlier, they began to change colour and to shrivel, passing through greenish-yellow, yellow, brown, or French grey, to almost black. At the brown stage the colour became pruinose, and the final blackening was accompanied by a pink eruption of Gloeosporium spores.

The spores occured on all parts of the fruit, but in the specimens figured they were most abundant on the basal half, being particularly abundant at the very base of the stem. (See Fig. 45.)

The disease extended to the entire bunch, which in consequence was rendered worthless.

No other disease-producing organism was to be seen on the specimens sent, which included most of the middle part of a bunch.

The sender wrote that he felt certain that cold weather had nothing to do with the matter. It was apparent that the disease had attacked the fruit at an early stage of its existence.

Later the fungus fruited freely on the main stem of the bunch of bananas. The facts observed seemed to establish the ability of the fungus to completely prevent the fructification of the banana.

\section{Ripe-rot fungus on Hawthorne. (See Figs. 28, 29, 30.)}

The Gloeosporium of the hawthorne was found growing naturally on the fruits of Crataegus oxyacantha in the middle of the month of June, near Sydney.

The pustules, which often covered the entire fruit, were about onetenth of a millimetre in diameter, and gave to the surface of the fruit 
a punctate appearance. The number of spores in each pustule was not great, but the spores were of large size, measuring $6.5-8 \times 18-32 \mu$. In form they were, for the most part, elongated,

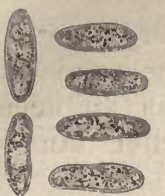

$\times 400$ but in some instances they were somewhat fusiform (Fig. 28). The colour was nearly that of the Gloesporium of the guava, but it was a trifle less brilliant, the iridescence being a little less marked. The vacuole characteristic of most spores of Gloeosporium was not plainly to be seen, the fine granulation being such as to obscure it, if it existed at all.

Fig. 28.- Spores of Gloeospor Hawthorne.

It will be seen that the spores of this form are larger than any others examined in the course of these experiments.

Although the spores when freshly removed from the pustules appeared to be one-celled, after twenty-four hours in water they were muiticellular, some two-celled, some three-celled, some four-celled, the latter being more constricted at the middle division. After the

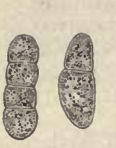
Fig. 29.-Spores of the Gloeosporium, found growing naturally on the berries of the Hawthorne. These are shown in the first stages of armination. It is not often that the spores become four-parted in this manner before throwing out a definite mycelial thread.

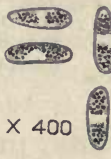

Fig. 30.-Gloeosporium, found growing on the fruit of Hawthorne (Crataegus), June, 1902, at Killara, New South Wales.

formation of these septa the vacuoles in the various cells appeared a trifle more discernible (see Fig. 29). The cells germinated vigorously, sending forth a mycelium that at the end of twenty-four hours was many times as long as the spore, and considerably branched, but with no tendency to produce conidia.

\section{Ripe-rot fungus on leaves of Passion-vine. (Fig. 31.)}

The Gloeosporium found on the leaves of the passion-vine was used to inoculate a pear, a banana, two apples, and a passion-fruit. After thirty days, the pear, which had become slowly infected from the first, was found overrun with Penicillium, in the midst of which, at least on the borders of the outbreak, pustules of Gloeosporium were to be found. These gave spores somewhat smaller than those of the pustules on the passion-vine leaves from which they were inoculated. The measurements are given herewith.

$14 \cdot 0 \times 6 \cdot 3 \mu$

$13.6 \times 6 \cdot 6 \mu$

$12.6 \times 5 \cdot 2 \mu$

$13 \cdot 7 \times 5 \cdot 2 \mu$

$13.3 \times 5 \cdot 2 \mu$

$12.6 \times 7 \cdot 0 \mu$

$13.3 \times 6.3 \mu$

$15 \cdot 3 \times 7 \theta_{\mu}$

$11.9 \times 8.7 \mu$

$14.0 \times 4.9 \mu$

$13.4 \times 6 \cdot 2 \mu$

It will be seen that the average dimensions are $6 \cdot 2 \mu \mathrm{x}$ $13 \cdot 4$, the limits being $5-9 \times 12-15 \mu$.

As many of the spores had germinated, it is not possible to give these measurements the weight they

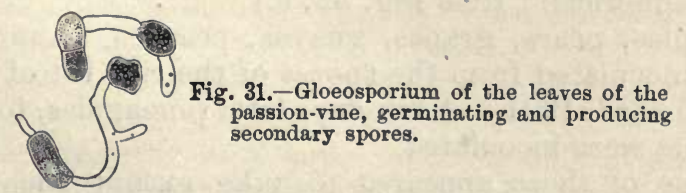

would otherwise have. The spores that had not germinated seemed to me to be dwarf spores, and those that had 
germinated were difficult to measure properly, especially in width, it being impossible to allow for the amount of collapse due to germination.

It should also be remarked that the growth was very slow and not very decisive; in fact, I felt convinced for a long time that no Gloeosporium was present, and that the disease was an accidental growth of Penicillium, and nothing else. An earlier microscopic examination would have been better.

I succeeded in infecting another pear with spores of this fungus.

\section{Ripe-rot fungus on Passion-fruit. (Fig. 32.)}

On the 22nd March, 1901, I received some passion-fruit suffering from a ripe rot, caused by a species of Gloeosporium not distinguishable in form from Gloeosporium fructigenum. The diseased spots also showed the concentric markings so characteristic of the ripe rot of

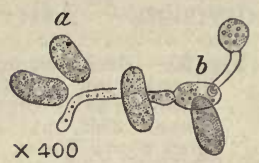

\section{Fig. 32-Spores of the Gloeosporium, found growing naturally on the fruit of the passion-vine. $a$, freshly removed spores; $b$, germinating spores, one of which has already produced a secondary spore.}

the apple and other fruits, presenting more or less of a buff colour with rings of a darker shade. The infested areas were usually of a circular shape, and sunken. As the disease progressed the spots collapsed, and the shell of the fruit became dry and brittle. The spore-producing pustules were less numerous than is usual on other fruits, but were of the usual size. The spores are shown in Fig. 32.

The diseased spots were at first small and green, but at this stage were not sunken as they were at a later stage. As the disease progressed the spots enlarged, and, while gradually sinking inward, assumed the above-mentioned buff colour with concentric markings.

The disease was said to be causing a great deal of damage.

On being cultivated, the spores germinated in precisely the same manner as those of the ripe rot of the apple, producing secondary spores in about fifteen hours. These are shown in the illustration referred to above. Prior to the germination, or pari passu, the spores became two-celled. Perhaps the prominence of the "nucleus," as ordinarily seen on removal of a spore from its pustule, is due to the condition in which the spore then exists-a condition preliminary to division.

The secondary spores are smaller than the primary, and are darker in colour, as well as more coarsely granular. In form they are somewhat spherical. (See Fig. 32, b.)

Apples, pears, grapes, guavas, peaches, bananas, and date-plums were inoculated from the spores of the ripe rot of the passion-fruit on March 23rd, 1901. A few days later pineapples, tomatoes, quinces, and peppers were inoculated.

None of these appeared to take except the tomatoes, which on April 9th showed three pustules on one small spot, as yet unripe, and not bearing spores. These appeared to be true Gloeosporium 
pustules, however. This growth was so slow that, even supposing it. to have been a good case of transmission, I doubted if the fungus was. on congenial ground. At a later date, however, when making a series of successful inoculations with the ripe rot from another source, I obtained a similar result on the grape. From this it may be inferred that certain inoculations though successful result in less robust growth.

\section{Ripe Rots and their Names.}

Whoever reads the literature of Gloeosporium will, I think, be. willing to admit that there has been considerable readiness to describe and name as specifically distinct a number of forms, mainly upon the ground of their host-plant being one upon which species of Gloeosporium. had not been previously seen. If, in addition to the novelty of the host-plant, some small distinction in the size and form of the spores. could be made out, there has apparently been very little hesitation in doing what is commonly called "establishing a new species."

In the course of observations made upon a considerable variety of Gloeosporium inoculations I have often had occasion to observe the diversity of form, size, colour, and structure that may be exhibited by-

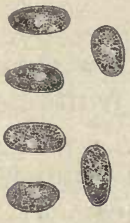

$\times 400$

Fig. 33.-Spores from an old pustule of the Gloeosporium, found growing naturally on the banana. Compare these with their prsgeny. (See Figs. 3439.)

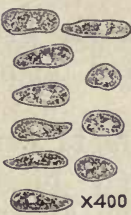

Fig. 34.-Spores of the Gloeosporium, obtained by moculating the date-plum with spores of the Gloeosporium found growing naturally on the

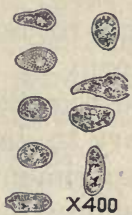

Fig. 35.-Spores of the Gloeosporium, obtained by inoculating a grape with spores of the Gloeosporium found growing natur. ally on the banana.

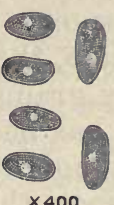

Fig. 36.--Gloeosporium spores, obtained by inoculating a banana. from a banana. These are very much likethe parent spores.

the spores of a single species. With a change in the nature or condition of the host-plant comes a corresponding change in the resulting spores. Mature spores from young growths differ from those

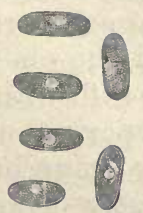

$\times 400$
Fig. 37.-Spores from inoculation on date-plum, secured by inoculating with spores from the Gloeosporium found growing naturally on the banana.

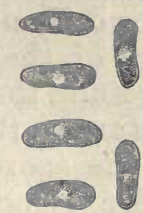

Fig. 38.-Gloeosporium spores obtained by inoculating a peach with spores from the Gloeosporium, found growing naturally on the banana.

produced by the same growths at a later date, not only in size and form and structure but also somewhat in colour. I observed that thesedifferences were not infrequently greater than those upon which various. authors had founded new species. 
Thus it appears that the granulation of the spores is coarser when young than when more mature. In the case of the spores of the guava (rloeosporium cultivated on the apple, the earlier spores from the first pustules that appeared were removed and examined before the pustules had burst, yet at a time when the spores were readily obtainable in large numbers. Several days later, when more pustules had appeared, spores were taken from a pustule that had begun to emit the spores in "tendrils." Comparison with the spores taken at an earlier date showed that these later spores were more regular in form and more finely granular, and had a more distinct vacuole than those of an earlier date.

Similarly in another case when spores were removed from a young pustule of the Gloeosporium of the banana inoculated on to the apple,

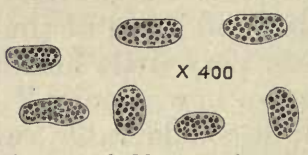

Fig. 39.-Spores of Gloeosporium grown on the apple from an inoculation from banana Gloeosporium. These spores are somewhat unripe, i.e., were taken from pustules of slow growth and not yet burst.

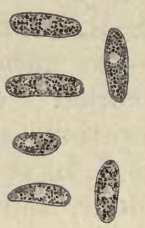

Fig. 40.-Spores of the Gloeosporium produced on apple by inoculating it with Gloeosporium 'spores found grow. ing naturally on the guava.

-the spores were found to be very coarsely granular and without a vacuole, the normal form of these spores on pomaceous fruits being finely granular. (See Fig. 39.)

It has been necessary to bear these facts constantly in mind while carrying on the experiments recorded in these pages. If, for instance, the earlier spores resulting from an inoculation on to a new fruit were compared with a mature spore from the original, the results of the comparison would be of less value than if the spores were mature on both occasions. No rule can be laid down for guidance in such comparisons because, on account of the varying composition of different fruits, the appearances of the ripe pustules vary considerably. It would seem that a pustule that is actively "spouting" spores might be safely taken as beyond question mature, and in the comparisons here made, as far as possible, spores for comparison were derived from "spouting" pustules.

Unfortunately, however, the varying nature of the epidermis of the various fruits is a factor difficult to allow for in making comparisons. To illustrate the nature of the comparisons made, and the obstacles encountered, and the results that may be obtained if the difficulties are not too great, let us return to the cultures of the Gloeosporium of the guava. We find that the spores of this form, as they occur on the guava, are rather more elongated than usual, coarsely granular, provided with a rather indistinct vacuole, and characterised by a peculiar colouration. When viewed in optical section the spore walls appear to be colourless and the granules nearly so, but with a delicate shade of green. If the lens be next raised a trifle, the spore wall takes on a pinkish tint, the change reminding one of the change of tint noticed in those substances, such as eosin, that in one light 
appear red and in another green. Similar appearances may be seen in other forms of Gloeosporium, but they are not usually so marked as in the Gloeosporium of the guava.

If, now, other fruits be inoculated with these spores, as grown on the guava, strong growths will be secured that present certain variations. In most instances (banana, apple, quince, pear) the spores contain

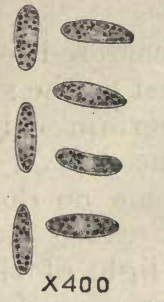

Fig. 41. -Spores of the Gloeosporium found growing naturally on the fruit of the guava. Compare these original spores with their progeny shown in Figs. 40, 42, 43, and 44.

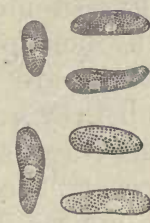

$\times 400$

Fig. 42.-Spores of the Gloeosporium obtain. ed from inoculating a pear with spores of the Gloeosporium found growing natur. ally on the guava. Compare this with adjacent figures.

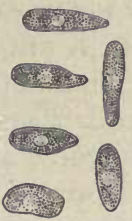

$\times 400$

Fig. 43.-Gloeosporium spores obtained from an inoculation on quince with spores from the Gloeospor ium found growing naturally on the guava. Compare this with adjacent figures.

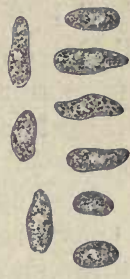

×400

Fig. 44.-Gloeosporium spores obtained by inoculating a banana with Gloeosporium spores found growing naturally on the guava. Compare these with Figs. 40-43.

finer granules and a more distinct vacuole. This is distinctly noticeable on the pomaceous fruits (see Figs. 40 to 44). Now, as the Gloeosporium ordinarily found on pomaceous fruits is more finely granular than the form seen by me on the guava and used in these observations, we may safely suspect that the guava Gloeosporium, when grown on the pomaceous fruits, varies in the direction of the form characteristic of those fruits. It is needless to point out that this is what we should expect if one of these Gloeosporia is a derivative of the other, and too closely related to be regarded as specifically distinct.

As to the variations in the size and form of the spores of fungi, we see in the measurements resulting from the inoculations already recorded what large variations may occur as the result of varying environment, such as is afforded by the various fruits employed. We may have spores varying in size from $5 \times 7 \mu$ to $6 \times 18 \mu$, and in form from nearly round through ellipsoidal and elongated to clavate. If any attempt had been made to secure extremes, it would have been easily possible to have exceeded the limits of size and form here set down.

A thoughtful review of the various colours displayed by the diseased spots resulting from the attacks of a given form of Gloeosporium on a variety of fruits will, I think, result in the opinion that these colours are in harmony with the physiological functions of the host, and I am sure that to a less extent the same is true of the colour and form of the pustules and spores. Thus the colour of the fruit itself enters to some extent into that of the diseased area, and the chemical reactions of the fruit's constituents have a decided influence on the colour of the rot. Some varieties of pears have a tendency to blacken the pustules of the fungus. Turning to the form of the spores, nothing could be plainer than that the peculiar epidermis of certain fruits, through its extra resistance to rupture, gives a peculiar irregu- 
larity to the form of the spores-spores that under other conditions would be symmetrical, becoming bent and clavate. With regard to the colour of the spores, I am not so certain; but I have seen quite perceptible changes of colour due, apparently, to the change of host-plant in the course of a series of inoculations. For example, I observed that the somewhat brightly-coloured spores of the Gloeosporium of the guava became less brilliant after two or three generations on pomaceous fruits.

All these various properties of the fungus should be considered to be to a considerable extent a function of the host-plant, just as the size, form, and colour of Phaenogamous plants are to a certain extent functions of the soil and climate in which they are produced.

If these ideas are correct, and my observations leave me no doubt that they are at least approximately correct, they must cause us to consider the size, form, and colour of spores in the light of their origin, and not refer to them indiscriminately as characteristics of the fungus, and make them the basis of descriptions of "species."

Consider for a moment the colours called forth on these same hostplants by other fungus diseases than the ripe-rot fungi. It is quite evident from such an examination that each species of fruit has certain ranges of colour in its rots, regardless to some extent of the exciting cause. These colours are due to certain chemical changes in the tissues of the fruit, and these changes are at bottom similar for quite a range of injuries. Here again we see that the resulting compounds and their colours are to a certain degree a function of the object attacked, and we cannot logically refer them indiscriminately to the attacking agency.

While these statements may not be capable of being set down as hard and fast laws, they embody too much truth to be so generally ignored as they have been in the past, particularly by systematists.

The facts strongly suggest that a considerable number of the various so-called species of Gloeosporium, showing as they do when grown on different fruits no greater variations than we expect to see in various plants when grown on a variety of soils, are in reality too closely related to require distinct names - are in reality one and the same form or species.

Other recent observers have arrived at similar conclusions as the result of more or less extensive experiment.

The fact that the ripe-rot fungus of a given fruit can be grown on a great variety of other fruits, and that it actually occurs in nature on a great variety of other fruits, may appear capable of another interpretation than that suggested by the foregoing paragraphs. It may be argued that in spite of the close resemblances among the various forms, there are as many species as there are kinds of fruit; that the mere fact of each such form growing on other fruits is no proof that it is not in itself a true species; that there are other important factors besides form, colour, size, and structure that enter into the idea of a species, namely physiological adaptation to environment, chemical composition, \&c., and that these do not find expression in any visible manner. 


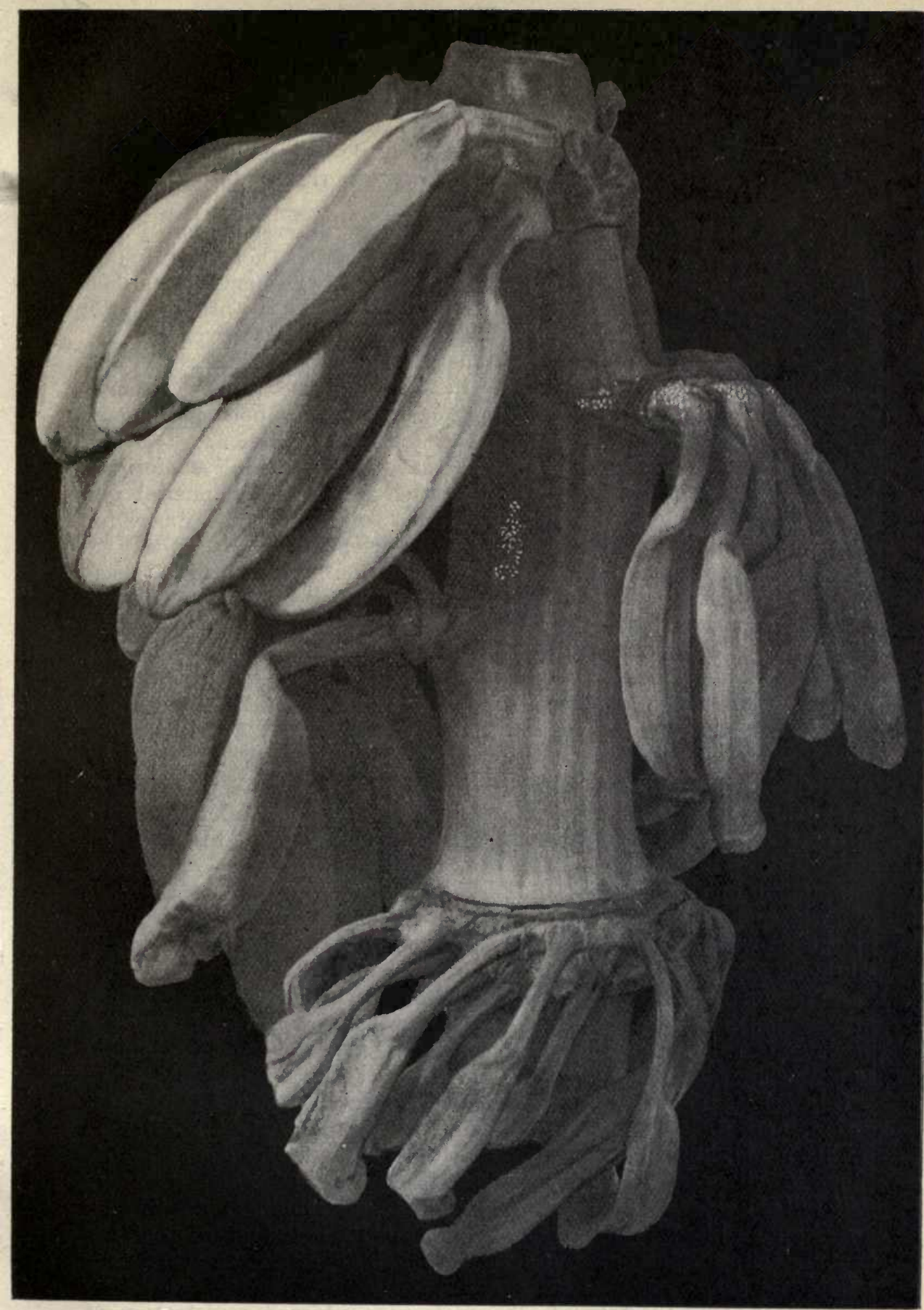

Fig. 45.- Middle portion of a bunch of bananas, attacked by ripe rot or Glocosporium. The three lower "hands" have been already killed by the disease, and the apper nne is badly smitten. The fructification of the fungus is seen most clearly at the stem end of each banana, and appears in the form of numerous salmon-coloured pustules. A collection of these pustules is also to be seen on the main stem of the bunch. Entire bunches were killed in the manner shown. 
The burden of proof that such is the case rests with those who hold such views, and until satisfactory proof of the existence of these elusive characteristics is brought forward, one may be pardoned for looking upon such views as too indefinite to be utilised in systematic work. We must fall back upon what we can readily test with our senses.

From an economic point of view it makes no difference that I can see, in the matter of the ripe rots of fruit, whether there is only one species capable of living on all sorts of fruit, or whether there are as many species as there are kinds of fruit, each so like the others that it is hardly possible to make a distinction, and each moreover able to effect an entrance into all other kinds of fruit and produce rot. The economic precautions required are the same in either case. From a scientific point of view, however, the question is an important one, and it is this fact that has led to this rather lengthy discussion.

One is almost tempted to declare that species-making sometimes becomes a kind of mania, - that altogether flimsy and whimsical, not to say unreasonable, differences have been seized upon as excuses for adding unnecessary descriptive matter to scientific literature. If we find that a particular kind of oats growing on sterile and sandy soil exhibits a dwarf growth and a yellowish colour, we do not immediately regard it as a new form, not forgetting to name it and announce the discovery. Let us congratulate ourselves! For it is not always thus among our scientific friends. Is a fungus species newly found on a peach? Call it new and name it pruni. Same genus on the grape? Call it new, name it ampelinum. On the apple? New, call it mali. On banana? Christen it musae.

What next? Sparrow in a pear-tree, Passer pyri?

The question may be less trivial than it seems. The different shades he may assume in the green shadow of pear leaves, his different attitudes due to the steepness of the pear twigs, the shape of his nest consequent on the angle of the forks - these are matters in the case of the sparrow somewhat on a par with the characteristics to be noted in the growth of a fungus merely as a consequence of happening to alight on a pear.

A reasonable allowance for the influence of environment would prevent much confusicn. It is not as if we were still in ignorance of methods of cultivating fungi, and were obliged to rely upon specimens as ordinarily found in nature.

Our criminal courts have learned some valuable lessons in identification, and they long ago gave up trying to identify a criminal by his name, knowing full well that the next time he comes before them it will very likely be under a new "alias." The "rogue's gallery" is a safer source of information than any criminal list. "What does he look like?", not "What is his name?", is the question of the expert. Measurements, photographs, indelible marks, these are the reliable data.

If this is so in the face of all our legally enforced registration of names, it is certainily calculated to make us pause before putting too much reliance on a mere name. 
Our predicament is not improved when these names are loosely bandied about and lightly given. The rule sometimes seems to be, if a thing is found in a new place, give it a new name, especially if it is a shade darker or a trifle larger.

We have gone to great lengths in this manner in the case of $x$ number of our common fungus genera. The sooner we devote some of this linguistic and glory-hunting energy to the creation of a firstclass "rogue's gallery," the better.

Measure, observe the behaviour, photograph, and above all, draw. I know some learned societies have tried to lay disabilities on drawings. That, however, is only an admission that a great number of the members cannot yet appreciate a drawing. In effect they say that the one who makes a drawing cannot be relied on to know anything about what he draws. My experience is quite the contrary.

It must be admitted that a knowledge of the name of anything too often passes for a knowledge of the thing itself. He who can promptly give the common and scientific name of a plant, animal, or other natural object, has a passport to the confidence of his fellows that one cannot help wishing may always be justified by a fuller knowledge to follow; while it may be admitted that this wish is satisfied in the majority of cases, there remains no small ground for thinking that much of our current knowledge stops short at the point that enables the possessor of it to "give it a name."

This, of course, is only another way of saying that the object of too much of our study is to the end of classifying, and to that end alone.

Such study, however necessary, cannot escape the criticism of being superficial. Moreover, it leads to an inordinate love of routine, and a contentment with knowing a little about a large number of objects, that prevents us, paradoxical as it may seem, from knowing much about this same series of objects; for in any series of related natural objects one is in reality very much like another in all essential features, and a knowledge of one member of the series is in many respects equivalent to a knowledge of the others. But our method of skimming over the surface, of giving superficial attention to so many objects, prevents us from getting below the surface and reaching those general phenomena which would furnish such data of a general nature as would lead to nearly all the results we now achieve and very much more beside.

It would be a splendid resolution, if carried into effect, for each of us who devotes attention to species-describing, to decide to periodically give a deep look into one of the organisms he is in the habit of studying, making it as exhaustive as his resources permit.

\section{Remedies for Ripe Rot.}

Care in Handling.-The observations recorded in the foregoing pages, and similar observations made elsewhere, teach no lesson more forcibly than that concerning the care which should be exercised in the handling of all fruit destined for lengthy storage. 
In a state of nature, one of the primary objects of the skin of a fruit is to protect the inner tissues from injury until such time as they may aid in securing that disposal of the fruit that will be useful to its species; and of all the agencies likely to upset this result few are more potent than parasitic fungi.

A careful review of the species of fungi that attack ripe fruit shows that very few of them have the power to penetrate the sound skin of fruit. It appears that for the most part it is only after some injury has made an opening for them that these fungi can gain an entrance.

It follows that the orchardist should give close attention to the various agencies that may injure the skin of his products be it ever so olightly. An injury so small as to be quite invisible to the eye is an ample gateway for these injurious rots.

It is almost an axiom of the hest fruit-growers, in the regions where fruit-growing is most successful, that fruit should be handled like eggs, and for precisely the same reason. The cracking of an eggshell is not more fatal to the keeping qualities of an egg than is a similar accident to the skin of fruit.

Beyond question the people of California are the greatest masters of the art of plucking, caring for, and marketing fruit; and it is in California that one observes the highest degree of attention given to preserving the skin of fruit in a perfectly uninjured condition. This is a matter to which I have given much observation in the half-dozen different fruit-growing regions of the United States, and in nearly a dozen other countries, in the course of tours devoted specially to the purpose of seeing with my own eyes the methods employed in the handling of produce. So far as such evidence goes, there can be no doubt that the most successful fruit-growers, from the commercial standpoint, are those that handle the fruit with the greatest care; and let it be understood that this care is usually exercised in the full knowledge that it is the rot fungi that constitute the danger. All their precautions, such as utmost care in picking and sorting and grading, careful wrapping, special vehicles to provide against jarring and oruising, the use of ice in warm weather,-are precautions based firmly on a knowledge that the smallest break in the skin of a single piece of fruit may mean the loss of an entire shipment. The fungi that cause the rotting of fruit, of which the Gloensporium is a prominent example, are almost omnipresent, and stand ever ready to take full advantage of the smallest opening. If they gain access to one orange or one apple or one cherry, in a case, it is not long before the entire case is doomed; for the rotting of one piece creates chemicals capable of so injuring the other pieces as to render them accessible to the rot fungi.

In the Orchard. - A number of conclusions applicable to orchard work are derivable from the foregoing pages.

In the first place, it is evident that if the fungi responsible for the occurrence and spread of the ripe rots are so indifferent to the nature of their host, we must give attention to other matters than the condition of the fruits that are being raised for profit in the orchard. If, for instance, we have a fruit that is subject to ripe rot and there is 
growing in the vicinity a hawthorn hedge, it will be necessary to attend to the condition of the hedge as well as to that of the fruit being cultivated for profit. Again, suppose a surplus crop of fruit of another sort is found unsaleable, something that not infrequently happens I am sorry to say, and this surplus be allowed to lie where it falls and to go its own road to decay? A considerable portion of it will become infested with ripe-rot fungi, and this will be a menace to all fruit in the vicinity, some of which may be valuable. In the same category as surplus unsaleable fruit must be placed left-over crops of certain vegetables. Rotting tomatoes may be a menace to ripening fruit on trees near by. So may rotting surplus cucumbers, pumpkins, and other cucurbits. Rotting fruit of any sort is a danger to ripening fruit of almost any other sort. The danger is not always confined to rotting fruits, as it has been shown that the ripe-rot fungi find a congenial breeding ground on the branches and foliage of a number of plants. It is quite probable that these fungi breed in non-living matter of certain kinds, for they may easily be cultivated on artificial media.

Special pains should be taken to ensure the destruction of all rotting vegetable matter in the vicinity of an orchard, and especially of any rotten fruit or rotting vegetables.

When applying sprays for the prevention of fungi, it would be well to have an eye to adjacent regetation, with a view to the possibility that it may be the source of ripe-rot fungi. Often it will cost little more while spraying the orchard to spray these other plants that may be in or near it. If, for instance, there be a hawthorn hedge on the border of the orchard, it may prove a paying investment to spray the hedge also.

The same principles that apply in the orchard apply also in the storage of fruit. It is useless to expect to keep fruit successfully in cases that have recently held rotten fruit, and the variety of fruit makes little difference. A box or other receptacle that has held ripe-rotten plums is just as unsuitable for the storage of apples or peaches as for plums.

The means for combating the ripe-rots in stores and shops are, of course, of a different nature from those suitable to the orchard. For disinfecting cases and boxes boiling water is cheap and efficient in many instances. Formalin is an eminently suitable fungicide for use in stores and shops devoted to the fruit industry; in fact, I am sure that if shopkeepers and merchants realised more fully the efficiency of this substance and the ease with which it can be applied, it would come into wide use for these purposes.

For disinfecting bins, whitewash is cheap and efficient. Though usually applied with a brush, it may be applied with a spraying machine, with the advantage that the whitewash is driven into cracks that could not be reached readily with a brush.

The precautions that are to be taken against the ripe-rot fungi are not by any means confined to the period after the fruit is plucked. In the orchard, long before ripening time, there are plenty of influences that open up breaches in the fruit through which the rot fungi may gain an entrance. This is notably the case with early varieties. To a large extent these early varieties owe their earliness to selection and 
breeding directed toward rapid growth, this rapidity being accelerated by the application of stimulating manures. Now all this means weak tissues, for nature cannot be hurried and yet do her work with the same thoroughness that would characterise her normally slower process. Beside being smaller, early fruit has poorer keeping qualities than later fruit, and this must always continue to be so ; we cannot "eat our cake and keep it too." Early fruit must from the very nature of things remain peculiarly susceptible to the attacks of Gloeosporium and similar fungi. Hence it follows, as before remarked, that in the orchard we must give especial attention to the agencies which open up the way for the entrance of these enemies. As far as it will prove profitable, we must attend to the action on our crop, of wind, rain, hail, sun, insects, birds-always bearing in mind that the minutest wound inflicted by any of these agencies is liable to be as injurious as though it were large enough to be visible.

In order to be more specific, it may be well to mention some of a the necessary precautions more in detail.

Drainage should be attended to, because it sometimes happens that after a period of dry weather a succession of rain storms gives to the crop such an excess of water that, the skin of the fruit having acquired a certain inaptitude to further expansion, the sudden pressure causes it to burst. Good drainage will tend to avert this loss by taking away all excess of water as fast as possible.

The sun is responsible for damage where the pruning is such as to admit too strong a light, and too much heat, to the fruit. This results in "sun-scald." It should be borne in mind that this injury is not so common as it is believed to be by some. There is an infallible test with regard to injury caused by the sun that is often overlooked. The sun injures only one side of the fruit,- the side it shines on. This seems so self-evident as to require an apology for referring to it, and certainly no reference would be made here were it not for the fact that the author not infrequently receives fruit injured on all sides, and yet accompanied by the suggestion that the injury is "sun-scald."

The wind is responsible for more injury to delicate-skinned early fruit than would appear at first sight. We must remember that at the time of ripening the skin of early fruits is particularly liable to injury. Falling twigs and bits of bark, flying debris carried by a gust of wind, are quite competent at this time to puncture the delicate skin of many kinds of fruit.

The continued chafing of one part of a fruit tree against another, the knocking of the fruit against twigs and leaves are things to be taken into account at the time of pruning. The provision of proper wind breaks in situations liable to windy weather is a feature of orchard work that leads to less loss from fungi as well as from wind-falls.

Improper spraying is occasionally the source of some little trouble in connection with ripe-rot fungi. It sometimes happens that the spray is applied at the wrong time; that is to say, at a time followed immediately by strong and hot sunlight. Such light acting through the droplets of spray is concentrated as it would be by passing 
through a lens, and the result is that the tissues of the leaves and fruit immediately under the droplet are heated so much as to lead in conjunction with the chemical action of the fungicide, to weak or broken skin, and after that to an attack of Gloeosporium.

While on this subject I would like to again emphasise the importance of a fine spray quickly applied. This is a matter upon which I have insisted for a long time without, as it appears to me, the result being what it ought to be. I have just alluded to the danger attendant upon the application of a spray at a time followed by strong hot sunlight; but such danger would be comparatively little if the spray were as fine as it ought to be. If the droplets of spray are so fine as to be almost invisible, their effect in conjunction with the hot sun would be trifling for two reasons. In the first place they would be so small that they could not collect enough heat to be injurious, and in the second place they would evaporate so quickly that they would be gone before they had time to collect sufficient heat to do any damage.

On other occasions I have given the strongest reasons why a spray should be applied in a very fine state of subdivision, namely, that under such circumstances the spots of poison are greater in number and the distances separating them are less, and in consequence of this the germinating spores of fungi are more likely to run against the poison spots and thus be killed. Of course, it would be useless to have the spray fine if the plants are "drowned" with fungicide. The idea seems to prevail with some users of fungicides that the object of applying a spray is to wash the disease off the plants. Nothing could be farther from the truth. The object of spraying is to place upon the leaves and other parts of the plant small spots of poison, and to place them so close together that any germinating fungi will soon come into contact with one of the spots and, absorbing some of the poison, be killed. A few simple observations will convince anyone that in a certain sense, that is to say after a certain point in the spraying is reached, the more spray applied the less good is done. Any orchardist that has not already done so should try the following simple experiment.

Spray a few leaves with Bordeaux mixture for a few seconds with as fine a spray as possible, using a well-made mixture and a high pressure. Simply pass the nozzle of the sprayer over the leaves once. Allow the leaves to dry, and meanwhile spray another similar lot of leaves for a longer time, observing how after the first few seconds the droplets of the spray collect together into larger and larger drops, until at last they roll off the leaves on to the ground. This latter kind of spraying is of little value, for if the leaves sprayed in this manner be allowed to dry, and then be compared with those sprayed as at first directed, it will be found that the leaves sprayed with a small dose have retained the larger amount of the fungicide, and are therefore better armed against the germinating spores of fungi.

I even go so far as to advocate a double application of fungicides in the following manner, and I would like to add that my opinion in this matter is formed after careful laboratory tests, followed up by corroborative field tests:-Go over the work rapidly, never allowing the nozzle of the sprayer to play for more than a second or two upon 
any one part, or perhaps only for the fraction of a second. Go over the whole plantation in this manner. After completing one round repeat the operation at once, making sure that the first spray is dry before the application of the second. This need not occupy more time than would be given to the spraying in the ordinary way. Simply decide how much time is to be given to the job, and devote to the first dose one half of the time, and to the second dose the other half. In the end no more time will have been consumed, and not much more labour and no more material, but the result, I can assure the reader, will be a decided improvement. The poison will be found to be placed on the leaves in smaller and more numerous patches, and in consequence it will be much more effective.

Varying Resistance.-The fact that the numerous varieties display a varying susceptibility to the attacks of Gloeosporium suggests an explanation of the varying results of spraying with fungicides. Different experimenters, after carefully-conducted experiments, have secured varying success in the application of fungicides for the prerention of this disease. Among the causes for these varying results we must reckon the varying susceptibility of varieties. A very susceptible variety. will naturally receive less benefit from a given series of applications of, say, Bordeaux mixture, than a less susceptible variety. It is noticeable that little attention has been given to this point in reports on experiments for the prevention of ripe rots. Often no note is taken of the variety sprayed, and never, so far as my reading goes, has allowance been made for varying degrees of susceptibility.

According to my experience, it is the early and non-keeping varieties of fruit that are most susceptible to the attacks of Gloeosporium, and of these two qualities, which, of course, often go together, and are so intimately associated that it is impossible to separate them, it is the fugitive quality that seems to exert the most important influence. If, for instance, an early sort is also a fair keeper, it will be found that it is at all times more resistant to the rot than the equally early sorts that do not keep so well. Apples with a russet skin are usually resistant to Gloeosporium, and the summer varieties with russet skin are examples of early, yet somewhat resistant, varieties.

Birds and insects are connected with the rot fungi in an indirect way. The peckings of birds, and the bites, stings, and scratches of insects are, of course, to be guarded against if immunity from fungi is desired. Insects, apart from the direct injury they do, are a source of loss in that they open up the road for the ripe-rot fungi. There seems to me to be some ground for believing that the aphides and, perhaps, the scale insects disinfect their punctures. At any rate it is difficult on any other ground to account for the fact that their punctures do so little harm in proportion to their number. But this is at present only a hypothesis. With many other insects the case lies otherwise, for it can be shown that various rots follow on their attacks.

I have often observed, in connection with my experiments, that no sooner do well-developed pustules of the rot fungi appear, than I 


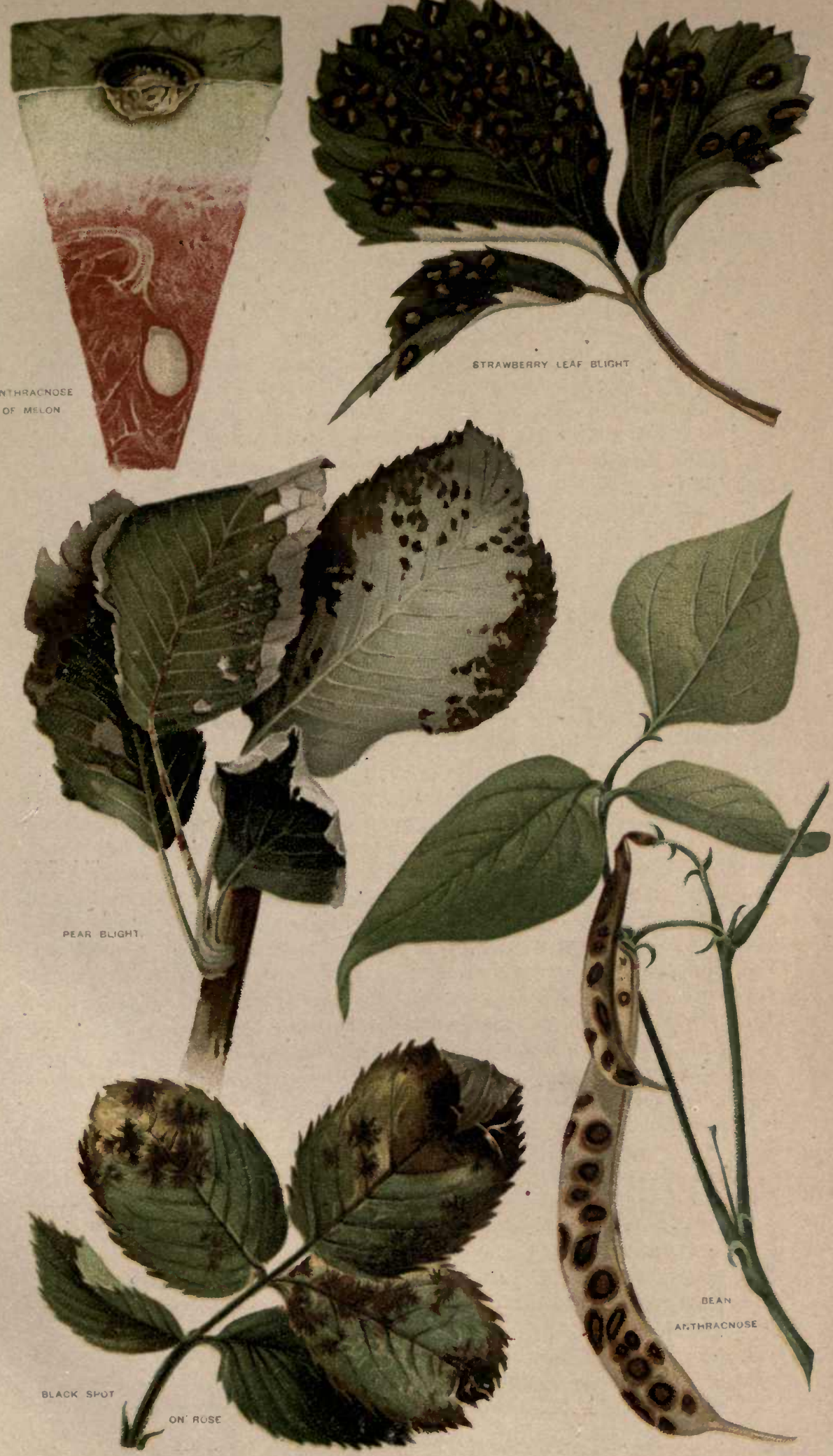




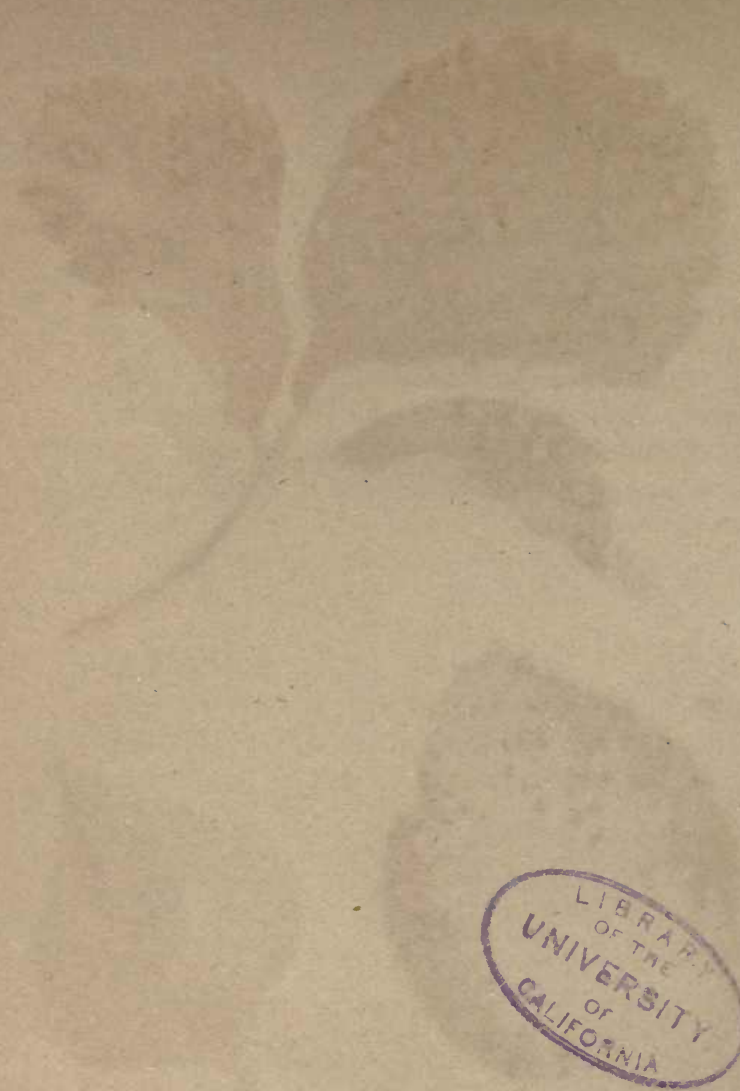


am troubled by the presence of certain mites or Acarinæ which apparently feed upon the fungi. It has occurred to me that these may be instrumental in spreading the fungi, although I have accumulated no evidence that such is the case. I mention the matter in the hope that it will lead others to make observations that may possibly lead to more definite results. Such mites must be abundant in orchards; in fact, it is established by observations already made that they are so, but it appears that there is yet much to learn concerning their economic importance.

\section{Banana Scab.}

THIS is a disease I have several times had occasion to notice in an official capacity, and one that does a considerable amount of damage ; it is, therefore, worthy of attention in the pages of this journal.

Scab occurs on bananas from our Northern Rivers, from Queensland, and from Fiji. I recollect having observed a similar disease on bananas in the Sandwich and Samoan Islands and in the United States of America, the fruit in the latter case being imported, in all

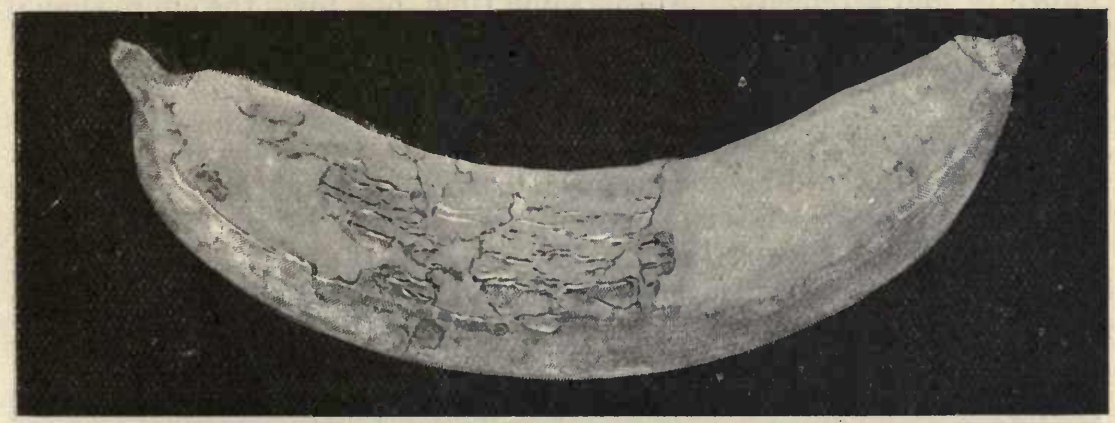

Fig. 46.- Secondary stage of banana scab. In this case the disease has attacked the half of the fruit next the stem. The discolouration and cracks are well developed.

probability, from the West Indies. From this it appears that the disease is a wide-spread one, a fact that renders it all the more important from an economic point of view.

Banana scab is well known to fruit-vendors, though not under any particular name. It seems to be looked upon by them as a more or less normal feature of the fruit, and they account for it in a variety of ways. "It is where the fruit rubs against the "tree" "; "It is due to frost"; "It is due to too much sap"; "It is due to lack of sap"; "It is sun-scald ;" "It is caused by impoverishment of the soil "; "It's nothing! You'll find it on all bananas"; - these are among the numerous explanations offered by retailers.

Whatever the cause may be, and we shall endeavour to state its nature in the following pages, the disease is very common, the 
majority of bunches showing more or less of it. He must be an unobservant buyer who has not rejected scabby bananas, and an uncommonly honest or clumsy dealer who has failed to slip in a few such along with their better fellows.

The reader will easily recall bananas that under an unpromisingly dry and scabby skin yielded a hard, brown, and, it may be, somewhat astringent pulp. That was the occasion on which the banana scab, having been bundled along from planter to shipper, and from shipper to wholesaler, and from wholesaler to retailer, at last found itself, along with the rest of the sins and shortcomings of the world, loaded on to the back of the consumer. This long-suffering individual is so used to repeating all day long, "Oh, well, it is a small matter, let it go," that we hear no more about it. It is, however, the province of the specialist to sum up these small individual losses, see what they amount to, and, if they are of sufficient consequence, to trace them to their source, in order to ascertain whether any remedy is to be had.

There will be little difficulty in convincing all who enjoy a good banana that the aggregate of inferiority arising through the presence of one or more scabby bananas in every few dozen sold must amount to something very considerable-quite enough to justify some small effort to find a remedy. At the same time, one feels the effort should be proportionate to the importance of the subject, which certainly, in this State, cannot claim to be very great.

At the present time more scab is coming to our shores from the neighbouring state of Queensland than from any other source. Not that this is discreditable to Queensland. The explanation is suggested by the well-known pseudo-conundrum, "Why do white sheep eat more than black sheep?" and its answer, "Because there are so many more of them." The Queensland banana plantations may yield more scab than those of our Northern Rivers for the same excellent reason.

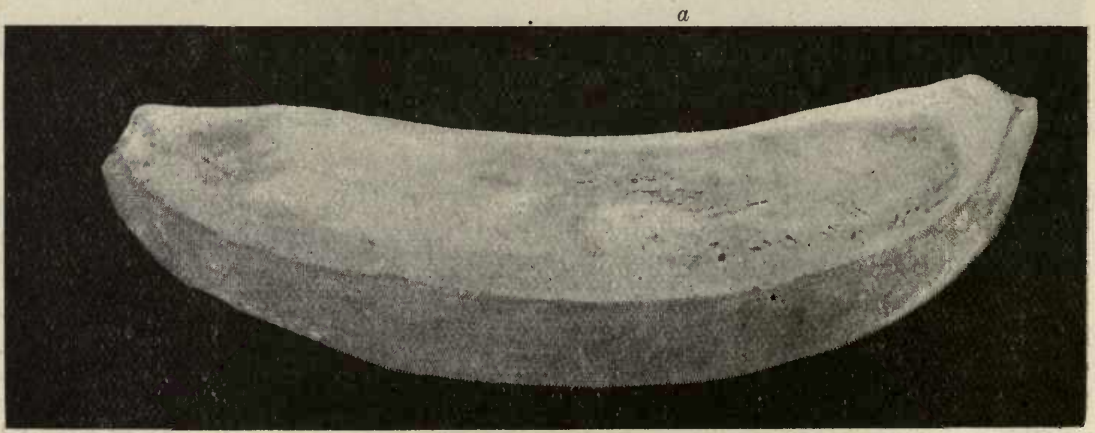

Fig. 47.-A banana, showing the initial stage of scab. The disease has made a beginning opposite $a$, where the skin is seen to be opening in small cracks. A stage later is shown in Fig. 48.

We will begin then by describing Banana Scab as it occurs on bananas imported into Sydney from the northern ports of Queensland.

The specimens from which the description is prepared came from Cairns, Queensland, and consisted of nearly full-grown bananas, the 
disease not having reached a climax in time to arrest their growth. Inasmuch as the smallest specimens were those worst affected, it would seem probable that the disease occurs on young fruit, and in that case dwarfs it, or it may be, destroys its value altogether. This inference is sustained by other observations.

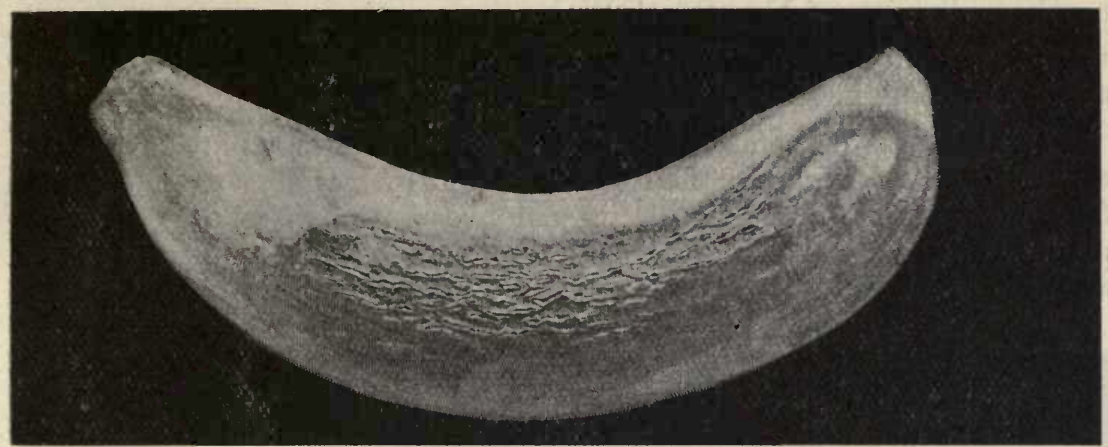

Fig. 48.-Secondary stage of banana scab. The discolouration and the cracks now cover most of one side of the fruit The later stages are shown in Figs. 49 and 50.

The earliest stages, as they occur on fairly well grown, but still green, bananas, such as would be cut for shipment, are as follows:A reddish-brown colour appears on the green skin in the form of minute transverse markings. These markings soon merge into a uniform brown area, often of considerable extent, some parts of which may become black. In the midst of this dark-coloured area numerous shallow longitudinal cracks make their appearance. Following upon the appearance of the cracks, the skin begins to dry up and take on a greyish brown colour, the cracks meanwhile assuming larger dimensions, though never becoming more than a millimetre wide, and seldom more than half a millimetre wide. The cracks finally run together more or less, so that the surface of the skin of the fruit reminds one of the appearance of crackled glassware. (See Figs. 48 and 49.)

In the early stages of the disease the inner layers of the skin or peel appear to remain intact, but as soon as the crackling sets in the skin begins to dry up and its inner layers to lose their green colour and succulency, so that the skin decreases in thickness on the diseased area, and so far fails to function that ultimately even the flesh of the fruit is affected. When such bananas are " ripened" in storage, preparatory to sale, the "ripe" fruit presents dry grey patches, from which the skin cannot, perhaps, be readily removed. Under such patches the pulp is often grey or brown, hard, dry, astringent and inedible. The flavour of the rest of the banana is also inferior. (See Figs. 49 and 50.)

It is unlikely that the reddish colouration noted in connection with the early stages of the disease is a uniform and reliable characteristic, for it will be remembered by all who are familiar with the behaviour of this fruit in commerce, that such discolourations may be produced by a variety of causes. The fact seems to be that as. soon as the skin. 
of the banana is injured sufficiently to allow the access of air to the broken cells beneath the epidermis an oxidation sets in that has the effect of producing reddish and brownish colouration.

The different species of banana, however, act somewhat differently in this respect, and this may account for the fact that this reddish colouration is less common and less marked on bananas from the northern districts of New South Wales than on those from Queensland.

The general appearance of the disease is that of one due to the attacks of some vegetable parasite.

In some cases it seemed as if the disease had started at a point on the fruit where the latter had been chafed by rubbing against other fruit in the same bunch; still, in many cases the disease occurred in places that bore no traces of chafing, and the only conclusion I could arrive at from this part of the examination was the provisional one that

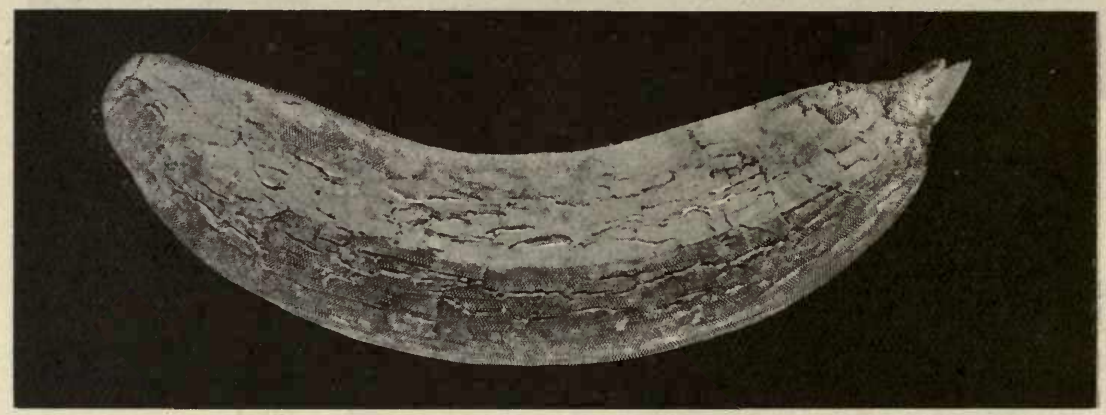

Fig. 49.-Advanced stage of the banana scab. The skin of the fruit is completely diseased, and the pulp is worthless. The skin is everywhere grey, dry, and crackled.

the malady was caused by a fungus having the power of attacking and penetrating healthy epidermis. This conclusion cannot be accepted without reserve until the disease has been produced on sound tissue through contact with germinating spores.

Sometimes the scab covers the greater portion of the surface of the fruit. In such instances it is out of the question that friction could injured so much of the surface. These cases add weight to the evidence already accumulated in favour of some fungus being able to. work its own way into the skin of the sound banana.

Some difficulties arise in searching for traces of the fungus causing. the disease. Pustules may be found scattered over the green or reddish parts of the skin in the form of minute raised points. They are to be found only on those parts manifestly suffering from the disease. These pustules have nearly the same general colour as the area on which they occur. Just previous to, or at the time of, rupture they measure three to four hundred micromillimetres in diameter, sometimes even six hundred micromillimetres.

If a recently ruptured pustule be cut away in such a manner that. little else is removed, and be then smashed in a very small amount of water, spores will usually be found, though not in great numbers. 
according to my experience, and it may be, in rare cases, none will be seen. The spores are not easy to make out at the first glance, because the broken remains of the banana tissue are often of about the same size as the spores, as are also the fragments of needle-shaped calcium oxalate crystals that may appear in some preparations. After an hour or so in water the spores are more easily seen. Still more readily are they to be seen after germination takes place. Thus, as a rule, after about twenty-four hours in an infusion of banana-peel the spores are readily made out. The most useful and positive results are obtained by this method, so far as relates to identifying the organism in the pustules.

\begin{tabular}{|c|c|}
\hline $\left.\begin{array}{l}7.0 \times 3.5 \mu \\
5.5 \times 2.5 \mu \\
4.7 \times 1.5 \mu \\
5.5 \times 1.0 \mu \\
5.4 \times 3.5 u\end{array}\right\}$ & $\begin{array}{l}\text { Measurements in } \\
\text { micromillimetres } \\
\text { of five spores } \\
\text { from one pustule. }\end{array}$ \\
\hline
\end{tabular}

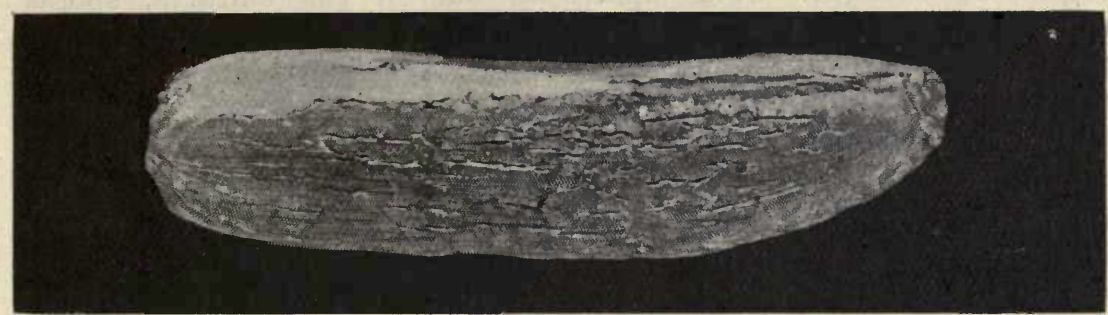

Fig. 50.-Final stage of banana scab. The skin is entirely dry, grey, and cracked, and the pulp is worthless.

The foregoing are the measurements of two sets of the colourless spores taken from pustules that precede the cracks on scabby bananas. Upon examining the diseased bananas with a magnifying glass, it appears that each crack is probably preceded by a minute pustular outbreak. Upon removing a pustule with the point of a needle, taking care to select a pustule that is recently ruptured or is just about to rupture, one easily secures spores measuring $4 \cdot 7$ to $7 \cdot \times 1 \cdot$ to $3 \cdot 5$ micromillimetres, as shown by the above measurements, and averaging $5 \cdot$ to $6 \times 3$. micromillimetres. These spores are ellipsoidal, or sometimes elongated, colourless, and without any definite and regular internal markings except an uncertain granulation. From the manner of their growth on minute basidia, these appear to be the spores of some Phomalike form. (See Figs. 51, 52, and 53.)

An examination of several carefully selected pustules that had not yet been ruptured revealed but few spores of any sort, but those seen were all of the character already described. These were allowed to lie for some time sealed up in an aerated water infusion of banana peel. Only elongated spores were revealed by this germination test.

In these examinations, care was taken to clean the tops of the pustules before removal from the diseased fruit. 
A number of experiments and observations of a similar nature led to the conclusion that the sole organism in the pustules is the fungus

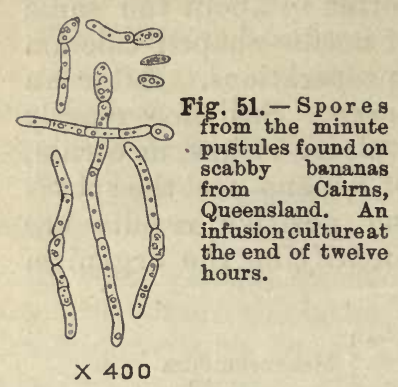
producing the elongated ellipsoidal spores, and to the conclusion that this fungus is probably the cause of the disease Banana Scab.

The above-mentioned spores on being subjected to water culture, or rather to growth in water impregnated with the juices of the banana peel, germinated promptly from one or both ends. (Fig. 51.) After the lapse of twelve hours the mycelial thread from the spore may reach the length of 75 micromillimetres. The mycelium at this stage is colourless, for the most part unbranched and without septa, nearly straight, and of about the same diameter as the spore from which it originated. Soon after reaching this size the mycelium begins to branch. Some spores in one of the cultures, spores apparently in other respects identical with those just described, gave rise to conidia by a species of division. (Fig. 53.) In one or two cases the mycelium, after reaching a length of 50 to 75 micromillimetres, appeared to be forming conidia at the end.

While it was at most times difficult to discern any trace of mycelium among the cells of a section cut from a pustule, it was always the case that after a few hours mycelium could be seen sprouting from the section in such a manner as to preclude doubt that it originated from

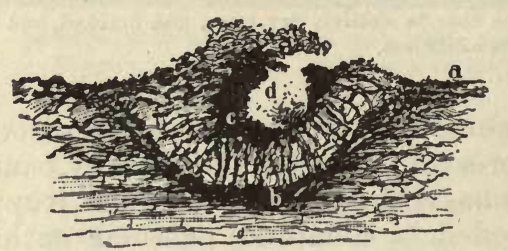

Fig. 52.-Cross section of a pustule of the banana-scab fungus. $a$, epidermis of banana; $b$, columnar alteration in tissue; $c$, wall of perithecium; $d$, spores borne on basidia. mycelium hidden away among the mazes of the cellular tissue of the banana. These branches of the mycelium of the disease-producing fungus often grew so vigorously as to pass entirely outside the tissue of the section and thus came into good view. The size of these mycelial threads was such as to lead to the belief that the mycelium, as it occurs normally in the tissues of the banana, is a very attenuated one, often measuring no more than one to two micromillimetres in diameter. A weft composed of mycelium of this calibre hidden away among dark tissues of a varying structure is necessarily difficult to make out, and I think this accounts for the failure to secure what may be regarded as altogether satisfactory data with reference to the internal structure of normal pustules.

The behaviour of the sections of the perithecium, when allowed to remain in an infusion of banana-peel for twenty-four hours to fortyeight hours, furnished data of a much more satisfactory nature.

It not infrequently happened that on examining a carefullyprepared section very few spores were found. When this was the 
case it was only necessary to allow the section, just as it came from the dissecting stage, to lie sealed in water for twenty-four hours or thereabouts to obtain spores in a state of germination. The spores, under such conditions, were either produced anew by the mycelium or were loosened so as to float out into view. (Fig. 52.)

The mycelium of the fungus, when freshly torn away and floated out where it could be seen, was often very fine, not much exceeding a micromillimetre in diameter.

If pustules are sectioned and placed in a sealed water-culture, the neighbourhood of the cut perithecium, after about forty-eight hours, is sometimes the scene of an active production of sporules. These originate at first from that portion of the fungus inside the pustule; and then, getting free, increase outside by division. In one instance I observed that this growth took place in a slightly gelatinous substance which was clearly concentric with the cut perithecium. The spores produced by this process are illustrated in Fig. 53. After

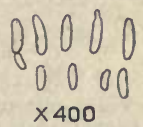

Fig. 53.-Secondary growth of spores from a section of a pustule found in banana scab, water-culture after forty-eight hours. These spores were enveloped in gelatine. forty-eight hours, this growth of sporules begins to show signs of failure; the later spores produced by division are much smaller, and are more attenuated. Adjoining are some measurements of spores arising in the manner just described.

1. $12 \cdot 0 \times 2 \cdot 5 \mu$

2. $11.0 \times 3.0 \mu$
3. $8.0 \times 3.0 \mu$

4. $7 \cdot 0 \times 2.5 \mu$

5. $4.0 \times 1.4 \mu$

6. $\left.3.6 \times 0 \cdot 7_{\mu}\right)$
Before being ruptured, the cavity of the perithecium is capped by tissue that in cross-section appears nearly black ; so also the bottom of the cavity when viewed in cross-section is dark red or nearly black. The whole is underlaid by a stratum of somewhat columnar cells which have apparently originated through an attempt on the part of the plant to counteract the parasite. Such columnar tissue is not to be seen elsewhere in the section-that is to say, in the more or less normal tissue beyond the borders of the pustule. (See Fig. 32.)

When material is scraped from the cracks present in well-developed scab, and the pulverulent matter thus obtained is placed in water under the microscope, it is easy to find in it the same spores that are charncteristic of the pustules. They are usually found in such considerable numbers that the conclusion suggested is that the reproduction of the fungus takes place quite as vigorously in the fullyformed scab as in the pustules which precede it. (Fig 54.)

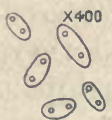

Fig. 54.- Spores obtained under the scab of banana. These may be derived from pustules similar to those described in the text.

At the same time one finds among the material derived from scab in this manner large numbers of yeast cells, and these show up with such regularity as to constitute a marked microscopic feature of this phase of the disease. Especially abundant are these yeast cells in cultures inoculated from loose scabby material. 
I cannot feel sure that this yeast is not a contributory cause of the scabbiness, through its action on the tissues first opened up by the attacks of the scab-fungus. The form of this yeast as procured from cultures in infusion of banana-peel are shown in Fig. 55.

Owing to the possibility that this yeast is a contributory factor in the disease, a few words with regard to it are not out of place.

When first removed, and therefore the result of what may be termed dry growth, in contradistinction to the culture growth soon to be mentioned, the cells of the yeast

$8 \infty 8 \infty$

(-) 0 \& 80 $\times 400$

Fig. 55. - Yeast cultivated from banana scab. are usually very small and nearly spherical. The cells are seldom obtained in a budding condition under these circumstances. While a vacuole may sometimes be seen, it is not a prominent feature. After a few hours cultivation in an infusion of banana-peel the cells appear larger, and often present a very distinct and bright vacuole near the side or end of the cell.

On being allowed to remain in the infusion for twenty-four hours this yeast buds vigorously, giving rise to such forms as are shown in Fig. 55. The longest chain seen consisted of seven spores; but such chains were very rare. After the growth had proceeded for a. while in the infusion, the vacuoles assumed a more central position, and became less conspicuous.

These yeast cells are never found in the interior of unbroken pustules, although they are often to be found in those that have only recently burst.

From this it follows that this yeast must be regarded as one that lives on the surface of the banana, and on the sweetish and gelatinous exudations originating in the ruptures produced by the fungus causing the pustules. It may be that this is the race of yeast utilised in the production of banana wine.

It will be seen that a marked feature of the disease as here described is the fewness of the spores to be found in the cavity of the perithecium, and the fineness of the mycelium. The preparations have, however, shown in a satisfactory manner that such spores are produced in the perithecium from minute basidia, after the manner of those fungi referred to the genera or "collections," Phoma, Myxosporium, \&c., and there can be little hesitation in assuming that the broad relationships of the fungus are thus made out.

A number of fungi of this nature, inhabiting the banana plant, have been described from different parts of the world; but seldom with sufficient completeness to give the descriptions much value, and when one has spent valuable time in hunting up such literature, it may occur to him to doubt the advisability of encumbering the nomenclature with a further addition, even if it be as the result of extended investigation, especially in view of the established uncertainty of the general relationships of many of the allied forms.

"A rose by any other name would smell as sweet"; doubtless this fungus, fitted with a Latin name, would spoil just as many bananas. 
I am, therefore, quite content for the present to leave this little pest outside the statistical fold, believing that when in the fulness of time those investigations are made which will lead to a real knowledge of the full life-history of such forms, there will be no difficulty in assigning to its proper place this scab-producing fungus of the banana.

\section{The Scabby Banana in Commerce.}

Several questions arise in connection with the handling and sale of scabby bananas. Should anything be done to check or prevent the importation of such fruit? Can anything be done to check the progress of the disease after the bunches are cut and forwarded?

I think the answer to both these questions must be negative. The time that elapses between the cutting of the bunches and the consumption of the fruit is not more than a few weeks, and the progress, of the disease during that time is not very great, and is of such a nature as to be beyond control except in so far as new infection may occur. I know no reason to suppose that such fresh infection does not occur, but there is good reason to believe that if it does occur it does very little harm. The greatest harm done by the disease is on young fruit; its effect when it attacks partially-grown fruit is not so serious. The progress of the scab is so slow in comparison with that of the growth of the fruit that the latter reaches a marketable size if the attack of the disease is delayed until it is half-grown.

Nor does a study of the disease lead to the conclusion that the importation of bananas suffering from it is in any way prejudicial to the fruit industry of any regions, except such as may be devoted to the cultivation of the banana itself. Leaving these latter out of consideration for the present, we will consider the importation into Sydney and the shipping inland by rail. Here we have the case of a tropical fruit whose diseases are for the most part likely to be of a nature different from those characteristic of the regions into which it is imported, especially when we consider that the fruit itself belongs to an order of plants widely different from those the possibility of whose infection we have in mind. These general considerations are borne out by all the observations set down in the previous pages. I do not know of a single disease of our temperate fruits that bears a sufficiently close resemblance to the banana scab to raise any suspicion that the two may be identical.

It is, however, possible to be too optimistic in such matters. There is another disease of bananas that, in spite of these plausible reasonings, is found to be capable of infecting all sorts of temperate fruit; I refer to the Gloeosporium or ripe-rot of the banana. (See pp. 7-9.)

Nor does it seem probable, so far as our importations are concerned, that any precaution as to the destruction of scabby bananas and their cast-off skins would pay for the trouble. We have on another page pointed out that greater care in respect to decayed fruit would lead to beneficial results in our fruit stores and shops, $*$ and in case the precaution is being taken for other reasons, it would be practically no additional trouble to include banana-scab in the same measures. 
It must not be forgotten that there is some loss from the fact that scabby bananas, if full grown, will not keep as well as sound ones. This may be easily verified by a few observations at any fruit-shop where scabby bananas are on sale, or by buying a few scabby and sound bananas from the same bunch and allowing them to go to decay.

The poor quality of scabby bananas is well-known to fruiterers, who as a rule are only too glad to get them off their hands.

\section{Remedies.}

Inasmuch as the spores of banana scab are prevented from growing by the salts of copper and lime that are used as fungicides, there can be no hesitation in recommending their trial for the prevention of banana scab. Care should be exercised in their application because it is not yet known to what extent the banana plant in its different varieties will stand the application of these compounds. It would be best to begin with the Bordeaux mixture in its weaker forms. These are not likely to injure even the most tender foliage. As the result of examinations and experiments I think the banana will not suffer from these applications, though opportunity has failed me for trials in those tropical regions where the banana is mainly grown.

The prevalence of showery weather is a drawback to the application of fungicides, and it is likely that some difficulties will arise in this connection. The spraying of banana plants is a comparatively easy matter so far as their form is concerned.

The applications will be most likely to be successful if made in the erening.

\section{On the Plantation.}

When disease appears in unusual force on a plantation, it is wise to give careful attention to the cultivation, and to the supply of plant-food in the form of manures. It is a well-known fact that disease is more destructive to plants that are poorly nourished than to those that are well fed and robust. All plants are endowed with an instinct that causes them to make an effort to ward off the attacks of their natural enemies, and a plant that is weak will be less effective in its defence than a plant that is robust.

The above fact has led sometimes to the expression of opinions that will not stand examination. I have heard people, supposedly well informed, say that all that is required in the matter of crop pests is to practice good culture and use the right manures, when everything else will take care of itself. Unfortunately this is not so. We have so changed the original nature of our cultivated varieties that in many instances they have become very susceptible to their natural enemies, so susceptible that unless we give especial attention to these latter the crops almost invariably suffer more or less, and not infrequently fail altogether. 'I'his is because we have by selection brought the plant to a pitch of unnatural productiveness or earliness that leaves it 
insufficient means to provide against the attacks of fungus and insect enemies, to which it succumbs readily if no care is exercised in its protection.

It is, therefore, the best policy to take advantage of every well-tried and successful means of dealing with these pests.

Among the various precautions suggested by the nature of the present disease is the destruction on the plantation of all scabby bananas, and the refuse from the same, as well as the destruction of all other parts of the plants harbouring the fungus. Care in this respect will be well repaid.

In the formation of new plantations care should be taken to secure sets free from the disease. While this precaution cannot be relied upon to keep the new plantation free from disease indefinitely, it will do something towards that end, inasmuch as the disease will be compelled to make its way to the new plantation by the aid of its spores borne on the wind or other carrying agency. The arrival of the pest by these means will not be such as to attract immediate attention, since it will be by degrees. A watch should therefore be kept, and measures adopted accordingly.

Where there are a number of plantations very near together it is to the advantage of each to have the neighbouring plantations as clear of disease as possible. The seeds of disease are for the most part easily carried between neighbouring plantations by wind and other agencies. It will be an impossibility to keep a plantation absolutely free from disease if there are diseased plantations adjacent. This fact should lead to more co-operative effort among neighbouring fruit-growers than usually exists.

\section{Scab on Fiji Bananas.}

The external appearance of this scab is the same as of that from Queensland, but on examination with a magnifying glass it was not always possible to find the pustules seen on the Queensland bananas. In one instance the examination of the fresh material did not show any spores among the débris from the cracks in the scab.

It appeared sometimes as if the scab started as depressions in the skin, as if from an insect puncture. Then, again, small scabs would be found that had no appearance of ever having been a depression. In this instance also the scab occurred on all sides of the fruit, a fact that precluded the idea that it originated from chafing.

Of samples sent in by Mr. Inspector Martin, part were of the ordinary form of gray scab, showing, after twenty-four hours' water culture, both mycelium and the elongated spores, of which measurements are given below. In contrast with the scabby bananas from Cairns, these did not yield an abundance of yeast cells in the water cultures. In the dry scab it was not easy to find the elongated spores. but occasionally they could be seen. 


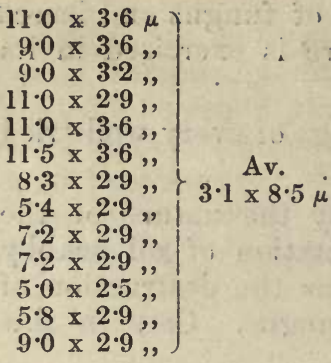

In the accompanying measurements it is probable that an excess of the larger spores:was measured. The average of the measurements of the spores as taken is $3 \cdot 1 \times 8 \cdot 5 \mu$, which is probably a little large. From this it appears that these spores are to all intents and purposes of the same form and size as those of the Queensland scab. Their general appearance was in all respects the same. There was this important difference, that generally no pustules could be seen, the Fiji spores being derived from the cracks in the scab.

Other spore-forms were seen on the Fiji bananas. In particular, mention should be made of some spores of Dinemasporium. These were drawn and measured, but no pustules were seen, and in fact the spores occurred in only a single preparation. (See Fig. 56.)

Two of these bananas from Fiji presented a red scab which had such striking peculiarities as to lead me to more than suspect it to be of a different character. It occurred in both specimens on the incurved side of the fruit, and this side was almost completely covered with a brick-red scab cracked in the characteristic manner. If this one side of the fruit had been carefully painted it

Fig. 56.-Species of Dinemasporium found on banana from Fiji. could hardly have looked more artificial. The margins of the terra-cotta colour were precisely coincident with the angles of the fruit. If there was any part of the coloured area that differed from the rest it was the lower part. Here it seemer as if the disease had not yet reached its full intensity, the original green of the skin being not yet completely covered.

The most careful search discovered no fungus pustules on this red area; only near the stem, where the red colour had been succeeded by a brown, were there traces of fungus spores. These have not yet yielded satisfactory data for an opinion as to their connection with the disease.

\section{STIGMONOSE.}

[See Coloured Plate opposite.]

A NUMBER of maladies of obscure origin have from time to time been

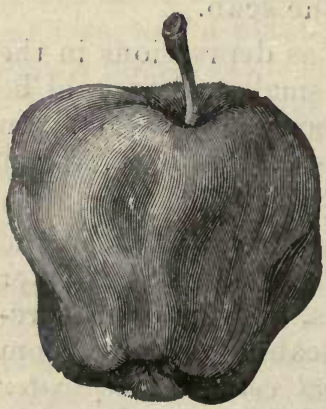

Fig. 57.-An apple suffering from an obscure disease, prob ably a kind of Stigmonose. brought into notice by correspondents who as a rule have forwarded samples in the shape of fruit and foliage. It is a peculiarity of these cases that they hail from all parts of the Commonwealth. Nor are they confined to any one class of crop, though they are usually either the fruit or the foliage and branches of fruit-trees. Apples, pears, and quinces may be said to be most frequently sent.

One of the first instances of this sort was the disease reported upon under the heading "An Obscure Disease of the Apple.". Next came a disease to which I applied the name "Bitter Pit," a name that has been widely 


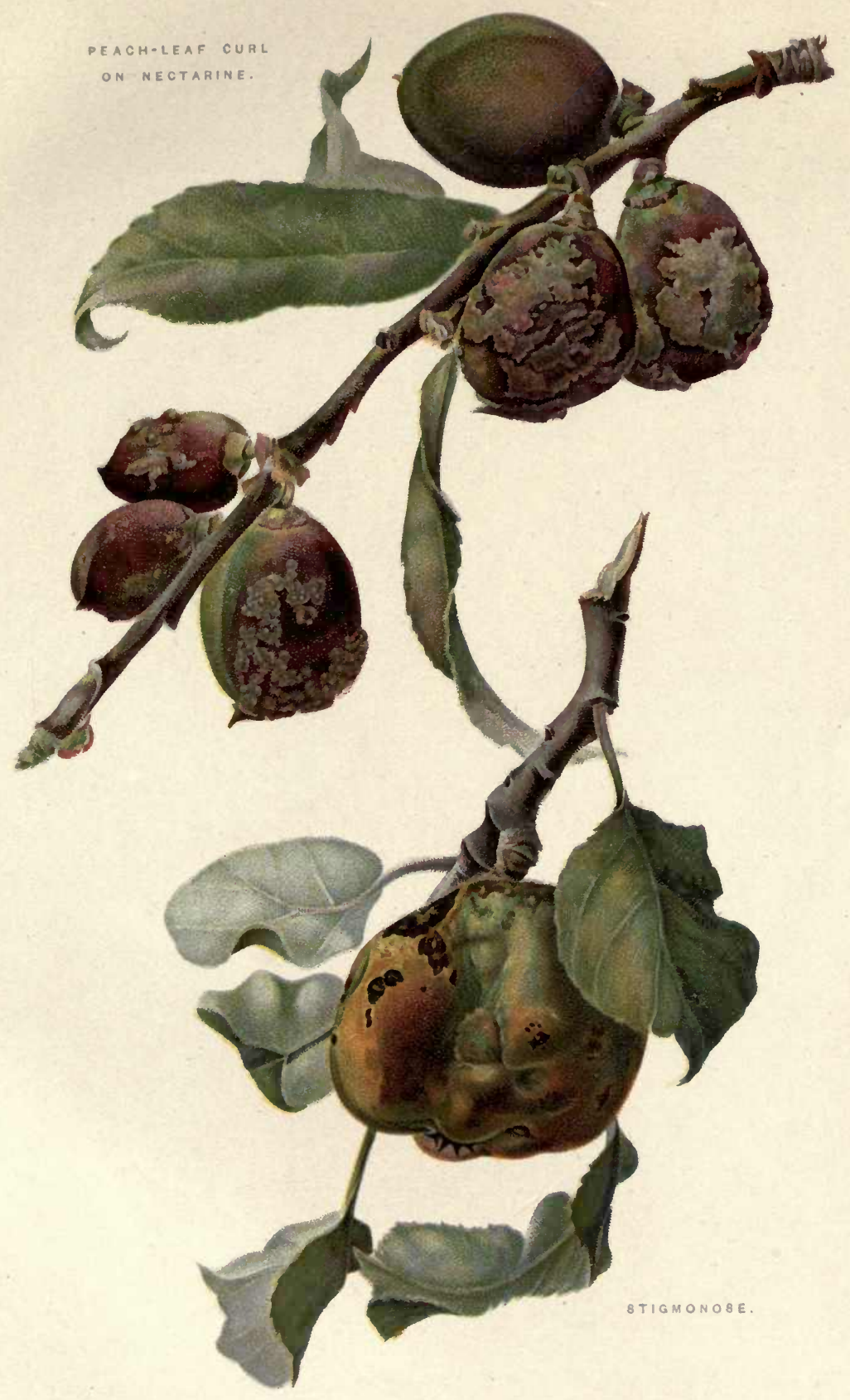

DISEASE OF THE APPLE AND NECTARINE. 



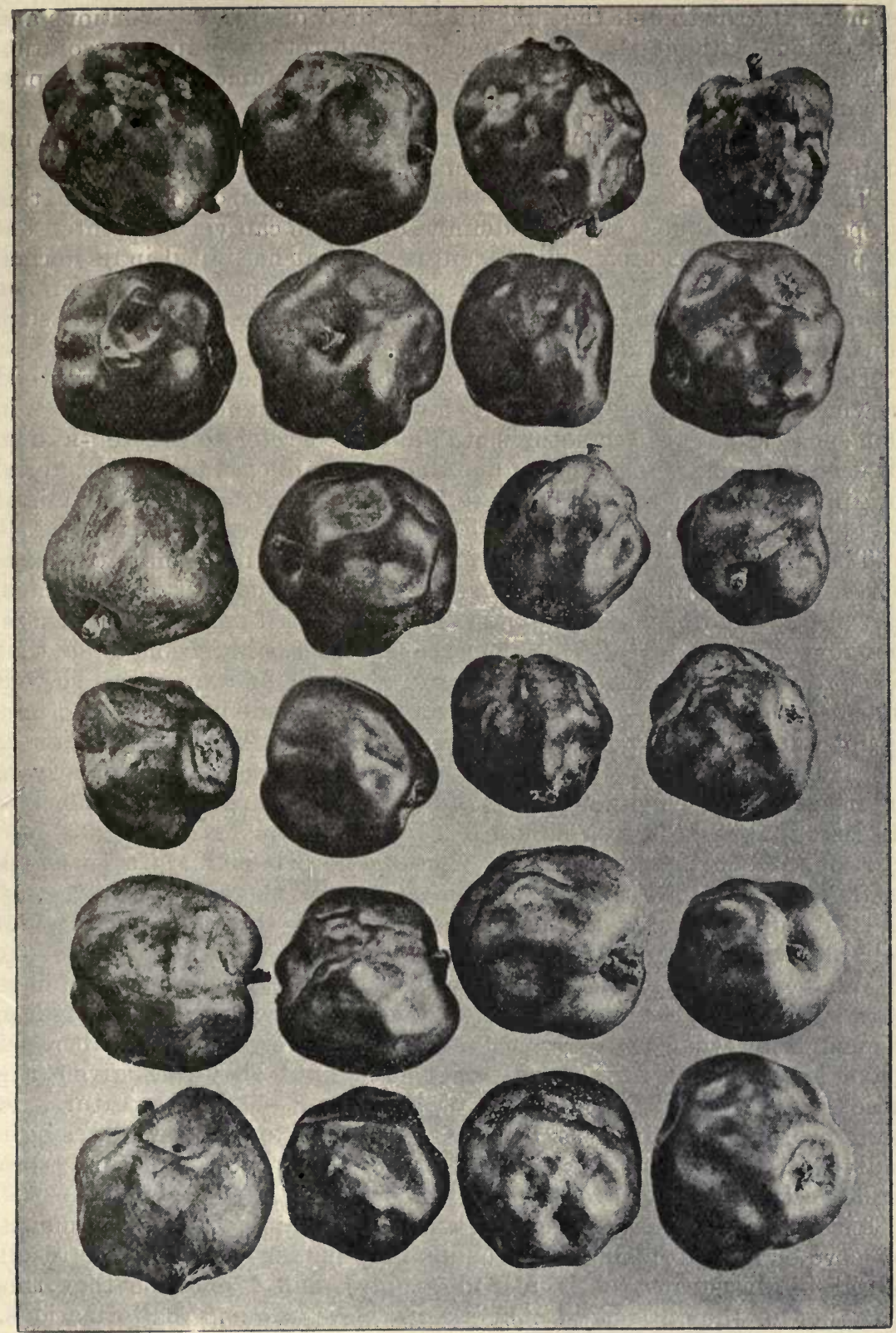

Fig. 58.-Apples suffering from a kind of Stigmonose. All these apples were infested with Woolly - Aphis, the insects being found in the core and the passage leading to the core.

accepted and definitely applied. These were followed by a variety of other distorted growths, mcstly among fruits. All these cases have 
some features in common, the most prominent of which is the stoppage of normal growth and the substitution for it of various abortions and distortions without the appearance of that rot and rapid dissolution which are wont to follow on the attacks of numerous disease-producing fungi and of some insects.

I find these various maladies gradually ranging themselves in $\mathrm{my}$ notes under the heading of Stigmonose.

These various diseases bear another resemblance to one another in this respect, that in most cases no definite organism can yet be pointed out as positively the cause. All present tissue that has failed in its normal functions, and, as before remarked, apparently without the interference of a micro-organism such as we ordinarily find associated with such appearances, say a fungus or a microbe.

Dr. Woods, of Washington, seems to me to have done very good service to pathological science in showing that the exciting causes in one such case are the punctures of aphides. I refer to the well-known disease of Carnations, which at one time was supposed to be of bacterial origin. He has called this disease "Stigmonose," and the term might be general in its application, as, I believe, he suggests.

There are a number of small creatures that make minute punctures in plants in the process of securing their food, not only aphides, but also mosquitoes, scale-insects, small bugs, red spiders, and others, not forgetting the free-living nematodes. The point seems to be that the proboscides of these animals are so small and probably so well sterilised by natural secretions that the wound made by their punctures is not entered by any micro-organism, and yet either the irritation or the chemical action of the injected animal secretions subsequently so interferes with the normal growth of the tissues as to give rise to marked disease, that is, to "Stigmonose."

It is, of course, possible that these puncturing creatures in some instances produce disease after the manner of the cattle-tick, i.e., by the introduction of some micro-parasite, but thus far there is no reliable evidence that this is the case.

What is wanted is careful and expert observation of all small puncturing creatures, especially during the early growth of various fruits, remembering that the presence of comparatively small numbers of them may account for considerable damage if they are given the necessary time. It is the habit of a number of these creatures to puncture, suck, then pass on and repeat the operation. A single individual acting in this manner would, if each puncture were sufficiently irritating, produce an appreciable effect.

It seems probable that these organisms are supplied with the means of more or less sterilising the wounds they make (otherwise the result might be disastrous to their food supply), and it may be that this accounts for the absence of parasites in the subsequent malformations.

Observation is gradually assigning each of these separate maladies, or varieties of Stigmonose, to its specific puncturing cause, but the progress is rather slow. Among the puncturing species that are under suspicion are Thrips, various Aphides, small Arachnids, and Nematodes. Among the Aphides, one species has been proved by Dr. Woods to be 
the cause of a disease in carnations. In the same connection some mites are laid under suspicion, also species of Thrips. I have shown the presence in the cores of apples of the woolly aphis at the same time that the apples were suffering from distortion and a checked growth. I have also called attention to the presence of Nematodes between the leaf stalks of celery, and the probability that they there cause damage, and possibly this may also come under the heading of Stigmonose.

In these latter years the Acarine species known as the Red Spider has often come under the gravest suspicion as the cause of a widespread and common disease of the pomaceous fruits, namely, the apple, the pear, and the quince. In order to bring the matter pictorially before the reader, I have inserted good illustrations of some of the. cases. The plate on page 39 contains photographs of some apples that were attacked by woolly aphis. Every apple contained living insects, and these were accompanied by so many cast-off skins as to prove that the insects had been inhabiting them

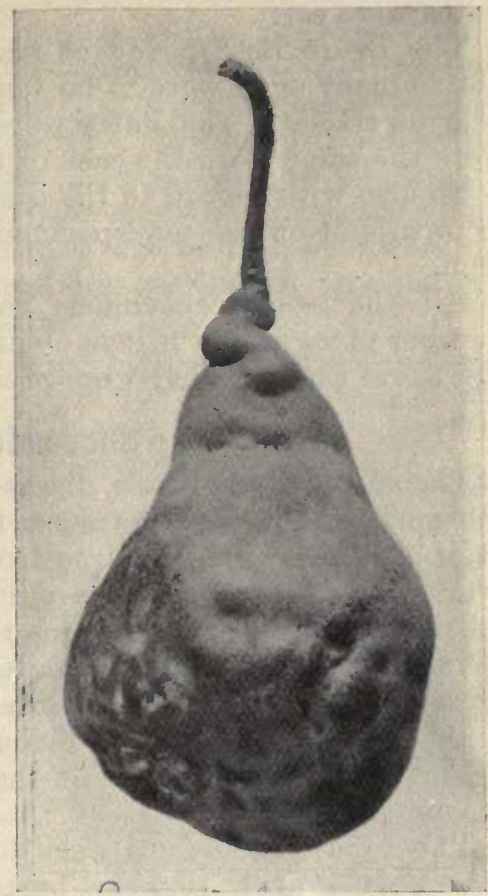

Fig. 59.-Pear suffering from Stigmonose. The fruit is much deformed and one-sided. From end to end the peculiar malformations are to be seen, though they are most numerous at the blossom end. for some time. Figs. 59 and 60 show the effects of a disease common in all the Australian states on apples, pears, and quinces, though less common on the latter. Such appearances are almost invariably accompanied by traces of what is known as red spider, in fact it is very rarely indeed that eggs, or some other signs of these, may not be seen in the eyes or elsewhere on such specimens.

On one occasion the apple varieties Winter Pearmain, Granny Smith, Winter Magetin, Kadwell's Nonpareil, and Fanny; the pear varieties Beure Bosc and Butter; the quince variety Mammoth; were examined with the following results :-

All the apple varieties were found

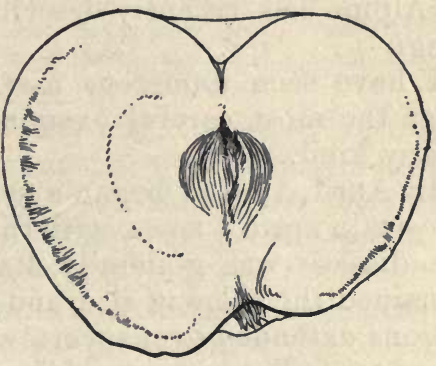

Iig. 60.-Section through an apple that is suffering from Stigmonose. The irregularity of the surface of the apple is indicated by the irregularity of the contour line of the section. A short distance under the skin there appears a layer of spongy brown tissue characteristic of this disease as it appears in full-grown apples. This is represented in the figure, especially on the left-hand side. 
to be infested with red spider. Eggs of the mite were found in abundance at the eyes of most of the specimens. Very few living mites were seen.

The Beure Bosc pear was manifestly infested with the spider, but not so many eggs were to be found as on the apples. On the Butter pear no traces of the mites were to be seen, although the deformities were the same as in the case of the other varieties.

So also with regard to the quince. The deformities were identical in form, but on the few specimens sent no definite traces of mites were seen.

All the above specimens came from the same orchard. The number of eggs in the eye of an apple reached two to three score in the worst cases. They were present in every apple examined.

\section{Shot-hole Stigmonose.}

The so-called shot-hole disease is one of the few serious diseases of the apricot. This fruit tree is for the most part very vigorous with us, if only it can be kept free from shot-hole. Not infrequently, however, this disease makes sad havoc with the crop. Every season specimens are forwarded to me representing badly diseased crops that have been a total or partial failure. The disease is almost universally present in a mild form, and only awaits the right conditions to make itself felt in the shape of obvious money loss.

For some time I have felt that.our theory of this disease did not account for all the facts.

The disease is commonly set down as of fungus origin, and remedies have been proposed on this basis, and these remedies have been more or less successful.

There can be no doubt that certain fungi do cause the so-called shotholes to appear in the leaves of the apricot and other stone-fruit trees. The fungus Phyllosticta circumcissa is that to which shot-hole used to be referred. I have described another form that is sometimes seen on the margin of shot-holes and of scabs on the fruit. Professor McAlpine has recently described quite a number of other shot-hole fungi.

I have seen numerous cases of this kind, however, that yielded, after the most careful examination, no traces of a vegetable parasite of any kind.

In April, 1901, I began a systematic examination of the shot-holes of certain apricot trees, with the result of proving that on mature leaves the disease was generally stationary. Week after week the holes remained the same in size, and new holes did not appear. The observations extended over several weeks. No traces of a vegetable parasite were seen. The opening of the following spring was awaited with much interest, as this would give an opportunity to extend the observations.

A continuance of similar observations proved that the shot-holes appeared on very young leaves, leaves that were still in the early stages of growth, and that they were preceded by very minute decoloured areas, in which, however, no vegetable parasite could be discovered. The holes in the young leaves increased in size with the growth of the 
leaf, and this appeared to be a mechanical result of growth. No parasite appeared at any subsequent stage, notwithstanding the increase in the size of the holes.

As the disease was traced farther and farther into the opening bud of the growing shoots, it was felt that an adequate cause for the disease must present itself, and suspicion fell upon a microscopic insect larva belonging to the Thripsidæ. In the course of the investigations several species of Thrips have been seen in apricot buds (and also in those of the peach), and these may also be injurious, but not to any such extent as the larval form first mentioned, which may belong to another genus of the Thripsidæ.

This latter was uniformly present in apricot buds on trees showing shot-hole, one or more inhabiting each bud. This was found to be the case in numerous orchards in Cumberland county.

I had not been long studying the various holes to be found in the leaves of the apricot before I had come to the conclusion that the holes

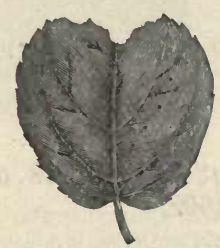

Fig. 61.-Young apricot leaf at the time it was pricked with an exceedingly fine-pointed needle which had been wined on the surface of an ant. The resulting shot-holes are shown in Fig. 62.

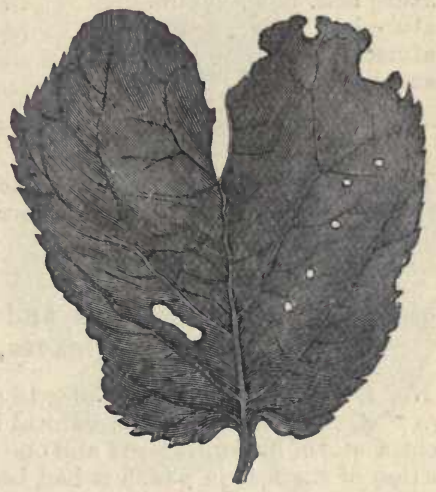

Fig. 62.-Mature apricot leaf showing row of five shot-holes, produced by very slightly puncturing the young leaf with an exceedingly fine-pointed needle. This is the leaf shown in Fig. 61.

were due to a variety of causes, and that they might arise as the result of mechanical injury and be in no way connected with parasites of any kind. Soon afterwards I was pleased to learn that other observers had already come to the same conclusion. The apricot leaf illustrated on this page, and showing five holes nearly in a line, was the result of one of my trials to see what effect mechanical irritation, in this case a series of minute punctures, would have in producing holes. Other experiments and observations proved that merely whipping the leaves about when they were young would cause holes to appear at a later stage of their growth, and that wind storms are in this way a cause of shot-holes. In a similar manner certain gnawing insects were observed to cause shot-holes. These were accustomed to gnaw away the tissue on the under surface of the leaves in small spots. These spots ultimately became "shot-holes." 
After I had become fairly well satisfied that certain very small insects, working in the opening bud, were instrumental in causing shot-holes, I . began a series of observations on such buds and their unfolding leaves. An account of some of these observations will now be presented.

\section{Notes on successive sizes and conditions of Apricot Shot-holes on mature leaves, March-April, 1901.}

\begin{tabular}{|c|c|c|c|c|}
\hline Initial Condition and Size. & & & After 15 days. & Final Condition and Size. \\
\hline 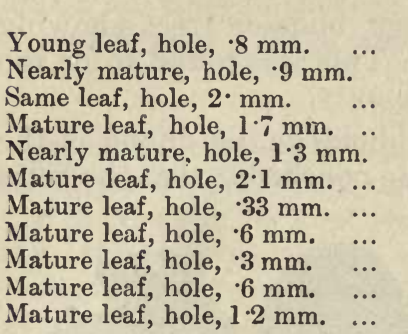 & $\begin{array}{l}\cdots \\
\cdots \\
\cdots \\
\cdots \\
\cdots \\
\cdots \\
\cdots \\
\cdots \\
\cdots \\
\cdots\end{array}$ & \begin{tabular}{l|}
$\cdots$ \\
$\cdots$ \\
$\cdots$ \\
$\cdots$ \\
$\cdots$ \\
$\cdots$ \\
$\cdots$ \\
$\cdots$ \\
$\cdots$ \\
$\cdots$
\end{tabular} & $\begin{array}{l}\mathrm{Mm} . \\
\cdot 8 \\
\cdot 9 \\
2 \cdot \\
1 \cdot 7 \\
1 \cdot 3 \\
2 \cdot 1 \\
\cdot 33 \\
\cdot 7 \\
\operatorname{lost} \\
\cdot 7 \\
1 \cdot 2\end{array}$ & $\begin{array}{l}\text { It will be seen that most of } \\
\text { the leaves were mature, } \\
\text { and that the holes showed } \\
\text { little, if any, signs of in- } \\
\text { crease. No marginal signs } \\
\text { of fungus growth were dis- } \\
\text { coverable with a powerful } \\
\text { hand magnifier used under } \\
\text { good conditions at the be- } \\
\text { ginning of the experiment. }\end{array}$ \\
\hline
\end{tabular}

It was concluded that at that season of the year (March 9 to April 27) this particular series of shot-holes were in a stationary condition.

\section{Notes on successive sizes and conditions of Apricot Shot-holes on very young leaves, October-November, 1902.}

No. 1. This leaf measured $36 \times 18$ millimetres on October 24 th, and at that time bore two " shot-holes" and a mechanical injury of another kind. Before the second measurement a storm had interfered and one of the two original holes had been torn off with the portion of the leaf in which it had been located.

\begin{tabular}{|c|c|c|c|c|c|c|}
\hline \multicolumn{5}{|c|}{ Initial Size measured in millimetres. } & After 10 days. & Final Condition. \\
\hline 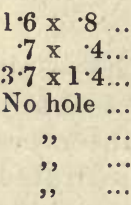 & $\begin{array}{l}\ldots \\
\ldots \\
\ldots \\
\ldots \\
\ldots \\
\cdots \\
. .\end{array}$ & $\begin{array}{l}\cdots \\
\cdots \\
\cdots \\
\cdots \\
\cdots \\
\cdots \\
\cdots\end{array}$ & $\begin{array}{l}\cdots \\
\cdots \\
\cdots \\
\cdots \\
. . \\
\cdots \\
\cdots\end{array}$ & $\begin{array}{c}\ldots \\
\ldots \\
\cdots \\
\cdots \\
\cdots \\
\ldots \\
\ldots\end{array}$ & $\begin{array}{l}\text { Missing } \\
1 \cdot 2 \times 2 \cdot \\
11 \cdot 2 \times 5 \cdot 7 \\
\cdot 3 \times \quad \cdot 3 \\
3 \cdot 6 \times 1 \cdot 6 \\
\cdot 2 \times \quad \cdot 2 \\
\cdot 7 \times 1 \cdot\end{array}$ & $\left\{\begin{array}{l}\text { The third hole measuring } 3 \cdot 7 \text { x } \\
1 \cdot 4 \text { is that mentioned as a } \\
\text { mechanical injury due to some } \\
\text { other cause than the usual cause } \\
\text { of these shot-holes. }\end{array}\right.$ \\
\hline
\end{tabular}

Another leaf on the same branch contained three holes, $\cdot 6,1 \cdot$, and 1.5 millimetres long, and these became larger in the course of ten days, as is indicated by the following measurements given in the same order as above : $1.4 \times 8 ., 3.7 \times 2$, and $5.4 \times 2$. The amount of increase shown by the figures $1.4 \times 8$, is deceptive, inasmuch as the great increase in length is due to the addition of two adjacent spots. The branch was broken by accident on the tenth day.

No. 2. This leaf was $19 \times 10$ millimetres at the beginning of the experiment, and had attained at the close of the experiment the dimensions $88 \times 75$ millimetres. Whenever examined the branch on which it grew was found to be free from aphides and ants, but some Thrips insects were seen. At the outset there was a single hole, and upwards of 
ten minute points at which it was evident that some sort of injury had been inflicted, the most prominent evidence being a more or less marked discolouration.

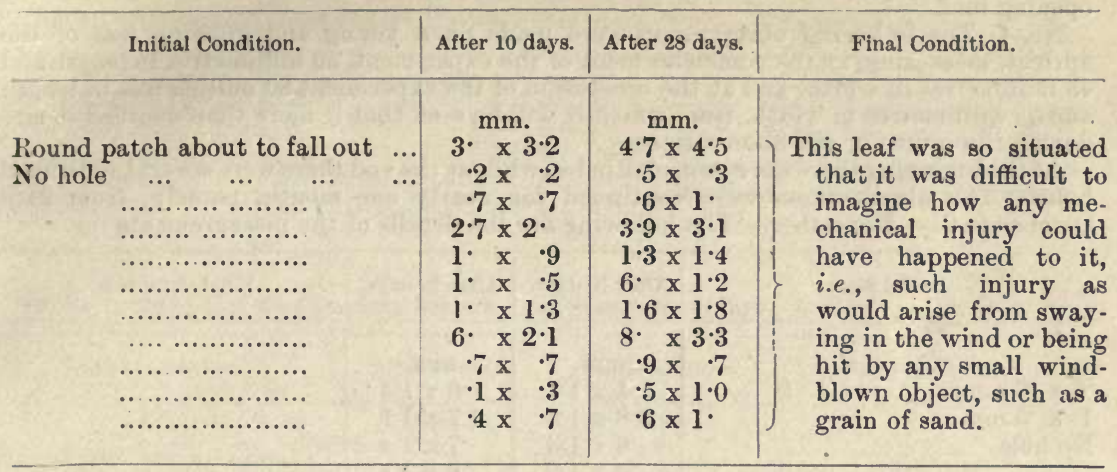

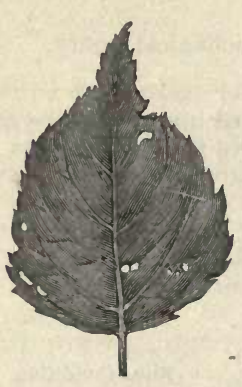

Fig. 63.-Apricot leaf at the beginning of an experiment. Compare with Fig. 64, which represents the same leaf at a later date.
Fig. 64. - Apricot leaf at the end of the experiment. Com. pare with Fig. 63.

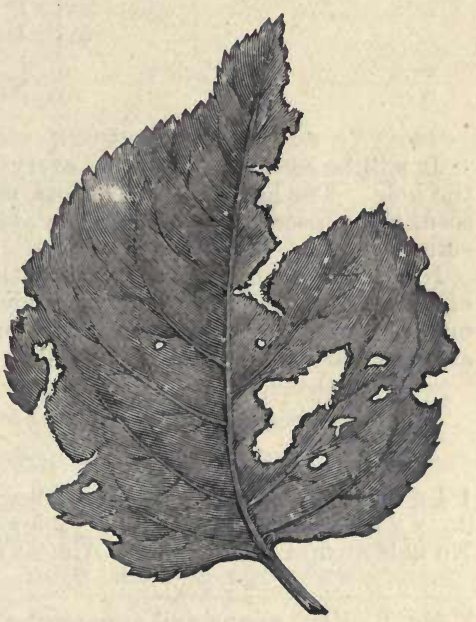

No. 3. This leaf measured $27 \times 21$ millimetres on 24th October, $49 \times 50$ on 4 th of November, and $60 \times 60$ on the 20 th November, thus showing an increase of three to four fold during the experiment. It was a young and rapidly growing leaf.

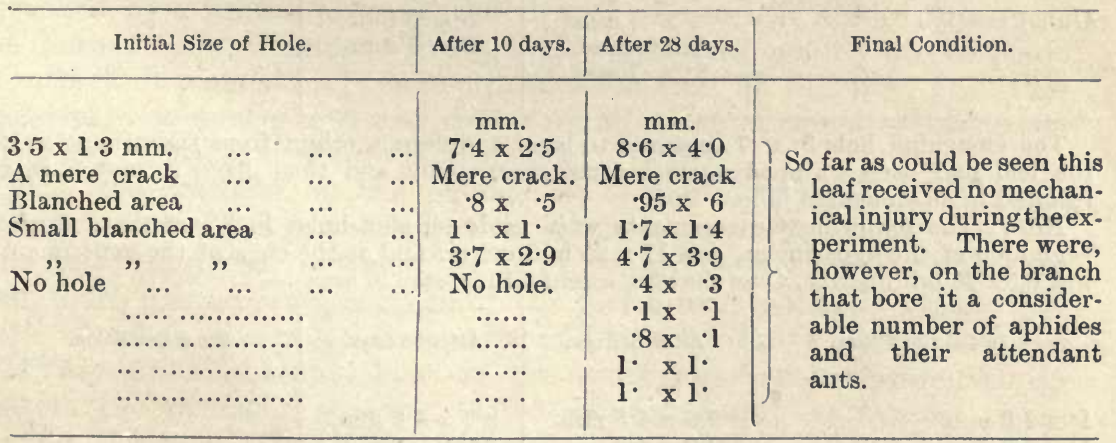

Nearly all the later holes of this series, and probably all, were visible at the com. mencement of the experiment in the shape of very small blanched areas. 
No traces of fungi were seen with the strong magnifier that was used in making the measurements. The injuries appeared to have started while the leaf was still in the opening bud.

No. 4. The following observations were made on a young and growing leaf of the apricot, measuring, at the commencement of the experiment, 50 millimetres in length and 43 millimetres in width, and at the conclusion of the experiment 80 millimetres in length and 77 millimetres in width, from which it will be seen that it more than doubled in size during the course of the observations.

At the beginning there were two small holes, while at the end there were several additional holes. The observations were continued for nearly one month, namely, from 24th October to 2lst November. The following are the details of the measurements :-

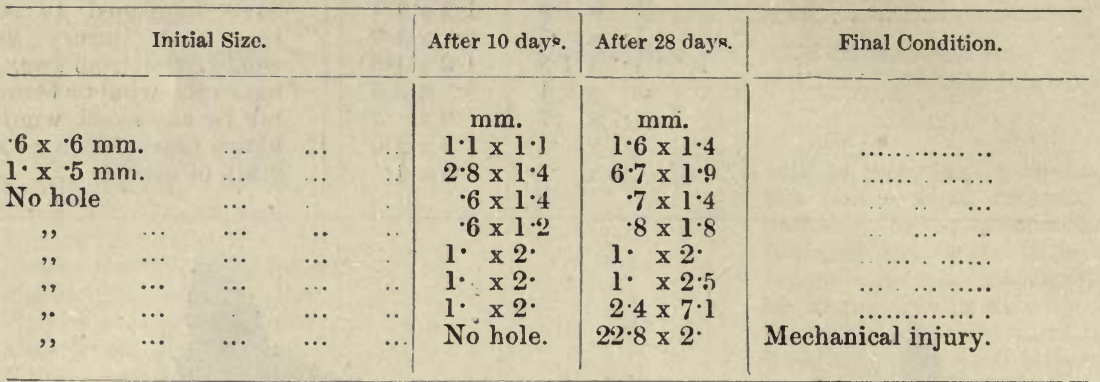

It will be seen that in nearly every instance there was a marked increase in the size of the hole. The holes began as spots, mostly of whitish colour. No fungus elements were seen, though searched for with the aid of the microscope. Cultures at the end gave no result.

No. 5. This leaf had two holes at the outset, and some trifling signs of the beginnings of several others. The leaf was under observation for four weeks, but auring that time only one new hole appeared. The original ones increased considerably in size, as did also the leaf itself.

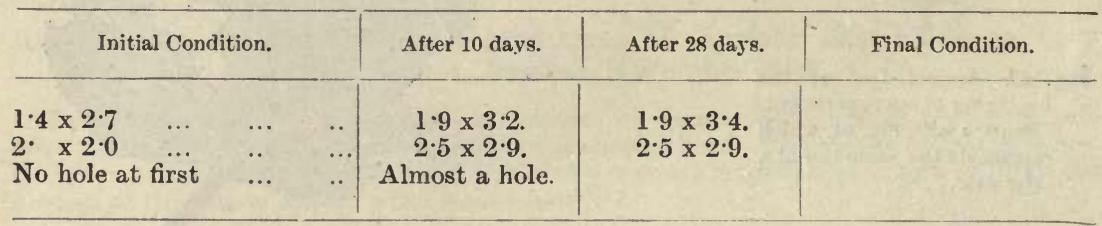

No. 6. Very young and apparently perfect leaf.

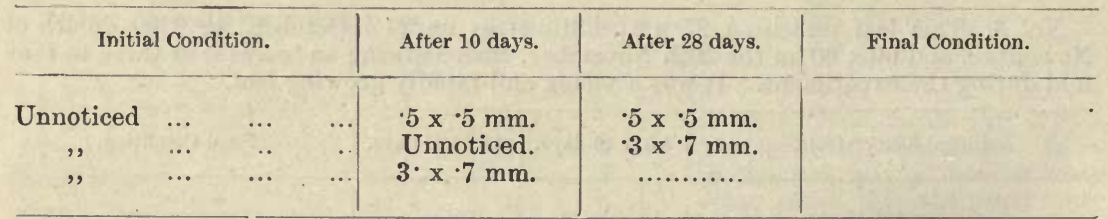

The elongated hole $3 \cdot x \cdot 7$ appeared to be of a different origin from the others, as if the leaf had been whipped against some sharp point and thus given a scratch that resulted in an elongated hole.

No. 7. The following measurements were made on shot-holes in a leaf that, at the beginning of the experiment, was $17 \times 25$ millimetres and at the close of the experiment was $62 \times 73$ millimetres, thus showing a tenfold increase in area :-

\begin{tabular}{|c|c|c|c|c|}
\hline Initial Condition. & & After 10 days. & After 28 days. & Final Condition. \\
\hline $\begin{array}{l}1 \cdot \times 1 \cdot 6 \mathrm{~mm} . \\
1 \cdot \times 1.6 \mathrm{~mm} . \\
\text { Mere pinhole }\end{array}$ & $\begin{array}{l}\cdots \\
\cdots \\
\cdots\end{array}$ & $\begin{array}{c}2.6 \times 4.5 \mathrm{~mm} \\
2.7 \times 4.8 \mathrm{~mm} \\
.7 \times 1 . \mathrm{mm}\end{array}$ & $\begin{array}{l}2.7 \times 5.8 \mathrm{~mm} \\
3.8 \times 5.6 \mathrm{~mm} \\
.8 \times 1.4 \mathrm{~mm}\end{array}$ & \\
\hline
\end{tabular}


No: 8. Another leaf on the same hranch gave the following results:--

\begin{tabular}{|c|c|c|c|}
\hline Initial Condition. & After 10 days. & After 28 days. & Final Condition. \\
\hline $\begin{array}{l}3.8 \times 1.3 \mathrm{~mm} \ldots \\
\text { Spot } \ldots \\
\text { Whitish spot... } \\
\text { Unnoticed } \ldots\end{array}$ & 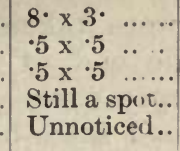 & 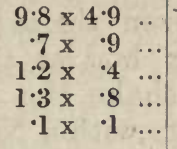 & $\begin{array}{l}\text { This leaf had a good many whitish } \\
\text { and reddish spots, and among } \\
\text { these some that were not at first } \\
\text { marked became holes afterwards. }\end{array}$ \\
\hline
\end{tabular}

No. 9. A third leaf on the same branch gave results as follows:-

\begin{tabular}{|c|c|c|c|}
\hline Initial Condition. & After 10 days. & After 28 days. & Final Condition. \\
\hline $\begin{array}{l}\text { Except for two marginal } \\
\text { notches, this leaf ap- } \\
\text { peared perfect. }\end{array}$ & 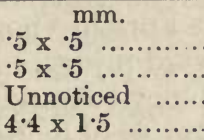 & $\begin{array}{l}\mathrm{mm} . \\
.8 \times 5 \\
\cdot 7 \times \quad \cdot 4 \\
1.7 \times 2.8 \\
6.3 \times 1.9\end{array}$ & \\
\hline
\end{tabular}

It will be noted that these measurements prove the growth of these shot-holes to have been concomitant with the growth of the leaves. In hardly any of the cases cited did the shot-holes appear as the result of a piece of the leaf falling away as is often the case when the holes result from the attacks of fungi. As the most careful examination failed to reveal any trace of fungus growth in the tissues at the margin of these holes, and as cultures made from these tissues failed to show any adequate cause for their appearance, I concluded that my suspicion as to their cause, namely, the small form belonging to the Thripsidx, was fully justified. I am quite familiar with the production of shotholes through the agency of various species of fungi, but careful search continued for a long time among the leaves of the trees experimented on did not result in finding more than a very few cases of holes due to this cause.

We are driven to the conclusion that the "shot-hole" is a function of the apricot leaf (no doubt the phenomenon is found in other genera) and not of any particular disease. When irritated mechanically, or attacked by a fungus disease, the tissues of the leaf act in this way, no doubt in self defence. Though the leaf yield readily at the point of attack it immediately sets up another line of defence, and this consists of a new growth of tissue on all sides of the attacked part, with the result that a hole is formed.

The observations on the shot-holes of the apricot having been interrupted in 1901, an attempt was made to continue them in 1902. The season proved, however, to be different from the previous one, and there was no reappearance of the larval form noted in connection with shot-hole the previous season, and in conformity with this there was very much less shot-hole on the trees that had harboured these insects the previous season. After careful search at various times during the spring had failed to bring these particular forms to light, it was determined to transfer other species of Thripsidæ to apricot buds in order to see whether they would consent to remain there, the 
object being, of course, to observe the subsequent effect on the leaves. The commonest of the thrips found on roses was the furm principally experimented upon, and the following is an account of the operations and their results.

On 5th October several dozen thrips were taken from roses and transferred to the unfolding bud at the end of an apricot shoot. I found it the best way to shake the rose over a smooth surface, and then to pick up the insects with a No. 1 sable brush, keeping the brush constantly wet with water or saliva, the latter having just the right degree of adhesiveness to prevent the thrips from springing off. The transfer has to be quickly made or the insects escape by throwing themselves loose from the brush. At first I used a magnifying glass; but soon discarded it. The insects were "fenced" in with a ring of cotton-wool tied round the apricot shoot. The shoots must be handled with the utmost care to avoid injury. They are very sensitive. The older insects displayed a tendency to wander about, and ultimately many of these got lost in the cotton wool or flew away. The younger ones soon ensconced themselves amongst the youngest leaves of the bud that were sufficiently spread to allow of their entrance, and they remained in that position. From time to time I looked at the bud with a magnifier, and satisfied myself that they were still there and alive, and to all appearances, well and happy. Whether they tried to feed I could not see. Twenty-four hours later they were all right. Accordingly, another bud was infested in a similar manner. A third bud was infested from the flowers of the white snapdragon. White's universal movement clamp was serviceable in this work, as it enabled me to place an $8 \times 10$ plate of glass in a horizontal position near whatever bud was to be infested, so that the insects could be shaken out on to a smooth clean surface, whence they could be easily and quickly transferred to their new quarters.

Forty-eight hours afterwards all these insects appeared to have left the buds, though it was impossible to be sure of this, as some might be hidden among the recesses of the bud. It would seem that some of them died, as I found one dead body. Starvation or poison might account for this ; there would be nothing surprising in such a result, considering the differences between roses and apricot buds, and especially the presence in the latter of a larger proportion of cyanogen compounds. The single death noted proves nothing, however, as it is quite possible that some of the insects were injured during the transfer. There were dark remains as of excrement in both the transfers from roses.

On 10th October one of these apricot buds had at least one small light-coloured thrips in it, possibly one that had been overlooked in the previous examination on the 7 th. Or it might possibly have hatched out since that date.

The leaves from the buds handled in this manner did not do well. They did not grow to full size, and they were not well formed. They did not develop shot-holes. If any conclusion can be drawn from the experiment it is that the common rose thrips refuses to inhabit the apricot bud. 
The apricot trees upon which the shot-holes were produced by thrips in 1901 also harboured aphides, and it naturally suggested itself that they might be responsible for some of the holes in the leaves. A colony of several score were established at the end of an apricot branch, and were isolated by means of a cotton-wool barrier tied round the branch. The bud was examined to make sure that there were no thrips in it. Ants were kept away by the cotton wool barrier-at least for the most part; for in spite of the obstacle a few ants, with a persistency worthy of a great cause, and after an arduous struggle, did make their way to the aphides. This happened so seldom that it may be said that this particular twig, at least in the part beyond the cotton-wool, was inhabited by aphides alone. The aphides located themselves principally on the stem and petioles and veins of the larger leaves. They never made their way into the narrow recesses of the inmost bud. The branch suffered severely from the infestation, and it may be here added died the next season, no doubt from this cause alone. Its leaves did not develop shot-holes.

On another occasion I infested a growing apricot bud with aphides taken from a peach tree, this being the same species of aphis as that mentioned above. The bud was colonised with fifteen aphides, including all sizes, up to and including the winged form.

In an hour's time they had all left the bud and settled on the stalk. I did not succeed in producing shot-hole in the leaves resulting from the bud thus colonised.

These slight experiments only go to confirm the induction that aphides have little or nothing to do with shot-holes. These insects are very common in trees, both apricot and peach, without necessarily being accompanied by shot-hole.

On numerous occasions during these experiments I found opportunity to examine with care the tissues at the edges of the "shot-holes," in order to see whether or not they were infested with fungus filaments. The results were so uniformly negative that I feel no hesitation, as will have been already remarked, in attributing the holes in the present instance almost entirely to other agencies, though I do not mean by this that such holes are not frequently produced by fungi. In all probability they are so produced in the majority of instances, but I know for a certainty that all the appearances of the disease on the apricot, as it has been hitherto known, can be produced without any such fungus or microbe cause being present as would appear to be in any manner adequate to the damage done.

The method I have most frequently adopted is that of making serial sections through the tissues at the edges of holes and through the tissues at the location of prospective holes. These sections have been cut about twenty micromillimetres thick, and have been examined in various ways, with and without the intervention of stains and chemical tests.

Sections prepared in this way have been placed in cultures and studied in that manner, both as to bacterial growths and fungus growths, but especially the latter. 
The shot-holes associated with Thripsidæ* are markedly different under these tests from those of the cases where the holes are the result of attacks of fungi. In the latter cases it is a matter of comparative ease to demonstrate the.presence of the fungus causing the disease.

- Note.-In order to leave no doubt as to the species under observation, the following anatomical notes are added. Other species were occasionally seen in stone-fruit buds, usually mature insects such as the commonest rose thrips, but this occurrence was only occasional, and not to be wondered at, for the season was marked by the abundance of thripsidæ on the rose and a number of other plants, and, in consequence, stray insects of this sor't were to be found in almost any situation. For example, one day in the middle of the city of Sydney, at a distance of nearly 150 feet from the ground, namely, at the top of one of the tallest buildings, it was possible to see these little insects at nearly every instant by keeping a sharp look-out against any dark object or shadow. The bright motes to be seen in such abundance, moving through the sunshine, were full-grown thrips of both sexes, and, of course, they alighted, and were to be found, in all sorts of odd situations.

The largest specimens of the larva found inhabiting stone-fruit buds as described in the preceding pages were about one millimetre long on the lst of November, and presented anatomical features as follows :-

The head, about as long as wide, was not set off by a very distinct constriction. The small, but prominent, red eyes consisted of some half dozen facets each, a much smaller number than in most species of Thrips.

The antennæ were of about the same length and average diameter as the front legs, and though apparently consisting of only four joints, were really made up of more than that number. The first joint, destitute of bristles, was the widest and shortest of the four prominent sections. The oblong second joint was a little narrower than the first, and one and a half times as long, and bore one row of bristles. The spindle-shaped third joint, bearing one row of bristles, was as long as the first and second taken together, and appeared denticulate in optical section. The mobility of the antenna is largely determined by the structure of this section, which is attached by a narrow and exceedingly short stem. The fourth joint was manifestly compound, very likely four-fold, and was lanceolate in contour and denticulate in optical section. It was blunt at the apex, as wide as the third, and nearly as long as the first three joints taken together. Taken altogether, it bore several rows of bristles on the distal half.

The conical nozzle was ordinarily so held as to terminate between the first pair of coxæ. Of the two pairs of palpi, one was composed of three cylindrical joints disposed like those of a short open three-fold sliding telescope, the whole being about as long as the front leg was wide, while the second pair of palpi were apparently two-jointed.

The thorax was two-thirds as long as the aldomen. The only prominent pair of spiracles was on the mesothorax, and appeared as a papilla half-way between the front and middle legs. The prothorax was smaller than the other two divisions, and was set off from them by a slight constriction. In form and size the mesothorax was much like the prothorax. The metathorax was much like the other two divisions, especially the middle division; it was seen to bear a pair of inconspicuous spiracles.

The oblate coxæ of the front legs were half as wide as the head, and were darker than the other joints. Each trochanter was half as long as the corresponding coxa. The femur and tibia were much alike in form, though the tibia was the smaller and more tapering; each was about as long as the terminal compound section of the antenna. Both tibia and femur bore scattered hairs, the former having a circlet of them near the middle and at the distal extremity. The tarsus was composed of two very short, almost naked jnints, supplied with a clawless terminal pad. The middle legs, though a little smaller than the front ones, were in most respects like them. The coxæ were half as large as those of the front legs, and it was difficult to make out the nature of the trochanter, which was perhaps consolidated with the coxa. The hind legs were a trifle larger than the middle legs, but otherwise were very much like them.

The thirteen-segmented abdomen was denticulate in contour, and bore twelve hairs on each segment, the hairs increasing rather regularly in length from front to back, being very short on the anterior segments; but the eleventh, twelfth, and thirteenth segments bore particularly long hairs. Beyond the features mentioned in connection with the thorax, nothing was observed of the tracheal system.

Habitat.-Found in the growing points of the apricot and peach in October and November in the vicinity of Sydney, N.S.W. From one to six individuals were found in each bud, were they lived at the expense of the young growth, determining the appearance at a later date of so-called "shot-holes" in the leaves. These larvæ are rather active in their movernents, but less so than most species of Thrips. 


\section{Mouldy Core of the Apple.}

IN 1892 attention was called in this magazine to a feature of the apple that has much to do with its keeping qualities, namely, the presence or absence of a channel leading from the eye of the fruit to the core chambers. An apple having such a channel was figured, and pointed attention was called to the desirability of excluding from our export apples, and other supposedly good-keeping sorts, all varieties that presented this feature in such a pronounced manner as to endanger the keeping qualities. I am sorry to record my opinion that we have made little progress in this direction in the last ten years. So far as I can see matters stand about where they formerly stood, and yet the point is one of much importance to the apple industry.

The facts of the case are as follows:- This open channel leading to the core cavities is nothing more or less than a cordial invitation to diseases to enter and make themselves at home. It is a royal road for the codlin moth larva, as well as for other small insect pests such as the woolly aphis. It affords fine protection for the red spider, and it is the regular road for the attacks of various fungi.

The fungi making use of this weak point in the structure of the apple are of several :sorts, such as the common bread moulds, Penicillium and Mucor, and doubtless some other less common moulds. The species of mould is not so important, for the result is the same in either case, namely, the destruc-

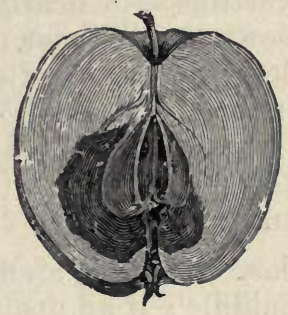

Eig. 65.-Mouldy Core.--Section of an apple placed eye down. A passage is seen leading from the eye to the core cavities, from which a dark rot is spreading outwards towards the skin. tion of the apple by the disease to which I originally gave the name - of Mouldy Core.

This is a diseased condition brought about by the presence of common mould in the core of certain varieties of apple. Outwardly such apples often appear to be quite sound; but on cutting them in halves the cores are found to be in a mouldy or half-rotten state. This, however, is only the beginning of the trouble, for sooner or later the whole apple becomes rotten and worthless. The rot arising from this cause has an appearance different from that of ripe rot, inasmuch as there are no concentrically arranged pustules; and, furthermore, this rot works from the centre of the apple outward, instead of beginning as a spot on the surface and working inward.

The way in which the mould gains an entrance to the core of the apple will be seen at once if one of the diseased apples be split into halves with a sharp knife. It will be found that the blossom end is open so as to form a passage leading to the core. Ordinarily, only the varieties with open blossom ends are subject to this disease. The course of the disease is as follows:-The spores of common mould -coming in contact with the surface of an apple with an open blossom -end, first adhere, then germinate, and send their threads into the 
aperture in the blossom end, and thence into the core-chambers of the apple. Here the threads grow and fructify until they finally attack the pulp of the apple, which they usually do at some point between the core-chamber and the blossom end. The attack on the pulp is accompanied by a brownish rot. A knowledge of this simple fact should prove of value to the apple-growers of the State. They are now endeavouring to place saleable apples on the English and other northern markets. Apples for that purpose must possess good keeping qualities. It is, therefore, a good thing to know that varieties with large open channels leading to the core-cavities are not likely to prove good keepers.

There is an apple of the pippin sort (I have heard it called the New York pippin), quite common in the Sydney market in the late autumn, that is very subject to mouldy-core. It is of medium size and fine flavour, and a nice-looking apple for the table; nevertheless it gives great dissatisfaction, because so many on opening turn out to be worthless, or nearly so. Many Sydney hotelkeepers, caterers, and housewives will bear me out in these statements. The sooner such apples are put out of date the better, for there are equally good sorts not subject to mouldy-core, which can be grown in their stead. They will soon be discarded if both growers and buyers will bear in mind that there is an easily and readily applied test that will at once detect them.

Place the apple stem downward and cut it in halves exactly through the middle; if an open passage leading to the core-chambers is found, then the apple must be regarded with suspicion; if the core contains the slightest trace of mould, then it is certain that before long the apple would have rotted. If among the first two or three apples of a case tried in this way one is found defective, it is certain that all will soon rot.

Recently I have given this matter further attention for the reason that it has come often under my notice as a cause of loss to the fruit industry, a loss which it seemed to me might well be prevented to a considerable extent by the application of selection, and of other measures that could be easily brought into action, if only the way were made plain.

Through the liberality of various prominent apple growers in the State, I have been enabled to examine a series of specimens of various kinds with the object of making a preliminary survey of the subject. My object has been to see to what extent the various kinds of apple differ one from another in respect to the presence and nature of the passage mentioned above as leading from the eye to the core cavities, and especially to see whether the different specimens of a given variety varied in this respect. If, for instance, it could be shown that some particular tree of a given variety was better in this respect. than any other, a way would be opened, by means of grafts from this tree, to improve the variety.

With this idea in view, the various orchardists were invited to mark their specimens in such a manner as to permit afterwards of referring 
back to particular trees if necessary. The season has not been a favourable one, and the specimens have left much to be desired in a number of respects, and this through no fault of those who have contributed specimens for examination. In a number of instances, however, the presence of Codlin Moth has prevented the examination from being satisfactory. Where there is a tendency to an open channel it is almost invariably made use of by the larva of this pest to find its way to a protected place with the least expenditure of energy, a place also where a supply of food is at hand. This brings prominently into notice the well-known fact, and it is an important fact, that this passage is the usual road for the attack of this insect, particularly when an open channel exists; but it at the same time prevented me from making measurements and comparisons for the reason that the channel was too much altered by the attacks of the insect to allow of reliable measurements.

In giving an account of these examinations I have omitted the name of the orchardist, merely giving the locality. All are skilful growers, and the names attached to the specimens could, I have no doubt, be relied upon. The names were verified as far as possible by comparison with specimens sent from the Government orchards under the charge of Mr. Allen, Fruit Expert to the Department, to whom I am indebted for aid in securing specimens. The notes made are intended to show whether a passage existed from the eye inwards, and, if so, the diameter and length of the passage, and whether it led directly into the core chambers, or whether it was blocked or closed at the bottom. By the bottom of the channel is meant that part of the channel which would be the bottom if the apple were placed on a table with the eye uppermost.

\section{Nature and size of the channel leading from the blossom end to the core cavity in the apple:-}

Seven varieties were sent from Goulburn, and were examined with the following results :-

HawthorndeN, 10 samples.-In five cases the passage was closed, so that there was a quarter of an inch of tissue between the bottom of the blossom cavity and the core. Two had a channel to the core cavities, but this was due to the codlin moth present. One had a narrow channel nearly to the core cavity. The remainder were intermediate between the last and the best. The sample especially marked " $\mathrm{H}$ " was among the best.

Anne Elizabeth, 10specimens.-All had the channel closed, the distance from the bottom of the channel to the core cavities being one-fourth to five-eighths of an inch. That specially marked "A" was intermediate in this respect.

Five-Crown Pippin.-All but one of the ten specimens had an open channel leading to the core cavity, varying in width from one-sixteenth to one-eighth of an inch. The channel was often conical or funnel shaped, and nearly closed at length. Two specimens were attacked by codlin moth through the channel. One had an abnormal cavity at the bottom. of the channel just above the core, due to the attack of some disease. One was blackened and mouldy in the core cavities. In nearly all cases there was an open and easy passage right to the core cavities.

Maмmoth.-In all cases there was an open channel, about one-eighth of an inch in diameter, leading to the core cavities. Several of the apples were already attacked internally by some fungus disease, and were ripening off prematurely in a punky manner. Very likely the disease was due to Penicillium or Mucor. 
Claygate Pearmain.-All the specimens, ten in number, had a channel leading to the top of the core cavity, but not into it. In some instances the channel was three-sixteenths of an inch wide; generally it was an eighth of an inch at the blossom end and narrow at the bottom,-about one thirty-second of an inch. It was very noticeable in this variety that the specimens that were ripening had the widest channel, and this led to the belief that the channel widens in the process of ripening. Similar evidence was obtained from other

The following samples were forwarded

White Winter Pearmain, 10 specimens.--In all but two cases a channel, oneeighth to one-sixteenth of an inch wide, led directly to the core cavities. In two cases the channel was closed at the bottom. Six of the specimens were already somewhat mouldy at the core.

Capper's Pearmain, 10 specimens.-In one case the channel was obsolete. In all the other cases there was a short channel, one-sixteenth to one-eighth of an inch in diameter, leading to the core cavities. In eight cases the core was mouldy.

LAXToN's Schoolmaster, 6 specimens. Two specimens only presented a passage, of which one was mouldy at the core. In the other four cases the channel was obsolete.

Missodri PipPin, 7 specimens.-From the deep eye of each specimen a very narrow channel led to the top of the core cavity, where it was closed. None were mouldy.

The following specimens were received from

Granny SMitH, 1 specimen.-Channel one-eighth of an inch wide, closed at bottom.

Stone Pippin, 1 specimen.-Channel closed.

Rome Beadty, 1 specimen.-Channel closed.

Cleopatra, 2 specimens.-In both an open channel, one-sixteenth of an inch wide, led into the core cavities, and one of the specimens was already mouldy.

Perfection, 1 specimen.--Channel, onesixteenth of an inch wide, closed at bottom.

Late Wine, 1 specimen.-A narrow closed channel.

JoHnston, l specimen.-No channel, i.e., obsolete.

Jonathan, 1 specimen.-Channel, onesixteenth of an inch wide, leading to the core, which had already begun to mould. varieties. Specimen specially marked "C" was average.

Summer Pearmain.-Open channel in only one of the ten specimens. The passage was never more than one-sixteenth of an inch near the entrance, ${ }^{\circ}$ and soon narrowed so as to leave some distance entirely closed. Two were nearly open.

Winter Pearmain.-All the ten specimens presented a narrow passage that led into the core cavity. Some specimens had already begun to mould.

rom Wagga:-

AnNe Elizabeth, 10 specimens.-All presented a channel, one-sixteenth to three-thirty-seconds of an inch wide, opening into the core cavities. Half the specimens were becoming mouldy at the core.

Stonk Pippins, 9 specimens.-Mostly with a narrow channel leading to the core. Two specimens somewhat mouldy. Channel, one-thirty-second of an inch.

Northern Greening. - All these specimens were suffering from Red Spider, and some with Bitter Pit. Six specimens. Two presented an open passage leading to the core, and were "going," as was one other that had a closed passage.

Reinette Franche, 2 specimens. - Both with a closed channel.

Cornish Aromatic, 9 specimens.Narrow channel to near the core. One core was mouldy.

Rome Beadty, 2 specimens.-Both with a very narrow channel, closed at the bottom.

Bathurst :-

KeNTUCKY ReDSTREAK, 1 specimen.Channel, one-sixteenth of an inch wide, closed for one-eighth of an inch at bottom, apparently sufficient to secure the core from invasion.

BLEк HeIM, I specimen.-Narrow channel closed at bottom.

Claygate Pearmain, 1 specimen.-No channel.

Sturyer Pippin, 1 specimen.-Channel obsolete.

MunRoE's Favourite, 1 specimen.Channel, one-sixteen of an inch wide, to near the top of the core cavities.

GranNy SMith, second specimen.Channel closed at bottom for a quarter of an inch.

The following specimens were sent from Pambula. Other specimens were also sent, but they became so mixed and stale in transit that I did not venture to examine them :-

Winter Peach, 5 specimens.-Three presented a closed channel. Two presented an open channel to the core cavities, and of these one was already monldv.
ROME BeAuTy, 14 specimens. - Three of these presented an open channel, and were a little mouldy at the core. The remainder showed very little signs of a channel, with one exception. This one had a closed channel one-eighth of an inch wide. 
Specimens from Orange :-

Claygate Pearmain. - All attacked by codlin moth through the eye, so as to be of no use for this examination.

Stone Pippin, 10 specimens.-Four of which had been rendered unfit for this examination by attacks of codlin moth. The other six had each a narrow passage leading from the eye to the core.

Gransy Suith.-Except those that were attacked by codlin moth, all the specimens had a narrow channel (onethirty-second to one-sixteenth of an inch) leading to within about one-eighth of an

\section{Miscellaneous :-}

RoMe BEAUTY, several specimens. - Had a conical channel, the outer diameter being three-sixteenths of an inch across. For three-sixteenths of an inch above the core cavities this channel was closed.

Five Crown Pippis, few specimens.Channel, one-fourth of an inch wide, leading to the already mouldy core cavities. inch of the core chambers, where it became entirely closed.

Five Crown Pippix, 10 specimens.Three attacked by codlin moth through the eye. One had only a narrow passage leading to the core. All the others had a channel one-eighth of an inch wide leading to the core chambers, and of these, two had alrearly become mouldy.

Cress's Seedlivg. - All that were free from codlin moth had a very narrow channel that was closed at the bottom.

RIMER, several specimens.-A very narrow channel led to the core cavities.

Winter Pearmain.-Channel nearly closed. The specimens, however, were green.

MaJeting.-Channel nearly closed.

The foregoing observations are hardly sufficient as a basis for much reasoning, but they serve to make plain the fact that there are considerable variations in apples of a given variety in respect to the channel at the blossom end. It is also clear that the channel varies in the same apple in the process of ripening, becoming wider as the apple ripens.

The number of samples examined is insufficient to throw much light on the question of how to proceed to select in order to combat the occurrence of this channel. It is hoped that the observations may be continued another year on a larger series of specimens. The subject is certainly one of importance in connection with the keeping qualities of apples, and it is, therefore, one that touches a fundamental problem of the apple industry.

\section{Quince Rots.}

IT is not often that the quince comes under the consideration of the experts of this department for the reason that it cuts a comparatively small figure in the fruit industry of the State, and also, no doubt, because the quince is eminently able to look after itself, being an exceedingly hardy shrub.

Now and then a fruit-grower is found making something of a specialty of this fruit, owing to the market demand for a fruit to mix with others of less piquancy. For the same reason nearly every private fruit garden contains its "quince bush."

From such sources I have from time to time collected or received specimens that give me some idea of the diseases that are most 
commonly to be found affecting the quince in this State, and among them I find two to be far more prominent than all others-namely, the ripe rot of the quince and a fungus disease caused by a species of Alternaria.

Some information of a technical character will be found on pages 8-11 in the account of the ripe rots of the various fruits. Here it need only be said that this disease has much the same appearance on the
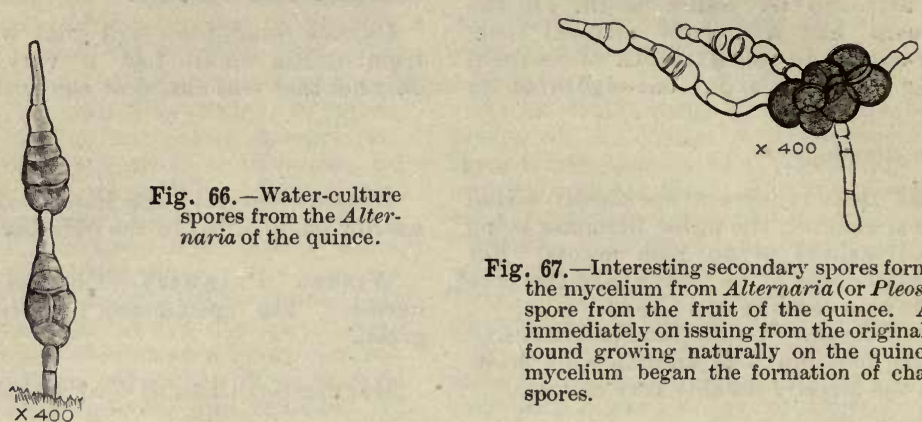

Fig. 66.-Water-culture spores from the Alternaria of the quince.

Fig. 67.-Interesting secondary spores formed on the mycelium from Alternaria (or Pleospora?) spore from the fruit of the quince. Almost immediately on issuing from the original spore found growing naturally on the quince, the mycelium began the formation of chains of spores.

quince as on the apple, where it is a much more common sight. The rot caused by the fungus is at first a surface rot which extends in a circular manner, at the same time penetrating farther and farther into the fruit until it is completely

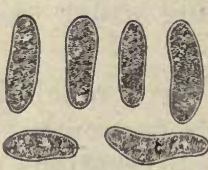

$\times 400$

Fig. 68--spores of Gloeosporium found growing naturally on the quince. destroyed. The rotten spot is almost invariably circular and of a dark brown colour, the colouration being, as in the case of the ripe rot of the apple, arranged in concentric rings of alternating lighter and darker shades of brown. By the time the rotten area on the surface of the fruit becomes half an inch in diameter there may usually be seen on its surface minute pustules of a darker colour, sometimes almost or even quite black, and these, becoming slightly raised after a few days, begin to emit a a tortuous light-coloured fibril which, upon being placed in water, completely "dissolves." Upon examination with a magnifying glass, or better with a microscope, it will be found that the fibril was composed of thousands of spores of the form shown in the adjacent illustration. If some of these spores be prodded into another quince with a small pointed instrument, the inoculation will

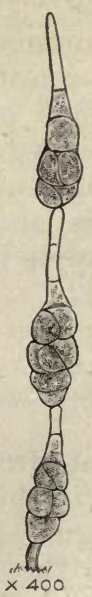

Fig. 69.-Alternaria of the quince. Waterculture growth of spores in chains. result in a rotten spot at the end of a week or two, the time depending on the state of ripeness of the quince. This simple experiment is the key to the remedies it is possible to apply. 


\section{Remedies.}

The skin of the quince is so tough and so well protected by its velvety covering of hairs that I am of opinion it is rarely, if ever, that the spores of the ripe-rot fungus make their entrance unaided. It is necessary for them to have some entrance prepared for them. The skin must be broken by a bruise or by the bite of some insect or animal. Now, the quince has a habit of growth conducive to bruises from the effect of winds. I refer to its slender branches upon which its heavy fruit is often hung somewhat after the manner of a weight at the end of a pendulum. If the bush be struck by a wind the "pendulum" is set swinging to and fro until finally the fruit is knocked against some sharp point, with the result of injuring it in precisely the manner most favourable to the entrance of the ripe-rot fungus. From this habit of the quince we may learn two lessons, the application of which to practice will lessen the losses from the ravages of the ripe-rot fungus. First, set the quince in a place free from winds. This is usually an easy matter. The tree is so small that some sheltered place can easily be found for it, either in some corner protected by buildings or among taller growths that afford a similar protection. Second, prune the quince with a view to this tendency to produce fruit at the ends of slender branches, or if it be thought best to allow the tree to take its own course to a larger extent, pass a few cords through the tree when the fruit begins to attain the dangerous size, tying the pendulous branches in such a way as to minimise the bad effects of their swaying in the wind.

The application of Bordeaux mixture to the quince is effective in checking the ripe rot. The applications must be made before the rot has made its appearance, and they may be made without fear that the trees will be injured. Full strength mixture may be applied two months before ripening and again a month later. It is doubtful whether this measure will pay for the trouble and expense unless other trees are being sprayed at the same time.

As the quince is a large fruit and, as a rule, is plucked in a hard condition, it may be sprayed right up to the time of harvesting, it being an easy matter to remove the Bordeaux mixture from the fruit. This is a fact it is well to bear in mind, because most of the diseases of the quince are connected with the ripe fruit.

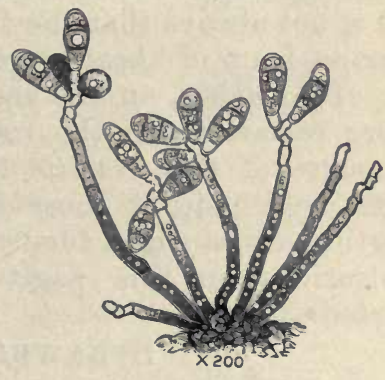

Fig. 70.-Fungus (Pleospora?) found associated with the Alternaria of the quince.

All infested quinces should be destroyed, and it should be remembered that the ripe rots of other fruits are a source of danger to the quince. This matter has been dealt with under the head of "Ripe Rots:" (Pp. 7-11, 18, 23.) 


\section{Black Rot or Alternaria of the Quince.}

The second disease of the quince to which attention will be directed has at a distance some resembiance to that just described. It is characterised by the presence on the fruit of rotten spots of a dark colour. In the present instance, however, the spots are very dark, being of a greenish velvety black. This dark green velvety growth may extend over the whole surface, involving the entire fruit in a kind of dry rot. The velvety surface growth is composed of multitudes of spores borne on short pedicels so crowded together as to closely resemble the pile of velvet. The spores are of the form shown on this page and are large enough to be seen with the aid of a good magnifying glass, appearing when placed on white paper as minute elongated specks.

The remedies that may be adopted in opposing this disease are the same as those for ripe rot. I will only add

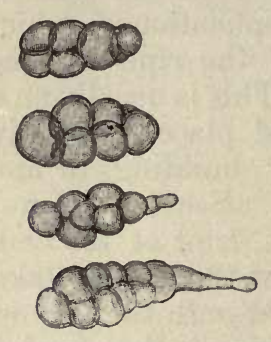

Fig. 71.-Alternaria of the quince. Spores found growing naturally on the fruit of the quince. $\times 400$. that although in this case I have very good reasons for thinking that several different classes of vegetation are subject more or less indifferently to the attacks of the same fungi, my experiments are not yet of sufficient completeness and importance to warrant their publication. They seem to be of such weight, however, that I now make them the basis of recommendations similar to those relating to ripe rot. In particular, I would call attention to the necessity of destroying all growths of this dark velvety nature even where they occur on such remotely classed vegetation as, for instance, the cucumber tribe. It not seldom happens that consumption fails to keep up with the growth of the cucumber patch or with that of the tomato bed, and that the ripened fruit or even the foliage of these vegetables bears fungi that may be inimical to fruit trees in the vicinity.

It is not always that the fungi referred to confine themselves to the overripe fruit of these vegetables, as they are found also, as in the case of squashes, on the young fruit and even the blossoms and, as before remarked, on the foliage. I have already called attention in the pages of this Gazette to a disease of young squashes that has as its cause one of these fungi, characterised by a velvety surface growth. As a slight further contribution in the same direction the illustrations on this page and those immediately preceding are inserted.

\section{Strawberry Leaf Blight.}

With the increase in the number of strawberries grown, there lias been an increase of the area over which this disease is known. It is a blight in which prevention is more than usually practicable. It is the only conspicuous disease of the foliage of this plant that is at all common, and hence its earliest stages are easily discovered by the watchful grower. (See Plate, opposite p. 26.) The plucking and destruction of the earliest traces of the disease is a measure that pays well. Care should be exercised while picking the diseased leaves not 
to contaminate the healthy ones. The hands become covered with the invisible spores, which may be unwittingly sown on to sound foliage unless such care is exercised. When the disease is bad, it is best to mow the beds, let them dry, then cover them with combustible material and set fire to it. The new growth following will be clean and can then be kept so. One per cent. sulphuric acid will also kill the diseased foliage if sprayed on thoroughly. Bordeaux is an effective remedy.

\section{CANKER.}

Under the name of canker I have been accustomed to include a disease differing from that ordinarily so called in Europe. There the disease is, I believe, usually attributed to the genus Nectria. I believe

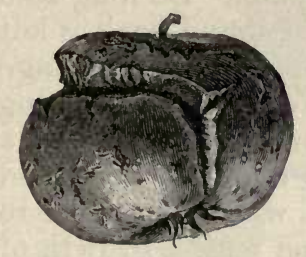

Fig. 72.-Apple apparently suffering from the attacks of cauker. the most common barkdestroying fungi on the apple in some other parts of the world are also, as here, not Nectria. The canker most commonly referred to in the pages

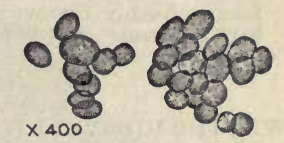

Fig. 73.-Canker fungus of the bark of the pear. of this Gazette is not caused by a fungus of that genus.

The disease is not confined to the apple in this State, but is found on the pear and quince as well. On another page will be found a description of a disease of the Hawthorn, which appears to be indentical with our canker of the apple.

The following are some incomplete notes on a peculiar case of canker occurring on the pear :-

The branches had been pruned, and it appeared as if the disease might have started from the cuts, having, perhaps, been the result of inoculation by means of the pruning shears themselves. The branches had a deformity in the shape of long radial swellings. At a stage when the perithecia of the fungus had not yet produced spores the outer bark was peeling off in thin flakes of considerable size. The perithecia were numerous and crowded, and gave to the naked limbs a sooty black appearance. Branches of mycelium grew out from the perithecia. The perithecia measured $250 \mu$ in diameter and were jet black,

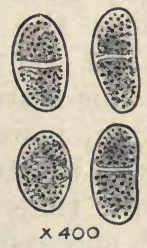

Fig. 74.- - ores from a case of canker, ur so-called "sour sap" of the pear. and for the most part situated on the surface. The subjacent mycelium was dark-brown.

In scars on the same branches were found spores of elliptical shape, measuring 10-12 × 20-27 $\mu$, two-celled and dark brownish-green in colour. It remained uncertain what was the origin of these spores, and whether they were connected in any way with the perithecia. These spores were borne on a dark mycelium which was in most parts an aggregation of ellipsoidal cells, having a tendency to break up into sporidia-like bodies. The spores were smooth on the surface. (See Fig. 74.) 
Remedies.-Where branches are already badly scarred with canker the best treatment is accomplished with the pruning knife or some larger sharp tool. Cut out the scar as cleanly as possible. Cut liberally. Remove wood until what is left has a perfectly sound

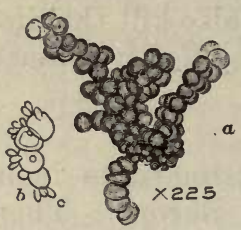

Fig. 75.-Sooty fungus growth on the surface of Orange twigs. This fungus destroys the bark. $a$, the fungus freshly removed from the bark; $b$, same growing in water. culture.

appearance. This is a vital matter, and it is better to overstep the limit than to cut too little. The disease often exists in fairly sound-looking wood. Little fear need be entertained as to the life of the branch, so long as it is not actually girdled. This may be a rather strong statement, but it conveys the correct idea in the main. So long as a fair connecting link of sound bark is left the branch will not perish. If breakage is feared tie on a stiffener. After cutting away the unsound wood and bark disinfect the cut surface with Bordeaux mixture or with a solution of bluestone, and when dry give it a good coat of first-class white lead paint. The wound will soon begin to heal over, and in time will become entirely covered with a growth of new healthy bark. The tree meanwhile should have good care.

\section{Peach Curl.}

[See Coloured Plate opposite, and also Coloured Plate opposite p. 38.]

FormerLy, in writing of this disease, I recommended treatment with Bordeaux mixture, and laid special stress upon winter treatment, pointing out that summer treatments which have to be made with the weaker forms of the mixture, were of very questionable value, excopt in so far as they might lessen the disease the next season. But while invariably giving this treatment a place among the measures for combating the disease, I have not been sanguine of satisfactory results. I am very glad that I can see reason for changing my tone in this matter, for I am able now not only to make the recommendation, insisting strongly, as before, on the value of the winter treatment, but to express the opinion that if the spraying be made at the proper time and with sufficient thoroughness, the result will be a decided success. This is owing to further inquiries incited by the results of some very complete and long-continued inquiries and trials conducted under the direction of Professor Newton B. Pierce, of Santa Ana, California. I wish to make this matter as clear as possible, and, with a view to doing so, will repeat here the entire article written for our fruit-growers twelve years ago and printed in the Agricultural Gazette :-

\section{Leaf-curl or Curl-leaf of the Peach and other Stone-fruit Trees}

This is a disease that attacks the leaves and wood of stone-fruit trees, more particularly the peach, to which it frequently does a great deal of damage. The following remarks are intended to apply only to the disease as it occurs on the peach-tree.

This disease is of fungus origin, and is readily recognised in its severe form, but often escapes notice in its mild form. It generally becomes 

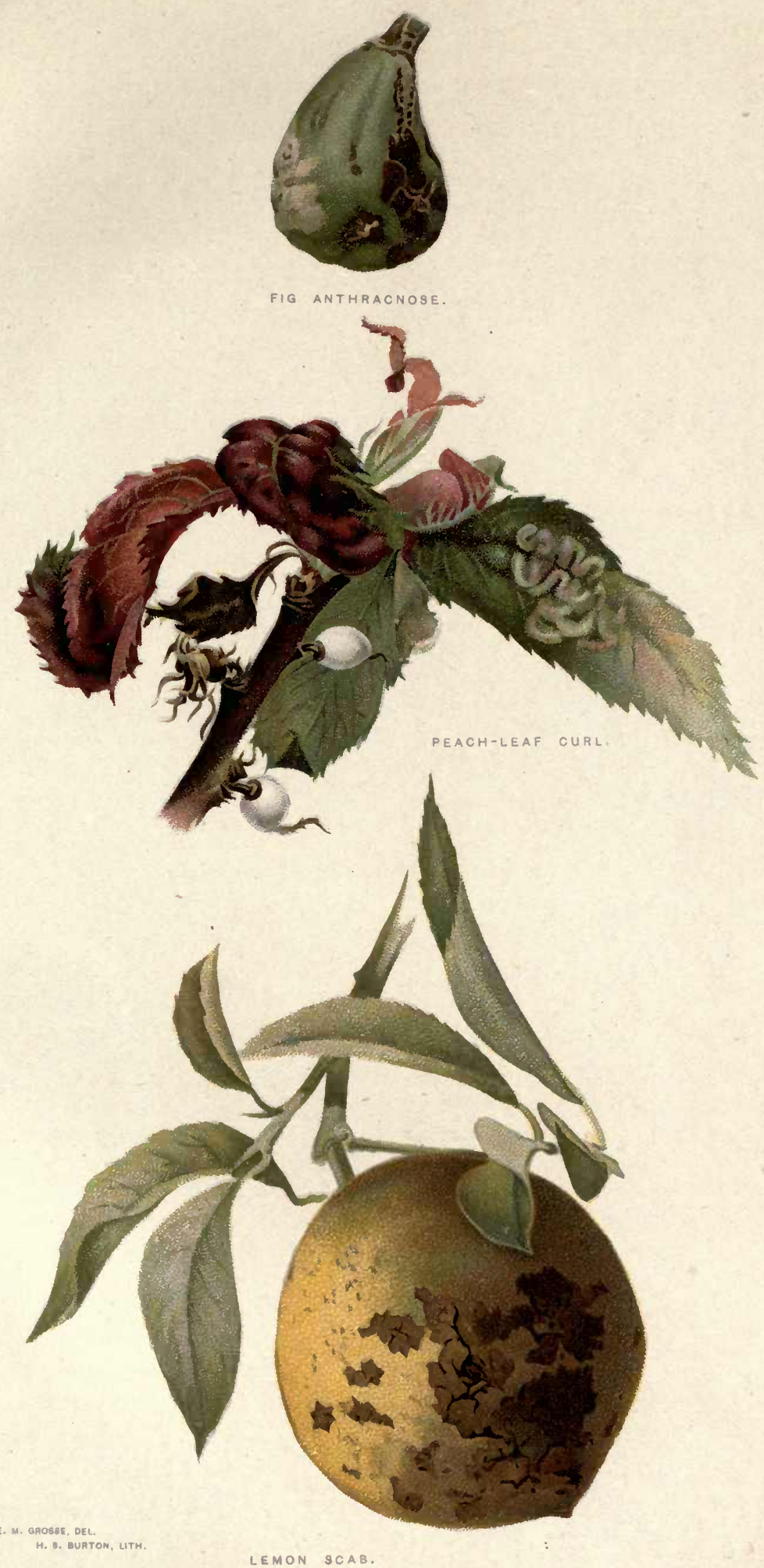

DISEASES OF PLANTS. 

noticeable as soon as the leaves appear in the spring. If severe, the disease causes the young leaves to become enlarged, discoloured, thickened, and distorted-in short, curled. The variety of colour displayed by the curled leaves is great. They generally assume a livid or white look; but sometimes they are red, sometimes purple, and sometimes mottled with various combinations of green and red and purple. The surface of the diseased leaves, instead of having the dull lustre characteristic of healthy peach-leaves, becomes shiny and brilliant. This feature combined with the brilliance of colour makes the diseased leaves very striking objects. (See coloured plate.) As the disease advances, the amount of overgrowth and distortion increases, until. finally the leaves become bulged out on the upper side to such an extent that pockets half an inch to one inch in depth are formed, into which one can easily insert the end of the thumb. About this time the purple colour, which is more common in the earlier stages of the disease, begins to disappear, and the lustre also becomes less brilliant. This is owing to the fact that the fungus which is the cause of the disease is now preparing to fructify. When this operation is finished the diseased leaves appear as if covered with frost, or with an exceedingly fine white powder. On examination with the microscope this apparent powder is found to be composed of very minute sacs packed together as close as possible in a single layer on the surface of the leaf. Each sac when ripe contains eight egg-shaped spores. These sacs and spores are of such a

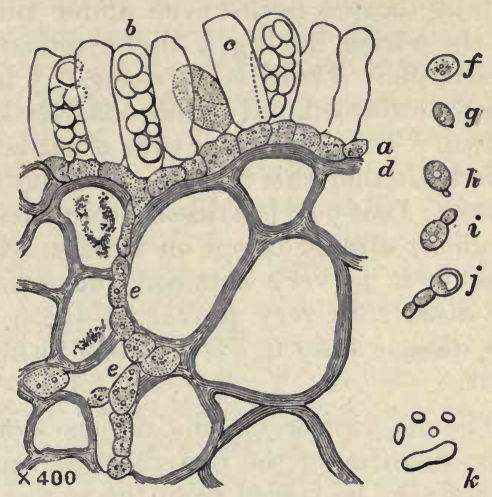

Fig. 76.-Microscopic details of the fungus (Exoascus. deformaus) causing leaf-curl of the peach. The. figure shows a small portion of a section through a diseased peach leaf; $a$, the mycelium of the fungus growing on the surface of the leaf, $d ; b, a$. sac or ascus arising from the mycelium $a$, and containing eight spores; $c$, au empty sac; $e$, $e$, mycelium inside the leaf growing among the cells; $f ; g, h, i, j$, ascospores budding in water; $k$, the same.

size that, according to a calculation I have made, a single square inch of diseased leaf may bear no less than twenty million spores, a number so large that it is not easy to comprehend. One comprehends it to a certain extent. on reflecting that if one spore was placed on each square inch of the surface. of the soil, twenty million spores would suffice to cover an orchard more. than a mile square. But this number of spores frequently grows on a single. diseased leaf, while on a single peach-tree thousands of such leaves may often be seen. The imagination is stunned by the numbers that represent theprolificness of this fungus.

When the disease has culminated - that is, when the fungus has fruitedthe spore-sacs burst and the spores escape; then the leaves, which have thus far remained succulent, begin to dry up, turn brown, and fall. Theseleaves having fallen, they are succeeded by others which, as a rule, are less severely attacked, and thus the disease goes on decreasing in severity. until in mid-summer the tree may have a crop of fairly healthy-looking leaves, and may bear a partial crop of fruit. In the severest cases, however, the fruit falls about three weeks after setting, and not a peach is left to ripen. This occurs on trees in which the disease is chronic and severe. Such trees are worthless, nay, worse than worthless; they are a constant menace. to all the peach-trees in the neighbourhood. The sooner they are cut down 
and burned, and thus utterly destroyed, the better it will be for the peach industry.

I have now described the disease in its worst form, a form in which it is not uncommon. The milder forms of the disease are much more frequent. Sumetimes only part of the leaves on the tree are attacked, or the leaves are only partially attacked and display the curl in one-half only, or at the end, or elsewhere. These appearances, however, are so similar to those already described that there can be no mistaking them. The curl is there; the distortion, the discolouration, the thickening, the lividness, are all present and unmistakable. There is, however, a masked form of the disease which usually escapes notice even under the eye of the expert. It may be known by the leaves having a slight tendency to overgrowth and a slight tendency to crimple. There is no deformity in this form of the disease; the leaves are well formed, only somewhat darker green than usual and slightly overgrown. Trees attacked thus often bear fairly well, and it may therefore be asked whether this form is worth notice. I think it is worth notice for this reason : Leaf-curl is a disease that varies from season to season; some seasons it is almost absent except on trees in which it is chronic and severe, and other seasons it is very common, widespread, and injurious. In seasons when the diseass is very prevalent those trees which in ordinary seasons show the disease only in its masked form break out badly and bear little or no fruit.

The description of this disease would be very incomplete without making plain mention of the fact that the fungus described above as occurring on the leaves may be traced from the leaves back to the wood. That is an important fact, becalise it leads to the conclusion that the disease is one that cannot be got completely rid of by any treatment of the leaves by spraying with fungicides. The fungus will winter in the wood, and be ready to make the most of its opportunities in the spring.

\section{Remedies and Preventives.}

1. Foremost in rank among the various methods of treatment which I advise is care in grafting and budding. This disease can exist in the wood even when the leaves show only slight traces of it. As already described, the diseased leaves of early spring are usually followed by fairly healthylooking summer leaves, so that except for a dearth of fruit (and even that may not be great) the tree may look quite fit to take scions from. Along comes the nurseryman or orchardist, bent on increasing his stock of trees, takes a look at this tree, and seeing nothing much the matter, proceeds to remove scions and graft them wholesale on fresh stocks. There can be but one result-diseased trees. I am confident that this is the manner in which the disease is commonly spread from one place to another at a distance. Orchardists, therefore, who have an eye to the future, and nurserymen who care anything for their reputation, will refrain from grafting or budding from trees that have this disease. Grafting and budding should be done only from peach-trees that have either never shown the slightest traces of curl, or from such as have been entirely free from it for at least two seasons.

2. Almost equal in importance with the foregoing is the selection of curlresistant varieties. It is a well-established fact that some varieties of peach resist the leaf-curl, and are but slightly injured by it, while others seem to be quite proof against it. I am sorry to say that no list of the resistant warieties has been obtained for Australia, so that we are completely in the 
dark. To make such a list is a matter of time and patience, and I am glad to say that Mr. Benson, fruit expert to the Department of Agriculture in New South Wales, has undertaken to give this matter attention. $\mathrm{He}$ has prepared a leaflet, which is to be sent to peach-growers, and they are requested to reply and give the names of varieties of peach which they find to be always free from curl, and of those they find to be very subject to it. When all the replies are received they will be collected and compared and the result made known so as to benefit all alike.

3. The destruction of diseased leaves is advisable. The reader who has had the patience to follow the description of the disease, must have been struck by the enormous number of spores produced by the fungus that causes curl. The spores, it is almost needless to say, are the seeds of the fungus. The chance of the fungus spreading is diminished by the destruction of its spores. There is only one method of doing this, namely, destroying diseased leaves. This can be done by pruning, by hand-picking, or by raking up the leaves that are dead and fallen owing to the disease. The material gathered in this way is, of course, to be burned. In a large orchard, badly diseased, none of these ways would pay. But they are one and all applicable to the small garden where the owner does not begrudge a little extra labour in order to supply the family with perfectly fresh and luscious fruit; also in the nursery where young peach-trees are being reared, attention of this sort will be well bestowed, and, in the case of large orchards, where the disease has not yet appeared in force, this method is one highly to be recommended. I have never yet been able to express myself forcibly enough with regard to nipping these things in the bud. A little prevention is worth more than all the cures in the world. There are very few pests indeed which come with a rush-there are such, but they are rare. In nearly every case the pest has a small beginning, and it is only after considerable time that it grows to be a nuisance. There is a time in the history of nearly all these pests when the agriculturist could crush them with his thumb and forefinger. How important it is, then, for him to make himself acquainted with these pests beforehand, so as to be ready to seize upon them while they are yet within his power! I am sure there are few things that will pay him better than the knowledge which will enable him to guard his crops from invasion by these insidious robbers of which the leaf-curl of the peach is an example. Now-a-days useful pamphlets and books treating of these subjects are easily obtainable, and an evening with them is often well spent. Specimens sent to Departments of Agriculture in almost any part of the world receive attention, and reliahle information is returned by mail. The peach-grower should make use of all these agencies in preventing curl.

4. Peach-trees suffering from curl should receive especial attention-for the matter of that, so should all diseased orchard-trees. The orchardist should make up his mind to one of two things - either to dig the tree out and destroy it root and branch, or to give it the best of care. Prune well, removing especially the diseased parts; cultivate well and apply manure liberally. This treatment will often ensure a crop from trees that would otherwise be useless; but, of course, the margin of profit is less, and to avoid loss it is well to count the cost carefully before entering on this treatment.

5. I would call attention to an observation of mine that when peach-trees suffering from curl are severely cut back, they often shoot from adventitious buds, that is, buds formed under the bark, and that such shoots from the side of large limbs are often free from curl. I think this severe cutting back in the winter may yet prove of use in curing badly affected trees. 
6. Finally, there is the application of fungicides, such as Bordeaux mixture, Eau Céleste, and Ammonio-carbonate of copper. None of these have yet been shown to be effective against curl, but I am of opinion that none of them have yet been tried with sufficient care. The ordinary formulæ given for these mixtures are too strong for the peach, being found to kill the foliage. If they are tried, they should be used at half strength or even weaker, unless they be applied in the winter, when the full strength will do no harm. I would advise anyone experimenting in this line to rely upon winter treatment, and treatment at the time when the leaves begin to appear. It does not seem to me likely that later treatments will do much good, unless, indeed, they diminish the force of the disease so as to lessen the damage the following season. The action of these fungicides is much less marked in a wet season, because they are washed off by the rain; in any case where a spraying is followed immediately by rain, little good can result unless the spraying be repeated as soon as the rain has dried off. A winter spray of sulphate of iron may be found useful, using one to two ounces of the crystals dissolved in a gallon of water. These treatments are of doubtful value, as far as curl is concerned, and were it not that they are useful in other ways I would not mention them.

Curl should not be confounded with peach-aphis. Seen at a distance the effect of the aphis is similar to that of curl, but on close examination the difference is apparent at once. In the case of curl, pure and simple, no insects of any kind will be found, while in examining peach leaves attacked by aphis the distorted leaves will be found swarming with small green and brown insects. The two diseases may, however, occur together; but even then there is little difficulty in distinguishing the distortions of curl from those caused by aphides, as those of the latter lack the livid thickening and bulging so characteristic of curl. The treatment for peach-aphis is entirely different from that recommended for curl."

This closes the quotation from my original article, and I wish to call especial attention to the second sentence in the sixth section of it:-

"None of these (copper compounds) have yet been shown to be effective against curl, but I am of opinion that none of them have yet been tried with sufficient care."

When I wrote thus, I did not know that several years earlier curl had been successfully treated in California with fungicides. Such, however, was the case, and from this beginning a method of treatment has been worked out which applies well to the conditions in this State, and which is a most profitable one in those regions where the losses from the disease are large and constant. The main points in the treatment are winter spraying, or rather early-spring spraying, with full-strength Bordeaux mixture, and care in the application of the spray. Fully approving them, from observations made on the disease in this State, I give here the main conclusions arrived at by Professor Pierce:-

\section{SUMMARY.}

(1.) Peach leaf-curl has a world-wide distribution, occurring in every region in which the peach is grown. In humid localities it is a leading hindrance to peach culture, and in portions of the Pacific coast States it has greatly limited the extent of the industry. 
(2.) The orchard losses from peach leaf-curl vary from a small amount of fruit to the entire crop, while in many instances young trees are killed. The national losses from this disease will amount to $\$ 3,000,000$ annually.

(3.) Curl is caused by a parasitic fungus known as Exoascus deformans, the ravages of which are largely dependent upon the atmospheric conditions prevailing while the trees are leafing out. Rains and cold weather at that time tend to increase the severity of the trouble by favouring the growth of the parasite and interfering with the proper functions of the host. For these reasons orchards near large bodies of water and in low or damp situations are more subject to curl than those in dry regions or in elevated situations.

(4.) Most of the spring infections of peach leaves are due to the spores of the fungus and not to a perennial mycelium, as formerly held, hence the efficacy of sprays.

(5.) Curl was first successfully treated in California during the period from 1880 to 1885 , the success depending upon the application of fungicides to the dormant trees. The disease was not successfully treated in Europe for ten years after its prevention in the United States.

(6.) The copper sprays are now found to be more effective than the sulphur or other sprays first used. Of the various sprays experimented with, Bordeaux mixture, in the proportion of 5 pounds copper sulphate, 5 pounds lime, and 45 gallons of water, gave the best results, the equal weights of the copper sulphate and lime being most effective when the mixture is applied shortly before the opening of the blossom buds. When it is desired to increase the durability of a spray by increasing the proportion of lime, the application should be made earlier or equal proportions of copper and lime should be maintained. The total saving of foliage increases with the increase of copper sulphate when the amount of lime remains constant, but the average saving per pound of copper'sulphate decreases with the increase of copper used.

(7.) In the treatment of peach leaf-curl, from 95 to 98 per cent. of the spring foliage was saved by spraying. A net gain of 600 per cent. in foliage over that retained by adjoining unsprayed trees resulted in the case of several different sprays. Bordeaux mixture when applied to the dormant tree increased the weight and starch-producing power of the leaves, and the sprayed trees showed a great gain over the unsprayed in the number and quality of the fruit buds they produced for the following year, the gain in the number of spur buds being over 100 per cent. in some cases. The lower limbs of sprayed trees showed a marked gain over those of unsprayed trees as compared with the upper limbs in both the number of fruit buds and lateral shoots they produced.

(8.) The average value of the fruit per tree in rows treated with the most effective Bordeaux mixture ranged as high as $\$ 6.20$ above that per tree in adjoining untreated rows, or the equivalent of a net gain of $\$ 427.80$ per acre where trees are planted 25 by 25 feet. Over 1,000 per cent. net gain in the fruit set has resulted in the use of some of the more effective sprays.

(9.) The trees should be sprayed each season, as the experiments proved that treatment one season will not prevent the disease the following year. Spraying should also be done even though the trees may not be expected to bear, as the loss of the crop of leaves is shown to result in as great a drain upon the trees as does the maturing of one-half to two-thirds of a crop of fruit.

(10.) The work demonstrates that peach leaf-curl may be cheaply and easily prevented in California, in western Oregon and Washington, and along the east shore of Lake Michigan, where curl causes great loss, as well as in all other peach-growing sections of the United States. 
(11.) The copper and lime sprays are less injurious to the trees than those composed of sulphur and lime. The use of lime in winter sprays has proven an advantage in enabling the workmen to see their work and complete it with greater thoroughness than would otherwise be possible. A proportional increase of both lime and copper sulphate is recommended for wet regions, and for very wet localities a second winter spraying is advised.

(12.) Cyclone nozzles with lateral or diagonal discharge are best adapted to the work.

(13.) The proper time for winter spraying and the number of applications depend to some extent on the locality, season, etc., but active sprays are likely to do most good if applied from one to three weeks before the opening of the blossoms in spring. The proper time to apply sprays for the prevention of curl is in dry, calm weather, and during the middle of the day, in order to avoid dew or frost upon the limbs as much as possible.

(14.) Of nearly 200 peach and nectarine varieties considered with a view of determining their comparative susceptibility to curl, it was found that very few were wholly free from the disease and that some were very subject. to it. Some of the choicest varieties, as the Elberta and Lovell, are seriously affected, but it has been demonstrated that a single winter treatment will prevent the disease upon even these varieties. It may be thus fairly claimed that the spraying methods recommended will save to the peach industry some of its finest varieties, as well as result in the saving of foliage and crops. already indicated.

\section{Alternaria of the Citrus Tribe.}

[See Coloured Plate opposite p. 60.]

UNDER this general appellation I shall include a large number of cases that have come under my notice during a series of years reaching back as far as 1890. The cases are numerous, and sometimes they have been

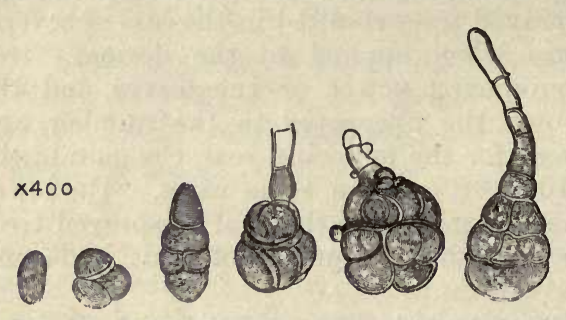

Fig. 77.-Macrosporium or Alternaria of the fruit of the mandarin. a source of loss to orchardists, though they were more often the cause of anxiety lest they should turn into something more serious. While I cannot. be certain that the cause in all these instances is the same fungus, it is certain, in my opinion, that no reliable difference of form can be pointed out. among the various specimens, in spite of the fact that they occur on various parts of various citrus species, and hail from various parts of the country. I shall therefore speak of "the disease" caused by this "fungus," although I wish to imply thereby only my suspicion that all are but forms. of one and the same thing. This will, I think, lead orchardists into no difficulty, as the treatment for all such cases must be practically the same until some proof is forthcoming that the various cases are different in nature.

Briefly, the disease is due to attacks of an Alternaria, the symptoms. being displayed as spots on the foliage, young branches, and fruit of the orange, mandarin, and lemon. 
Though the spots bear some resemblance to each other in all these various situations, they vary more than does the form of the fungus which produces them. This fungus is of a dark colour, somewhat greenish-black, and appears in larger or smaller tufts on the discoloured surface of the plant. Frequently these tufts are of microscopic size, appearing to the unaided eye merely as minute specks on the surface. Sometimes the tufts are run together in larger areas, but this is not often the case. When run together in this rare manner the entire growth presents a somewhat velvety appearance. The elements of which these tufts are composed are represented in the illustration on the previous page.

A considerable number of fungi of this kind have been described as growing on citrous hosts. They have been assigned to the genus Macrosporium and the genus Alternaria, though it seems to me probable that most, if not all, of them are of the form usually assigned to the genus Alternaria, and that when they have been assigned to the genus Macrosporium, it has been without the knowledge that the spores, which, upon casual observation, appear to be borne singly, are in reality borne in chains. Observation, unless carefully made, would often lead one to the erroneous conclusion that the spores are borne singly, so easily are they shaken apart, and so almost invariably are they washed apart in the water in which they are,

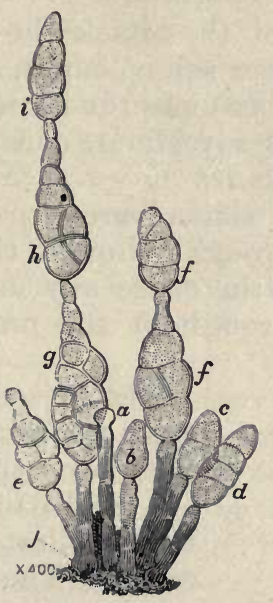

Fig. 78.-Typical growth of Alternaria. Spores of the Alternaria of the tomato as found growing on the fruit: $a$, an aerial hypha, at the top of which a spore is just beginning to form; $b$, a young spore before it has begun to divide in the muriform manner; $c$, a young twocelled spore; $d$, a young four-celled spore; $e, a$ spore approaching maturity; $f$, two spores borne tandem ; $g, \bar{h}, i$, three spores borne tandem; $i$, mycelium from which the spore-bearing hyphæ spring.

as a matter of course, ordinarily examined. One is almost tempted to think that some observers have never seen these spores growing upon their stalks in a natural position, for they are frequently figured upside-down-a position in which they would naturally be arranged by one who did not know their method of growth. It is my experience that these fungi almost never fail to give rise to spores in chains in the perfectly still atmosphere of the cultivation chamber. I cannot pretend to anything like a complete knowledge of these large and almost universally distributed form-genera, but certainly so far as my observation does extend, it points towards a more complete synonomy of Macrosporium and Alternaria.

I find that, according to their situation, these fungi vary much in the size and form of their spores, and I think this fact has led to a needless multiplication of specific names. Very small variations in the form and size of the spores, especially if associated with a new or different host or different part of the world, have been considered sufficient to warrant the application of new names. Of course, by 
small variations I mean comparatively small; it will be seen by the measurements given on this and succeeding pages what interpretation must be put upon this expression, for it can be there seen what is the actual variation among spores derived from the same mycelium.

The earlier stages of this disease, as it occurs on the leaves of the orange, are characterised by irregular roundish or elongated yellow patches of considerable extent. These patches are from five to twentyfive millimetres or more across. A striking feature of the spots is the early appearance of reddish blotches on the yellow background. These reddish blotches make their first appearance on the primary yellow of the discolouration in the form of small reddish dots, which eventually run together in the middle of the diseased spot, though they may continue to appear as isolated dots near the margins. In consequence of this a diseased area in its secondary stage has the following appearance :-A reddish central part bordered by small reddish spots arranged on a yellow background.

In the final stages of the attack the reddish central patch of the secondary stage becomes ash-coloured, and bears the Alternaria, the fructification of which assumes the form of minute tufts of dark green, or almost black, aerial mycelium, consisting of unbranched hyphae, bearing spores in chains.

Around the central ash-coloured spore-bearing area is a brown margin which pales through yellow to the normal green of the plant.

None of these growths cause any material thickening or swelling of the leaf, which throughout the progress of the disease remains normal in thickness.

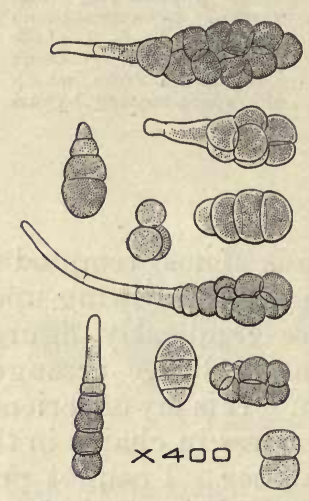

Fig. 79. - Spores of an Alternaria found growing on the leaves of the orange.

The adjacent measurements show the range of size of the Alternaria spores. The longest are 15 to 20 celled, while the smallest are 2 to 4 or 5 celled. The adjoining woodcut shows some of the spores from which these measure-

$70 \times 12 \mu$

$62 \times 18$,

$40 \times 15$,

$25 \times 12$,",

$22 \times 10$,

$18 \times 10$,

$20 \times 12$,

$25 \times 10$, ments were made. The spores are invariably smooth-walled. It may therefore be said that the full-grown spores are 15-20 celled, and measure 12-18 × 60-70 $\mu$.

Small one- and two-celled spinous or warty spores of the form referred to Cladosporium, were occasionally seen among the typical Alternaria spores, but it was impossible to more than conjecture the part played by them. Only a few were seen, not more than three or four among many hundreds of the Alternaria spores.

When pieces of infested orange leaf were placed in water-culture, the mycelium of the Alternaria grew from the leaf tissue out into the water and air, and these new growths produced spores after the manner of Alternaria, i.e., in chains, and the spores produced under these conditions did not differ very materially from those produced in 
the normal manner on the leaves. They had less colour, and were somewhat smaller. It was in part upon this evidence that the fungus was assigned to the group Alternaria.

As an example of the occurrence of the disease on citrus fruit, it may be mentioned that on one occasion three mandarins of the variety "Emperor" were examined, each with a single well-marked spot, at which the fungus had injured the skin and caused an unsightly blotch.

The mandarins were green, but would soon have ripened. The location of the diseased areas was marked by a premature " ripening," the diseased spots being surrounded by a yellow area, which shaded off into the normal green of the fruit. At the centre of the spot the tissues had been almost completely destroyed nearly down to the pulp. The original succulency of the tissues was completely gone. The tissue of cells composing the rind had been used up by the parasite, and in their place was a cracked and dried-up mass largely composed of the mycelium and spores of the fungus.

With a knife-blade it was easy to break away the brittle mass of diseased material, which might, therefore, perhaps be called scabby in its nature, though the growth was somewhat sunken, not raised. This scabby material was light gray or ash-coloured, except at the surface, where, owing to the presence of the fungi, the colour was darker-dark-green or nearly black. The diseased spots measured about five millimetres across-that is to say, not far from a quarter of an inch. Two fungus forms were found on and in the diseased tissue, an Alternaria and a Phoma.

$11 \times 7 \mu, 2$-celled, not muriform. The Alternaria was in all respects $36 \times 11, \quad 4$-celled, not muriform. of the same form as that just described $22 \times 11, "$ 3-celled, not muriform. from the leaves of the orange, and

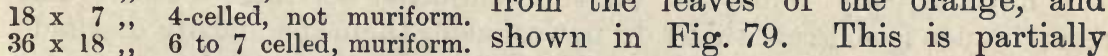
$47 \times 14,, 10$ to 12 celled, muriform. shown by the neighbouring measure$65 \times 22, " 18$ to 20 celled, muriform. ments.

An exceptionally wide cell gave $58 \times 21 \mu$. It may be said that the mature spores having six to twenty cells measured 14-22 × $36-65 \mu$. Taking the complete range of spores in the two cases, i.e., the orange leaf and the mandarin fruit, we have the following comparison :-

\section{On Orange Leaf, 10-18 x 15-75,}

On Mandarins, 7-22 x 11-65,

in which we see a practical identity. The form, colour, and structure were as nearly as possible identical in the two cases. In the case of the mandarin, however, the spores were not seen growing tandem. That method is assumed on the ground of complete general resemblance.

The curved or crooked pelicels on which the spores were borne were two to five celled, and measured $44-90 \mu \times 4 \cdot 7-5 \cdot 6 \mu$. The locations of the septa were indicated by slight irregularities in the exterior of the hypha. These pedicels grew in tufts of five to ten, and were readily to be seen with a good hand lens. Both the pedicels and their spores were of a greenish-brown colour, except the terminal cell of the spore, which was nearly colourless. 
When we consider the close resemblance between the fungi in the two cases under consideration, the case of the orange leaves and the case of the green fruits of the mandarin, and the close resemblance botween the results to the tissues attacked, it is difficult to escape the conclusion that the two diseases are identical, so far as we have now proceeded.

It is, however, necessary to next take notice of the occurrence in the diseased tissues of the mandarin skin of a Phoma-like form. The

$5 \cdot 8 \times 3 \cdot 6 \mu$

$8 \cdot 0 \times 4 \cdot 3$, ,

$7 \cdot 2 \times 4: 3$,

$10.0 \times 3.6$,

$110 \times 4.3$,

Range,

$5 \cdot 8-11 \times 3 \cdot 6-4 \cdot 3 \mu$.

Average, $8 \cdot 5 \times 4 \cdot 0 \mu$. dark-brown, nearly spherical perithecia of this form were $72-90 \mu$ in diameter, and from within a parenchymatos shell yielded colourless spores $3 \cdot 6-4 \cdot 3 \mathrm{x}$ $5 \cdot 8-11 \mu$. The perithecia were numerous in some cases, and it was impossible to aroid the conclusion that they had much to do with the disease. Adjacent are some measurements of the spores of the Phoma.

Both forms of the spores found in connection with this mandarin disease were submitted to culture in a sealed infusion of mandarin peel.

In a few minutes the Alternaria spores started to throw out four to five colourless septate threads, which in twenty-four hours became four to forty times as long as the spores themselves, beginning to branch somewhat after they had reached a length several times as great as that of the spores.

The spores of the Phoma, after twenty-four hours, began to germinate in a partial manner. In no instance was the new mycelium longer than the spore itself. In some cases buds were formed at one or both ends of these spores.

I have already remarked on the similarity of these cases. The resemblance is so great that I do not consider them specifically distinct; they are one and the same thing in my opinion, though of course this opinion is based on form, not on complete culture experiments.

\section{Melanose (?) on Oranges.}

THE following notes may be worthy of attention in connection with the cause of the disease I formerly described in this journal under the title "Melanose (?) ":-

1. The disease starts at the stomata. This fact points in the direction of the cause being a vegetable parasite; we know of a number of fungi that effect an entrance by this door, and these fungi belong to widely different groups. On the other hand, is there a single animal parasite that enters by way of the stomata? Is there one well known to choose the stomata as the scene of its operations of any kind? Any small insect, to take a supposable example, that wished to utilise its beak for sucking the juices of the plant, would hardly find it convenient to utilise the stomata, for it is precisely here that the tissues sought as food are least accessible, on account of the subjacent air-space and loose parenchyma. 
2. The disease is exceedingly common on trees that have yielded no apparent insect cause. Where the fruit, leaves, \&c., are so thoroughly infested, it is hardly even conceivable that an insect cause could have been overlooked by competent observers.

3. The disease yields to treatment with Bordeaux mixture. This points distinctly to the cause being a vegetable parasite.

4. Fungus elements are found associated with the disease. Cultures may be necessary for the satisfactory verification of this statement.

All these items are in the nature of inferences, it is true, and no single one of them can be taken, in the form stated above, as a proof of the vegetable origin of the disease; but taken together they seem to me to form an almost overwhelming argument in favour of vegetable origin.

The following cultures were made in infusion of orange peel :-

1. Water culture of healthy epidermis of an orange attacked by Melanose (?). After twenty-four hours there were only two growths. These were from spores resembling those of Coniothecium and manifestly lying on the surface of the peel. The epidermis was shaved off very thin at a place where there were no traces of the disease to be seen. All the stomata, on examination with the microscope, proved to be entirely free from discolouration.

2. Water cultures were made from stomata just beginning to show traces of the disease. These stomata were barely yellowed or decidedly brown. In no case could any satisfactory traces of a parasite be seen after twenty-four hours. If a vegetable parasite is present it must be in a very attenuated form. Of interest in this connection is the fact that in cultures of the well-developed scab the yeast-like conidia, as they go on dividing, decrease in size until they are very small indeed. Is it not possible that there is a generation of exceedingly minute size? Will this account for the difficulty in making out the parasite at the time of the beginuing of the attack?

3. Cultures of well-developed scab have yielded the results already described and figured in this Gazette. The scab of orange gave very little of the Coniothecium form, but the production of conidia was so like that of the culture of the lemon scab that I could see no difference in the two forms of conidia, except the more constant occurrence in the latter of vacuoles. The same diminution in size occurred in each.

\section{Melanose (?) on Lemons.}

From the same orchard that furnished the oranges upon which the foregoing observations were made, some lemons were forwarded as suffering from the same complaint as the oranges.

In the case of the lemons it was not possible to show that the spots originated at the stomata. Fungus elements were found among the tissues of some of the scabs of the lemon corresponding with the Conoithecium scabrum of McAlpine. The form found in the tissues as taken from the dry scab and examined at once in water, consisted almost 
entirely of loosely aggregated dark-coloured, sub-spherical cells. These occurred in groups of from four to several scores.

On being subjected to water culture in an infusion of lemon-peel, these cells gave rise to a vast multitude of yeast-like conidia, which fell off and continued to bud and separate like yeast, yet without the formation of chains and with a rapid diminution in size. Each of these conidia had one or two vacuoles. The phenomena closely paralleled those recounted by me for the similar fungus found connected with the scab of lemon bark (Vol. VI, p. 865, Agricultural Gazette).

Beside producing these yeast-like conidia, the cells of the Coniothecium gave rise to colourless mycelial threads, divided by septa into cells two to six or eight times as long as broad.

\section{Black Spot of the Citrus Frutts.}

Ir is not at all unfrequent to hear it said that this disease spreads fronj one fruit to another, and that it develops and spreads in the cases of fruit after they are placed in storage. Some observations and experiments lead me to the conclusion that there may be some misconception about this.

The spores of this disease do not readily germinate under the laboratory conditions ordinarily brought to bear in their examination, and in this respect they differ from most spores found in connection with prevalent fungus diseases. The following observations, though they are inconclusive, are inserted here out of regard to the rarity with which I have observed these spores to germinate:-

Spores of this fungus were ringed in with a small supply of water and numerous air bubbles. 'The spores, which were entirely like those figured in "Letters on the Diseases of Plants," Agric. Gaz., vol. VIII, p. 230, after twenty-four hours had failed to germinate in those parts where they were completely'surrounded by water. Spores located at the edges of air bubbles where on one side they had access to air, each sent out into the air a single very fine unbranched mycelial thread about one micromillimetre wide, though slightly wider at the free end. The mycelium was colourless, and so fine as, under the circumstances, to preclude observation as to septa; none were seen. At the end of twenty-four hours the length of these hyphæ averaged several times the length of the spores.

As to the spread of the Black Spot disease among citrus fruit in store, the following observation may be of interest:-

A ripe lemon that presented a pronounced case of this disease was utilised to test its communicability. Spores were removed from a well-developed pustule and inoculated into a healthy portion of the rind of the same lemon. It was thought if the disease spread on fruit in store, as sometimes claimed, this inoculation ought to give a positive result. Two inoculátions were made, but neither gave any 
signs of activity. The lemon was kept under observation for one month, but during this time the inoculations gave no sign of developing into diseased spots. At the end of a month it was with difficulty that the places of inoculation could have been located had they not been previously marked.

This would tend to show that this disease, if it does develop in cases of fruit in store, does so from spots that are already started but invisible. If this is so, and if it is also true that the disease is not spread from one fruit to another in storage, the fact may be of use in instances where it is claimed that fruit has contracted the disease in storage. Further tests in this direction are desirable.

Associated with the ordinary fructification of this disease I have noticed, on at least one occasion, those of another sort; the perithecia are of about the same size but ascophorous.

\section{LEMUNS DECAYING WHILE ON THE MARKET.}

At times one finds in the market lemons which are light in weight but to all external appearances quite sound. On being opened they are found filled partially with air, the pulp being a trifle dirty and showing small whitish spots. Kept a few days in a warm room, these lemons show a brown discolouration at the stem end, and as this spreads toward the tip or other end of the lemon a grayish-green fungus appears, generally near the stem. This resembles Penicillium in appearance, and bears spores such as are pictured on this page. The rind of the lemon in the vicinity of the outward sporebearing portion of the fungus is permeated by copious mycelium, and this mycelium extends beyond the brown colouration. For example, where the brown colouration extended one-fourth of 'an inch to half an inch from the stem, the mycelium was found in the more healthy-looking tissue an inch away. Sealed in under a cover with water, sections of the lemon peel containing mycelium gave conidia and new growth of mycelium as shown in Figs. 82 and 83.

The lemons that were most carefully examined in this connection were imported from Italy, but I have no doubt the rot is one found in connection with Australian-grown: lemons. The disease would appear to have been introduced at the stem end of the fruit at harvest.time or during storage.

One of the most useful hints that can be

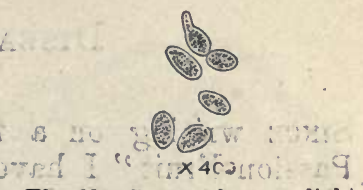

Fig. 82.-Spores from a light: weight lemon starting to
germingte in water-culture given for guidance in connection with this rot is the fact that the fruit is often of light weight. This is due to the fact that the attack of the rot results in evaporation of the water of the fruit, its place being taken by air. This lightness comes about while the fruit isi still to all outward 
appearances sound and saleable. I have known worthless lemons of this character to pass along in the trade from hand to hand until they at last found their way into,-well, we will call it consumption. At any rate the consumer paid the bill. Beware of light-weight Temons that appear to be fresh and juicy in the skin, for they are most likely of this worthless sort, and so will become mouldy, and besides are already past using. Their acidity is tainted with a bitterness that makes them unfit for culinary purposes.

In calling attention to the lightness of the smitten lemons there is no failure to remember that good lemons sometimes become light in weight. Good lemons becoming light in weight become so by drying up, and are therefore easily distinguished from those that are light from rot, since the latter have a juicy skin. Lemons that are merely

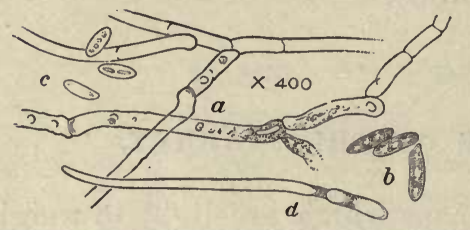

Fig. 83.-Mycelium and spores from the rind of a light-weight lemon. $a$, Mycelium; $b$, spores; $c$, spores. somewhat smaller than those shown at $b ; d$, spore germinating. dry in the skin often contain excellent acid.

As the disease enters at the stem end we might expect that any fungicide or disinfectant applied at the stem-scar would be effective in preventing the entrance of the fungus, and this is actually the case. This operation may be accomplished most effectually at the time the lemons are being packed for storage or for a long journey. 'The operation should not be delayed long after plucking.

Care in the harvesting of the lemons will do much to leave the scar unbroken, and this care should always be exercised if the lemons are to be kept for a long time, as when exported or placed in storage.

The ordinary fungi that attack bruised fruit are much more common at some seasons than at others, and when they are prevalent special care should be exercised in harvesting and handling the fruit. Damp weather, especially if continued through several days of moderate temperature, is very conducive to the growth of these fungi, and it is during such weather that special care should be exercised. The weather that causes old boots, bread, and cheese to mould is the sort of weather in question.

\section{Diseases of the Passion-Vine.}

[See Coloured Plate opposite.]

SINCE writing on a former occasion on the "Woodiness of the Passion-Fruit" I have kept the diseases of this crop more or less in view, with the result that it is now possible to give a much more complete sketch of the fungus diseases to which it is subject. These turn out to be quite numerous, and they present a considerable variety. Besides the woodiness, which still remains more or less of a mystery, there is a ripe rot of the fruit which appears to be found also on the foliage, a shot-hole or leaf-corroding fungus, a Macrosporium disease, and one or two others. 


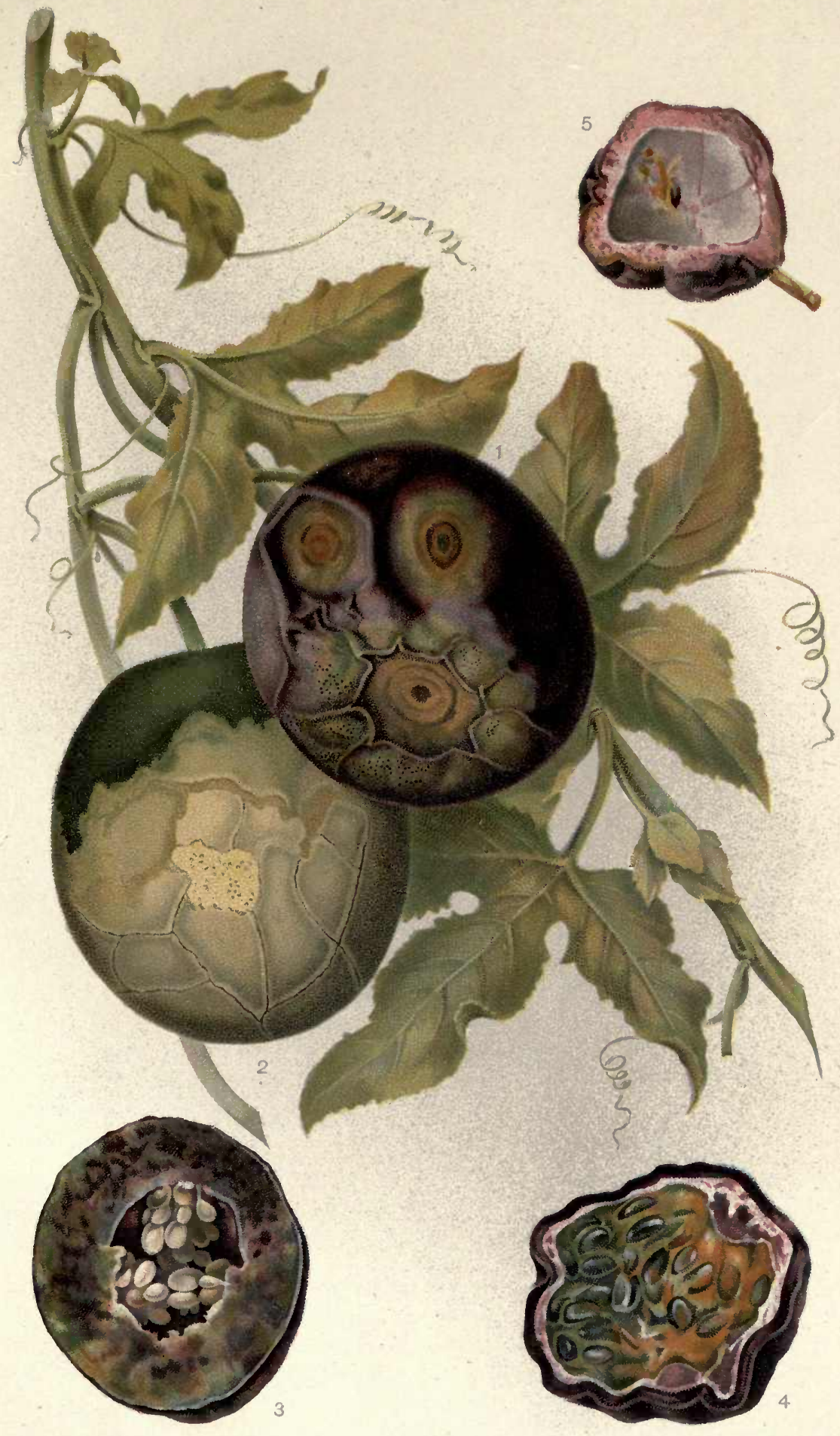

DISEASES OF THE PASSION-FRUIT. 



\section{Woodiness of the Passion-Fruit.}

Fig. 7, p. 411 Agricultural Gazette, 1901, illustrates green passionfruit beginning to be woody and cracked, whose further history is as follows :-

The portions of the surface which crack-generally the lower parts as the fruit hangs on the vine - turn to a dirty white or very light russet colour, and the surface cracks off in thin layers, leaving a rougher and more russety surface; - that is to say, a dry corrosion takes place. Before the dirty-white area cracks away its margin is sometimes separated from the green and intact parts of the fruit by a green area where the cells seem to have collapsed without losing their green colour. If a fruit showing the foregoing appearances is plucked it will, after 48 hours, begin to "crinkle" on the green parts, but will remain unchanged in the woody parts-remain quite hard, dry and "woody."

\section{Macrosporium of the Passion-Vine.}

The following are details of a Macrosporium found on the leaves of the Passion-vine :-

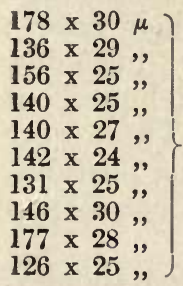

spores.

As seen through the microscope the spores are of a light brownish colour. The size varies, as shown in the adjoining table of measurement of ten spores, from $24-30 \times 126-178 \mu$. The twelve to seventeen cells of the spore are arranged in a muriform manner.

The distal ends of the spores are more slender than usual, and it is seldom that one sees at this end of the spore the slightest indication that it has been connected with others of its kind. In no case were the spores seen growing in chains, although spores in situ were examined to a considerable extent. It thus seems as if we may here have a species entitled to be classed among the forms assembled under the name Macrosporium. The germination of these spores is very prompt and vigorous. The above wood-cut gives additional details.

The spores were borne on four to five-celled basidia of somewhat irregular diameter swollen between the septa and especially at the base, and of the same colour as the spores. They were nearly straight and measured $6 \times 60 \mu$.

As has just been noted, a so-called species of Alternaria or Macrosporium, probably the latter, is sometimes present on the leaves of the Passion-vine, and this species is identical with that to be found 
in connection with a certain well-known disease of the ripe and halfripe fruit, the main characteristics of the disease on the fruit being as follows :-

Spots which at first are greenish on the purple background of the fruit, later turn brownish or buff, and show a somewhat concentric arrangement of slightly varying colours. Ultimately the skin or shell of the fruit becomes very thin and brittle at the diseased spot and caves in of its own accord or as the result of some slight accident.

As before remarked, a fungus (the Macrosporium) occurs on this diseased area, and its presence is denoted by the appearance of tiny tufts of a dark fur-like growth of small dimensions.

Notes were made on a large lot of passion-vine fruit and leaves collected in July.

Undoubtedly by far the most common fungus was the Macrosporium, which on these specimens I was able to prove to be such by examination in situ with the aid of reflected light. The spores could be plainly seen to be borne singly on the stalk.

I should say that nine out of every ten spots on the fruit examined were infested with Macrosporium, and in no case would I care to say that this fungus was entirely absent.

Not infrequently there were found associated with the Macrosporium dark pustules, and upon examination it was found that these pustules were an immature form with stalks growing from near their bases; they contained no ripe spores. These were oblate, and dark in colour.

Some spots that showed the Macrosporium also showed deliquescent pustules of Gloeosporium of a dirty transparent colour. There were spots that were composed almost altogether of Gloeosporium pustules, but I could not be sure that there was no Macrosporium in connection with these spots.

On the leaves the main fungus feature was the Macrosporium, though, in most cases, the fungus had not yet broken out. In a few cases the dark-coloured perithecia occurred, the same as those mentioned above as being unripe. No Gloeosporium was seen. These specimens were from a plantation where there had been considerable loss from disease.

\section{Pleospora on Passion-Vines.}

This Pleospora was first found on the rind of diseased ripening fruit in the form of perithecia, most of which in the month of July were not yet ripe. The perithecia were more than half submerged and of a dark colour, but not necessarily black. Round the bases and in the vicinity of the perithecia there were hyphr that bore, on short stalks, minutely echinulate 8-10 celled yellowish spores more than half as wide as long, and measuring about $25 \times 17$ micromillimetres. These spores germinated in water, and in doing so sometimes produced at the ends of hyphæ not much longer than the spores themselves secondary spores of a similar nature to the primary spores, but of a lighter colour. (Fig. 85.)

Returning now to the perithecia, it may be said that the few ripe ones contained asci bearing eight yellowish spores, each averaging 
$27 \times 13$ micromillimetres and varying as follows: 11-14 x 22-31 micromillimetres. These somewhat elongated, but occasionally ellip-

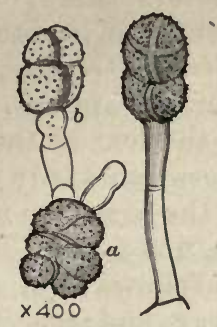

Fig. 85.-Germination of the aerial spore-forms found in connection with the Fleospora of the fruit of the passion-vine. $a$, spore that has fallen from an aerial hypha such as that shown at the right; $b$, a secondary spore produced in a water culture.

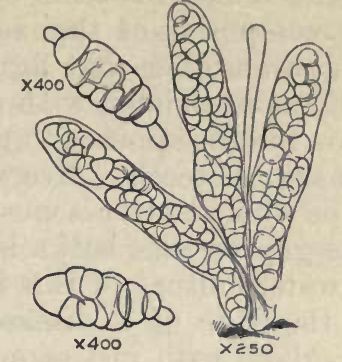

Fig. 86.-Sketch of Pleospora from the rind of a passion-fruit. The spores shown, magnified 400 diameters, are just beginning to germinate, the end cells starting first.

soidal, spores were crenate in contour, and were transversely divided about seven times, the middle four to five parts being muriformly sub-divided. The polar cells were undivided. Sometimes there were two cells in succession at the pole undivided. Their greenish yellow transparency allowed the observer to see that the contents of the cells were only slightly granular.

The asci were about six times as long as broad, and the contained spores were arranged in a spiral manner in two rows. Between the asci were transparent colourless septate sterile hyphæ one third as wide as the ascospores.

On escaping into water the ascospores seemed to be at first surrounded by a layer of transparent and almost invisible gelatine. These thin-walled ascospores were quick to germinate in water, and it was the polar cells that were the first to throw out hyphæ, though sometimes the other cells were quick to follow suit.

The perithecia were about seventy micromillimetres in diameter, but it may be that this measurement is deceptive, as only one or two ripe specimens were seen. The measurements were from ripe perithecia.

\section{Faulty Leaves on the Passion-Vine.}

The leaves of the Passion-vine are sometimes imperfect in shape, the imperfection being manifested in a torn appearance, more especially at the edges. Occasionally there are holes, as in the shot-hole disease of the apricot. Such leaves are also somewhat distorted, but not so much so as in the disease I have named "Woodiness." The diseased leaves look as if pieces had been torn out of them.

- If the apparently torn edges are examined with a magnifying glass, it will be found that instead of being torn they are eaten away by a fungus, the fungus itself, or at least the fruiting part of it, being visible when lnoked at against a strong light. On certain parts of the 
corroded edge an almost imperceptible fringe can be thus made out by careful examination.

Under a magnification of one hundred diameters this fringe is seen to be composed of the aerial fruiting filaments of a fungus, very much resembling that figured in the Agricultural Gazette, vol. III, p. 289, as associated with a shot-hole disease of the apricot.

This fungus appears to gain its entrance to the leaf at the points of the marginal teeth. Every stage of its progress can easily be traced, and the whole matter is most interesting. From the corroded tooth-point to the gap whence half a lobe has disappeared, not a stage is wanting.

A water culture of this fungus was made as follows:- A small piece from the edge of a diseased leaf was cut away and placed under a cover-glass, with just enough water to moisten it. The water applied for this purpose, of course, as usual, washed away the spores from the projecting hyphæ, and they were left bare. These loosened spores were sketched and resembled those shown in Fig. 89. The coverglass was then sealed on, and the fungus left to develop in the moist chamber thus provided.

After fifteen hours the edge of the piece of leaf presented a vastly different appearance. Aerial hyphæ had shot up and produced a copious crop of spores, as represented in Fig. 89. These spores were

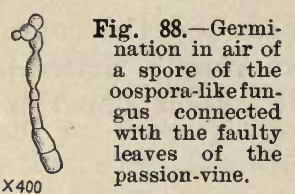

spores to fall off, sometimes in clusters.

This gives us the time required for these spores to develop and ripen; and the speed with which it is done explains clearly the ability of the fungus to corrode and completely destroy a large fraction of a passionvine leaf in a few weeks.

The spores spoken of as falling away on the application of water were kept under observation, and were found to germinate in two different ways, according as they were in water or

$15 \cdot 8 \times 6 \cdot 3 \mu$ )

$13.0 \times 6 \cdot 3$,

$9 \cdot 1 \times 4 \cdot 2$,

$12 \cdot 6 \times 6 \cdot 3$,

$13.3 \times 4.9$,,

$12.6 \times 5 \cdot 6,$, Average,

$11 \cdot 2 \times 5 \cdot 3,, 5 \cdot 7 \times 12 \cdot 6 \mu$.

$12 \cdot 6 \times 5 \cdot 3$,

$12 \cdot 3 \times 6 \cdot 7$,",

$10.9 \times 6.3$,",

$14 \cdot 0 \times 5 \cdot 6$,

$14 \cdot 0 \times 5 \cdot 3$,

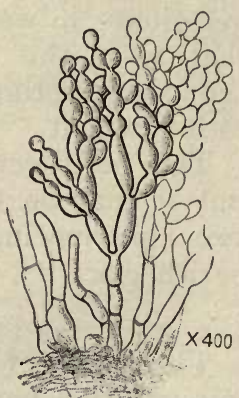

Fig. 89.-Oõspora-like fungus connected with the faulty leaves of the passion-vine. sketches were made when the growth was twentyfour hours old. As will be seen from the adjacent measurements, the spores of this fungus, which bears the closest resemblance to that found and recorded by me on the edges of shot-holes of the almond and the apricot, range in size from 4-6 $69-16 \mu$, and average $5 \cdot 7 \times 12 \cdot 6 \mu$. 
They are of a smoky or slightly greenish colour, and present a raised scar at each end at the places where they were formerly articulated together.

It remains uncertain on what part of the leaves these tested spores. grew, but there can be very little doubt that it was at the margins of erosions. Nothing was seen that contradicted this. T'he spores wereseen only in slide preparations of the spots from the leaves. The spores were the main feature of the preparations as they cameoriginally to the microscope.

The spores of this Oospora-like fungus on germinating become in. many instances two-celled. Sometimes they are two-celled on removal, but this is exceptional. On being cultivated in water-infusion of passionvine leaves a large proportion of the spores become two-celled, and in this condition still possess many of the features of the spores as they fall from the aerial chains in which they grow. On becoming two-celled the spores send out from either end, and sometimes also from the sides, of the component cells, colourless mycelium composed of cells, having somewhat the form of the component cells of the spore. In other words the septa of the mycelium are separated from each other by a distance from one and a half to two times as great as the width of the mycelial thread itself.

It appeared to me that the mycelium produced conidia, which were at first ellipsoidal, but which, through a process of budding, decreased

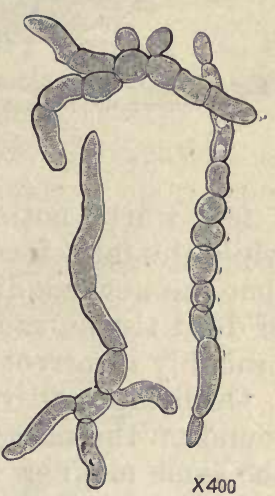

Fig. 90.-Germination in water of the spores of the Oospora-like fungus connected with the faulty leaves of the passion-vine. in size, and became nearly spherical while continuing the process of budding. In one case I saw growing side by side from the end of a. spore four such ellipsoidal conidia. In other cases I saw the same conidia growing from the side of well-developed mycelium that had grown within twenty-four hours from one of the original spores. (Fig. 90.)

\section{Comparisons.}

The edges of the holes in apricot and almond leaves are often fringed in the manner described in the case of the corroding fungus of the Passion-vine. A comparison of the spores in the two cases. discloses no essential difference. They are borne in the same way, and are of the same shape, colour, and size.

Examination of the edge of an apricot shot-hole for all the kinds of spores discoverable gave on one occasion the following results :-

1. The above-mentioned spores in proportion of ten to one of anyother kind.

2. Quite a number of Alternaria spores.

3. Few spores resembling those of Cladosporium, but possiblybelonging to Alternaria.

4. One each of three other kinds of spores, manifestly erratic. 
Phyllosticta was abundant on the patch that had been removed from this hole. The question, therefore, naturally arises, are these fungi new growths taking up the destruction where the Phyllosticta leaves off, or are they spore-forms of the Phyllosticta? In this connection
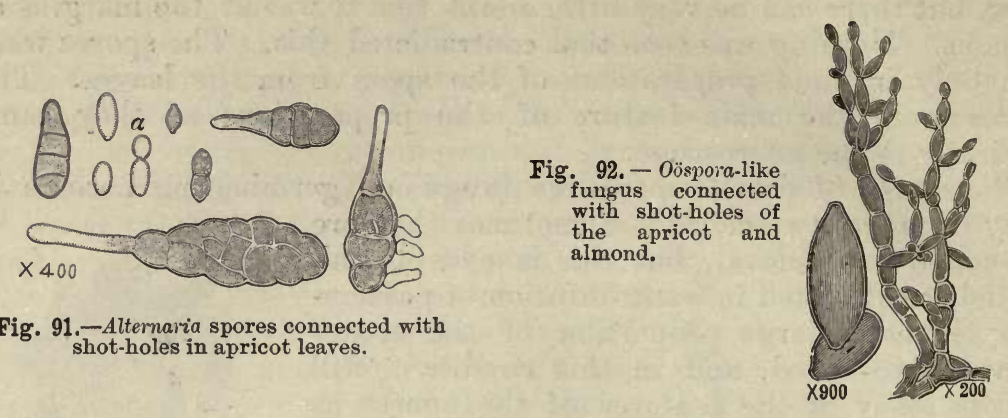

a fact worth noting is that the Phyllosticta is a sub-cuticular form, while the later forms are aerial in their fructification. It seems possible that the new conditions, brought about by the falling away of the circle of dead tissue, cause the mycelium to produce new spore-forms. It is probably incorrect to attribute all the damage to the Phyllosticta form.

On being cultivated in a moist chamber the Oöspora-like fungus, found on the margins of the shot-hole of the apricot, grows in precisely the same manner as the fungus found corroding the margins of the leaves of the Passion-vine. A careful comparison shows absolutely no .difference in form, and, moreover, the rate of growth, \&c., are the same.

\section{A Ripe-rot Fungus on Passion-vines.}

A Gloeosporium, or Ripe-rot fungus, was observed growing on

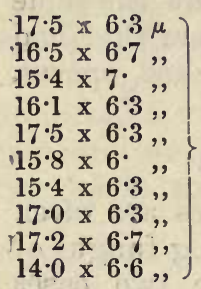
Passion-vine leaves. Passion-vine leaves that showed at the time of gathering only Macrosporium and accompanying pustules already described, were placed on moist blotting paper Average, in a moist chamber. In five days Gloeosporium $6.4 \times 16^{\cdot 2 \mu}$. pustules were so well developed that the spores were being "spouted" forth. The Gloeosporium appeared separate from the other fungi on the leaves, the spots being scattered over the lamina of the leaf and on the veins. The pustules had the same appearance as the Gloeosporium of the apple, the mass of spores being -salmon-coloured or brownish, and the pustules being of the same size. The measurement of ten spores taken at random are given above, the average falling at $6.4 \times 16.2 \mu$, and the range in size being represented by the figures $5 \cdot 6-\$ \cdot \times 12 \cdot 6-17 \cdot 5 \mu$.

The elongated, slightly greenish, straight or somewhat curved spores had a clearly defined vacuole near the centre; if the spore was lying -so as to appear curved the vacuole often had a lateral position on the incurved side on the spore. The granulation of the spores was coarse, 
so coarse that four to five granules side by side would occupy the width of the spore. The smallest spores seen measured $5 \cdot 6 \times 12 \cdot 6 \mu$, but such were not common, and were not taken into account in the above measurements.

On being placed in water culture these spores germinated in the same manner as those of the Gloeosporium of the apple and those of the Colletotrichum of the Bean. There were two distinct methods of germination :

1. The spore became two-celled, and from one of the halves a short unicellular mycelium bore a dark-coloured secondary spore of an ellipsoidal or sub-spherical form, with coarsely granulated contents.

2. The spore either without or with a primary division into two cells threw an unbranched mycelium, colourless, and composed of cells eight to ten times as long as broad.

Sometimes the same spore showed both sorts of germination, and there were various intermediate stages. The secondary spore sometimes germinated soon after its formation.

The granulation of spores of Gloeosporium presents a variety of appearances according to the species to be sure, but also and

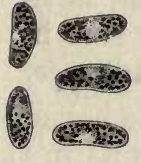

$\times 400$

Fig. 93. - Spores of the ripe-rot of the leaves of the passion-vine.

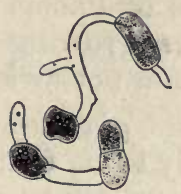

Fig. 94.-Ripe-rot spores of the passion-vine leaves germinating and producing secondary spores.

in particular according to the state of the spore itself. Sometimes the granulation is coarse and distinct, and sometimes it is indistinct, and all these phases may be exhibited by the same species in the course of a few hours, showing how uncertain a feature this is :and how misleading it may be to the systematist unless he is carefu! to include in his characterisation all the various phases. The matter .composing the granules seems to disperse and collect according to the vicissitudes of growth. At one time the granules may appear very distinct like the grains of rice in a pot of water about to be boiled, and not long after they may appear indistinct and run together in almost the same manner that the grains of rice might run together .on being boiled.

\section{DIseases OF THE WALNU'T.}

Hitherto the walnut has been grown in this State only on a small scale, and its diseases have consequently had comparatively little attention. Occasionally the diseases have received some little notice and I will record here the few scattered notes I have made upon their nature. 
One of the worst diseases known to this tree is of bacterial origin. In other countries it sometimes carries off the bulk of the crop. It attacks especially the fruit and leaves, and the chief characteristic of the disease is the appearance on these parts, often early in the season, when the disease is likely to do the most damage, of soft black spots, which affect particularly the new growths and frequently kill the young nuts. Nuts attacked later in the season, when the shells have partly formed, do not suffer so severely, but their husks are attacked, and their proper ripening is prevented. These statements are taken from the writings of foreign observers. I will only add that I have good reasons for thinking, as the result of examinations, that this disease exists in this State.

No satisfactory treatment is known, but it is stated that a winter treatment with full strength Bordeaux mixture appears to have done good. The greatest hope seems to be that resistant varieties may be developed. As the disease winters in the husks it is advisable to give them special attention, not allowing them to accumulate and rot under the trees. It is comparatively easy to adopt methods of culture, harvesting, and curing that will allow of the burning of husks and foliage, and, in my opinion, this should be done.

A species of Phoma and an ascomycetous fungus have come under my notice as growing on the nuts of the walnut tree in New South Wales. I am not aware that they do very much damage.

Penicillium glaucum, one of the commonest of the household moulds, is frequently to be found on the husks of the walnuts in the orchards, and it appears to be common in the marketed nuts. Beyond doubt there is an interesting field for work in connection with the fungi so commonly associated with musty nuts, and I have often longed for time to go into the matter, but have never been able to find it. I think it most probable that these fungi make their entrance at the orchard, or during curing, and that very likely something could be easily and cheaply done to minimise their evil effects, if only we had some clue as to their methods of access and action. When the nuts are bleached for market by the use of chlorine they are less likely to go musty, if the process is skilfully carried out. It has always seemed to me that a germicidal temperature might be brought into play in curing walnuts if proper chambers were utilised.

\section{Leaf-CuRl of the Potato.}

THIs blight of the potato is known, I believe, wherever potatoes are grown. It is a common disease in America, Europe, and Australia. It is caused by a fungus of the Macrosporium tribe, and is characterised by the appearance of a curl in the leaves of the potato plant at a time when there is little external evidence of any fungus growth. Later the fungus appears on the leaves and stems in the form of dark green 
velvety growths composed of spores of the form shown in the illustration below.

Though originally described as a distinct form from that found on the tomato and other related plants, more recent observers begin to doubt whether it should be so regarded, but the careful study necessary to settle the point has not yet been made. In form the fungus is certainly so much like the similar fungus found on other solanaceous plants that it is difficult to point out a real difference, provided the data are derived from a good range of specimens taken at various times of the year, and from various parts of the host plants. This will be partially evident from an examination of the various forms pictured in these pages.

Potatoes suffering from this blight have come under notice in this State with considerable regularity for some

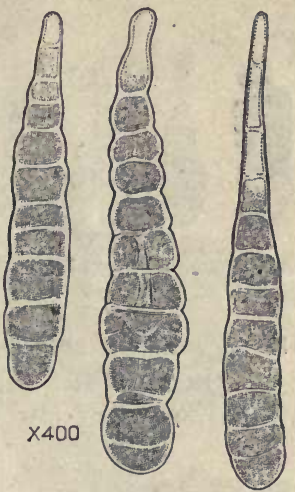

Fig. 95.-Spores of the Macrosporium of the potato, the cause of the Leaf-wilt or Leaf-curl of the potato.

years past, so that it seems to be a fair inference that the disease is not uncommon; still the grower's complaint is seldom great, and the malady must be ranked among those of secondary importance, partly, I doubt not, on account of the general dryness of the climate.

In every instance it has been brought under notice at a date too late for the profitable application of fungicides. The early application of Bordeaux mixture will hold the disease in check. This has been proved to be the case in other countries. Hence, if any grower suffers regularly from this easily-recognisable disease, he may feel sure that if he assumes from the time of planting that the disease will appear, and sprays in anticipation of the attack, he will be adopting one of the best known methods.

Combined with this measure should be the careful destruction of all infected material, not only of diseased potato plants, but also of tomatoes, chillies, and, in fact, in my opinion, of any plants or parts of plants known to suffer much from fungi of this class.

The disease seems to start from the ground, or, at any rate, to enter the base of the stalks first. This accounts for the peculiar curl of the leaves, which results in part at least from poor functioning of the stalk. This means, of course, that the fungus is already inside the plant, and hence already beyond the reach of fungicides. The course of the disease therefore indicates that care should be given to the ground as the source of infection, and as it is a fair inference in the present state of our knowledge that the disease arises from spores similar to those produced on the leaves, we should pay particular heed to what becomes of all such spores. They should be carefully destroyed, the best means to this end being the destruction of all diseased plants, as recommended above. 


\section{Disease of Chillies.}

VERY closely related to and perhaps identical with the black rot of the tomato is the present rot of the Chilli. The fungus, whose spores

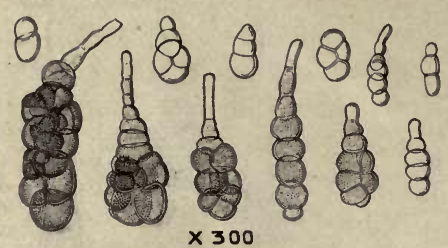

Fig. 96.-Spores of the black rot of the fruit of Chilli. are shown in Fig. 96, occurs on the fruit, often in its eye. In this respect as well as in the form of the spores it resembles the similar rot of the tomato.

I have met this disease but once, and have no experience as to the effect of fungicides on it, nor do I recollect any writings on the subject of diseases of the Chilli. The best suggestion seems to be that remedies found useful for the black rot of the tomato may be expected to act favourably on this very similar disease of the Chilli.

\section{Onion Disease.}

The following appearances were noted on some imported onions, and

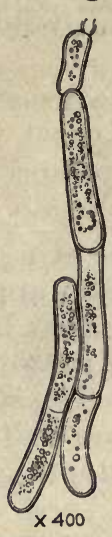

Fig. 93.-Mycelium of the dis. ease of the onion bulb. gave rise to inquiry

as to whether there was any danger to the crops of the State from the importation of such bulbs.

Most of the bulbs composing the shipment were perfectly sound. Yellowish holes through the outer scales appeared on some of the specimens. These holes were six to ten millimetres across. The sunken and diseased

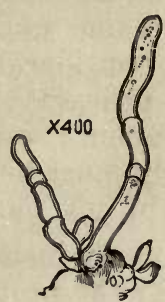

Fig. 97.-Mycelium of the dis ease of the Onion bulb.

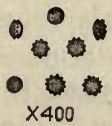

Fig. 99.-- Spores from a fungus disease of some stored onion bulbs.

tissue contained a strong growth of colourless mycelium, in the midst of which dark, spherical, smooth or warty spores were found which measured 4-5 micromillimetres in diameter. There was no positive evidence that the spores were connected with the mycelium beyond that of juxtaposition. The examination was conducted for the guidance of inspectors under the vegetation diseases act. The evidence was not considered of sufficient definiteness and importance to warrant any definite action.

\section{Anturaciose of the Fig.}

With us the foliage of the fig does not suffer much from fungus disease; but there is an anthracnose not uncommon, which sometimes does considerable damage. The appearances produced by this disease are shown in the plate opposite. As a result of the disease, the fruit 


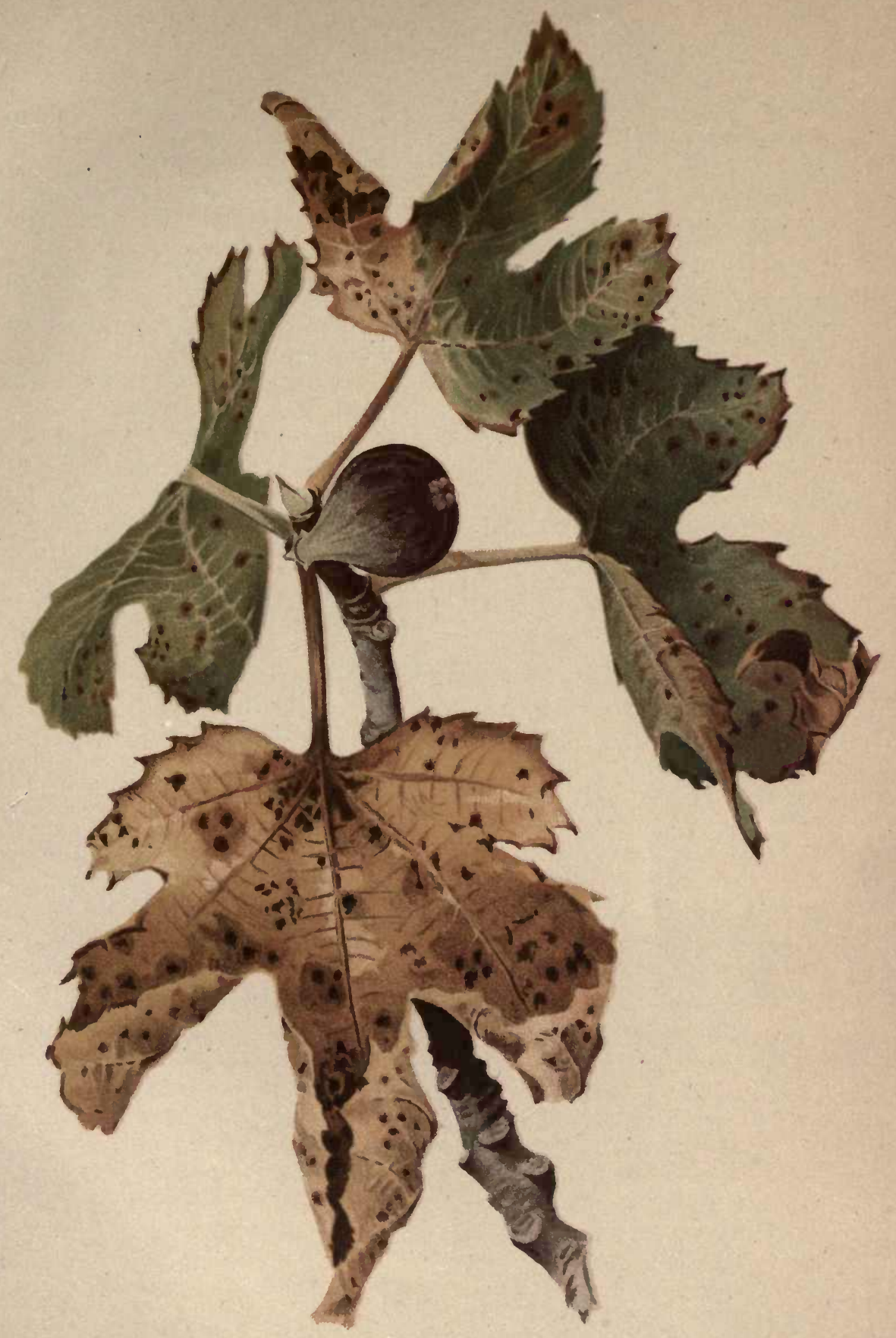

ANTHRACNOSE OF THE FIG. 

falls prematurely; and even if it remains on the tree and attempts to ripen, the colour is pale and unnatural and the taste rather insipid. The destruction of such foliage is advisable, and this is not a very expensive matter in the case of this large-leaved tree, especially if the trees are not too large. The application of Bordeaux mixture may be proceeded with without fear of injury to the foliage, the full strength mixture being used. The effects of this treatment are beneficial.

\section{Root Rots and Timber Rots.}

From time to time I have collected or had submitted for examination a considerable variety of specimens suggestive of a class of diseases which fortunately seem not to be so destructive in this State as they are well known to be in some other countries. I refer to those rootrots and timber-rots caused by fungi of the toadstool and puff-ball order. These innocent looking fungi are by no means so local in their growth and effects as we are wont assume, in fact if all other matter in the vicinity of one of these fungi could be removed so as to give us an unobstructed view of all of the ramifications of the "toadstool" or "puff-ball," as we call it, our astonishment would be great. Minute thread-like "roots" pass from the bottom of the fungus, as we see it perched on the surface of the ground, downward and outward for long distances, and, in the case of certain species, do not end except in some source of food such as the roots of some plant or tree. There in the roots of the plant or the trunk of the tree is elaborated the material used in producing the "toadstool." We sce the treetrunk gradually going to decay, little realising that its substance high up in the air is being secretly taken away through the microscopic roots of the toadstool, carried down into the soil, and there elaborated and stored in readiness for some spell of wet weather when it suddenly comes to light as a bunch of "toadstools." Sometimes these fungi are not quite so secret in their operations, and then we see them fructi. fying on the very surface of the tree-trunk in the form of bracket fungi.

Not only do standing tree growths suffer in this manner but also cut timber lying on the surface of the ground, or in any other damp situation. Fence posts and vineyard posts suffer in the same manner. I have in the vicinity of my residence a number of posts that every now and then, during some spell of wet weather, send up near their bases whole battalions of "toadstools." I know well the source of their growth and have kept them under observation for the purpose of learning more of their habits, but I would not advise any professional orchardist or gardener to act similarly, or at any rate would warn him that he does so at the expense of his property.

Although this field has been as yet but very imperfectly explored, it seems probable that these fungi are mostly unable to fight their way into living and growing tissues so long as these are free from injury, and this fact gives a clue to remedial and preventive measures, as we shall presently see.

As already remarked these diseases seem to be less common in Australia than in other countries. Possibly our droughts have something to do with this, for it should not be forgotten that our severe droughts undoubtedly kill off many pests as well as many crops. Still, 
in a matter like this, it is unwise to assume on such negative evidence that we are well off, for it is quite possible that these diseases are doing more damage than appears, simply because they work in such an obscure, hidden and ill-understood manner. I propose therefore to recount the particulars of some of the instances that have comc under my notice in the hope that greater watchfulness may be exercised.

On a later page, under the head of a "Disease of Larkspur," will be found the particulars of a definite case of the kind we are considering. Here the plants were killed outright, dying suddenly when full grown from the effects of a sort of root rot or collar rot. Plants of other sorts, such as Gladiolus, in the same gardens were also affected in a like manner.

Some years ago Mr. Scobie of Maitland called attention to a disease occurring in his vineyard which presented some features that led me to the conclusion not only that vines are subject to attacks of this kind, which would be merely a confirmation of a former article on Pourridié, but that it is to be feared especially in the vineyards in the moister districts of the State. The case was not a very clearly defined one, for there appeared to be several causes at work, and it was impossible to unravel all the tangled threads of evidence. Several fungi that would account for some damage were found on the leaves of the vines, but in other instances the roots were found to be in an unhealthy condition.

The affected vines shed their leaves before ripening their fruit and in consequence the fruit ripened in an abnormal manner. It appears that this was not in all cases an evil, as Mr. Scobie related that one year he netted more from the diseased vines than from the sound ones. Instead of being black as they should have been, the berries were amber coloured, and had a fair flavour. The disease appeared to skip about from year to year, and to be of a not very. serious nature.

From this it will be seen that the evidence was not very clear.

Suspecting the disease might be the beginnings of the so-called Californian Disease, Mr. Scobie sent specimens to Prof. Pierce of Santa Ana, for an authoritative decision and received the comforting reply that the disease was not the one passing under that name in the United States.

A search on the leaves that had been shed by the vines in the premature manner described showed that two fungi were present, the Tufted Leaf Blight of the vine, already described in this Gazette as a pest of the vine, and an Alternaria of precisely the form described in connection with Take-all of wheat, a fungus that is not at all uncommon on decaying vegetation.

It was plain however that these would not account for all the damage done, even if they did account for some of it, and moreover it was difficult to see why healthy vines should exist alongside diseased ones if these fungi were the prime cause of the disease in such cases. When diseases are spread by means of spores borne on the wind it is customary to see plants attacked in a rather uniform manner unless there are marked variations in the adjacent plants, such as variation in variety and hence in suscentibility. 
There were found on the roots of some of these vines what appeared to be broken puff balls. Only the filaments and spores of these parasites were seen. They are carefully illustrated in Fig. 100. Their nature is such as to leave little doubt as to their origin, and to the suspicion that we have before us fairly good evidence of the attacks of a root rot. such as we have set out to elucidate.

Not infrequently Galls, so called

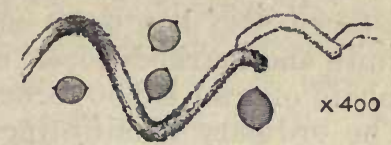

Fig. 100.-Fungus elements from a disease of the roots of a grape-vine.

"Crown Galls," have come under notice from vineyards, not only from the moister parts of the State but from the drier districts such as the vine regions of the Riverina district. No definite fructification is as yet known in connection with these "Galls", and their origin is still obscure, but they are commonly supposed to be of fungus origin. Experience has proved that these particular galls may be successfully fought by methods presently to be described.

\section{Remedies.}

1. Whenever trees, vines or plants are seen to die or fail without apparent reason such as the appearance of some insect or fungus pest, the soil should be examined for traces of fungus growth and attention should be given to the appearance in the neighbourhood of any puff-balls or toadstools. If soft, fragile, white or light coloured threads are found in the soil they should be examined to see whether they are ordinary rootlets or the soft spongy growths of underground mycelium. If such mycelium is found in the vicinity of dead or dying plants it is presumptive evidence that they are suffering from the attacks of one of the root-rotting or timber-rotting fungi. These threads are likely to be most numerous in the vicinity of the roots of the attacked plants, and often concentrate at some obvious injury on one of the roots.

Of course anything that can be done to prevent the spread of these threads in the soil will be beneficial, and one of the first precautions that suggests itself is the application of some chemical disinfectant, and for that reason we will deal with this phase of the question first, though such measures are not the most important that can be adopted.

Without going into the matter minutely it may be said that one of the best substances for this purpose is quicklime, applied at the rate of one, two or more tons to the acre. It should be worked in to a considerable depth, the sooner after application the better. Nearly all injurious soil-inhabiting fungi are checked by this treatment, which has the advantage that it is often advisable for other reasons connected with the fertility of the soil. Fresh wood ashes may be used in the same manner.

Another substance that may be used in somewhat the same way is sulphate of iron. It may be applied in the form of pulverised crystals, or as a solution. If applied in the form of crystals these should be fine and be very evenly and thinly distributed and worked in immediately, 
the deeper the better, within economic limits. If the solution be used, it should be sprinkled on, and it may be best to work it in somewhat. This sulphate may be applied at the rate. of $2 \mathrm{cwt}$. per acre. This substance also has some manurial value. Except in cases of very definite and marked local infestation of the soil the application of sulphate of iron is not recommended.

The ordinary disinfecting solution of Formalin may be used in the same manner in a small way, as for instance in a flower garden.

2. Whenever a tree, vine or post is attacked by a timber-rotting fungus, and there is other valuable vegetation in the neighborhood, it is well to isolate the diseased area by means of a trench all round, dug deep enough to cut off the thread-like underground growth of mycelium. The depth to which the trench should be carried can be easily judged in some cases, but not so easily in others. Before commencing on the trench dig down where the fungus filaments are most abundant in the soil, and observe to what depth they penetrate. After measuring the maximum depth to which the filaments penetrate dig the trench to this depth and a little more. The location of the trench should receive careful attention, after the same manner; put the spade down at various distances from the centre of the infestation and turn up the soil and examine it for threads of the fungus. When their limit has been found locate the trench well beyond that limit, for it is usual for these growths to taper off, and thus their exact limit is usually considerably beyond the apparent limit. This measure is one that is of considerable practical value, especially in those cases where the trenches can be made to serve at the same time to secure better drainage.

3. The timber-rotting fungi are more common in soils that are poorly drained than in those that are well drained, though lands that are soaked constantly may not be very subject to their attacks. Good drainage is therefore to be recommended as a means of minimising the bad effects of these pests.

4. It is a paying precaution to treat the bottoms of fence and vineyard posts in a manner known to hinder decay, and this is especially the case with posts composed in any degree of decayed wood. It goes without saying that posts with signs of decay should, if possible, be avoided. Charring or covering with tar are highly to be recommended as representing money and labour well invested on the underground portions of posts.

5. The presence in the soil of any insects gnawing the roots of plants renders the plants more liable to attack, for as before pointed out, there is good reason to suppose these root-rotting fungi are mostly unable to make their way into plants except through some injury in the bark. In like manner in an orchard or vineyard where there is reason to fear the attacks of these fungi special care should be exercised not to injure the roots when cultivating.

6. Of course all infested posts, tree-trunks, and infested stalks should be removed and destroyed, preferably by fire. Roots of infested trees and vines should be dug out and destroyed.

7. Turning now to the "galls" found on roots of vines and fruit trees the best remedy is the removal of the galls. Plants suspected 
of attack should have their roots uncovered and all galls removed and destroyed, usually best by fire. They should be pruned away with a sharp tool, when it will often be found possible to leave half or more of the root intact. It is best to cut liberally, as the disease is likely to extend beyond its apparent limits. The cut should be covered with some antiseptic and water-proof substance such as is used in pruning and grafting. If a root has to be severed the cut off part should be removed and destroyed. A little digging will soon reveal the maximum depth to which it is necessary to dig for the galls, this depth being seldom more than one foot. It is quite as important to remove the small galls as the larger ones. The smaller ones are more. easily seen if the root is washed with the aid of a smart hose, or even with a brush and water, an operation that is easily performed if the earth be removed in a manner to allow for it. Where a tree or vine is manifestly on the road to ruin it is much better to remove it and destroy it than to allow it to take its own course.

\section{Disease in Seed Potatoes.}

"ARE these seed potatoes sound?" is a question that arises continually. If this fact is due to the repeated warnings published with regard to the great danger of spreading Root Gall through the medium of seed potatoes, we have some cause to feel gratified. For

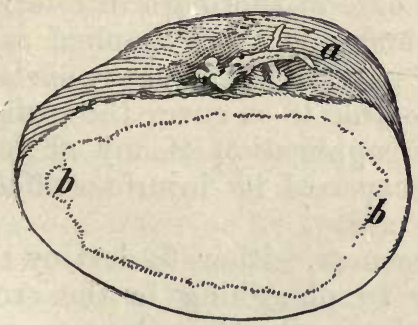

Fig. 101. - The sprouting of a potato suffering from the initial stages of wet rot $a$, Sprouts ; $b b$, indications of the wet rot. The sprouts are weak and spindling. Compare with the adjacent illustration.

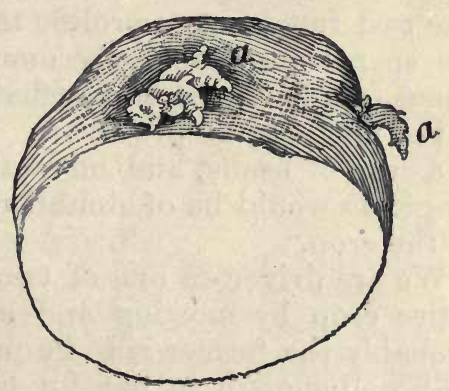

Fig. 102.-The sprouting of a healthy potato. Tu be compared with Fig. 101. aa, Sprouts.

there is no doubt that scrupulous care should be exercised to prevent this pest from spreading as it has been allowed to do in the past. It is equally certain that it is largely through the medium of seed potatoes that it has become so widely spread.

The present note, however, does not relate to the Gall Worm, but to another common pest of the potato, namely Wet Rot. The drawings on this page point a moral. They represent two potatoes from the same lot, some of which, however, sprouted much better than others,and no wonder! From the outside all the potatoes looked about equally good, yet a large part of them were diseased. The sketches show the manner in which the diseased seed differed from the sound. Though in this case no cultures were made to verify the assumption, there can be no doubt that the diseased seed was suffering from the 
initial stages of the common Wet Rot. When planted the diseased seed did not sprout well and the plants were of small promise.

Potatoes derived from a crop that suffered from Wet Rot should not be used as seed. The principal point here made is that by cutting, as shown in the illustrations, it is possible to detect the initial stages of the disease, and so provide in a measure against its attacks. Although the sketches give a fairly good idea of the appearances that should be regarded with suspicion, it would be best to educate the eye to the appearances by cutting and examining some unquestionably sound seed of the kind being planted. The appearances are quite striking once the eye has become accustomed to them.

\section{BeAN Rust.}

[See Coloured Plate, Frontispiece.]

WhILE this is not a common disease in this State, it is one that can at times do considerable damage, as witness the coloured figure in the frontispiece, which was drawn from a typical specimen taken from a crop of considerable size. Such cases are not common.

No words of mine could give a better idea of the general appearance of the disease than that conveyed by the excellent coloured drawing from which the lithograph has been faithfully produced. It will be seen that the leaves and pods were thoroughly infested. Though the crop was not destroyed it was much diminished.

The disease is of such a nature that it is very difficult to combat. The rust fungi are so prolific that in the case of thorough infestation the spores are practically omnipresent, and any spray applied as a means of relief must, to be effective, cover practically the entire surface of the plants to be protected. It is impossible to so cover the surface of a crop of beans, and moreover such an application of any efficient fungicide would be of doubtful utility because of its injurious effects on the crop.

We are driven to one of two other measures, either to destroy the entire crop by mowing and burning, or to ploughing in the crop. Probably the former is to be preferred. It may be that the crop will bear well enough to pay for harvesting, and in that case it may be wise to consider whether it may pay to let the pods ripen and then, after the harvest, burn off. This course is the less to be feared as the disease is not a common one, and appears only under exceptional circumstances, and hence may give little further trouble, no matter what course is adopted.

\section{Cabbages atracked by Peronospora.}

Plants suffering from this disease are easily distinguished from their healthy neighbours. The leaves are covered, more especially on the under side, with a frost-like growth consisting of erect threads bearing a snow-white crop of spores. All these appearances occur while the infested leaves are still green and before they droop and wither away.

The individual spores are large enough to be seen with the aid of a powerful magnifying glass. The drawing placed on this page shows the microscopic appearance of the growth. 


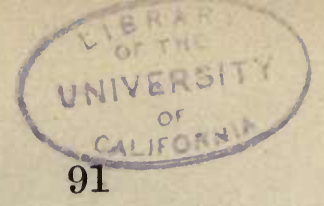

This is a fungus disease related to the Potato Murrain, and acting in the same manner. Peronospora parasitica is the parasite, and it is found mostly on young cruciferous plants growing in damp shady places. It is not found on fullgrown plants except under unusual circumstances.

Remedies.-1. Secure good drainage, especially for seedlings in beds, and look out in general that the place is not too moist and shady.

2. Destroy at once all affected plants, otherwise the disease is likely to spread from them to other young plants, not only to cabbages, but also to turnips, radishes, and other crucifers.

3. I know of no experiments with fungicides made upon this particular fungus, but the use of Bordeaux mixture is effective with the potato blight or murrain, and some others of a similar character. I therefore have no doubt that the Bordeaux mixture could be applied with good effect. Cabbages will stand the application of the mixture. It should not be applied in the middle of warm sunny days, but in the morning or evening, or on cloudy days. One or two applications, I think, would be sufficient. The first two measures should suffice unless considerable money is at stake.

If a bed has to be destroyed on account of the disease it would be best to disinfect it with boiling hot water or by sprinkling thoroughly with concentrated solution of sulphate of iron. Facts that should be remembered are that the disease is very likely to spread down hill, and in the direction of the prevailing wind.

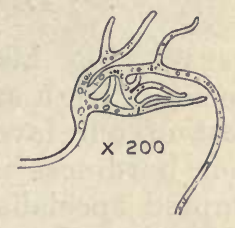

Fig. 104.-Final ramifications of the nycilium of Cabbage Peronospora as grown in water culture ; showing the peculiar dichotomous branching mentioned in the text.

\section{Black Spot or Fusicladium of the Loquat.}

[See Coloured Plate, Frontispiece.]

THERE is a disease of the Loquat-very common some seasons, much less so others - that deserves mention, though it is among the pests of minor importance, unless indeed the disease proves to be dangerous to other vegetation. I refer to the "Black Spot" of the fruit of this tree. Though most apparent on the fruit, it occurs also on the foliage, in this respect resembling the Fusicladium fungus of the black spot of the apple and pear, to which it is very closely related, to say the least. The specific differences among these various fungi seem to me to be open to question, but I am not yet prepared to publish evidence such as that given on previous pages in connection with the ripe rot fungi.

The chief object of this note is to call attention to the precise appearance of the disease, and to the fact that it may be combated in 
a manner similar to that employed for the black spot of the apple and pear. The foliage of the loquat will stand the application of the Bordeaux mixture, and so will the fruit. The spores of the disease are killed by the fungicide. The value of the crop can alone determine whether it will pay to spray. In most cases the loss from the disease is slight, and I am inclined to think that unless spray is in use for other purposes the operation will not be a paying one, except in the few cases where orchards contain a considerable number of trees. From observations made I would recommend that spraying be commenced in July or early August, and as the foliage does not wet very easily the spray should be as fine as possible and be applied quickly and the operation repeated as soon as the first application is dry, as explained elsewhere. If apples and pears are grown to any extent in the same garden or orchard and suffer from black spot, I should regard this as an additional reason for giving attention to this disease of the loquat. Otherwise than this I should not be inclined to spend time and money in spraying loquats.

According to my observations the disease is much more common on neglected trees than on those well taken care of ; in fact, except in damp situations the disease is rather uncommon on thrifty trees, from which it may be inferred that cultivation and care will, as a rule, be rewarded with clean crops.

\section{Diseases of the Flower Garden.}

Disease, like his offspring death, is no respecter of persons - or species. High and low, plain and fair, wither under his dread touch. Most of our favourite garden flowers, however, are such because of their hardiness as well as their beauty. Now and then a species has tempted specialists into productions that are delicate, but the rule holds good that hardiness is an essential quality in a favourite flower. It must thrive under ill-treatment; under all sorts of discouragements it must raise its head and smile forth in blossoms. Such sturdy qualities bode ill to would-be parasites, and it is not often that we have to give attention to the diseases of the ordinary flower garden. Its roses, dahlias, daisies, cosmias, and all the rest of the cheering host, hold their positions largely by virtue of their resistance to disease.

\section{Notes on a Disease of Cosmia.}

The specimens consisted of half-a-dozen pieces of the stalk of Cosmia, about five-eighths of an inch in diameter. The fungus growth consisted of an olive green "fur," nearly a quarter-inch deep in the denser parts, where it completely obscured the stalk of the Cosmia. This growth was composed of sparsely branched mycelium, ending in the usual Botrytis spore-formation. These aerial hyphæ were several times branched. Elsewhere the growth seemed more recent, and had a more "frosty" look, and was shorter, and appeared as in Fig. 105, the hyphæ being unbranched until near the apex where the spores were clustered in snowy masses that completely hid the ramifications of the hyphæ. 
On one of the branches of the Cosmia numerous peritheca were found, black and flattish, about $400 \mu$ across, often elongated with the drying of the tissue in which they were imbedded. These bore strongly bilocularly marked spores $1 \cdot 8-2.9 \times 5 \cdot 2-7 \cdot 4 \mu$, and averaging about $3 \times$ $6 \mu$, being rather rod-shaped with rounded ends

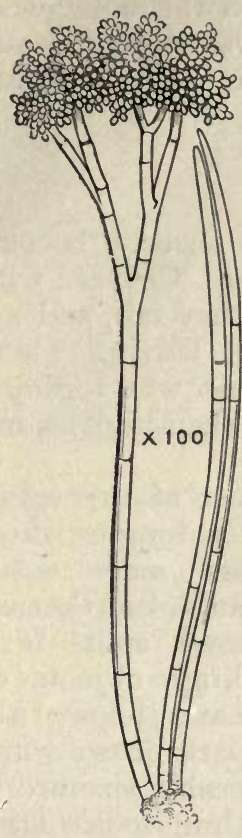

Fig. 105.-Botrytis found growing on stems of Cosmia. The specimen shown was one of the smaller growths mentioned in the text.
Fig. 106.-Terminal portion of one of the branches of the fungus shown in Fig. 105, more highly magnified.

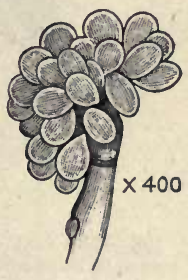

Outbreaks of Botrytis are usually found only on rank growths in damp places, and the fungus
plants are beyond recovery, so that in the past appears only after the plants are beyond recovery, so that in the past
it has been the custom to describe the species of this genus as growing it has been the custom to describe the species of this genus as growing
on "dead and decaying matter." This

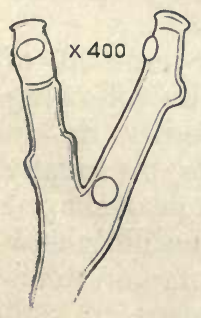

Fig. 107.-Terminal portion of the aerial hypha of the Botrytis shown in Fig. 105, with the spores removed; showing the receptacles on which the spores are clustered.

of other varieties. Spraying with Bordeaux mixture has been shown to be effective against some species of Botrytis, and may be tried with
hope of success in this case. hope of success in this case. may, however, have been a mistake, in fact certainly was a mistake in some cases.

Remedies.-Examine the plants and ascertain what are the first symptoms of the disease ; then pull up and destroy all plants that show any such symptoms. Unless this is done it is probable that the disease will spread to other Cosmia plants, and to plants
ith Bordeaux mixture has been shown 


\section{A Disease of Hollyhocks.}

The hardy hollyhock has few enemies, yet there is one, the mallow rust, to which it occasionally falls an easy prey. This is a malady common to a number of related species, among which the hollyhocks are the worst sufferers. When in its grip, with leaves drooping and yellow, putting forth blossoms in a half-hearted manner or not at all, they are no longer-

"Queen Hollyhocks,

With butterflies for crowns";

their tall and ragged forms, no longer courted by insects, become reminiscent rather of the other end of the social scale. Covered with

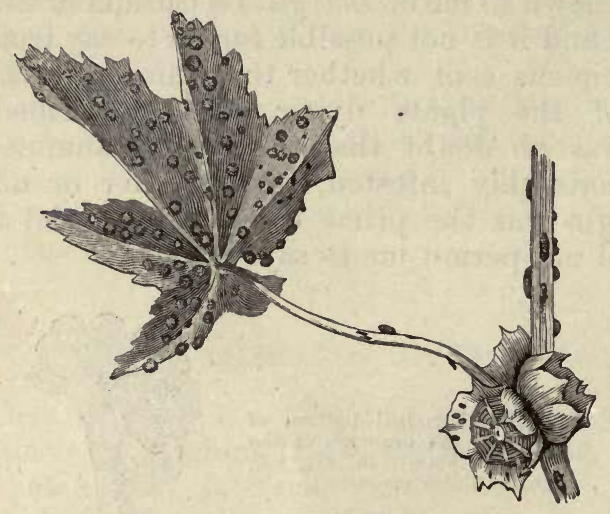

Fig. 108.- The rust of the hollyhock as it appears on the leaves of the commion weed known as Mallow, to be found in or near most flower gardens. The dark raised warts or pustules are the most obvious signs of the disease. They occur on the leaves, stalks, and fruits. an apparently sound plant may succumb in a few days' time. As the warts increase in size, and begin to take on their final dark-brown colour, the leaves of the Hollyhock lose their normal greenness, and assume various shades of yellow and brown. Later they dry up completely in the worst cases.

If we examine the full-grown warts we find them composed of immense numbers of spores of the form shown on the following page. These when they germinate, which they readily do in water in our cultures, or in dew on the surface of plants, or in any moist situation, appear as in Fig. 110, the small dark and pear-shaped sporules being those that are capable of again infecting the hollyhock or any one of a number of its congeners, such as the common dooryard weed, the Wild Mallow.

As a leaf of the hollyhock often bears several hundred warts, and each wart contains several hundred spores, each of which, if it secures a proper chance, will produce ten or twelve sporules, we need not wonder that this disease sometimes becomes quite a scourge. 
Prevention.-The preventive measures that may be taken have been foreshadowed in the description of the disease. First of all destroy

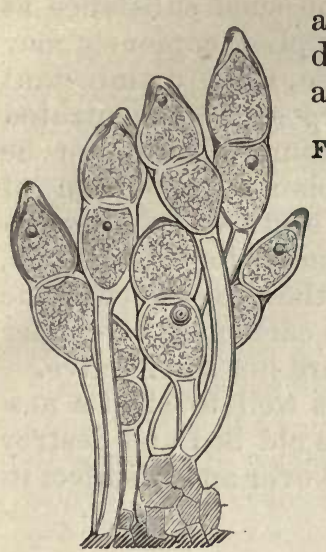

all the wild mallow in the vicinity. This may be done with "elbow grease," which, when properly applied, is very effective. I have noticed that

Fig. 109.--Spores of the Mallow Rust, Puccinia malvacearum. These spores, which are elongated or somewhat fusiform and have a slight constriction at the middle, are massed together in scattered, round, and raised compact brown sori, which, however, are elongated on the stalks and petioles. These sori have a habit of falling away and leaving scars or holes, in which case the ground underneath the plant becomes a breeding-place for the disease. The smooth yellowish-brown spores, measuring $15-25 \times 35-75 \mu$, are borne on pedicels once to twice as long as themselves. There are no paraphyses.

where the disease is rampant on Hollyhocks it is almost invariably to be found on wild mallows in the vicinity, and I am sure that the disease in this State is carried over. from season to season through the agency of this weed, and if the weed be kept down the Hollyhocks will be benefited. In my opinion it is a good plan to keep the Hollyhocks from seeding too freely. If a considerable number of the seed pods are cut as soon as the blossoms. are past-i.e., of course, supposing the blossoms are allowed to remain on the plant as garden ornaments, a use to which they are so eminently adapted,- the result will be a good growth of foliage. This will mean a good supply of food stored up in the roots for next season, with the result that the plants will start vigorously the next spring.

The plants are such rank growers that it is best to give them a good supply of food. Any stinting in the growth is sure to lead to greater liability to disease. It will be noted that the smaller and weaker plants are the first and the worst sufferers from the disease.

When the summer's growth is over, destroy all the old foliage and the stalks.

The symptoms of the disease are prominent ones, i.e., the growth of the abovementioned warts, and this leads to a measure that may be of use in some cases, namely, the plucking of the leaves of the Hollyhock as fast as they become sources of danger. Do not allow any of the warts to assume a brown colour. Up to the time the warts begin to turn brown they are not spreading the disease, and the leaf is still of use to the plant. Soon after they become brown

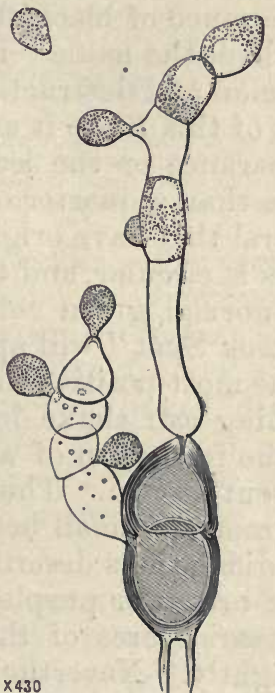

Fig. 110.-Teleuto spore of the hollyhock rust, germinating and producing secondary or pronycelial spores. The small dark pear-shaped bodies are the promycelial spores. These are the spores most active in spreading the disease. They sometimes appear in such numbers as to give the surface of the rust pustules a frosted appearance.

they are capable of spreading the disease, and they should be removed by plucking the leaf they are on. 
Where the disease has once occurred, it is probable that the ground near the diseased plants is covered with germinating spores. Hence it is advisable to disinfect this ground with some such substance as lime, applied in a liberal manner. Wood ashes applied copiously may be used, and will act as a manure. Failing these, some disinfectant may be applied with a sprinkler. For this purpose a concentrated solution of sulphate of iron is useful, but the ground should not be saturated with it, as that might injure the plants. Solution of formalin may be used. Merely digging over the earth will do good.

Bordeaux mixture is known to be an efficient remedy for this disease, but it is rather out of place in a flower-garden, as the appearance of the sprayed plants is far from attractive. Ammonio carbonate of copper and Eau Celeste are less objectionable, but they are not so effective.

Where Hollyhocks have suffered severely it is well to start a new bed at a distance from the old one. Root out the old bed and destroy the stalks and roots, and then dig the ground well over and disinfect it.

\section{Diseases of the Rose.}

Black Spot.

[See Coloured Plate, Frontispiece.]

There are at least two distinct diseases of the rose characterised by the :appearance of blackish spots on the leaves. Of the two, the present, to which the name "Black Spot" will be applied, is probably the more common and destructive. Under the climatic conditions of the greater part of this State it appears at all seasons, and is characterised by the appearance on the leaflets of dark spots varying in size but seldom more than a quarter of an inch across, except by the amalgamation of -several that have originated near each other. The normal form of the spots is circular, and the first indication of their presence is the loss of the normal, green colour of the leaflet at the place where the future "Black Spot" will appear. Though very inconspicuous, this symptom is the most positive indication that the disease has secured a hold that nothing can shake loose, for such a beginning must lead inevitably to the formation of a typical diseased spot in spite of any remedy at present known. The only preventive is to destroy the infected leaflet.

From this small beginning the spot increases in size until it reaches the dimensions described above, changing colour meanwhile through dark brown or purple to almost black. Not infrequently a single leaflet bears scores of these spots, which most people would describe as unsightly. Nevertheless, I must not forget to mention that I know more than one person of artistic temperament that, on making up a bouquet of roses, seeks out one or two of these diseased leaves for their effect in the composition of the bouquet. I am compelled to admit that the colouration of the discased leaves is sometimes of an agreeable nature, and that a leaf or two with picturesquely arranged spots, or leaves that have taken on a bright yellow colour preparatory to final dissolution, when skilfully disposed in a bouquet lo give an added charm, perhaps by way of contrast with the perfection of the roses that droop above; though I am almost afraid to admit such heretical statements into the literature of pathology. 
At last these dark spots turn white, or at least ash-coloured, at the centre, and this is an indication that the fungus, which is causing the disease, is about to fructify or produce spores. The spores are formed in very minute pustules that can be seen only with the aid of a good magnifying glass, and yet so fertile are they that a single spot of the disease may give rise to many thousands of spores, each capable under proper circumstances of producing a fresh infection.

The disease runs its full course in a few weeks time, as may be readily ascertained by examining the youngest leaves that display full-grown spots. It is usually the lower leaves on the plant that suffer most severely,for the reason that through the action of dews and rains an abundance of spores are washed on to them from above. Nevertheless, the highest leaves are often found infested, a proof that the wind also plays an important part in the distribution of the spores.

The different varieties of rose vary considerably in their susceptibility to the disease, and different plants of the same sort show variations according tolocality, age, and so forth. New gardens started from carefully selected cuttings, and at a little distance from other roses, may remain free from the disease for

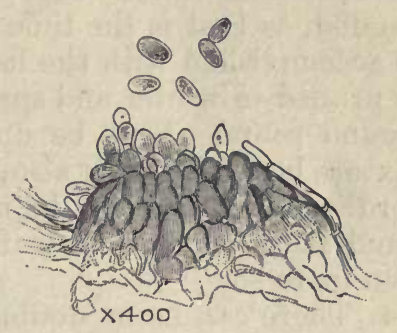

Fig. 111.--Spores of Phyllosticta Rosarum Pass, the cause of the Black Spot of the Rose. The simple, smooth, colourless, ellipsoidal spores, measuring $5 \cdot-7 \cdot 2 \mathrm{x}$ $2 \cdot 2-3 \cdot 2 \mu$, and averaging $5 \cdot 5-2 \cdot 6 \mu$, are borne in minute black, nearly spherical perithecia, about $100 \mu$ in diameter, which are partly buried in the epidermis of the dead tissue of rose leaves in the midst of more or less circular spots found on the upper surface of the attacked leaves, and characterised by a distinctly concentric arrangenient of a striking series of colours, namely, an ashcoloured or nearly white centre, surrounded by brown, purple, and black.

some time. Some varieties appear almost never to suffer from the disease, and these are particularly the small-leaved and climbing sorts. The rank growing sorts, producing large and succulent leaves, are the worst sufferers. This disease is readily distinguished from the other common spot-producing disease of the rose by the fact that the diseased areas are in the present instance never radiate or star-shaped. Moreover, the spots of the "Star-shaped Leaf Spot" are very seldom so dark as those of the present disease, though they are often much larger. (See coloured Plate opposite p. 26.)

Remedies.-1. Foremost among the remedies must be placed hand picking, which, if carried out watchfully, will in most cases be sufficient. It is not sufficient to remove simply those leaves that show black spots. The eye must be trained to see the beginnings of the disease, and so become able to indicate what other leaves should be destroyed. Where a few roses are grown as a recreation or for ornament this is the method that will most commend itself. The labour is not great, and will not be grudgingly bestowed where it is being expended for love rather than for profit.

2. Pruning is a more severe measure that may be resorted to in those cases where the plants are much infested, and where it is desired to reduce the disease at one stroke. As in the case of the plucking of the leaves the parts removed had better be destroyed. 
3. Spraying seems rather out of place in an ornamental garden, and will probably be resorted to only as an extreme measure, as when it becomes necessary to revive a neglected garden that has become overrun with pests. Most roses will stand Bordeaux Mixture of full strength, and all will stand it in its weaker forms, and in either strength it is a valuable agent with which to combat either this disease or the Star-shaped Leaf Spot. In those parts of the State where the leaves fall in winter some form of winter treatment may be recommended, as that is the time of the year at which the greatest good can be accomplished with the least expenditure of energy. If the plants be pruned in winter and sprayed well right down to the roots, and the ground round about be dug up slightly, and some of the spraying mixture be applied to it also, the results will be very beneficial. Strong Bordeaux Mixture may be used for this purpose. Whitewash will be found fairly efficient on leafless plants; lime, sulphur and salt mixture even more so.

4. There can be no doubt that the rose plant has the power when in the best of health to resist somewhat the attacks of the disease, in fact, this is one of the most important features of the whole matter, and it points to the advisability of securing well-drained soil containing a good quantity of the right kind of plant food. As to the soil it may be said that, with the exception of a very loose and sandy soil, almost any kind will answer. If, therefore, the growth of the rose-bush is

$$
\begin{aligned}
& 00000 \\
& 00000 \\
& 0 \times 400
\end{aligned}
$$

Fig. 112.- Spores of the Black Spot of the Rose, Phyllosticta rosarum, obtained from the surface of the leaves, and mounted in water and drawn at once. It will be noted that these spores are smaller than those produced in a water-culture shown in Fig. 111. not vigorous, thought should be given first to the surrounding conditions with the idea of finding out whether they can be so improved as to give a more vigorous growth. Above all the rose is a lover of plenty of air and sunlight, and will not do its best where there is a lack of either. The ideal rosebush stands by itself in a sunny and airy place. Though no ground is too poor to produce some sort of growth in a rose, it is useless to expect perfection except plenty of good food be present in the soil. If it becomes necessary to supply manure it should be dug in in a shallow manner and be of a suitable kind. With reference to disease, it may be said that nitrogenous manures tend to cause a softer and more susceptible growth than other manures. Manures characterised by potash, lime, and phosphorus, rather than by nitrogen, are those that should be applied to roses suffering from leaf-spot.

\section{Diseases of Larkspur.}

Plants of Larkspur or Delphinium have been submitted to me that had died suddenly - in twenty-four hours it was said. The plants were full grown and in blossom. A number of seedlings had been lost in the same manner. Other gardens were affected at the same time, February.

The soil attached to the base of the plant contained threads of white mycelium, after the manner of soil harbouring certain timber-rotting fungi of the toadstool family, and the base of the plant was decayed 
just where it left the ground and below that point, so that the tissues were easily poked apart with the finger, and the interior of the base of the stalk was seen to be affected with a similar looking fungus growth. The threads in the soil and the mycelium inside the tissues of the stalk were composed of similar elements, as shown by the sketches.

Although the stalk for an inch or two above ground appeared to be discoloured, it was not soft and rotten as was the portion below ground, nor on examination could any fungus elements be found in the tissues. The hollow of the stalk, which appeared to be a likely place to look for signs of the disease, showed no traces.

It appears that the manner of attack is to destroy the bark and subjacent parenchyna near the surface of the ground. In other words, the disease produces a kind of girdling or collar rót, or root rot.

Lime at the rate of at least one ton per acre is recommended for such attacks.

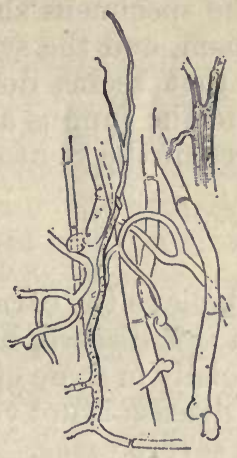

Fig. 113.-Fungus elements found about the roots of larkspur suffering from a fatal disease of the roots.

Trenching off the diseased area so as to isolate it was also suggested. The details of these remedies are given on page 983 , October number of this Gazette.

\section{Leaf Disease of the Chrysanthemum.}

This is a disease of the Chrysanthemum that attacks the leaves principally, the plants sometimes dying from the effects of the attack. The lower leaves succumb first, and thence the disease travels upward.

The principal symptoms are seen on the leaf blades, which turn yellow and then brown, either in spots or all over. The colours change from the normal green, first to Naples yellow, then gradually through light brown to dark brown.

The fungus causing the disease is a species of Septoria, produced in perithecia so small that even with a magnifying glass it is not easy to see them. On leaves where the spores were so numerous as to befound in great numbers in every water preparation made from pieces of leaf five millimetres square, the pustules, which must have been very numerous, were to be seen only with difficulty.

Remedies.- I have had no opportunity to test the effects of fungicides on this pest. It is known that a similar disease of the tomato can be easily controlled by the thorough use of Bordeaux Mixture. I have seen only one case of this disease, and in that case the plants were killed. The

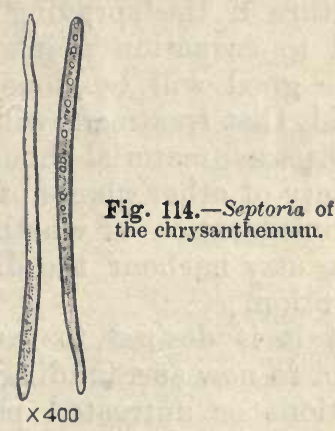
disease seems uncommon, but it must be remembered that florists do not make such frequent calls upon the resources of the 
Department as do fruit-growers and gardeners, and as such calls would be in this particular instance one of the main sources of my information, it may be that the disease is more common than I think.

The specimens showing the above symptoms had numerous red mites on them, and the symptoms may have been complicated by this fact, but that seems doubtful. Probably the diseased appearances were due to the fungus alone. The mites may have been feeding on the spores of the Septoria.

\section{Rust of the Carnation.}

I believe the carnation, even in a state of nature, suffers considerably from this disease, but under cultivation it suffers much more severely, especially in some of the more rank and tender of the florist's creations. The disease is not very common in this country, but I have occasionally seen severe cases. The attack is marked by the appearance on the foliage and stalks of streaks of a dark brown colour and a powdery nature breaking through the epidermis.

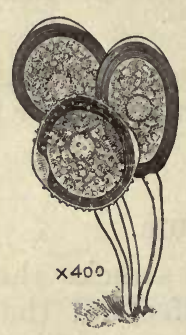

Fig. 115.-The rust of the carnation, Uromyces caryophylorum. Two ellipsoidal teleuto spores and one nearly spherical uredo spore. The uredo spore has three nearly equatorial germ-pores. The teleuto spores have each a single terminal germ-pore. The brown or reddish powder becomes loose, and through its agency the disease is spread from one plant to another. The rust fungus causing the disease, of which the abovementioned powder constitutes the spores, is enormously productive, and under favourable conditions the disease spreads rapidly, and does much damage. Plants in greenhouses are quite as subject to attack as those in the open.

There is more than one rust that attacks the carnation, but that seen by $m e$ in this country is Uromyces caryophylorum, the spores of which are shown in the accompanying illustration.

The disease may be treated with some success with Bordeaux Mixture if the spraying be well done. Such mixtures do not cling well to carnation plants, and, unless care is used in the application, little good will be done. If the plants are sponged with Condy's Fluid, that treatment will mitigate the disease.

Diseased material should be destroyed. The disease also attacks a variety of other plants of the pink family. This fact should lead to a consideration of whether there are any other plants in the vicinity that may harbour the disease. If any such exist they should receive attention.

If it is desired to save plants already attacked, it is well to move them to new surroundings, taking special precautions that no diseased portions or untreated plants are removed. Patiently and carefully removing and destroying all diseased material should be the main reliance in most cases, though the application of fungicides will be a paying operation in the larger plantations of the florist. 


\section{The Hawthorn Hedge.}

I am of opinion that the Hawthorn hedge is a mistake in fruitgrowing districts unless it receives the same care as the orchards themselves.

The Hawthorn is closely related to the apple, pear, quince, and some other common fruits, and in consequence the various pests of these species find a convenient refuge in Hawthorn hedges. This opinion is not based on a mere surmise; I have frequently, as others have done, seen the pests actually in the possession of the hedges. It is said that the codlin moth can live in the Hawthorn berry, with what truth I do not know from actual observation, never having seen such a case myself. There are other insect pests injurious to the pomaceous fruits that thrive on the Hawthorn and find a lurking place there.

As to fungus pests, I have found several destructive pests of the orchard to be common on the Hawthorn. Ripe-rot and canker fungi are both very common on it. I believe it would be almost impossible to find a Hawthorn hedge without these diseases.

The edges of the leaves are frequently eaten away after the manner of the pear-leaves examined and reported upon some years ago in this journal. Among the debris to be scraped away from the edges of such leaves may be found minute spores, which appear to have originated from very small perithecia. After lying for an hour in water the spores appear in masses supported in a gelatinous transparent substance, as if they had been forced out from a hidden receptacle where they had been previously packed away. The time of their

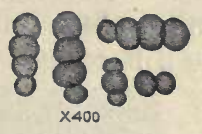

Fig. 116.-Canker fungus of the bark of hawthorn. appearance is too soon after the preparation is made to admit of the supposition that they have grown from a single spore or a few spores, or from mycelium.

The bark of the Hawthorn is often eaten away by a canker fungus. The external and microscopic appearances are the same as on appletrees. The bark is destroyed down to the wood.

A species of Gloeosporium was found on the Hawthorn, a description of which will be found in the notes on Ripe-rot.

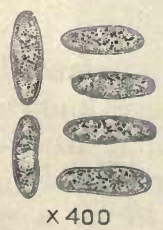

Fig. 117. - Spores of Gloeosporium of the hawthorn.

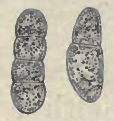

Fig. 118.-Spores of the Gloeosporium found growing naturally on th berries of the hawthorn. These ar shown in the first stages of gernination. It is not often that the spores become four-parted in this manner before throwing out a definite mycelia thread.

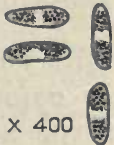

Fig. 119.-Gloeosporium, found growing on the fruit of hawthorn (Crataegus): June, 1902, at Killara, New South Wales.

The berries are often found covered with a blackish growth, and upon removal this is found to be composed of spherical dark-coloured 
elements, $7 \cdot 2-11 \mu$ in diameter, and variously grouped and grown together. The appearance of the fungus is similar to that found in the lemon scab.

In a water culture after twenty-four hours the above mycelium gives rise to colourless septate hyphæ, which in turn produce conidia that bud after the manner of yeast.

What seems beyond doubt the same fungus occurs on the leaves, but the spherical elements are grouped into larger communities. While on the fruit the rule is two to six or eight together, on the leaves the groups are composed of twelve to twenty elements. The aggregations on the leaves are also of a darker colour.

Another difference noted was the occurrence on the leaves of a mycelium of the ordinary form, composed of cells one to one and one-half times as long as wide. This mycelium was of about the same colour as the spherical elements of the Coniothecium. Very little of such mycelium was to be seen on the berries. Whencesoever derived, this mycelium had the property in water cultures of proliferating in the form of colourless threads, septate, and composed of cells one and a half to two times as long as wide. This mycelium, as well as the elements of the Coniothecium form, has the power to produce conidia that bud after the manner of yeast.

The spherical elements in the growth on the leaves are somewhat smaller than indicated by the measurements given above $(7 \cdot 2 \times 11 \mu)$. The differences are shown in the illustrations.

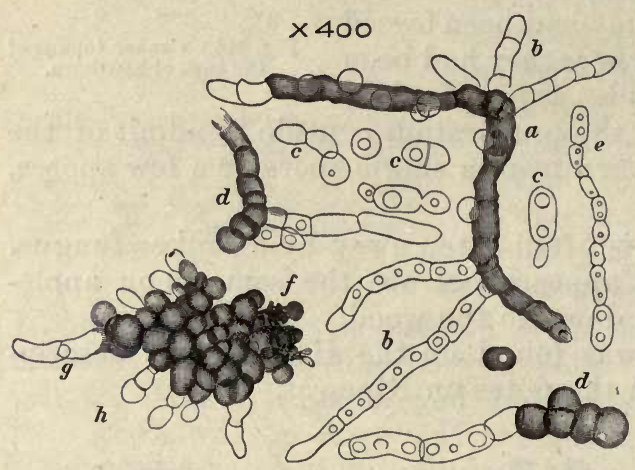

Fig. 120.-Cultivations of the fungus found growing on the leaves of Cratægus, forming there a kind of black incrustation; $a$, dark mycelium made up of some. what elongated cells; $b$, transpareut colourless mycelium, appearing in the water-culture ; $c$, yeast-like cells dewater-culture ; $c$, yeast-like cells de-
tached from $b$, and growing by a budding process; $d$, a piece somewhat similar to $a ; e$, detached mycelium resembling $b$, which is not yet detached; $f$, mycelium composed of sub-spherical nearly black cells, and comprising much of the sooty growth on the Cratægus or Hawthorn leaves.

It will be noticed that the Hawthorn-hedge pests enumerated as having come under notice are either identical with those known to infest the apple, pear, and other pomes, or are very similar to them. This is a sufficient proof that an infested hedge is a source of danger to orchards. Under the circumstances it would seem to be a wise precaution to spray such hedges when spraying the orchard. This will at the same time improve the hedge. If the hedge underwent the winter treatment with lime, sulphur, and salt, that would also be a benefit.

This matter is mentioned here on account of the author's knowledge of the existence of a number of infested hedges near orchards. 


\section{Preparation of Bordeaux Mixture.}

It is unnecessary to say that the proper preparation of the Bordeaux mixture is an important matter. I am convinced that a very large amount of improperly prepared mixture is annually used. I do not think that trees are often injured by such imperfect mixtures, but I am sure that money is wasted in their use, and that some discouragements to growers follow, together with disparaging remarks with reference to spraying in general. I am naturally proud, as one of those mainly responsible for the introduction into this country of modern spraying on a commercial scale, of the rapid progress the method has made; but at the same time I am sorry to know that at this late date there are still orchards minus a spraying outfit, and orchardists that neglect this method of easily adding to their profits. This I attribute in some degree to the use of improperly prepared mixtures. Bordeaux mixture is one of the most important of the mixtures applied in the form of a spray, and a word about this important matter is hardly ever out of place.

The materials should be pure. They are easily procured in a state of purity. In particular the lime should be quite fresh and "quick." It should be quite free from what is called air-slacking, i.e., it should have been so kept in tight receptacles that it has not absorbed and combined with moisture from the air.

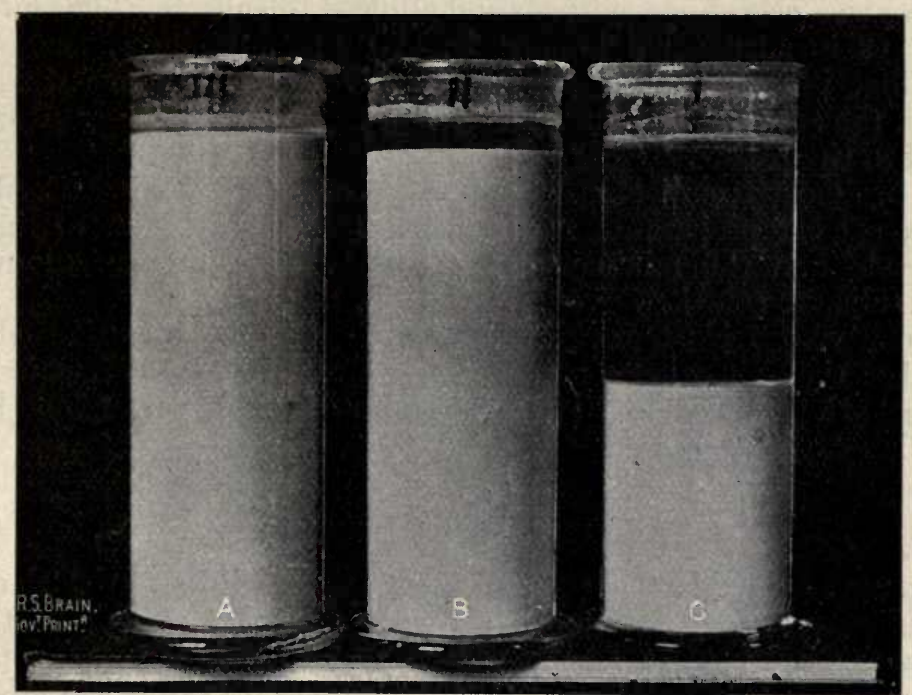

Fig. 121. - Three glass cylinders containing Bordeaux mixture made in different ways and allowed to settle for one hour. It will be seen that mixture $A$, on the left, is the best, having settled least. A, dilute lime and dilute bluestone, poured evenly into a third vessel; B, dilute lime porred into dilute bluestone; c, strong lime poured into strong bluestone.

In making the milk of lime the aim should be, of course, to have it as smooth as possible. To secure this result water should be added 
sparingly until the lime is completely slacked. The lime should not be deluged with water. Hot water may be used, often with advantage, especially at the outset. If too little water is added the lime will become overheated, and this is an objection. Water should be added fast enough to prevent this overheating. The aim should be to produce a very thick and smooth paste, which when it is afterwards diluted with water will be perfectly free from lumps or granulation. A good plan for the novice is to try a small portion of lime at first, and from the lesson thus learned to go on to the larger matter of preparing his mixture. The thick paste should be watered gradually, and not all at once. As most lime contains lumps that will not slack, it is necessary to strain the milk of lime after it is prepared and before it is added to the sulphate of copper solution.

It is far better to mix the two solutions in a dilute form than to mix them in a concentrated form and afterwards dilute them. The milk of lime should be run very gradually into the copper sulphate solution, and the two liquors as they are mixed should be constantly agitated. This results in a superior mixture.

This superiority has been well illustrated in an article by Professor McAlpine of Victoria, and I have secured from the Department of Agriculture, through the courtesy of the Minister, the use of the blocks so forcibly illustrating the non-settling properties of the properly made mixture.

It will be seen on examining the illustrations that the Mixture was prepared in three different ways, and each of the three resulting mixtures was placed in a cylinder and allowed to subside. The mixture that slays in suspension longest is, of course, the best, the reason being that it is in the finest state of division, and hence will work through the spray nozzle most freely and act most efficiently after it is applied to the plants.

The two most technical parts of the process of making Bordeaux mixture are the preparation of a smooth fine-quality milk of lime or whitewash, and the mixing of the same with a proper amount of copper sulphate solution.

Anyone who feels uncertain about the former operation should remember that there are numerous skilful preparers of whitewash and that the chance to witness the operation as performed by an expert is easily secured.

\section{Adulteration of Sulphur.}

It appears probable that sulphur is sometimes adulterated with cheap forms of starch, such as unsalable flour. Samples submitted to me for examination showed among the grains of sulphur much starch. Sulphur mixed with starch it is almost needless to say is less effective as a fungicide than pure sulphur, and when applied dry in combating disease, such as the Oidium of the vine, such adulterated material might lead to poor results.

In one instance grapes showing the after effects of Oidium were submitted to me for examination. I did not ascertain whether the 
starch had been added by the person treating the disease or by a dealer unbeknown to the buyer, but think it best to call attention to the matter for the reason that the adulteration of sulphur with starch could be easily accomplished and not easily detected, except by microscopic examination.

I should not mention this matter if it were not for the fact that the disease in the above-mentioned case appeared to be Oidium, and that a proper treatment had apparently failed to ward off the bad effects of the disease as it should have done.

If any grower is interested by these remarks, and wishes the sulphur he uses to be examined, that could be done if he would forward to the Department of Agriculture a sample of the sulphur in the form in which he proposes to use it.

\section{Fungi grow from Cuttings.}

The spores of fungi are so often mentioned as their organs of propagation that it might seem to a non-expert that they were the only means of propagation. This is far from being the case. Just as in the higher plant species may be propagated by cuttings and by layering and by grafting, so among fungi there are ways of multiplying quite apart from the spores, though these latter are the more usual propagating forms.

An illustration of this feature of fungus life is presented in the illustration, in which we behold a "cutting" from a fungus in the act of throwing out "roots," a method of some importance in the life history of some fungi. Here we have the stalks of a species of Alternaria "germinating" much as if they were spores. If these stalks, which

Fig. 122.-Growth in water culture of mycelium from the old aerial hyphae of the Alternaria of the quince, showing that these, as well as the spores, may spread the disease.

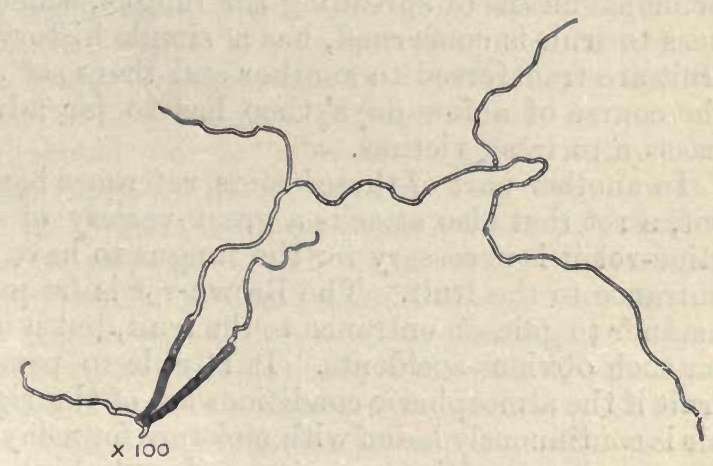

are produced in enormous numbers on the surface of some diseased plants, are torn loose, and transferred to a favourable place, they have the power to grow and continue the life of the pest in a vigorous manner. 


\section{The Brown-rot of Frutt.}

THrs is a rot of fruit caused by the fungus Monilia fructigena-a rot most prevalent under moist conditions and confined to no particular kind of fruit, though it does most damage on cherries, peaches, and plums. It will attack a great variety of ripe and ripening fruit, and will even attack tender foliage under encouraging conditions.

The Brown-rot has come under notice in this State from time to time for a number of years, but it seems that it is only during our moist seasons, or in our moist districts, that it is to be feared. The disease appears with us to be quite as common on the cherry as on any other fruit, and the damage done is sometimes considerable, though I have never known of any such severe losses as have been reported in other countries,-where the destruction has sometimes reached enormous proportions. Cases are on record where the losses from this disease were variously estimated at from $£ 50,000$ to $£ 100,000$ in a single fruitraising district, and very serious losses on a smaller scale have been of frequent occurrence. It appears that this fungus is one to be reckoned with seriously if it should become an established pest in our orchard districts. The portions of the State where it is most likely to do damage are those having an abundant rainfall during the spring and summer, and possessing the orchards necessary for its nourishment,for we have no indigenous fruits upon which it is likely to flourish. Those parts of the State best adapted to cherry growing are the parts referred to.

The appearance of the fungus causing the Brown-rot of fruit should be well known to all observant fruit-growers. The softened fruit becomes covered with a grayish growth of spores, in some respects resembling the familiar green mould of bread, which is also frequently to be seen on fruit. The grayish growth just mentioned is made up largely of the spores of the fungus and it is these spores that are the principal means of spreading the fungus, which, so far as its injuriousness to fruit is concerned, has a simple history. The spores from one fruit are transferred to another and there set up the disease, which in the course of a few days' time has so far advanced as to be able to pass on to fresh victims.

In another part of these letters, reference has been made to the Riperot, a rot that also attacks a great variety of fruits. In the case of Ripe-rot it is necessary for the fungus to have a way prepared for its entrance to the fruit. The Brown-rot is frequently aided in the same manner to gain an entrance to the fruit, but it is not entirely dependent on such obvious accidents. It is able to penetrate apparently sound fruit if the atmospheric conditions are of the right kind,- that is, if the air is continuously laden with moisture for a day or two and the temperature at the same time remains uniformly high, say at 80 to 90 degrees Fahrenheit. Under these conditions, apparently sound fruit may be attacked by this fungus with fearful rapidity; so that fruit in a ripening condition is swept off in a wholesale manner,-rotting on the tree or falling off. It not infrequently happens that the rotten fruit dries up and hangs on the tree, if undisturbed, for a long time. The appearance of the pulp of the fruit when in the grip of the disease is 
rather characteristic. The colour is a uniform brown, changing from a light shade to a darker with the progress of the disease. The diseased flesh has a watery appearance and a disagreeable look, though the taste is not very disagreeable. Advantage is sometimes taken of this latter fact to use up at canneries fruit that is in the first stages of the attack. The practice is not to be commended, as such fruit, though it may not be actually injurious to health, is certainly inferior in quality.

The injury to the foliage is of a more obscure nature, and is often overlooked, or mistaken in character and referred to some other cause. It is usual in this State for the orchardists sending in samples of fruit attacked by Monilia to say that the foliage is not attacked at all. As a matter of fact, I have never seen the characteristic spores of the disease growing on the foliage or branches of fruit trees, and I do not recall at the moment any record of this character in the writings of other observers; but there can be no doubt that the disease enters the bark of tender tissues in the vicinity of diseased fruit, and numerous instances of this are on record. There is nothing remarkable in this, as the same is known to be true of a number of other fungi attacking fruit and foliage of orchard trees. The fact is one of importance in its bearing on possible remedial measures. For this reason it is well, wherever this disease appears in the fruit, to give careful attention to the appearance of the foliage and new growths, both at the time of the attack on the fruit, and at later dates, in order to determine whether they have suffered from disease. If they have done so, the evidence will be found in the blighting of the twigs, the appearances not infrequently resembling "fire blight," or insect girdling.

Remedies. -The principal feature in the fight against this disease is the careful destruction of the diseased fruit; and where there are a number of orchards near each other, the same measures must be adopted in all, if much good is to follow. It is of little avail that one grower destroys his infected fruit, if his near neighbour, attacked in a similar manner, fails to do so. The spores of the disease are so abundant, and are so easily transported by various agencies, that neighbourly co-operation is very essential to good results.

The diseased fruit should not be allowed to accumulate on the ground, nor should the dried-up fruit on the trees be allowed to remain there. Either of these is liable to cause a continuance of the pest-in fact, there is at present, I believe, no other known source of infection, so that the problem is much simplified so far as concerns a knowledge of what ought to be done. The destruction of this infected fruit must be carried on systematically. Spasmodic efforts are not likely to be rewarded with a full measure of success. It should be borne in mind that this disease may exist on many different sorts of fruit, and though it does serious damage in this State to only a limited number of kinds, those other fruits upon which it finds but a bare subsistence may nevertheless be the means of its passing over from season to season.

The absolute destruction of the diseased fruit is what should be aimed at, although it must be admitted that this will sometimes involve considerable expense. Fruit attacked at or near maturity can 
be profitably fed to pigs in some instances, but it should first be boiled. Burying should be deep if it is resorted to at all. Burning is to be recommended.

The application of chemicals to infested fruit has this disadvantage, that the chemicals seldom penetrate far enough to kill all the mycelium, and hence at a later date the uninjured inycelium may revive and again produce spores, even after it has lain dormant all winter.

From what I know of this fungus, I fully agree with all who have attempted to suggest remedial measures in the direction of fungicides applied to the fruit and foliage. There seems little hope that much can be done in this manner if the weather is favourable to the disease. The disease does comparatively little harm with us unless the weather is very warm and moist, and it is in such weather that treatment with fungicides is least successful. Everthing should be done that is economically possible to keep down the number of the spores of the disease, and of course it would be useless to deny that any treatment of the trees that reduced the number of the spores when they were

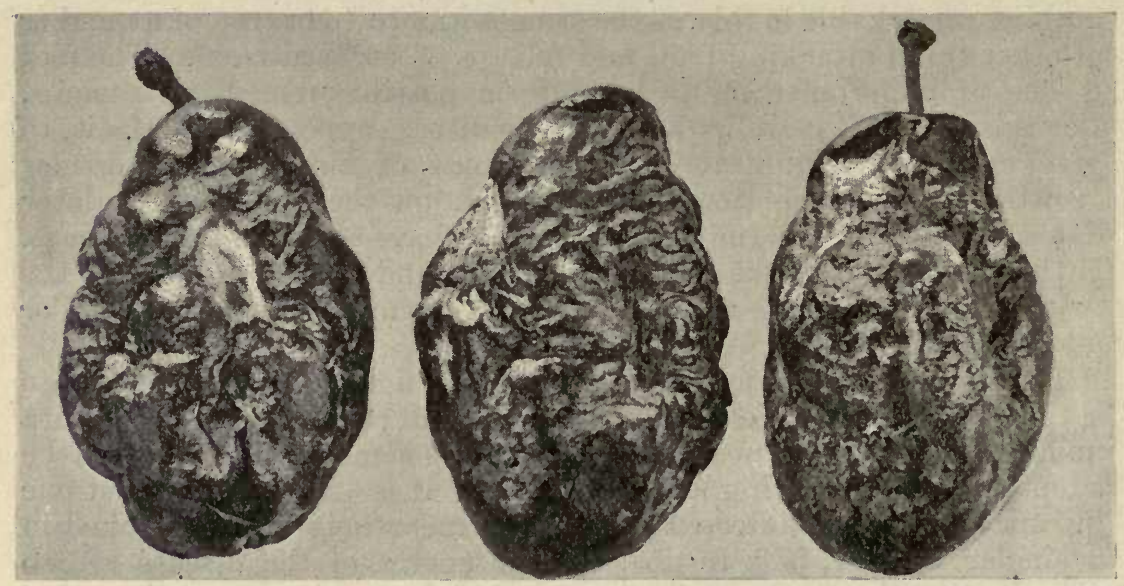

Fig. 122a.-Three plums destroyed by the same fungus as that attacking the cherry-fruit, shown in Fig. 123 on the opposite page.

few would be valuable if at a later date the weather conditions should become more favourable. Among the treatments that may be recommended on this score are various winter treatments, such as that with lime, sulphur, and salt. As this winter treatment has a value for many other purposes, its application to the present disease constitutes for it a further recommendation. The same may be said with considerable force with regard to all the different fungicides. If they are being applied for any other disease they will have some effect also on the Brown-rot. But too much weight must not be attached to these statements with regard to the use of fungicides for this disease, for, as before remarked, the disease is unlikely to do serious damage in this State unless the weather conditions are favourable to it; and it is precisely the weather conditions favourable to it that are most unfarourable to the usefulness of fungicides. It seems absolutely 
impossible to fight the disease with the aid of fungicides alone. The other main reliance must be care in the destruction of all diseased fruit.

I should be sorry if the foregoing remarks left the impression that the disease is found in our orchards only in wet seasons. That is not the case. It is to be found at all times, probably, but in limited quantity, a quantity safely to be neglected if it was the only diseasein existence. If, however, the proper conditions arrive, it has a peculiar faculty of reviving with suddenness and destroying a large quantity of fruit. During and after such a season it is best to be specially careful, as there is greater probability than ever that spores of the disease will be left over to give the pest a fresh start the following: year.

\section{A Cherry Blight New to the State.}

THE cherries are attacked at blossoming time, and the effects become visible at that time or soon after. The young fruit, as soon as the petals have dropped, and while it has still the elongated form characteristic of

Fig.123.-Two different blights of the cherry, one on the fruit and the other on the leaves. That on the fruit, due to a fungus variously classified, is shown at $a$, $b, c, d$. $a$, a fruit attacked at blossoming time and killed at an early stage of growth, the pedicel being also attacked and withered up : $b$, young fruit with its pedicel killed at a slightly later stage than $a$; $c$, fruit half grown attacked on one side and showing an out. break of spores at the lightcoloured areas on the darkened and shrunken flesh $d$, half grown fruit attacked near the stem end and having its stem also attacked. The upper and largest cherry is free from the disease, and shows the stage to which all the fruits should have advanced but for the disease. The spots and holes on the leaves in the case illus trated are due to a second disease, although the fungus here shown on the fruit does cometimes attack the foliometimes attack the folj. age. The microscopic characteristics of the fungus are shown in the next illustration. See also Fig. $122 a$ on opposite page.

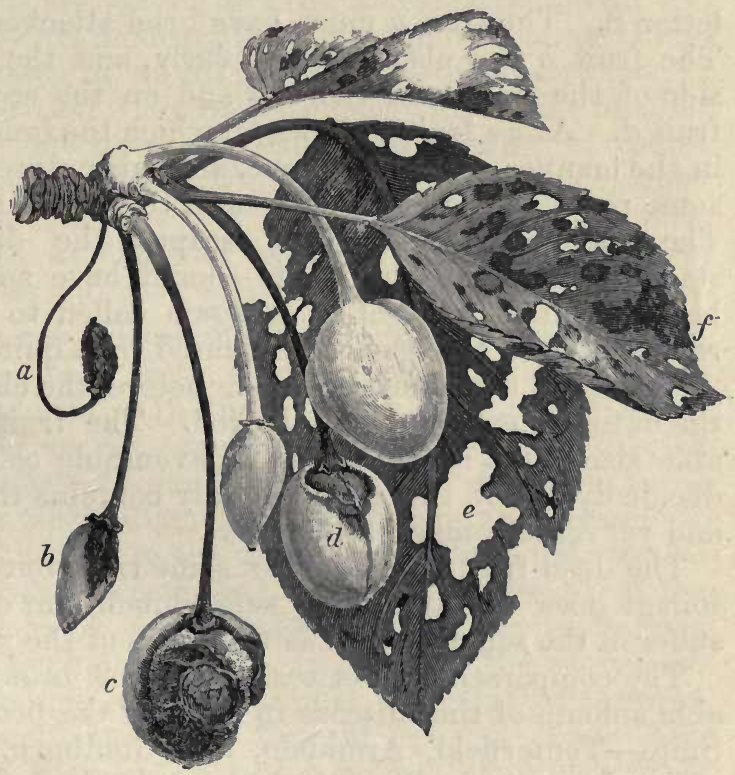

the earliest stages, looses its normal green colour and becomes brown and shrivelled, sometimes almost black. In such cases the stem of the young fruit is also attacked, the indications being a brown colouration, and a shrivelling and drying up in a curled and distorted fashion. The fruits attacked at a little later stage also assume an unnatural. colour, but they do not dry up so readily or so completely. They are more likely to present some portion of the surface where the disease is most intense, this portion being marked by a slightly darker colour at first and by a nearly black colour at last. If the fruit reaches. the ripening stage, the ripening is characterised by unnatural colours. 
Instead of a rich transparent creaminess, we behold a leprous appearance in the early stages, and when at last the reds and purples appear they are not pure and transparent but have a dullness somewhat like that of raw meat.

The actual outbreak of the spores of the fungus causing the trouble occurs on the darker areas just mentioned, and these outbreaks may occasionally be seen on even quite small and immature fruit; and I think it quite possible that they may occur on the stems of such young fruit, though I have not observed this. I have seen on the stems areas that had precisely the same appearances as those on the young fruit except that they bore no spores.

The naked eye characteristics of this disease are very well shown in Fig. 123, which is a life-size illustration of the disease as it appears on growing fruit of the cherry. The fungus shown in the same illustration as producing holes in the leaves is altogether different and has no connection with this disease of the fruit. On the smallest of the cherries shown, the disease has already completely destroyed the fruit, and it has become brown and shrivelled; the pedicel of the fruit has been also attacked and it has shrivelled and curved into the form of a letter S. The fruit $a$ must have been attacked at the blossom stage. The fruit $b$ was also attacked early, and the disease is seen on one side of the fruit near the top and on the stem. Similarly with the fruit $d$. At $c$ a fruit is shown on which the fungus has produced spores in the manner described above, and this outbreak of spores is shown on some parts of the diseased area in the form of a whitish incrustation. The uppermost cherry has escaped the disease, and shows the stage to which all the fruits should have advanced if they had not been blighted. Attention is again called to the fact that the holes represented in the leaves are caused by a quite distinct disease.

Most of the damage is done before the cherries are half ripe, and the entire crop may be destroyed. The fruit that reaches a marketable size has a more or less unfavourable colour, and the flavour is decidedly flat if the fruit actually contains the fungus, as it may do, and yet reach a marketable size.

The dead fruit hangs on for some time, but finally drops off. The foilage does not appear to suffer much, but does to a certain extent suffer in the same manner as the stems of the young fruits.

The comparatively wet season of 1903 brought to light a considerable amount of this disease in some of the best cherry districts of the State-Tenterfield, Armidale, and Goulburn. A number of young orchards were badly attacked, and the losses must have totalled several hundred pounds.

At the time of the outbreak of the spores, which may be at any time after the fruit has set, though it seems to occur most frequently at the time the fruit is quarter grown, and from that time on, the spore-bearing areas become darker than the surrounding tissues and apparently more watery, as is indicated by an increased transparency in spite of the darker colour. The spores are collected on exceedingly short hyphæ, grouped in minute cushion-like clusters, which at first in some cases are snow white, but which later on become light brown. 
The spore-clusters are quite distinct at first, but may run together after a short time, and the entire surface appear to be covered with an incrustation of spores if the air be dry, or with a somewhat gelatinous covering if the air be moist.
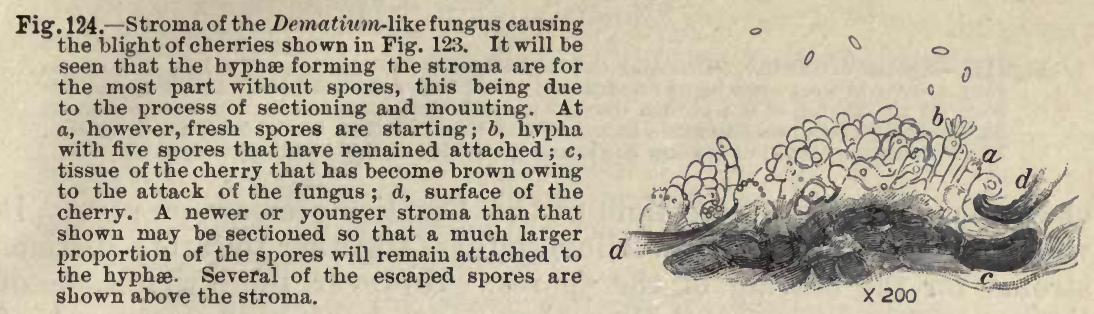

As to the spores themselves, the measurements of ten spores, taken at random, are given in the margin, and it will be seen $7.5 \times 3.7$ that the average is $10.5 \times 3 \cdot 2 \mu$., the range being $2.5-20$ ${ }_{20} 0^{\circ} " 5^{\circ} \times 1.3 \times 1.5 \mu$. This range in the size of the spores is far 10.6,", 4.5 greater than is usual among fungus species. When $11.8,2.8$ these spores are placed in water they have not, with me, $2 \cdot 5,1 \cdot 5$ so far, shown a tendency to sprout and form a mycelium. $10 \cdot 4,, 2.8$ When placed in an infusion of cherries, however, I $8 \cdot 3,3$. have noted that they bud copiously after the manner $6 \cdot 5,, 2 \cdot 7$ of yeast, and from this cause the number of spores Av. $10.5 \times 3.2$ increases, while their size decreases. The spores, when undergoing this process of budding, often show vacuoles, while the original spores, as obtained from the surface of cherries, were often without vacuoles and with very little internal differentiation.

Sections across the areas where the snow-white cushion-snaped spore masses have been pushed forth, show slightly-raised beds from which the spores are produced. In the sections mounted in water these beds are destitute of spores, except of the very smallest size, all the others having been washed away. The hyphæ upon which the spores are borne are of a larger diameter than the spores themselves. On sume occasions it is possible to see these small spores growing on the ends of the hyphæ of the stroma, and it is then apparent that the spores are borne in numbers on each hypha. In sections made from fresh material, while the hyphæ are $9-13 \mu$ in diameter the spores are $1 \cdot 5-5 \mu$ in diameter. The spores are ellipsoidal or elongated in form, being very seldom of exactly the same form at the two ends. The broader hyphæ on which they are borne are several times as long as the spores themselves, and are unbranched and packed close together in the stroma, which is only slightly raised above the surface of the diseased area. All these appearances can be seen only with the aid of medium or high powers of the microscope. The smallest stroma seen was not more than four to five times as wide as the sporebearing hyphæ-that is to say, measured $40 \mu$. The larger spore beds measure $180 \mu$ and upwards. (See Fig. 124.)

'I'he septate mycelium seen in the diseased cherries was colourless, and varied in diameter from 3 to 9 micromillimetres, one of its 
striking characteristics being sudden changes from the minimum diameter to the maximum. None of the clamp joints, such as are

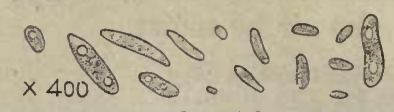

Fig. 125.-Spores of the fungus causing the blight figured in illustration No. 123. The spores vary greatly in size, some being hundreds of times larger than others. As the spores are born on the hyphæ of the stroma they do not differ so much in size, but by a process of budding they often increase much in number, at the same time diminishing much in size. The illustration attempts to show the range of size due to this budding process.

characteristic of the mycelium of the Basidiomycetes were seen. It will be observed that the mycelium gathers together to form a distinct stroma for the bearing of the spores. However, there were some of these spore-beds so small that they must have been composed of comparatively few hyphæ.

I have inoculated green hedge-plums, green nectarines, and ripe cherries, loquats, apples, and bananas, from cultures of the spores, but, so far, with negative results.

\section{"Take-all,"-a Disease of Cereals.}

Some years ago there appeared in the pages of this journal a report on the series of diseases usually treated of under the name of "Takeall." Since that time further observations have been made, and the results of these observations appear worthy of abstraction from the letters on the subject and arrangement in a connected form. The most important result is the discovery of what seems to be a reliable method of treatment.

It is plain that the disease is one connected with a moist condition of the soil. We have heard little of it during the drought, but during the present season, 1903-a moist season-numerous cases have been observed, and the losses have been considerable. The appearances are the same as those formerly reported, and the species of fungi are the same, giving rise, as before remarked, to the opinion that the term "Take-all" is one that must be understood to include a number of different diseases which further study may isolate and prove to be physiologically more or less related.

The disease, or the diseases, may be combated by the application of lime, used at the rate of not less than one ton to the acre.

I have seen cases of "Take-all" that were connected in the most manifest manner with certain slightly depressed areas where storm waters stood for some time in puddles and finally sank into the soil. If the storm occurred at a stage when the cereal growth was still soft and tender and therefore susceptible, the plants went off with typical "Take-all."

Of course, in the last analysis, all the foregoing points to lack of efficient drainage as one of the prime causes of these diseases, and anything that can be done to improve the drainage will be beneficial. Even an extra deep tillage of the right sort will do good, as it often happens that the damage is done in a short time by standing water, the damage being apparently due to the lack of air about the roots of the 
plants, the same being excluded by the water. Such instances would be less common if the soil were rendered more porous by deep culture, the small improvement secured in this way being sufficient to permit the waters of small storms to sink in rapidly enough to allow the plants to escape "drowning." These slight depressions in the paddock may in some cases be gradually filled in by the right method of ploughing, which constantly turns the soil from their margins towards the centre of the depression. I have seen extensive areas subject to "Take-all" that could be dealt with in this manner and cured in the course of a few years, but of course such a combination of circumstances is not common.

Since dealing with the matter in 1893 I have found that the following treatment is almost invariably followed by good results. At a time when the disease is showing, which it always does in patches of greater or less extent, mark the patches with stakes, and after harvest and before the following ploughing apply lime, or wood ashes known to have a large proportion of lime, at the rate of at least one ton to the acre, better more. Of course only the diseased areas need be so treated.

This treatment is based on a general knowledge of the causes of the trouble and the fact that the disease continues from year to year in the same place. It is possible that if one year is very favourable to the disease and it is followed by a year that is very unfavourable to the disease the patch will not persist, but this is exceptional and does not upset the rule. If the season is very favourable to the disease or there is a succession of such seasons, the disease may appear so as to cover large areas. It appears that such was the case in 1903 in some districts.

While on the subject of "Take-all" it may be well to mention that Sorghum has been known to suffer from the attacks of Cladosporium in the same way as wheat and other cereals. The appearances of the cases examined by me are much the same as those formerly described in connection with wheat and oats. I have seen Sorghum dead and dying in patches with no other signs of parasitic growth than the abundant growth of Cladosporium, so that it seems a fair inference that this grass is also subject to "Take-all."

\section{VARIOUS RUSTS.}

More interesting than destructive is the rust of the White Clover. Though not uncommon, it is never, so far as $I$ have observed, so prevalent as to do very much damage. Not infrequently it happens to

Fig. 126.-Aecidium of the rust of the common White Clover (Trifolium repens). Magnified 10 diameters.

Aecidio-spores.-The nearly colourless, closely verrucose, polygonal or rounded æcidio-spores measure 16 to 18 by 20 to $25 \mu$ and are borne in cup-shaped pseudoperidia, having everted whitish dentate edges. The diseased spots are about two millimetres across.

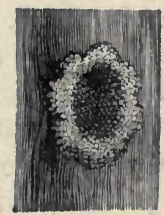

attract the attention of some observant person, who, influenced by its general resemblance to other more destructive rusts, makes inquiry as 
to whether it is not the same as wheat rust or some other dreaded rust. Fortunately this rust is not the same as wheat rust, however much it may to the ordinary observer appear to resemble it. Confined as it is in its attacks to the white clover, it does little harm. In other countries it attacks red clover, but I believe there is no record of such a case in this country.

It is unnecessary to enter upon any discussion of remedies, as the disease is of no serious consequence. It would not receive attention here but for the fact that it is sometimes forwarded by needlessly

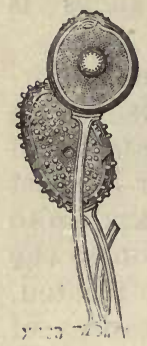

Fig. 127.-Uredo-spore and teleuto-spore of the rust-fungus, Uromyces trifolii (Alb. and Schw.), of the Common White Clover.

Uredo-spores. - The scattered cinnamon brown sori bear roundish or ellipsoidal pale brown echinulate spores, measuring 25-35 × 15-18 $\mu$, each possessed of two opposite equatorial germ pores.

Teleuto-spores.-The sori are darker than those of the uredo-spore stage and bear more nearly spherical smooth dark-brown spores of a diameter varying between 20 and $35 \mu$, and each having a iarge germ pore at the thickened apex, where there is often one or more papillæ.

alarmed correspondents. No uneasiness need be caused by the appearance of rust on white clover.

\section{Oat Rust.}

On one óccasion my inquiries on this subject covered a considerable area devoted to dairying on the Tweed and Richmond Rivers, for the most part consisting of lands similar to that in the vicinity of the town of Alstonville. A score or more of paddocks in a dozen or more localities were examined both as to the amount of rust and the nature of the rust. I found that the paddocks in the vicinity of the settlements were, as a rule, more severely smitten with rust than paddocks elsewhere. Thus I found considerable rust in paddocks in the vicinity of Lismore, Murwillumbah and Alstonville. In general the amount of rust seen was not such as to cause surprise or even concern. As à rule, I found the oat crops comparatively free from this disease. Nodoubt the larger amount to be seen in certain paddocks near the towns was accounted for by the continuous growth of oats in those paddocks or near by. Under such circumstances the disease is bound to accumulate. The continuous growth of any crop for a long series of years on the same land always has this result. Though at first the diseases of the crop may be light their intensity increases year by year. A little thought will show that this is only what must be expected, not only with crops of oats, but with any crop, or any class of stock. Thus the comparative freedom of new clearings from rust is in accordance with this law. It does not of course follow that a new paddock may not be severely smitten with rust. Such a thing may occur, but in the natural course of events this will be less common than a similar visitation on an old paddock that has borne oats for a succession of years. In the course of my inquiries I had my attention 
ralled to the fact that the oats had spots of rust on the leaves as soon as the first two leaves had appeared. There is nothing uncommon in this. In seasons when rust is prevalent it often appears on the crops soon after they show above ground. The fact that this observation can be made in any particular season only shows that the season is one rather favourable to rust and that the disease is present ready to take advantage of the fact. It is very uncommon to see a crop of oats that is entirely free from rust in a climate such as that characteristic of our northern rivers.

Considering the severity of which this disease is capable I do not consider that there is much occasion for alarm, though it is beyond question wise to give close attention to the progress of the disease in various districts.

The amount of loss is what must govern any action taken. It is evident that oats are considered as one of the best of winter feeds in some districts and that anything that threatened this crop would at present be regarded as a serious danger. From what I saw I think we may without fear continue the growth of this crop for that purpose for some time to come, but I fear that the continuous growth of this crop year after year on the same land for a long time will compel us in the long run to abandon its growth, especially if meanwhile nothing is done to minimise the disease. In the course of this report I intend to suggest some lines of action that will enable dairymen, if they so desire, to continue the growth of this crop for winter feed. At the same time I would advise that attention should be given to some other :sources of winter feed suitable for dairy cattle.

At a meeting held for the discussion of this question I had the honour to call attention in a pointed manner to the exact nature of the rust disease. I showed with the aid of the microscope that rust is a microscopic plant that propagates in a manner similar to that followed by oats, with this important difference that the "seeds," or :spores, of the rust are so minute that they can be easily carried on the wind for long distances. The number of the spores, as I showed,

Fig. 128.-Teleutospores of the common Australian rust of the oat. These occur in linear, black, more or less confluent sori, that remain for a long time completely covered by the cuticle. As the figure shows, the brown cylindroid to conoid spores are borne on very short pedicels, measure $40-60 \times 12-20 \mu$, and are characterised by bearing at the truncate distal end 6-7 blunt irregularly fingershaped processes.

The orange-yellow spheroidal to ellipsoidal faintly echinulate, uredespores are borne in very pulverulent, elongated, often confluent sori. Size, $15-20 \times 20-28 \mu$.

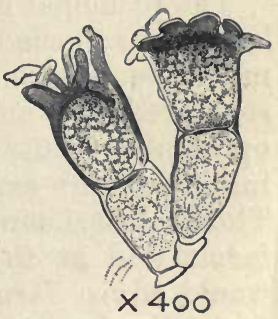

is so great as to be almost beyond calculation. The number of spores . on a single leaf of rusty oats might reach millions. It is no wonder then that the disease is widespread, especially when we remember that it runs its course in a few days' time. Already the rust is so common in some - districts that the spores are to be found almost universally distributed. I found them on the fences, high up in trees, and in the dust of the Jhotel rooms in all parts where the rust was particularly prevalent. 
There is however nothing unusual in this. It is a common feature of this rust disease, and only shows how likely an outbreak of the disease is; once the conditions are favourable to it.

The rust found upon oat crops is one that is well known so far as I am able to say at present, in fact it would be remarkable if this were not so. I hope to examine specimens later in the season that will set at rest all doubts upon this head. From an examination of the uredospores the species appears to be Puccinia coronata.*

The conditions that favour the spread of the rust disease are warmth and moisture. As these factors vary from season to season it is easy to understand why the disease varies in intensity in different years. It is sometimes said that rust has "suddenly appeared" in a district. Such a statement is rarely true, the fact being that it has been all the time present. What is meant is that it has suddenly increased in intensity. This is due to favourable weather conditions. It is very necessary to bear this in mind in reasoning about the disease, otherwise there is danger of arriving at wrong conclusions.

The species of rust that attack the various cereal crops thought similar to one another are not always the same. The tendency of recent research is toward the belief that each species of rust is very particular about its host plant, and that although two rusts may resemble each other very closely they are often found each to be associated with a single crop or a very limited number of related crops. From this it follows that we should be careful about confounding rusts found on various crops. The rust of wheat is a different rust for instance from that most common on oats. Yet if a crop of wheat were found growing alongside oats and both were found to be rusty it would be natural to think that both crops were suffering from the same disease, if we did not allow for the abovementioned fact. Nevertheless the chances are that the two crops would be suffering from different diseases derived from quite different sources, having no connection with each other. These facts are mentioned to put farmers on their guard in reasoning about the occurrence and prevalence of rust.

The principal interest centres in what can be done to minimise the losses due to the disease. What one will do depends entirely on how much he is losing and how much he fears he will lose. As before remarked, the amount of oat rust at present is not such as in my opinion to cause great alarm. But it is enough to justify making inquiries and experiments as to how the losses can be minimised. Those experiments could be most profitably carried out on private farms and at the Experiment Farms located in various districts. I would advise farmers to beware of experiments and opinions derived from districts other than their own, unless it is quite certain that such districts are similar in all respects to their own district.

The experiments that in my opinion would be advisable relate to trials of various varieties of oats, to the use of other sorts of winter feed, and to the trial of ensilage. 


\section{Varieties of Oats.}

It is a well-established fact that the various varieties of oats vary in their resistance to rust. The rank-growing varieties as a rule suffer most. Of course it may be that the varieties that are the most resistant are not the best for fodder. But analogy would lead to the conclusion that resistant sorts can be found that will be entirely suitable fodder for milking cows. As I said before, only experiments in various districts can determine what varieties are the best, and if such experiments have not been already made, it would be advisable, in my opinion, that they should be made without delay if this crop is to continue to be a main dependence for winter feed as at present. Such trials, however, will be useless unless, when completed, farmers can make sure of securing seed of the best varieties. It would therefore be best to so conduct any trials that the source of the seed is quite well-known and is such that the seed can be reliably supplied from year to year. This, of course, involves arrangements with some reliable seedsmen and growers. It ought to be possible to make such arrangements.

\section{Other Fodder Crops.}

There appears at present to be very little else than oats grown on the Northern Rivers for winter feed, doubtless because that crop has shown itself well adapted to local conditions. There is good reason, however, to doubt whether it will always continue to be as suitable as it is at present; in fact the present inquiry is a hint in that direction. The reason for this doubt has been already indicated, namely, the tendency when a single crop is grown continuously on the same land, for the diseases of that crop to accumulate until the crop is no longer profitable. It would be advisable, in my opinion, that steps should be taken to provide against the possible arrival of a time when oats will not do so well as they have in the past. The eggs are now all in one basket. A severe rusty season would do great injury under the present system.

Apart from this, it is well-known that the too exclusive use of one fodder may lead to poor results. A variety of fodder is the natural ration of most ruminants, and appears to be essential to high and continuous milk production. It is hardly necessary for me to specify what crops may be experimented upon. Sorghums, wheat and other cereals, millets, rape (though the latter may not be suitable for milking cows), and many other things could be tried with some hope of success.

Ensilage appears to have been but little tried in the Northern River districts. I heard of three small lots, though I did not see a single stack or pit. I was assured, on good authority, that good ensilage had been prepared; and if there is no natural climatic reason why ensilage cannot be prepared and kept, it seems as if it should receive a fair trial, although it cannot be expected to be so profitable as in more severe climates where the growth of winter feeds is impossible. 
Treatment of Seed Oats for Rust.

There is no reason to think that any treatment of seed oats will be beneficial in preventing rust. This question has arisen more than once. The question has been very carefully studied, and the best authorities agree that no treatment of the seed has ever been shown to be beneficial in preventing rust, though it is different with smutanother disease of oats.

\section{Rusty Oats as Fodder.}

Rusty oat plants, so long as they are still alive and fairly green,. may be used as fodder with comparative impunity. The nutritive value of rusty oats is less than that of non-rusty oats, and that is about all that can be said. After the tissues are killed, as the result of rust, the fermenting dead and dying parts are unsuitable for fodder, and will not be chosen by stock if succulent food is at hand. Any doubt on this point may be inexpensively settled through a co-operative experiment by feeding a healthy animal upon rusty oats.

\section{Sunflower Rust. \\ Puccinia Helianthi, Schw.}

The Sunflower also suffers from the attacks of a rust. The diseaseis rather common in this State and the attacks are sornetimes of a serious character, the yield of seed being much diminished. As, however, the crop is one of minor importance it has never been possible among the numerous calls of a more important character to. give any detailed attention to this disease. The present paragraph is merely the outcome of the slight accumulation of data I find on hand as the result of semi-occasional specimens and inquiries.

The appearance of the disease, as manifested on the Sunflower is unmistakable, and needs little description. In all well-marked cases. the leaves become covered with a rust-coloured powder composed entirely of the spores of the rust fungus. There.

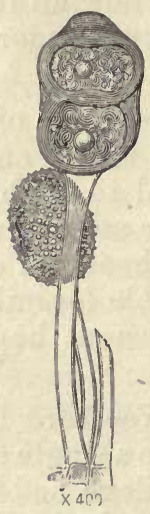

Fig. 129.-Spores of the rust of the Sunflower.

application of Bordeaux mixture, (2) the plucking of all infected leaves as soon as they appear to be a source of danger to the healthy parts of the plants, (3) thinning out the 
plantation so as to admit plenty of sunlight, (4) good culture and the application of suitable manure as a top-dressing. The manure should not be of a highly nitrogenous nature.

With regard to the application of Bordeaux mixture it may be said that it will certainly prevent the germination of all the spores with which it comes in contact, but it will be necessary to make the applications frequent if the result is to be beneficial, for the spores are produced in abundance and with rapidity, so that two days after an application there may be another crop of spores ready to produce further infection. The weaker form Bordeaux mixture will not injure the Sunflower plants, and if the mixture be properly made an almost unlimited quantity of it may be applied. The suggestion is to apply the mixture every two to three days, the best time of day being evening or early morning. * * * *

From time to time for a number of years inquiries have reached the writer, showing that more complete information on the various genera of Rust-fungi would be acceptable to a considerable number of readers of this Gazette. There is no Australian work dealing comprehensively with this subject. The insertion in these letters of copies of a number of classical illustrations from the works of Tulasne, de Bary and Plowright may do some little service in this direction. The originals are for the most part in comparatively inaccessible scientific publications. All the most important genera of the Uredinex, or Rustfungi, are illustrated and explained, the explanation of each plate being placed opposite. (See final plates.)

\section{Smut of the Prairie Grass.}

The season of 1903, following on a succession of droughty years, and being itself rather a moist season, gave rise to some unusual fungus developments. One of these was the appearance of smut on Prairie Grass. The species of smut found on this grass is already known in this State, though not previously seen on this species of grass. It is a species of smut reported from various parts of the world on grasses of the genus Bromus. It is not generally supposed to do much harm. It has appeared in one instance in this State as a marked attack on Prairie Grass self-sown on a paddock formerly remarkable for its crops of smutty maize, and the question arose whether the two had any connection. As the two smut:3, that of maize and that of the Brome grasses, are different species, the occurrence in the same paddock in successive years, can be looked upon only in the light of a coincidence. It may well be that the particular paddock is one in which the conditions are very suitable for the growth of smut fungi. It may be safely assumed that the conditions, other than the host-plant condition, required by two smuts so like each other as the smuts of maize and Brome grass, would be similar, and no doubt if maize had been grown in 1903 in this paddock the smut proper to it would have made its appearance. 
When the Brome grass is attacked by this smut the inflorescence is completely filled with a sooty collection of spores. Such diseased

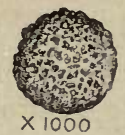

Fig. 131.-Spore of the smut of Prairie Grass more highly magnified than in the preceding illustration, showing the irregularities on the surface of the spore.

plants are unsuitable for fodder, though I do not know that they are actually poisonous, as they have sometimes been reported to be.

\section{Disease in the Fruit of the Banana.}

Two green half-grown bananas sent in by Mr. Martin, fruit inspector, from cargo received at Sydney, gave rise to the following notes:-

The fruits, two in number, appeared hollow and discoloured in cross-section. The pulp had partly disappeared, a "pipe" having appeared throughout the length of the fruit. The pulp around the pipe had taken on a brown or purplish brown or even a purple colour, the interior of the fruit having thus acquired quite a lurid appearance. The cross-section of the rind presented an unusually yellow and viscid appearance, reminding one somewhat of the appearance of recently cut gummy cane. In case of one of the two specimens sent, a hole, as of an insect, was discovered at the distal end of the fruit, but no insect was to be seen, nor were there any definite traces of an insect having occupied the cavity of the fruit.

Microscopic AppeARANCES.-There was no trace of a fungus-no mycelium or spores. There were microbes in some parts, and the appearances gave rise to a suspicion that possibly there might be a definite disease present, due to this cause. The stems of both specimens were black, dry, dead and corroded. It is not impossible that the appearances were due to injuries to these parts of the fruit, but there was no evidence of a wrench or twist of any sort.

\section{Tomato Rosette.}

The following notes by a correspondent are of interest in connection with Tomato Rosette which has now apparently disappeared :- "In the April number of the Gazette appear particulars of a tomato disease' Rosette.' I have about thirty vines growing here on virgin soil. Tomatoes have not been grown within miles of these vines, this being the heart of what was a sheep station. The seed was obtained from three sources, viz., Yates, Anderson's, and from fruit bought at a local fruit store, yet this disease has shown itself. At first only two vines were affected, but as the dry weather became more severe more vines fell victims to the disease, until more than half the vines are badly affected. Where a few vines were constantly watered no signs of the disease occurred. This led me to the conclusion that the disease is altogether due to the drought, as we did not receive in all an inch of rain from the end of November, to the end of March, and it was only by constant cultivation that the vines were kept alive." 


\section{Bark and Wood Diseases Spread by the Pruning Shears.}

I am inclined to think that the method of pruning may have had much to do with the diseased condition of orcasional specimens submitted to me. It not unfrequently happens that diseases of the bark and wood are unwittingly spread through pruning with infected shears or other tools. To give an illustration, suppose that at the first cut the shears pass through a pustule of some disease, such as is to be occasionally found on almost any tree, in connection with the dead or weakened branches that need cutting away. The shears thus become smeared with the spores of the disease, and at the next cut these spores are transferred to another part of the tree, where they may have a good chance to establish themselves so as to do much harm. The operation just described constitutes an almost ideal method of spreading the disease by inoculation, and there can be little doubt that in the case of certain diseases, especially of the bark, this is one of the most common methods by which the disease is spread. The obvious remedy is to disinfect the shear cuts, and this can be done by the application of any one of several substances, such as good white lead paint, whitewash, thick Bordeaux mixture, or even hot grafting wax.

Of course, after the disease has got a good hold at an old pruning mark it is not easy to eradicate it. The best way to proceed is to scrub or scrape down the trunk and larger branches so as to remove all the old bark possible. These scrapings should be burned. Afterwards apply the lime, sulphur and salt mixture, or thick Bordeaux mixture to the trunk and branches, preferably in the winter. If it appears on the preliminary examination that the old marks of pruning present rotten and soft wood, and there are no signs of the wound healing over properly, it would be well to give these special attention by cutting away until the wood looks fresh and healthy. If these new cuts are treated with paint as mentioned above nothing further can be done for them. In the case of roses and some other plants, if the tree has become much weakened, it would be well to keep it well pruned so as to encourage it to throw new shoots from below. These, if the roots are still good, will in time in certain instances replace the old trunk.

\section{Technical Notes on Citrus Diseases. Notes on the Gray Scab of the Orange.}

These notes have reference to the scab on the fruit of the orange that afterwards becomes cracked, and which ultimately scales off, and leaves a smooth depressed scar, often of an elongated shape. A few weeks after its formation the scab contains minute black perithecia, carrying oval unicellular spores.

As soon as the scab is well formed, it will be found possible to remove it in a cleanly manner by working patiently with a small scraper. The scab comes away rather easily, except at certain points which are concentric with a darker colour, as if the new skin were attempting to form new oil glands. Even these parts can be removed by patient scraping, leaving the new skin quite whole and with a good natural-looking surface. 
Microscopic examination of this new surface does not show any stomata, and there are no oil glands. The mycelium of the fungus

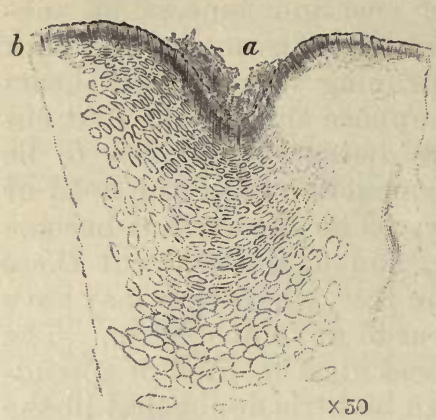

Fig. 132.-Depressed portion of the gray scab of the fruit of the orange. Section through the attachment of the scab and a portion of the rind of the orange :- $a$, the attachment point of the fungus; $b$, the surface of the fruit. ostiole $15 \mu$. On the leaves of trees bearing scabby fruit of this sort are sometimes to be found smallish spots which eventually become gray and papery, and this papery part at last falls out, leaving a "shot hole." The perithecia to be found in these papery tissues are of the same size, form and structure, as those in the gray scab. The spores derived from the perithecia on the leaves measure $7 \times 2 \cdot 6 \mu$.

\section{Cladosporium of the Orange.}

Specimens of fruit and foliage of the orange have been received, somewhat attacked by a fungus belonging to the genus Cladosporium. I could not be certain whether this fungus disease was causing much damage. My doubt was increased in this case by the presence of a considerable number of scale insects on the specimens examined.

I am not aware that this particular species of Cladosporium found on the citrus trees has ever been specially treated with fungicides, and it is therefore impossible to say with absolute certainty what the results of treatment will be. There is, however, no reason to doubt that the application of Bordeaux mixture as for Melanose (?) will be entirely successful. The Cladosporium of the citrus tribe is so much like that of the peach and other stone fruits, as to make me believe that what will answer for one will answer for the other. It is known that Bordeaux mixture is efficient for the Peach Freckle, Cladosporium carpophilum.

\section{Diseases EITHER CAUSED BY OR ASSOCIATED WITH BACTERIA.}

IT is now coming to be an accepted fact that bacteria are responsible for a number of diseases of plants. A dozen years ago there was hardly a single authenticated and well-known instance of such a disease, and even to-day the dispute continues in some quarters as to the trustworthiness of the evidence on this matter. Most of the instances mentioned below belong to the more authentic class of bacterial diseases of crops, though some are still in need of further investigation. Those who doubt the possibility of microbes being the cause of 
disease in plants have as one of their final defences the assertion that. microbes are not the primary causes in the cases held up as examples. among plants of diseases of that nature. "A way has to be prepared for these microbes," it is said. Without at all admitting the truth of this assertion, one may ask to what extent can it be proved that the bacteria admitted to be the cause of various diseases of animals do not have to "have a way prepared for them"? Who. knows the road by which bacteria enter the animal system sufficiently well to assert that no way is prepared? Possibly some of the remarkable. instances of immunity are simply cases where no way has been prepared. Who can say? Is the freedom of adults from diseases peculiar to. infancy because a way is no longer open? It seems to me that the proof of the ability, or otherwise, of a microbe to force its way unaided into the tissues is too remote a possibility at present to makeit the universal main test of causation.

\section{Gumming of the Sugar Cane.}

This disease, though it continues to exist in the State, no longer causes uneasiness. During the last two years, not a single case of this disease has been referred to the Department of Agriculture. This appears to indicate that this disease, once so prevalent in certain parts of our cane districts, no longer attracts much attention.

\section{A Mulberry Disease.}

Occasionally the foliage of the mulberry is attacked by a peculiar disease. One of the symptoms is the appearance of microbic-nodules. on the leaves. The mulberry is such a minor crop in this State that no attempt has been made to investigate the relation of this microbeto the disease.

\section{Gummosis of the Tomato.}

The Solanaceous plants suffer from an infestation of microbes, and occasionally samples of this disease are met with in this State; most frequently, I think, in tomatoes. The symptoms of the disease are of such a nature that growers would do well to trust to expert examination before resorting to combative measures. The attacked plants should be destroyed, and no attempt should be made to grow tomatoes, potatoes, or other solanaceous plants in the same ground for some time to come. In small, highly-valued gardens trenching, together with an attempt at disinfection, may be advisable in some instances.

The following are notes of a peculiar disease in tomatoes in which microbes were suspected to be the cause of the trouble. It was impossible to follow the matter further, for lack of suitable material. Some accurate coloured drawings of the diseased fruits were secured. and it is hoped that further progress may be made if further instances. of the disease appear. On examination, the only micro-organism seen was in the form of bacteria in some of the stems. It remained undeterminable whether these had originated during transit, but it seemed probable that they had not so originated. In form, the bacteria closely resembled B. termo. The blossoms and fruit were the parts that seemed more particularly diseased. The blossoms seemed to be off colour, and the stamens appeared as if mouldy, but without yielding any satisfactory 
data. The hard, green fruit had a pronounced mottling of ivory white. In some cases the half-grown fruit appeared more white than green, and the white tended to occupy the blossom end, while the green tended to occupy the stem end of the fruit. As the fruit ripened the white parts became yellow while the green parts became red, and as the yellow parts appeared somewhat watery the outward appearance of the "ripened" fruit reminded one somewhat of a water-cored apple. The taste of the ripened fruit was insipid, or somewhat offensive and slimy. No microbes were seen in the fruit. The plant was said to have been grown in a dry season, and to have been sufficiently watered. The fruit was smooth and bright, with no other appearances of external disease. The only conclusion reached was that the disease might be of bacterial origin. The season was very dry.

\section{Black Spot or Fusicladium of the Apple and Pear.}

The fact that a number of diseases of the apple and pear cause darkcoloured spots renders the name Black Spot unfortunate for any one of them, but in spite of the mistakes resulting from this nomenclature, some of them costly, it seems useless to protest against it. Any grower who feels himself at all uncertain about the appearance of this disease may save himself trouble and needless expense if he will submit specimens to an expert before expending much money on combative measures. Some varieties of apple and pear are so very much more susceptible than others to Fusicladium that treatment with fungicides is not likely to be profitable in a season favourable to the disease, like that of 1903 , unless the treatment is very thorough. The fungicides must be well made and well applied. Both these features of the case have been previously mentioned in these letters, but the importance of the subject justifies repeated reference to it. The double method of spraying described on a previous page (p. 650, July, 1903) might be developed into a triple or even multiple method with advantage in extreme cases.

For reasons that are quite beyond our present knowledge, crop diseases vary much in their intensity from season to season, and it is quite probable in some orchards where treatment for these diseases is the rule rather than the exception, that in some instances treatments are made that are not a paying investment if considered apart from the general average of loss. If having insured my property I am blessed with freedom from loss by fire, and then complain that my insurance money has been wasted, I take up an unsound business position. Knowing this, I am not disturbed by my careless neighbour, who carries no insurance, even if he should twit me on my vanished premium while flaunting his own cash in hand "saved" by ignoring the precaution of insuring. In a somewhat analogous manner an orchardist need give himself no serious concern if, in some seasons, he sees his neighbour, who does not spray, harvest just as good crop as his own. Of course, if we could know beforehand the exact nature of the coming season, we might sometimes with advantage dispense with some of our treatments, just as if we could know beforehand that no fire would occur on our property we could dispense with insurance. The difficulty is that we cannot know these things beforehand. 


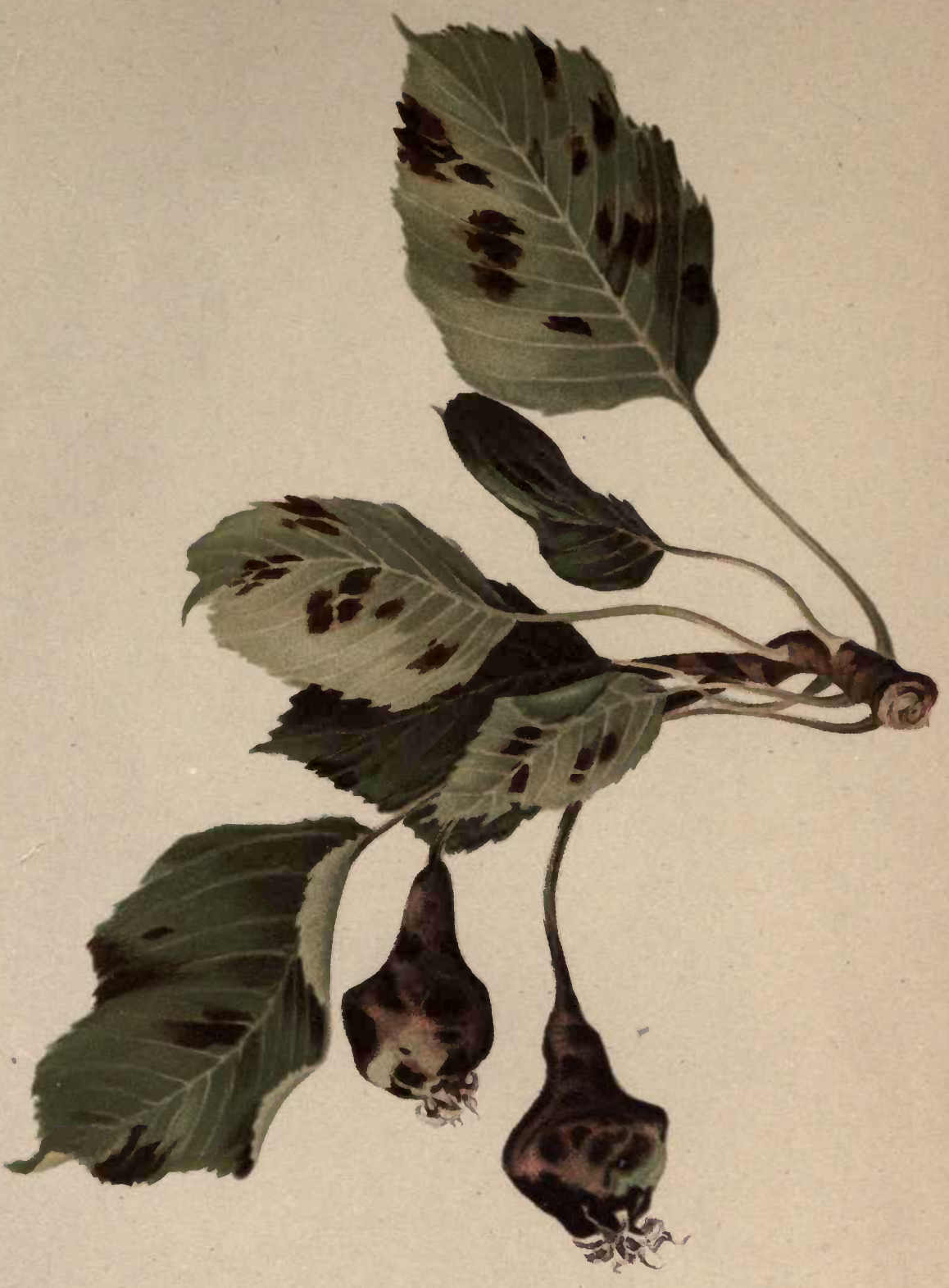

FUSICLADIUM OR BLACK-SPOT ON THE

FRUIT AND FOLIAGE OF PEAR. 




\section{EXPLANATION OF PLATE.}

1. Spermatia of Aecidium ranunculi repentis, after 48 hours in sugar and water ; $x 865$.

2. Same as taken from the spermogonium; $x 865$.

3. Two capitate hyaline paraphyses of the uredo-spores of Puccinia anthoxanthi: $x 170$.

4. A basipetal series of aecidiospores of Chrysomyxa rhododendri, showing alternate abortive cells. After De Bary; x 510.

5. Spermatia of Aecidium ranunculi repentis, after 12 hours in sugar and water; $x 865$.

6. Spermatia of Aecidium bellidis; $x \mathbf{8 6 5}$.

7. Teleutospore of Tribhragmium ulmariae, germinating; $x 410$.

8. Spermatia of Aecidium bellidis on 6th day in honey and water; $x 865$.

9. Abnormal germination of one of the uredospores of Puccinia graminis; $x 410$.

10. Teleutospore of Uromyces fabce, germinating; $x 170$.

11. Spermatia of Aecidium bellidis, after 12 hours in honey and water, germinating; $x 865$.

12. Spermatia of Aecidium punctatum, budding; $x 865$.

13. Spermatia of Aecidium bellidis, after 12 hours in honey and water, germinating; $x 865$.

14. Promycelial spores of Puccinia phalaridis piercing by their germ tubes the cuticle of Arum maculatum; $x 410$.

15. Three teleutospores of Coleosporium senecionis, the upper cells of which have germinated and produced each one promycelial spore; $x 260$.

16. Spermatia of Puccinia adoxce; $x 865$.

17. Aecidispore of Puccinia poarum, after 12 hours germination, showing circumnutation of germ-tube; $x 410$.

18. See No. 5.

19. Spermatia of Aecidium berberidis ; $x \mathbf{8 6 5}$.

20. Aecidiospore of Gymnosporangium clavariceforme, with 6 germ pores; endochrome migrated to end of germ-tube; $x 410$.

21. Aecidiospores of Puccinia poarum; germ-tubes entering the stomata of Poa trivialis; $x 410$.

22. Teleutospore of Puccinia coronata, germinating; $x 180$.

23. Germ-tubes of the uredospore of Puccinia graminis enterino stomata of wheat $; 410$. 


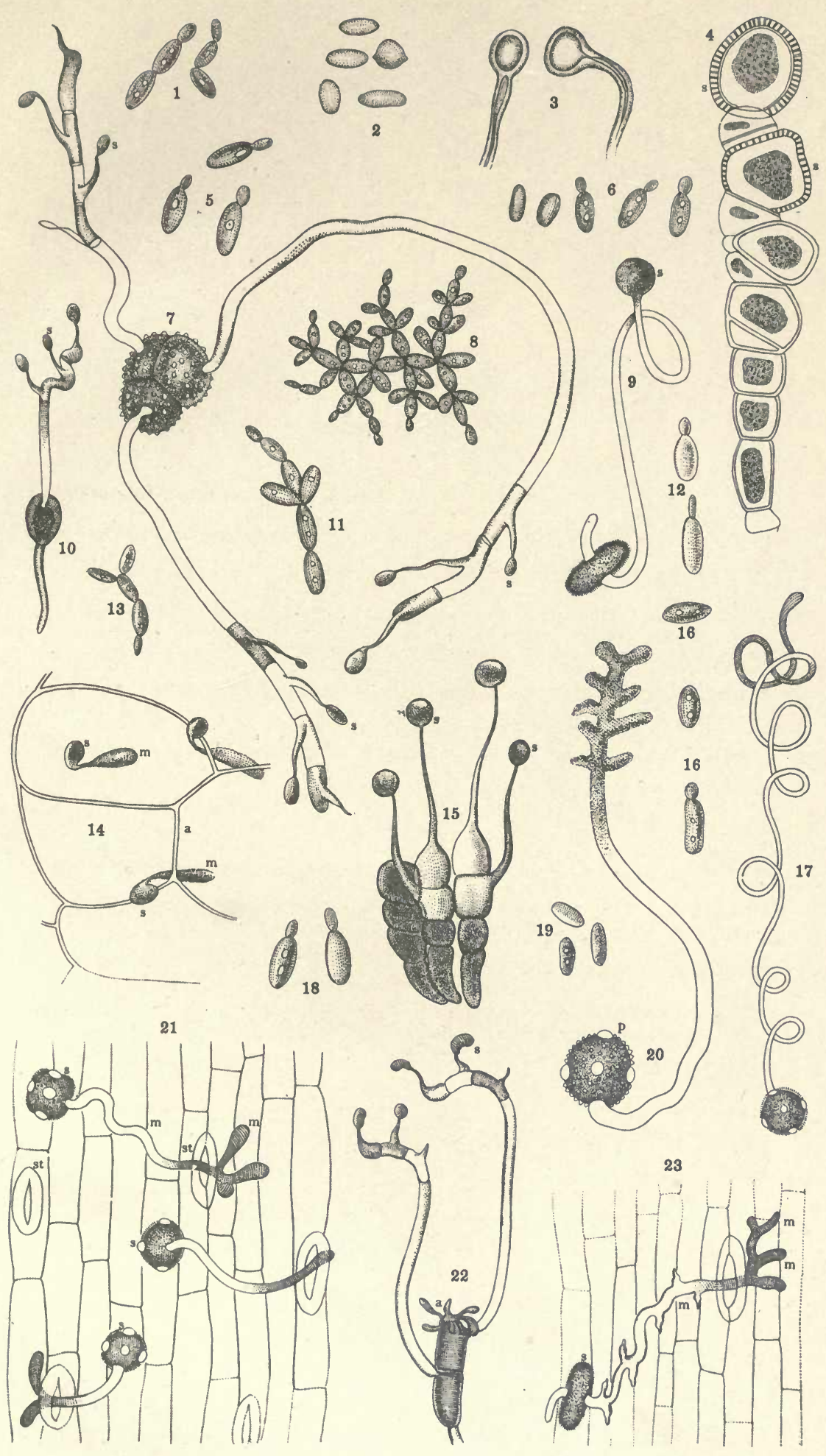

UREDINEA; ILLUSTRATIONS COPIED FROM TULASNE, DE BARY, AND PLOWRIGHT. 


\section{EXPLANATION OF PLATE.}

\section{(Altered from Tulasne.)}

1. Spores of Phragmidium incrassatum, Link, from the leaf of cultivated Rosa centifolia.

2. Spore of the same treated with sulphuric acid, and showing minute verrucosities; $x 460$.

3. Spore of Phragmidium obtusum, Schm. and Kze. ; $x 370$.

4 and 5. Spores of the same fungus germinating and producing promycelial spores.

6. Spore of Uredo suaveolens, Pers., showing 3 germ-pores ; $x 460$.

7. Promycelial spore of Phragmidium bulbosum, Schmidt and Kze., which has germinated and produced a secondary spore.

8. Spores of Phragmidium bulbosum, two cells of the larger of which have germinated.

9. Germinating spore of Uredo suaveolens, Pers. ; $x 460$.

10. Uredo suaveolens, Pers., in Cirsium arvense; $x 430$.

11. Teleutospore of Puccinia compositarum, Schl., from leaves of Cirsium arvense ; $x 460$.

12. Teleutospores of Uromyces appendiculatus (Fabœ), Lk., which have germinated and produced promycelial spores ; $x 430$.

13. Podisoma juniperi communis, Fr.

14. Longitudinal section through one of the growths shown in 13 ; the right side of the figure shows the surface of the fungus and the manner of producing promycelial spores.

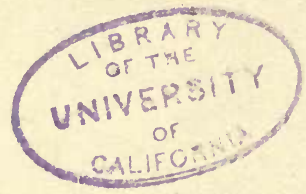




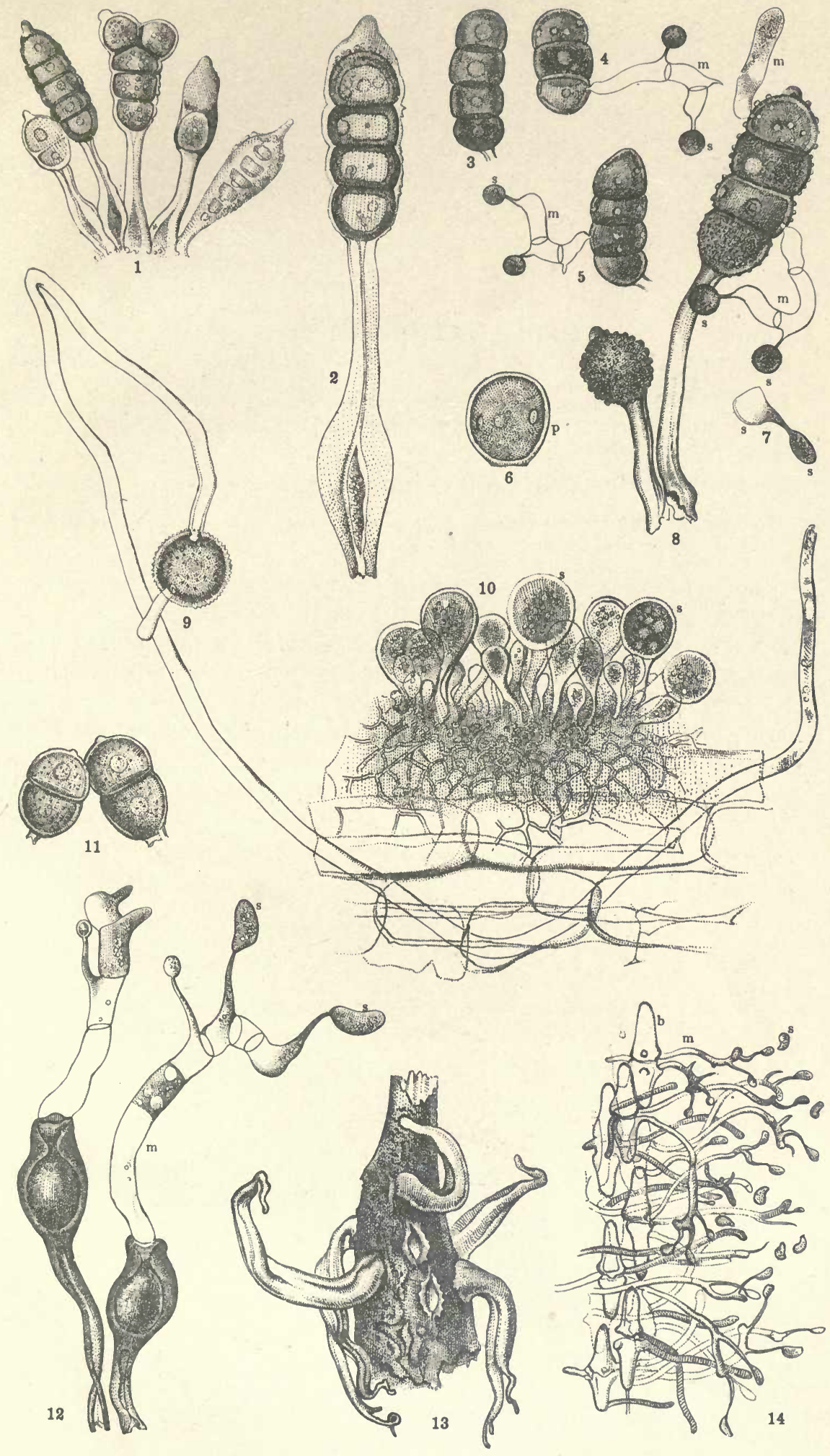

UREDINEA; ILLUSTRATIONS COPIED FROM TULASNE. 


\section{EXPLANATION OF PLATE.}

1. Part of a section through a sorus of Coleosporium sonchi, Lév., from Sonchus oleraceus, $L$. $-b$, multicellular spores; $f$, promycelial hyphe issuing from the germinating spores; s, promycelial spores.

2 and 3. Promycelial spores of Coleosporium tussilaginis, Pers., germinating.

4. Germinating promvcelial spore of Coleosporium sonchi, Lév., which has produced a secondary promycelial spore; $x 460$.

5. Section through a sorus of Melampsora salicina, Lév. - u, uredospores; p, m, teleutospores; $x 240$.

6. Four spores from a sorus of Coleosporium tussilaginis, Lev. One of the two that have germinated has produced promycelial spores at the ends of the promycelial hybhce; $x 320$.

7. Promycelial spore that has germinated and produced a secondary promycelial spore; $x 340$.

8. Uredospores and paraphyses of Melampsora betulina, Desm., from Betula alba, L.; $x 330$.

9. Uredospore of Melampsora salicina, Lév., germinating.

10. The same as 9.

11. Uredospore of Melampsora populina, Lév., germinating.

12. Promycelial spore of Coleosporium tussilaginis, Lév., germinating; $x 330$.

13. Part of a section through a sorus of Melampsora betulina, Desm., from Betula alba. $r$, hyphe; $b$, teleutosbores; $s$, promycelial spores; $e$, stomatum; $p$, parenchyma.

14. Promycelial spores of the same fungus beginning to germinate; $x 460$.

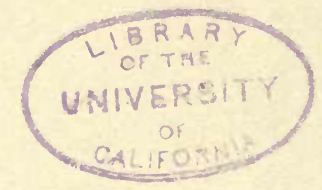




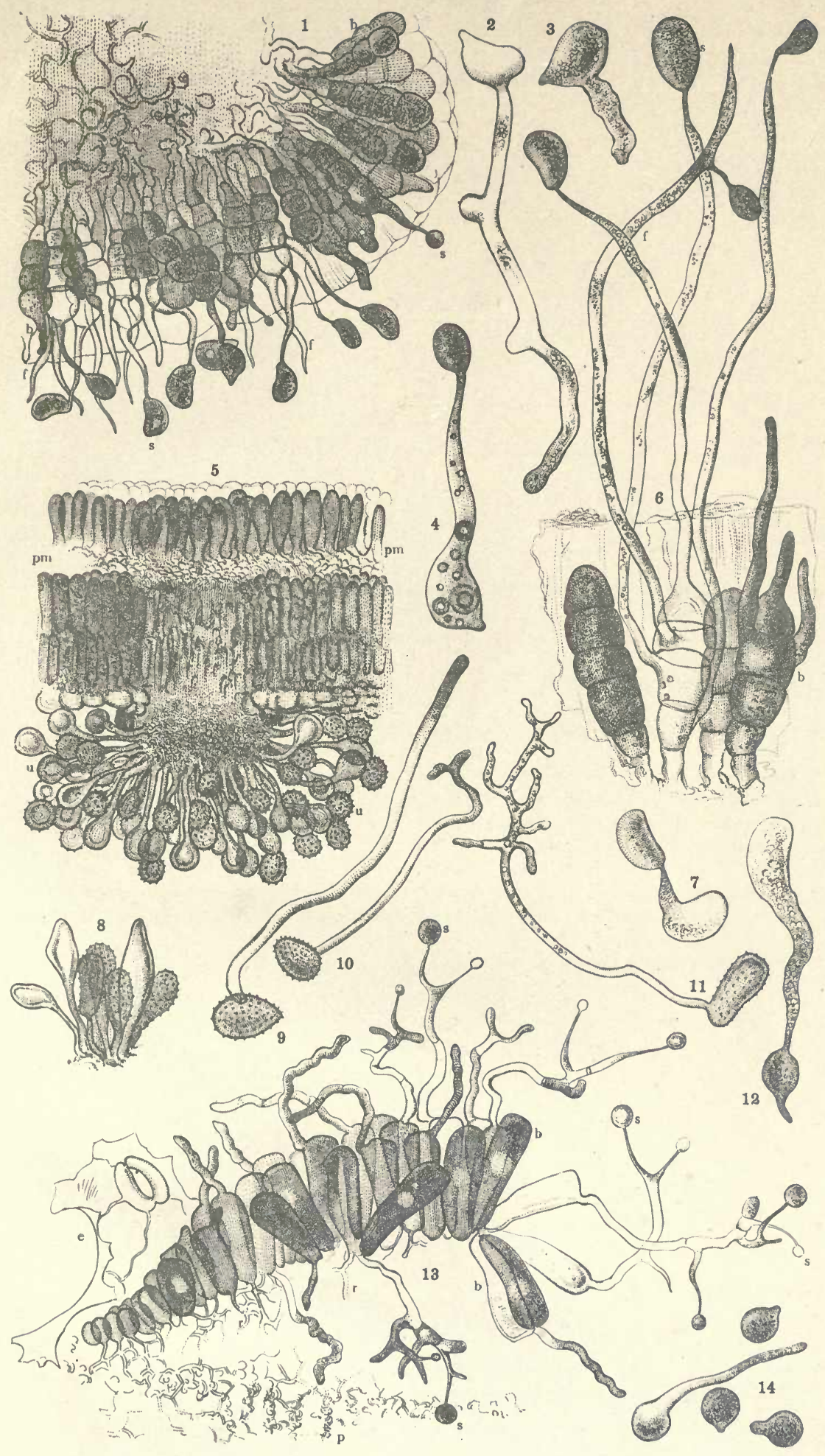




\section{EXPLANATION OF PLA'TE.}

1 to 5 . Germinating uredospores of Cronartium asclepiadeum, Fr.; $x 330$, except Fig. 3 , which $=x 370$.

6 and 7 . Base of the ligules accompanying the uredospores.

8. Transverse section through a ligule, showing the same to be solid, not tubular.

9. A ligule in process of germination.

10, 11, and 12, show more precisely the manner of producing the promycelial spores.

13. Promycelial spores germinating.

14. The uredo sorus of Cronartium asclepiadeum, showing the uredospores escaping through an aperture in the peridium.

15. Section through a more advanced uredo sorus after the appearance of the ligule; the peridium is thrown back, and shows the manner of growth of the uredospores; $x 230$.

16. Section of the same, taken longitudinally through the axis of the ligule. 


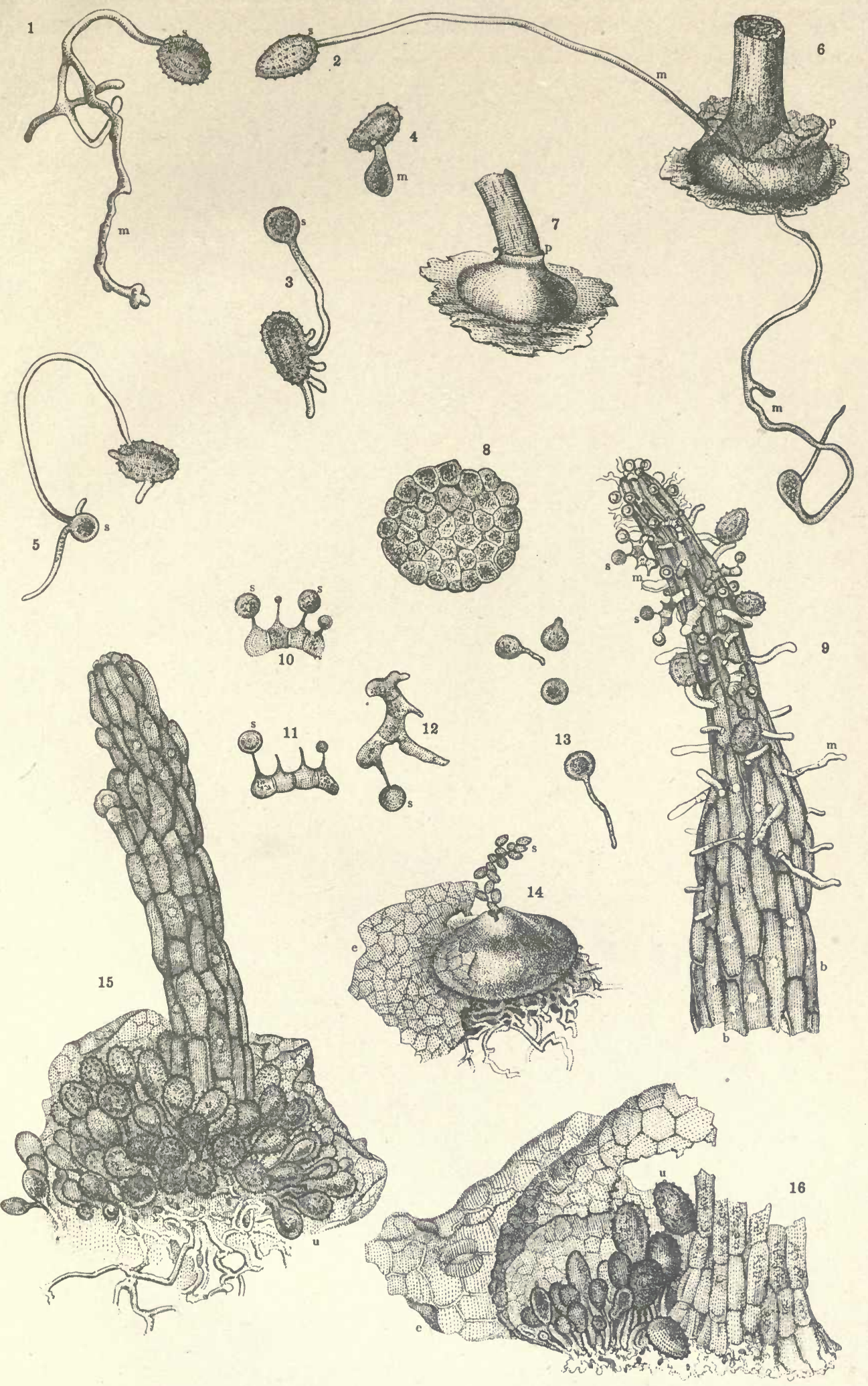

UREDINEF; ILLUSTRATIONS COPIED FROM TULASNE. 



\section{INDEX.}

I'here a subject is illustrated the page number is starred.

carin species and Stigmonose

ecidium bellidi (see final plates).

Aecidium Berberidis (see final plates). of White Clover punctatum (see final plates).

ranunculi repentis (see final plates).

Agricultural experiments should be in the district $\begin{array}{lllll}\text { they are intended to benefit } & \ldots & \ldots & \ldots & 116\end{array}$ lternaria of the Citrus tribe .. ... losses from $\quad . . \quad \ldots \quad$.. $\quad$..

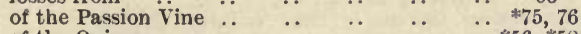

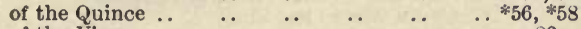

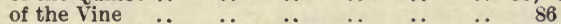

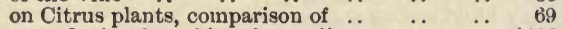
reproducing from bits of mycelium $\quad \ldots \quad \ldots * * 105$ See Macrosporium. $\begin{array}{lllllll}\text { spores on the Apricot } & \ldots & \ldots & \ldots & \ldots & 79\end{array}$

Ammonio-carbonate of copper for Hollyhock rust .. 96 for Peach Curl.

Anne Elizabeth appl Grape, No. 6 of the Fig of the Loquat, coloured figure of ... $\quad$.. $\quad$ Frontispiece

of the Rose, coloured figure of $\quad \ldots \quad$... Frontispiece

Aphides and Apricot buds as the cause of Stigmonose of Carnations 49 Apple affected with Ripe-rot, coloured illustration of and Mucor as a cause of Mouldy Core in Frontispiece and Penicilium as a cause of Mouldy Corc in .. 51 and Ripe-rot .. and Ripe-rot of Passion Fruit

and the size and nature of the channel leading

from the eyes to the core cavities .. 52, 53, 54, 55 attacked by Stigmonose $\quad . \quad \ldots \quad \ldots \quad \ldots \quad \ldots \quad * 41$

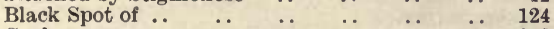

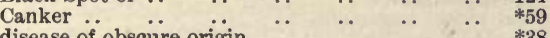

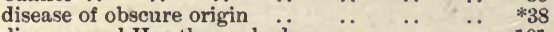

diseases and Hawthorne hedges .. $\quad \ldots \quad \ldots 101$

diseases of, mode of entrance $\quad \begin{array}{lllll} & \ldots & \ldots & 51\end{array}$

Gloeosporium, complete list of the hosts of ... 4

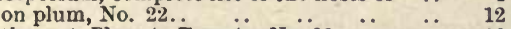

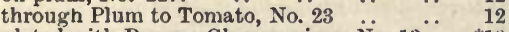

inoculated with Banana Gloeosporium, No. $13 \ldots \quad * 10$ with Gloeosporium of Quince, No. $20 \quad$.. $\quad * 11$ with Guava Gloeosporium, No. 16A .. . . * *10 with Pepuer Gloeosporium, No, 24 .. $\quad \ldots \quad 12$

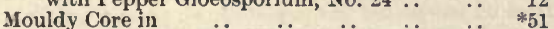

Apples, pears, and quinces suffering from Stigmonose sound looking, suffering from Mouldy Core ... 51

to test for Mouldy Core

variety, attacked by Red Spider

Application of a spray, best method

Apricot buds colonised with Thrips

harbouring Alternaria

harbouring Cladosporium ..

harbouring Phyllosticta

leaves, sensitiveness of the young

leaves or buds and Aphides

Shot-hole

Shot-hole associated with Thripsidae

A rachnids and Stigmonose

Artificial Shot-holes

Aureobasidium (Dematium, Exobasidium)

Racteria as the cause of plant diseases

acterial disease of the Walnut

disease of the Tomato

diseases. .
Banana and Ripe-rot

and Ripe-rot of the Passion Fruit ${ }^{-\ldots, 2,3,12,}$

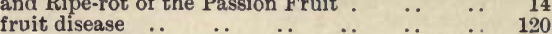

Gloeosporium inoculated on to Grape, No.6 6 ..

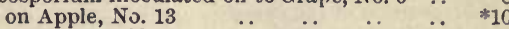

on Banana, No 4 . $\begin{array}{llllll} & 4 & \text {.. } & \text {. } & \text {. } & * 8\end{array}$

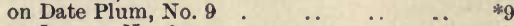

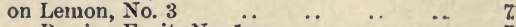

on Passion Fruit, No. $1 \quad$.

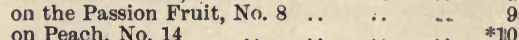

on the Pear, No, 7 ...

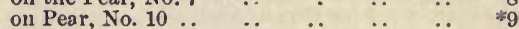

on Quince, Nos. 11 and $12 \quad \ldots \quad \ldots . \quad \ldots \quad * g$

passed through Quince to Banana, No. 5 .. 8

spores grown on Apple, No. 13 .. .. *10

inoculated with Gloeosporium of Guava, No. $\ddot{18} *_{11}$

Ripe-rot of $\quad \ldots \quad \ldots \quad \quad \ldots \quad \quad \ldots \quad 2,3,12, * 19,35$

Bananas attacked by Dincmasporium... . . . $\quad$ *38

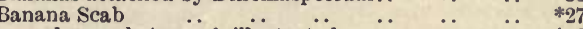

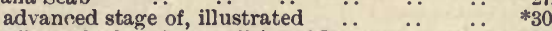

affects the keeping qualities of Bananas $\quad$.. 36

alleged causes uf $\begin{array}{llllll}* & \ldots & \ldots & \ldots & 27\end{array}$

and co-operative effort at eradication $\quad . . \quad \ldots \quad 37$

and the formation of new plantations ..

can it be checked after the bunches are cut and forwarded?

described

destruction of

.

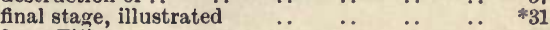

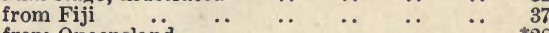

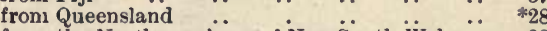

from the Northern rivers of New South Wales.. 28

fungicides for .. $\quad \begin{array}{llllll} & \ldots & \ldots & \ldots & \end{array}$

fungus associated with $\quad \ldots \quad \ldots+\quad \ldots \quad \ldots 32$

fungus left unnamed, because unsufficiently known

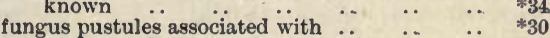

fungus spores in the cracks of $\quad \ldots \quad$.

$\begin{array}{lllllll}\text { how it spreads.. } & \ldots & \ldots & \ldots & \ldots & \ldots & 3 \%\end{array}$

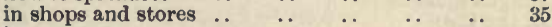

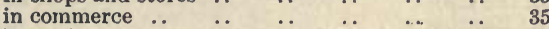

$\begin{array}{llllllll}\text { losses from } & . & \ldots & \ldots & \ldots & \ldots & \ldots & 28\end{array}$

pustule, illustrated .. $\quad . \quad \ldots \quad \ldots \quad \ldots \quad$ *32

measurement of spores associated with .. $\quad$.. $\quad 31$

mycelium associated with ... ..

not prejudicial to temperate crops $\quad$.. $\quad$.. 35

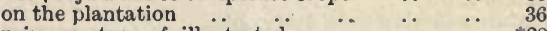

$\begin{array}{lllll}\text { primary stage of, illustrated } & \ldots & \ldots & \ldots & * 28\end{array}$

second illustrated

travels on the wind $\ldots \begin{array}{lllll} & \ldots & \ldots & \ldots & 37\end{array}$

yeast associated with $\begin{array}{llllll} & \ldots & \ldots & \ldots & \ldots & 37 \\ & & \ldots & \ldots & \ldots & 33, * 34\end{array}$

Bananas, diseased, from Byron Bay $\quad \begin{array}{llll}3 & \ldots & \ldots & 12, * 19\end{array}$

Bark-destroying fungus of the Orange $\quad \ldots \quad \ldots \quad * 60$

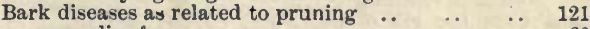

remedies for $\quad \begin{array}{llll} & \ldots & \ldots & 121\end{array}$

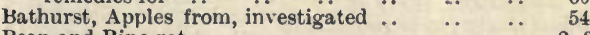

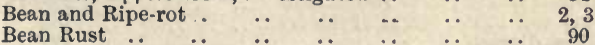

coloured illustration of $\quad \begin{array}{llll}0 & \ldots & \ldots & \text { Frontispiece }\end{array}$

Beans, ploughing in of $\ldots$.

Betula alba, rust of (see final plates).

Birch, rust of (see final plates).

Birds and Ripe-rot

Bites of insects and Rive-rot

$\begin{array}{lllll}\cdots & \cdots & \cdots & \cdots & 26\end{array}$

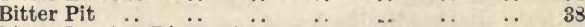

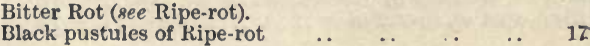


Black Rot of the Chilli of the Quince.

Black Spot and seasons of the Citrus fruit, germination of the spores of $\ddot{*} 7$ of Grape, No. 6 of the Lemon, attempted inoculation of.. $\quad$.. 72 $\begin{array}{lllllll}\text { of the Loquat .. } & \ldots & \ldots & \ldots & \ldots & \ldots & 91\end{array}$

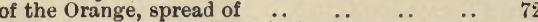
of the Rose (see also Frontispiece) $\quad$.. $\quad$.. $\quad * 96$ on Oranges … on the Apple and Pear on the foliage of the Citrus tribe.

Black Spotted Citrus fruit in store

Blenheim Apple

Bluestone for bark diseases

Boiling water as a disinfectant for fruit cases

Bordeaux Mixture and bark diseases .

Botrytis fungus

Cabbage Perou

Carnation Rust

Chrysanthemum disease

Cladosporium of the Orange

Leaf-spots of the Rose

Melanose

Peach Curl ... ... ... .

poor results from improperly prepared ..
Potato Macrosporium

preparation of..

pruning wounds Banana Scab

the bacterial disease of the Walnut

the foliage of the Loquat

the time of day to apply

the weather

wet regions

wet seasons

Botrytis on Cosnia

Botrytis vulgaris

Brome-grass Smut.

Brown-rot and th: weather $\begin{array}{lllll} & \ldots & \ldots & \ldots & 107\end{array}$

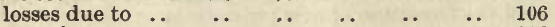

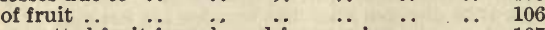

$\begin{array}{llll}\text { Brown-rotted fruit for sale and for canning } & \ldots & \ldots & 107\end{array}$

Byron Bay, diseased Bananas from

Mabbage, Peronospora of

Uabbage Peronospora, remedies for.

Cairns, Queensland, Banana Seab from

Canker

fungi and Hawthorne hedges

fungus illustrated

of the Pear

on Hawthorne.

Capper's Pearmain apple..

Care exercised in Califormia and other advanced fruit countries in handling fruit.

Care in handling fruit ..

Carnation Rust

Carnations suffering from

Cases, fruit, disinfection of

Causes of Shot-hole

Califormian disease of the Vine..

Cereal disease

Cereal rusts.

Channel from eye to core chainbers of the Apple widens in ripening

Channel from the eye of the Apple to the core chambers, study of

Chemical treatment of rotted fruit

Cherry and Plum, blight of the fruit ..

Chillies, disease of .

Chrysanthemum, disease of

Chrysomyxa rhododendri (see final plates).

Cirsium arvense, rust of (see final plates).

Citron and Ripe-rot

Citrus alternaria, comparison of

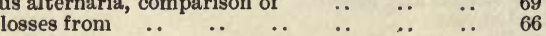

Citrus fruit, attacked by Black-spot .. . . .. $\quad 72$

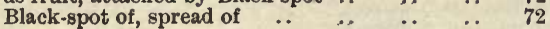

Citrus diseases

trees and the Macrosporium fungus

tribe and its Alternaria fungi

Cladosporium as conuected with Take-all connected with Orange disease

of the Orange ..

of the Peach

on the Apricot

Claygate Pearmain apple

Cleopatra apple

Climate as related to Rust related to Timber-rots

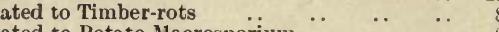

Codlin moth and the channel leading to the core cavities of the Apple

Coleosporium senccionis (see final plates) sonchi (see final plates).

tussilaginis (see final plates).

Colletotrichum of the Bean inoculations with

Colour of, Gloeosporium spores.

Ripe-rot a partial function of the host .. $\quad . . \quad 1$

Ripe-rot as related to the host .. ... .

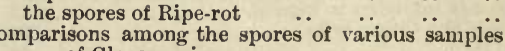
of Gloeosporium.

Commercial success in fruit industry dependent largely on care in handling

Commerco, Scabby Bananas in

$\begin{array}{lllll}\text { Condy's Fluid and Carnation Rust } & \ldots & \ldots & \ldots & 100 \\ \text { Coniothecium and Hawthorne .. } & \ldots & \ldots & \ldots & * 109\end{array}$

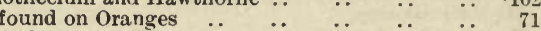

scabrum on Lemons.

Co-operation in the destruction of Brown-rotted fruit

Copper mixtures fö Peach Leaf-curl

Copper sprays for Peach-curl

Core cavities of apple

Cornish Aromatic apple.

Cosmia, disease of

Crataegus and various fung suffering from Ripe-rot

Cress's Seedling apple

Cronartium asclepiadeum (see final plätes).

Cropping continuously as related to Rust

Crown Gall

Cruciferous plants and Peronospora

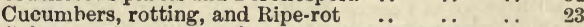

Culture of fungus associated with Banana Scab $\quad \ldots \quad * 32$

Curl-leaf and winter treatment.

Curl-leaf of the Peach

and nurserymen

and winter treatments

Cyclone nozzles

Tate-plum, and Ripe-rot of Passion Fruit..

te-plum, inoculated with Gloeosporium of the Banana, No. 9

peculiar properties of the skin of, No. 9. . $\quad \ldots$

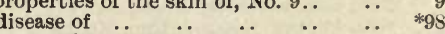

Dematium inoculated unsuccessfully on green fruits of the stone fruit and other fruit..

Diagram of Ripe-rot inoculations

Dinemasporium spores on Bananas from Fiji

Disease and good culture $\quad \cdots \quad 36$

and manures ...

and selection ...

Diseased material, importance of the destruction of

Disease of the fruit of the Banana plants endowed with an instinct to ward off -

$\begin{array}{lllll} & \end{array}$

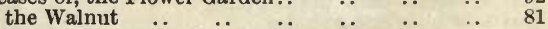

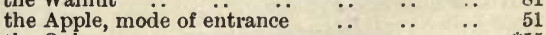
$\begin{array}{llllllll}\text { the Quince } & \ldots & \ldots & \ldots & \ldots & \ldots & \ldots & * 55 \\ \text { the Rose } & \cdots & & & & & \end{array}$

Diseases, various, coloured plates of ..........Frontispiece,

Diseases, various (see Host Plant).

Double spraying

Drainage and Take-all

Drainage as related to Ripe-rot.

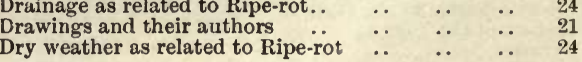

$\begin{array}{lllll}\text { Drainage as related to Ripe-rot.. } & \ldots & \ldots & \ldots & 24 \\ \text { Drawings and their authors } & \ldots & \ldots & \ldots & 21 \\ \text { Dry weather as related to Ripe-rot } & \ldots & \ldots & \ldots & 24\end{array}$
$38,60,74,124$

14 
Tarly stages of disease, importance of recognising Harly varieties and Ripe-rot Erliness and susceptibility to Ripe-rot

Eau Céleste and Peach-curl for Hollyhock Rust

Egg plant and Ripe-rot $\ldots$. $\ddot{\text { from the }}$ attacks of Alternaria fungus $\ddot{\ddot{r}}$ in species making ment, to be al

Epidermis as related to Ripe-rot

.

perennial inycelium of

perennial mycelium of 0 .

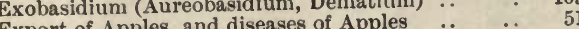

Export of Apples, and diseases of Apples

Hailure of the present system of nomenclature of

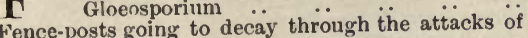

toadstools
treatment of the underground part for timberrot

Fiji, Banana $\mathrm{Seab}$ in

.

First experiments in Ripe-

Flight of Thrips

$\begin{array}{lllllll} & & & & & & \\ \end{array}$

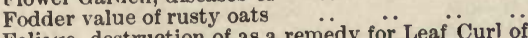

Foliage, destruction of as a remedy for Leaf Curl of Peach

of the Orange when attrcked by Aiternaria : of the Passion Vine with Ripe-rot fungus

Formalin as a disinfectant for fruit-cases

for root-rots

Form of the spores of Ripe-rot as related to the skin of the host

Fruit and regetahles inoculated with Ripe-rot cases, disinfection of

in shops and stores, care of $\quad \begin{array}{llll}\because & \ldots & . & 35\end{array}$

protected from Ripe-rot by its skin $\quad$.. $\quad$.. 22

$\begin{array}{llll}\text { Fungi and their nomenclature .. } & \ldots & \ldots & 20,21,67\end{array}$

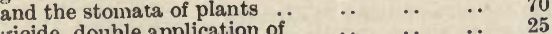

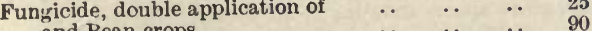

$\begin{array}{lllllll}\text { and Bean crops } & . . & . & . & . . & . & 90\end{array}$

and rain

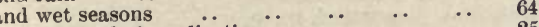

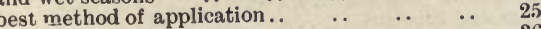

$\begin{array}{lllllll}\text { for Banana Scab } & . & \ldots & \ldots & \ldots & . . & 36\end{array}$

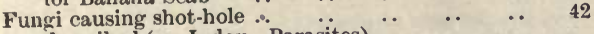

described (see Index-Parasites).

related to that associat $\begin{aligned} & \\ & \text { reproduced from other parts than spores }\end{aligned}$

reproduced from other parts than spores of the

Fungus gaining entrance at the tooth points of the 78

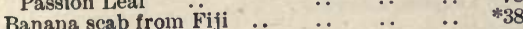

spores and the effect of a spray on the same $\quad . . \quad 25$

$\begin{array}{lllll}\text { Fusarium of the Passion Vine } & \ldots & \ldots & . & \end{array}$

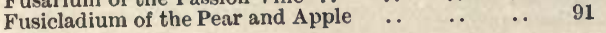

$\mathrm{C}$ alls on roots, treatment of

alls on the roots of Vines and trees

Gasteromycetous fungus of the Vine. ed fuliage and fruit

mases of spores of Gloeosporium

of the spores of the Passion Fruit Ripe-rot $\quad \ldots \quad * *_{14}$

Genera of the Uridineae, illustrated (see final plates).

Gladiolus attacked at the roots by subterranean fungus

Gloeosporiand early varieties.. and Hawthorne and their names

as related to early varieties $\quad$.

Gloeosporium causing serious disease of Bananas at Byron Bay

colour of the pustules

fructigenum, Ber

germination of

growing naturally on the Tomato.

rowing naturally on various vegetation

inability of to penetrate the sound skin of fruit
Gloeosyorium, indifference to host

PAQE.

22 of the Apple, coloured illustration of ... Frontispiece of the Apple, complete list of the hosts of .. 4 of Apple passed through Plum to Tonato, No. 23 of Banana, No. 4

illustration .

on Apple, No. 13 .

on Date Plum, No. 9

on Grape, No. 6

on Lemon, No. 3

on the Passion Fruit, No.

on Passion Fruit, No. 1 .

on Peach, No. 14

on the Pear, No. 7.

on Pear, No. 10

on Quince, Nos. 11 and 12

spores of, on Peach, No. 14

of the foliage of the Passion Vine.

of the fruit of Passion Vine, reseniblance to that

*10 of Pomes

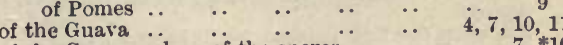

of the Guava, colour of the spores $\quad$. $\quad \ldots \quad 7,{ }^{* 10}$ on the Apple, No. 17

on Banana, No, 18.

on Hawthome herries, No. 16

on Passion Fruit, No. 2 . $\quad$. $\quad$. . $\quad$..

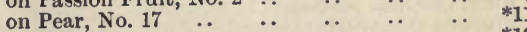

on Quince, No. 15 .. … $\quad \ldots \quad$. $\quad \ldots \quad * 10$

passed through Quince back to Guara, No. $19 \quad 11$

of leaves of Passon foliage on Pear, ํ. $21 \ldots \ldots \ldots * * 12,14$

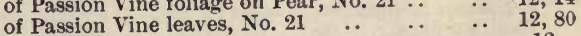

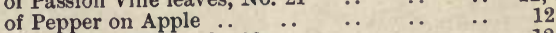

of Plum on Apple, No. 22 .. $\quad$..

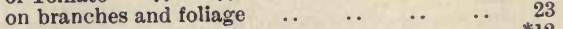

$\begin{array}{lllllll}\text { on Crataegus ... } & \ldots & \ldots & \ldots & \ldots & \ldots & * 12\end{array}$

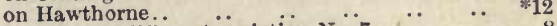

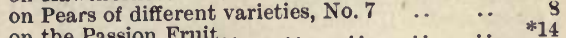

on the Passion Fruit.. $\quad$.

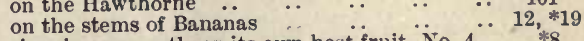

ripening promptly on its own host fruit. No. 4.. $* 8$

$\begin{array}{lll}\text { species making in the genus } & 18 \\ \text { spores becoming two-celıed before germination } & * 13\end{array}$

germinating and producing secondary spores $*^{*} 13$

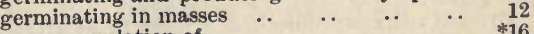

$\begin{array}{lllllll}\text { spores, grallulation of } & \ldots & \ldots & \ldots & \ldots & * 16\end{array}$

omnipresence of $\ldots \quad \ldots$

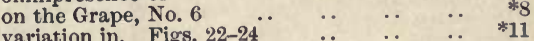

$\begin{array}{llll}\text { variously resisted by various varieties } & \ldots & \text {.. } & 26\end{array}$

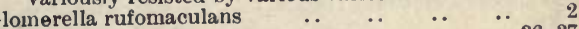

Good culture and disease $\quad \begin{array}{llll}\ldots & \ldots & \ldots & \ldots 36,37\end{array}$

Goulburn, apples from, investigated 0 Leaf Curl of

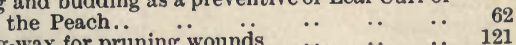

Grafting-wax for pruning wound

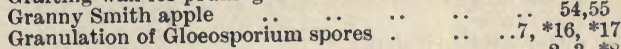

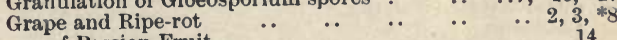

of Passion Fruit $\quad$ anana Gloeosporium, No. $\ddot{6} \quad \begin{array}{ll} & 14\end{array}$

Grape inoculated with Banana

Gray Scab of the Orange .

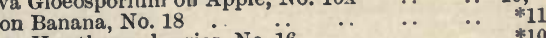

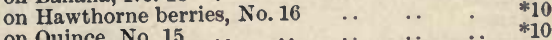

on Quince, No. 15 .

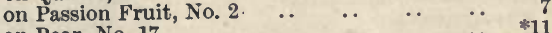

passed through Quince and back to Guava, No. $\ddot{19} \quad 11$

spores from Quince, No. 15.. .. $\quad$. $\quad$.. $\quad * 10$

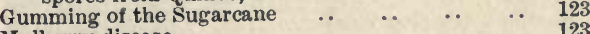

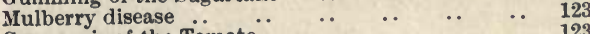

Gummosis of the Tomato

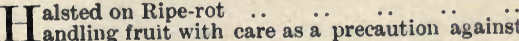
Ripe-rot

Hand-picking of leaves $\begin{array}{llllll}. & \ldots & \ldots & \ldots & \ldots & 21 \\ \end{array}$

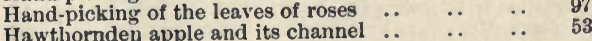


Hawthorne berries inoculated with Guava Gloeosporium, No. 16 .

Canker .

Coniothecium on

Gloeosporium ..

hedges and Ripe-rot spraying of .

Ripe-rot fungus

Hedges of Hawthorne ... ...

Host fruit as related to the colour of the Ripe-rot..

Host Plant-

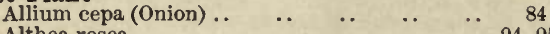

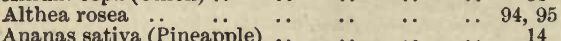

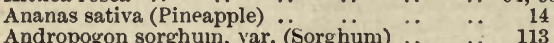

$\begin{array}{lll}\text { Apple } \ldots & \ldots & 2,3,4,10,11,12,14,38,41,51-55\end{array}$

Apricot .. (see final plates). "(Milkweed.)

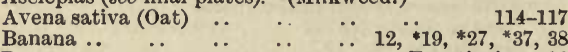

Bean $\because \cdots$ Frontispiece, 90

Betula alba (see final plates). (Birch.)

Birch (see final plates).

$\begin{array}{llllll}\text { Brassica campestris (Iurnip) } & \text {.. } & \text {. } & \text {.. } & 91\end{array}$

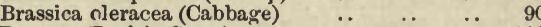

$\begin{array}{llllll}\text { Bromus (Prairie Grass) } & \text {. } & \text {. } & \text {. } & \text {. } & 119\end{array}$

.. 90

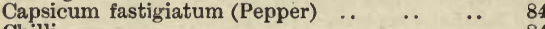

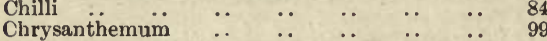

Cirsium arvense (see final plates). "(Thistle.)

Citron $\cdots$.

Citrus aurantium (Orange). $. \quad 60,6 \ddot{6}, 69,70,121,122$

Citrus Limomun (Lemon) $\ldots \quad 2,3,7,66,71,72,73,74$

Citrus medica (Citron) $\quad$ ․

$\begin{array}{lllllllll}\text { Clover } & \ldots & \ldots & \ldots & \ldots & \ldots & \ldots & \ldots & 113 \\ \text { Cosmia } & & & & & \end{array}$

Crataegü Oxyäantha (Hawthorne) $10, \ddot{12}, 23, \ddot{5} \dot{9}, 101,102$

Cucumber

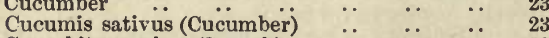

$\begin{array}{lllll}\text { Cucurbita maxima (Squash) } & \ldots & \ldots & \ldots & 58 \\ \text { Pepo } & \ldots & & & \end{array}$

Cydonia vulgaris (Quince) $2, \ddot{3}, 9,11,12,14,38,4 \dot{1}, 55-58,101$

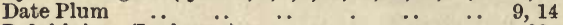

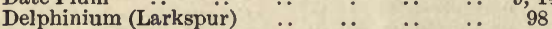

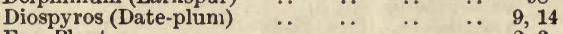

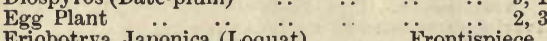

Eriobotrya Japonica (Loquat) $\quad$.. $\quad$ Frontispiece, 91

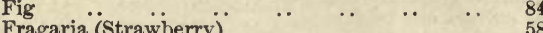

$\begin{array}{llllll}\text { Fragaria (Strawberry) } & \ldots & \ldots & \ldots & \ldots & 58\end{array}$

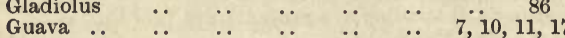

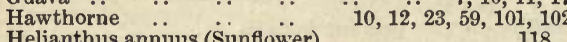

Helianthus annuus (Sunflower) $\quad$. $\quad$. $\quad$. 118

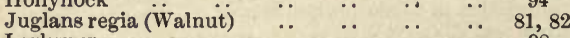

$\begin{array}{lllll}\text { Larkspur } & \ldots & \ldots & \ldots & \because 3,7,766,71,72,73,74\end{array}$

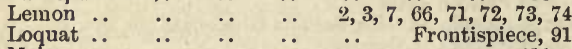

Maize

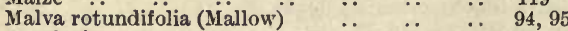

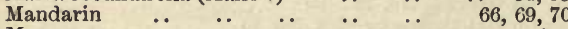

Mango

Milkweed (see final plates).

Musa (Banana)

Oat

$12, * 19,27, * 37,38$

114-11

Orange $\cdots \quad \cdots \quad 60,66,69,70,7 \ddot{1}, 121,12$

Passiflora (Passion Vine) $\quad \cdots \quad 7,13,14,74,75,76,77,80$

Passion Vine .. $\quad . \quad \ldots \quad 7,13,14,74,75,76,77,80$

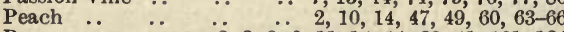

Pear $\quad . \quad \ldots \quad 2,3,8,9,11,13,14,38,41,101,124$

Persimmon

84

$\begin{array}{lllll}\text { Phaseolus (Bean) } & \ldots & \ldots & \ldots & \text { Frontispiece, } 90\end{array}$

Pineapple

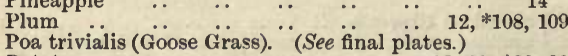

Potato.

Prairie Grass ...

$82,83, * 89,90$

domestica (Plum) ..
119

$12,108,109$
Host Plant-

PAGE.

Prunus Persica (Peach) .. 2, 10, 14, 47, 49, 60, 63-66 Psidium Guaiava (Guava) $\quad$. $\quad \ldots \quad \ldots 7,10,11,17$

Pumpkin $\quad \ldots \quad$.. $\quad \ldots \quad \ldots, \quad \ldots, 23$

Pyrus cydonia (Quince) $\quad \ldots \quad 2,3,9,11,12, \ddot{14}, 38,41$, $\begin{array}{lll}\text { Quince } & & \end{array} \quad 2,3,9,11,12,14,38,41,55,56-58,101$ Radish ... .. $\quad . \quad \ldots \quad \ldots . \quad . \quad . .90,91$

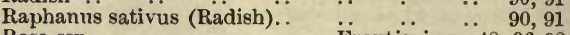
Rosa ssp. $\quad$.. $\quad$.. $\quad . . \quad$ Frontispiece, 48, 96-98

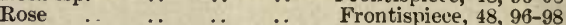
Saccharum officinarum (Sugarcane) .. $\ldots 123$

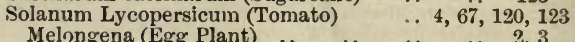
$\begin{array}{llllll}\text { Melongena (Egg Plant) } & \ldots & \ldots & \ldots & \because & 2,3 \\ \text { tuberosum (Potato) } & & & & 82,83,89,\end{array}$

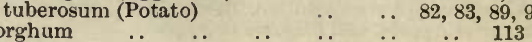

Sorghum

Strawberry

Sunflower

Sugarcane

Trifolium repens (White clöer) ${ }^{\prime} \quad \ldots 4,67,120,123$

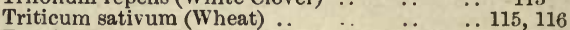

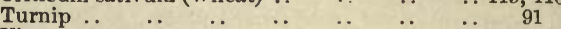

Vine $\begin{array}{llllll}\because & \ldots & \ldots & \ldots & \because & \ldots 8,85,86\end{array}$

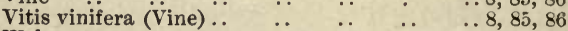

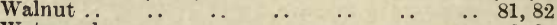

$\begin{array}{llllllll}\text { Watermelon } & \ldots & \ldots & \ldots & \ldots & \ldots & \ldots & 2,3\end{array}$

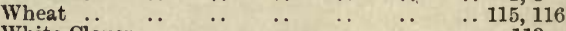

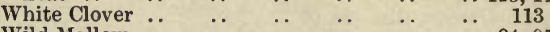

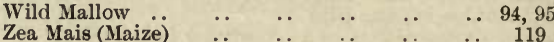

Host Plants of Ripe-rot

of the Apple Gloeosporium.

of the Bean Colletotrichum

of the Citron Colletotrichum

of the Egg Plant Colletotrichum

of the Gloeosporium of the Apple, complete list.

of the Grape Gloeosporium.

of the Melon Colletotrichum

of the Pear Gloeosporium .

of the Pepper Gloeosporium

of the Tomato Gloeosporiun

ce, use of, as related to Ripe-rot

mmature spores differing from those of mature growth

Importation of scabby Bananas

Inoculations, diacram of Ripe-rot

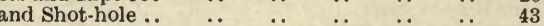

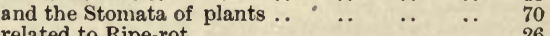

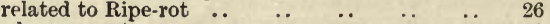

Introductory note .

Irregular spores due to pressure of tough cuticle $\ldots \frac{6}{6}$

$\begin{array}{llllll}\text { Irritation and Shot-hole } \ldots & \ldots & \ldots & \ldots & \ldots & 47 \\ \text { Italian Lemons, diseased } \ldots & \ldots & \ldots & \ldots & \ldots & 73\end{array}$

Tarring in carriage of fruit, as related to Ripe-rot

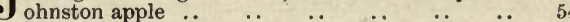

$\begin{array}{llllllll}\text { Jonathan apple } & \ldots & \ldots & \ldots & \ldots & \ldots & \ldots & 54 \\ \end{array}$

T entucky Bluestreak apple .. $\quad \ldots \quad \ldots \quad \ldots$

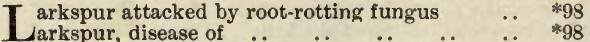

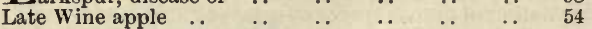

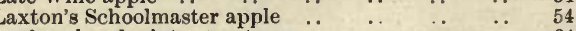

$\begin{array}{llllll}\text { Leaf-curl and winter treatment } & \ldots & \ldots & \ldots & 64\end{array}$

of stone fruits, fecundity of $\quad \begin{array}{lllll} & \cdots & & & \end{array}$

$\begin{array}{lllll}\text { of the Peach, time to spray for } & \cdots & \ldots & \ldots & 62 \\ \text { of the Peach }\end{array}$

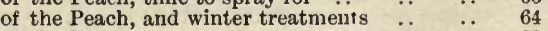

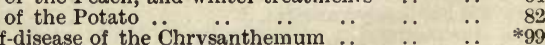

Leaf-disease of the Chrysanthemum ..

mon, Alternaria

bark attacked by a füngus disease

bark attacked by a fungus disease

Lemons, bitter

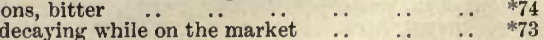

imported, disease of ... ...

harvesting of

harvesting of

suffering from Melanose 
Light-weight Lemons

Lime, as a remedy for Take-all . for root disease of Larkspur to slack properly

Lime, sulphur, and salt after pruning. for Brown-rot of fruit for Rose disease

Loquat anthracnose, coloured iliustration Black Spot of

Losses from Peach Curl :
PAGE

113

99

108

98

Frontispiece

Macrosporium. (See also Alternaria.)

1 acrosporium and Alteruaria, more complete synonomy of ...

of the Citrus tribe

67

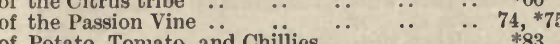

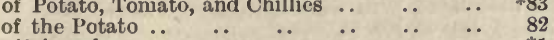

$* 1$
$* 66$

*66

69

and Orange Alternaria, com

Mandarins attacked by a Phoma-like form ... premature ripening of, through attacks of disease

Maize smut ..

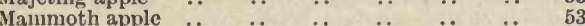

Manure and disease $\quad \ldots \quad \ldots 36,119$

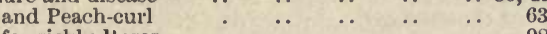
for sickly koses

Mature spores differing from those of younger

$\begin{array}{cccccc}\text { growth } & . . \\ \text { Maturity of pustules, criterion for } & \ldots & \ldots & \ldots & 15 \\ \end{array}$

McAlpinc on Shot-hole $\ddot{\text { Mechanical causes of variation in the form of spores }}$ the outbreak of spores.

Melampsora betulina (zee final plates) populina see final plates). salicina (see final plates).

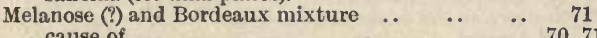

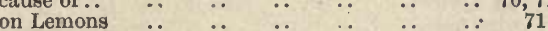
on Lemons

Metbod of applying a spray

Milkweed Rust (see final plates).

Missouri Pippin apple

Mites and Ripe-rot and Stigmonose

Monilia fruetigena. apparent outward soundness of Apples suffering from of Apple

of the Apple and Mucor

of the Apple and Penicillium test for

Mucor and Mouldy Core in Mammoth apple of the Apple

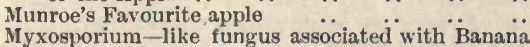
Scab

Tames and culprits

ture and size of the channel leading from the eye of the apple to the core-chambers ..

Nectria as a cause of Canker

Nematodes and Stigmonose

New South Wales, Banana Scab in

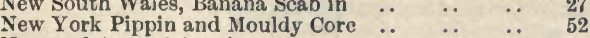

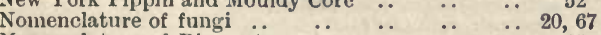

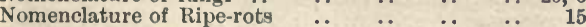

Northern Greening apple $\quad \cdots \quad \ldots \quad \ldots 4$

Northern rivers of New South Wales, Rust of Oats on 114

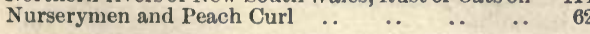

Oat Rust ...

continuous growth of, on the same land .. 117 varieties of, as related fo Rust $\ldots \quad \ldots \quad \ldots 118$

Object of spraying.

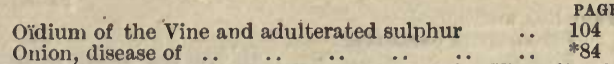

Oosspora-like fungus on the leaves of the Passion Vine *78, 80

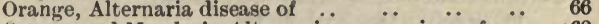

Orange and Mandarin Alternaria, comparison of $\ldots \quad 69$

Orange and Melanose (?) .. $\quad . . \quad \ldots \quad \ldots l \quad \ldots \quad 70$

Orange, town of, apples from, investigated $\ldots \quad \ldots \quad 54$

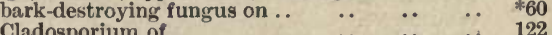

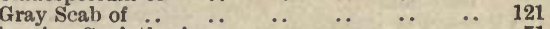

$\begin{array}{lllllr}\text { bearing Coniothecium } & \ldots & \ldots & \ldots & \ldots & 121 \\ \end{array}$

Orchard work in connection with Ripe-rot $\ldots \quad \ldots \quad 22$

Daint for bark disease

arasites mentioned-

Aecidium bellidi (see final plates)

berberidis (see final plates).

punctatum (see final plates).

ranunculi repentis (see final plates).

trifolii

White Clover $\quad \cdots \quad$.. $\quad$..

..*113, 114

. .

$\begin{array}{lllllllll}\text { Apricot } & \ldots & \ldots & \ldots & \ldots & \ldots & \ldots & 79\end{array}$

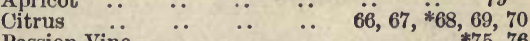

Passion Vine $\quad . . \quad \ldots \quad \ldots \quad \ldots \quad \ldots * 75,76$

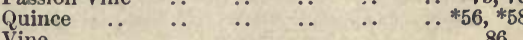

Arachnids $\quad \ldots \quad \ldots 40,100$

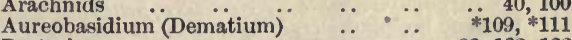

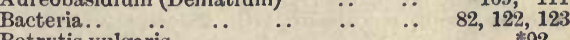

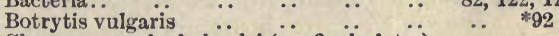

Chrysomyxa rhododendri (see final plates).

Cladosporium- -

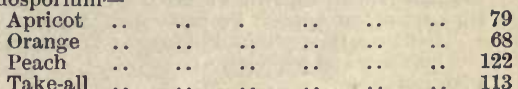

Coleosporium senecionis (see final plates) sonchi (see final plates).

tussilaginis (see final plates).

Colletotrichum Lindemuthianum. .

$\begin{array}{llllr}\text { Coniothecium of Hawthorne } & \ldots & \ldots & \ldots & 81 \\ * 102\end{array}$

$\begin{array}{lllllll}\text { of Orange.. } & \ldots & \ldots & \ldots & \ldots & \ldots & 71\end{array}$

scabrum, on Lemons $\ldots$ … $\quad \ldots \quad 71$

Cronartium asclepiadeum (see final plates).
Dematium (Exobasidium, Aureobasidium) *109, *111

Dinemasporium of Ballana.. .. .. .. *38

Exoascus deformans .. $\quad . . \quad \ldots \quad \ldots$

Exobasidium (Denatium, Aureobasidium) *109, *111

Fusarium of the Passion Vine .. .. $\quad$.. $\quad * 77$

Fusicladium dendriticum $\ldots$.

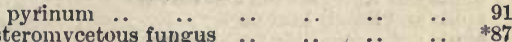

Gloeosporium-

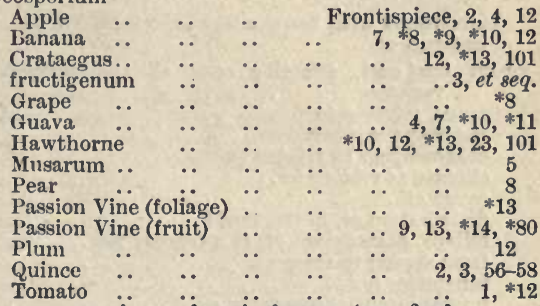

Gymnosporangium clavariaeforme (sëe final plates).

Macrosporium -.

Chilli

Citrus $\quad \ldots$

Passion Vine

Potato

*84

$\begin{array}{llllllll}\text { Tomato } & \cdots & \ldots & \ldots & \ldots & \ldots & \ldots & * 83\end{array}$ populina (see final plates). salicina (see final plateg).

$\begin{array}{llllllll}\text { Monilia fructigena } & \ldots & \ldots & \ldots & \ldots & \ldots & 106\end{array}$

$\begin{array}{llllllll}\text { Mucor mucedo } & \ldots & \ldots & \ldots & \ldots & \ldots & 51,53\end{array}$

Oidium Tuckeri

Oöspora..

Penisillium : 
Parasites mentioned-

Peronospora parasitica

Phragmidium bulbosum (see final plates). incrassatum (see final plates).

Phyllosticta-

Apricot .

Shot-hole

Pleospora of Quince...

Podisoma juniperi (see final plates)

Puccinia-

adoxae (see final plates)

anthoxanthi (see final plates).

compositarum (see final plates).

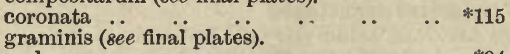

malvacearum .

poarum (see final plates).

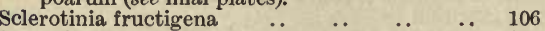

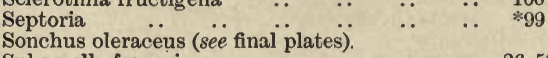

Sphaerella fragariae ..

Triphragmium ulmariae (see final plates)

Uromyces appendiculatus (see final plates). fabae (see final plates).

caryophyllorum ..

Ustilago bromivora.

Passion Fruit, inoculated with Gloeosporium of Banana, No. 8

inoculated with Guava Gloeosporium

inoculated with Ripe-rot of Banana

Ripe-rot of, on Apples, Pears, Grapes, Peaches,

Bananas, Date-plums, Pineapples, Tomatoes,

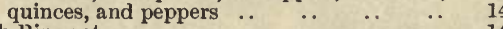

$\begin{array}{lllllll}\begin{array}{l}\text { with Ripe-rot } . . \\ \text { woodiness of }\end{array} & . . & . & . & \ldots & \ldots & 14\end{array}$

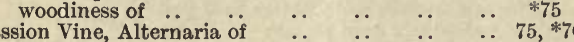

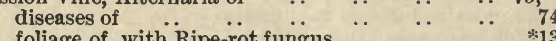

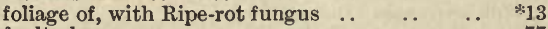

$\begin{array}{lllllll}\text { faulty leaves on } & . & . & \ldots & \ldots & . & 77\end{array}$

leaf Gloeosporium of, inoculated on Pear, No. $\ddot{24}$

leaves of, with Oöspora-like fungus $\quad . . \quad$..

Macrosporium of

Pleospora of

Ripe-rot of

Peach, and Ripe-rot

and Ripe-rot of the Passion Fruit

aphis and Apricot buds and leaves

aphis and Peach Leaf-curl

aphis not responsible for Shot-hole

Cladosporium .

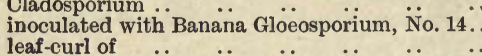

Peach Leaf-curl, affecting some of the choicest varieties

aphis, relation to

Bordeaux mixture for

cold weather as related to ..

climate as related to.

cause of

distribution of, in the worl

foliage, destruction of, as a remedy for ..

from season to season

fungicides for

humid localities worse for

infections in spring ..

losses from

manure for

nurserymen spread it

off seasons, effect of .

orchards in damp situations more liable to orchards near water or in damp situations prevented cheaply

perennial mycelium of

profitable treatment of

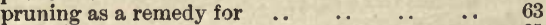

remedies for $\ldots$.

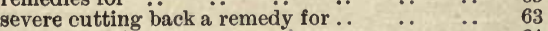

sulphate of iron for .

time to spray for

treatment, early, successful on ..
GE.

0,82

42

\section{2
$* 78$}

$* 75$

80 ,*77

2
14

49

64

49
129

*10

60

66

64

65

61,65

64

63

65

64

64,65

63

65

65

65
65
65

65
65

65

65

64
66
65
Peach Leaf-curl, variation on varieties of Peach weather as related to

wet seasons, action on

winter treatment for.

Peach Shot-hole and Thripsidae

Peach-skin, in connection with Gloeosporium, No. $\ddot{14}$

Pear and Ripe-rot . and Ripe-rot of Passion Fruit $\quad \begin{array}{llll}* & \cdots & & \end{array}$

Pear attacked by Stignionose illustrated $\quad \ldots \quad$... $* 41$

Black Spot of ..

diseases of, and Hawthorne hedges

infected with the Gloeosporium of Passion Vine foliage

inoculated with Gloeosporium of Banana, No. $\ddot{7}$ inoculated with Gloeosporium of Banana, No. 10 inoculated with Gloeosporium of the Guava,

No. 17 woculated Gloeosporium of Passion Vine leaves, No. 21

Pears, Apples, and Quinces suffering from Stigmonose Penicillium and Mouldy Core in Manmmoth apple. and Mouldy Core of the Apple .. $\quad . . \quad \ldots$ glaucum and the Walnut .. and Ripe-rot of Passion Fruit $\ldots \ldots \ldots$. $\quad \ldots \quad \ldots, 3,1$

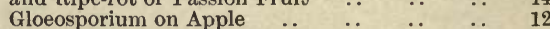

$\begin{array}{llllllll}\text { Perfection apple } & \ldots & \ldots & \ldots & \ldots & & \ldots & 54\end{array}$

Perithecium of Banana Scab, illustrated .. $\quad$.. *32

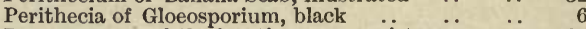

Peronospora and the location as to moisture $\quad$.. 91 $\begin{array}{lllllll}\text { of the Cabbage } & \text {. } & \text {.. } & \text {. } & \text {. } & \text {. } & 90\end{array}$ parasitica

Persimmon and Ripe-rot $\ldots$..

Phoma in connection with disease of Mandarins ...
Phoma-like form of fungus associated with Banana

Phoma-like form of fungus associated with Banana

on Mandarins

associated with Bariana $\mathrm{Scab} \quad \cdots, \quad \cdots$

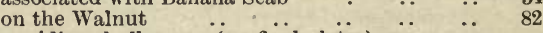

Phragmidium bulbosum, (see final plates).

incrassatum (see final plates).

obtusum (see final plates).

Phyllosticta as the cause of Shot-hole.. $\quad$. $\quad$.. 42

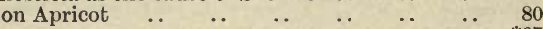

$\begin{array}{llllllll}\text { rosarum } & \ldots & \ldots & \ldots & \ldots & \ldots & \ldots & * 97\end{array}$

Pineapple and Ripe-rot of Passion Fruit $\quad \ldots \quad$.

Pleospora of the Passion Vine .. $\quad \begin{array}{lllll}76, * 77 & \ldots & \ldots & 757\end{array}$

Pleospora (?) of the Quince $\ldots$...

Plum, inoculated with Gloeosporium of "Apple, No. 22

Poa trivialis, rust of (see $\ddot{\text { final plates) }}$

Podisoma juniperi conmunis (see final plates).

Posts, charring and tarring the underground part of Potato, Leaf-curl of

Macrosporium and climate.

Macrosporium, losses from.

Macrosporium of

Macrosporium, treatment for

murrain..

Prairie-Grass Smut

Prevention of disease by knowledge of the appearance of early stages

Preventives of Leaf-curl of the Peach $\quad \ldots \quad \ldots .62$

Pronycelial spores of Puccinia malvacearum . $\quad$. $\quad * 95$

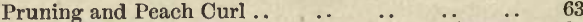
as a means of spreading bark and wood diseases 121

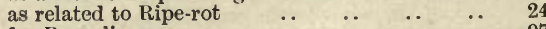
for Rose diseases

Prunus Leaf and Shot-hole

Puccinia adoxae (see final plates).

anthoxanthi (see final plates).

compositarum (see final plates).

coronata

coronata (see final plätes).

craminis (sce final plates)

Helianthi .

phalaridis (see final plates).

poarum (see final plates).

Puff-balls and the Vine .

and Timber-rots

Pumpkins and Ripe-rot

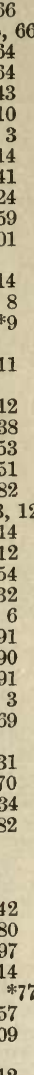

24
97
47


Punctures in the skin of ripening fruit, cause of

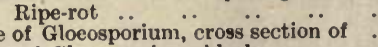

Pustule of Gloeosporium, cross
Pustules of Gloeosporium, black of Gloeosporium of a dark colour, No. 7 cases, No. 9 of Ripe-rot, arrangement of

PAGR.

ueensland, Banana Scab in .. Quick-lime for Root-rots

Quince, Altermaria of and Red Spider

and Ripe-rot

and Ripe-rot of Passion Fruit

Black-rot of

diseases, and Hawthorne hedges

diseases of Gloeosporium Apple, No. 20

Gloeosporium on Apple, No. $20 \quad$.. $\quad$..

inoculated with Banana Gloeosporiun, No. 11, 12 inoculated with Guava Gloeosporium, No. 19 .

Pleospora (?) of

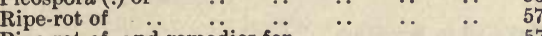

Ripe-rot of, and remedies for $\quad \ldots \quad$.

Apples and Pears suffering from Sitigmonose .

Radishes and Peronospora

Rain and Fungicides

Rain as related to Ripe-rot

Red Scab on Bananas from Fiji.

Red Spider and Stigmonose

Reinette Franche apple

Remedies for, Leaf-curl of the Peach .

Ripe-rot. of the Quince

$\begin{array}{lll} & & \\ & & \\ & & \end{array}$

esistance to Gloeosporiuin varies with variety $\quad$.. 26 varying, to Ripe-rot .

Resistant varieties and Leaf-curl of the Peach $\quad \ldots \quad 62$

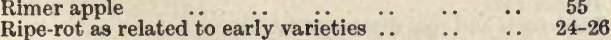

pe-rot as related to early varieties $\ldots$.. $\quad . \quad$.. $24-26$

birds, relation to

coloured illustration of

compared with Brown-rot

differs from rot of Mouldy Core in Apple

growing naturally on various sorts of vegetation

inability of to penetrate sound skin of fruit .

indifference to host

insects as related to $\ldots \begin{array}{cccccc}. . & \ldots & \ldots & \ldots & \ldots & 22 \\ \end{array}$

inoculations of

in the orchard.

of Apple

of the Banana

of Banana, plate of

of branches and foliage

of Crataegus

of foliage of Passion Vine

of Hawthorne

of the Passion Fruit

of the Passion Vine

of the Pepper...

51

12

22

Frontispiece, 2, *4

of the Quince

$\begin{array}{lllll} & \cdots & \ldots & \ldots 2 & 3,11,56^{-58}\end{array}$

of Quince, Bordeaux mixture a remedy for .. 57

of stems of Bananas ..

progress of the disease

pustule of, in cross section.

remedies for

and nomenclature

skin of the host, relations to

species, distinguishing amons

$7, * 8, * 9, * 10,12, * 19,35$

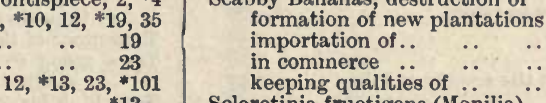$$
\text { is } \because \cdots \text { *13 }
$$$$
12, * 13,23, * 101
$$$$
\text { *14 }
$$

spores beconling two-cell

spores, granulation of

spores of, on hyphae.

spores, omnipresence of

transmission in cases of fruit

variation in colour of, due to variation of host.

$12, * 19$
Ripe-rot, variation in the spores of $\quad$ PAGE. variously resisted by varieties wind, rain, heat, sun, insects, birds, relations

$\begin{array}{llllll}\text { among } & & \ldots & \ldots & \ldots & 24 \\ \text { Rogue's gallery for Fungi } & \ldots & \ldots & \ldots & \ldots & 20\end{array}$

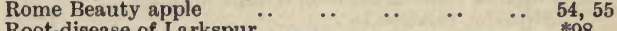

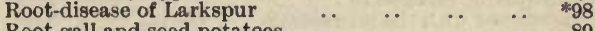

\begin{tabular}{llllll} 
Root-gall and seed potatoes & $\ldots$ & $\ldots$ & $\ldots$ & $\ldots$ & 89 \\
\hline
\end{tabular}

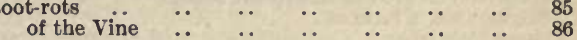

$\begin{array}{llllllll}\text { remedies for } & \ldots & \ldots & \ldots & \text {. } & \ldots & \ldots & 87\end{array}$

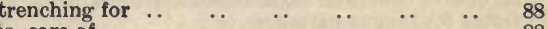

Rose anthracnose, coloured figure of $\ldots \quad \ldots$ Frontispiece

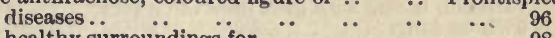

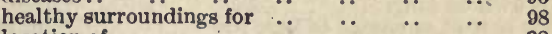
location of $\begin{array}{lllllll} & \cdots & \ldots & \ldots & \ldots & \ldots & 98\end{array}$

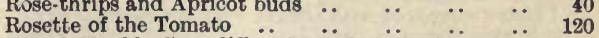

Rot of Mouldy Core differs from that of Ripe-rot of

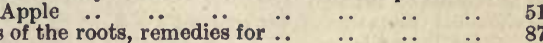

of the Quince

Rots of timber and roots.. $\quad . \quad \ldots \quad \ldots \quad \ldots 5$

of various vegetables, possible related to fruit rots..

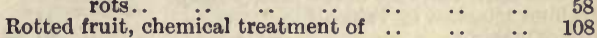

Rotting fruit in the orchard on the ground, as related to Ripe-rot .. .. .. 23

Rotting vegetables and Ripe-rot $\begin{array}{lllll} & \ldots & \ldots & \ldots & 23 \\ \end{array}$

Running together of spray after application.. $\quad \ldots \quad 25$

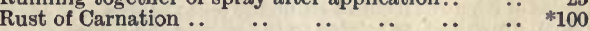

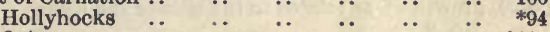

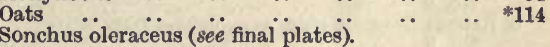

the Bean ... .. .. 90

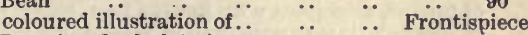

the Rose (see final plates).

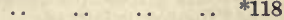

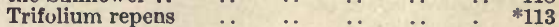

$\begin{array}{lllllll}\text { various cereals } & \ldots & \ldots & \ldots & \cdots & & 116\end{array}$

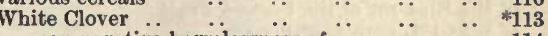

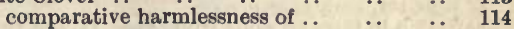

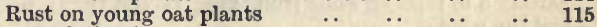

relation to $\quad \begin{array}{llllll} & \ldots & \ldots & \ldots & \ldots & 115\end{array}$

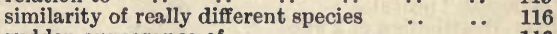

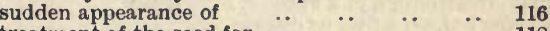

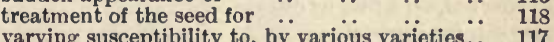

113

various, illustrations of (see final plates).

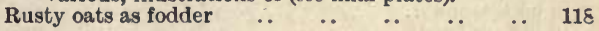

Aamoan Islands, Banana Scab in

andwich Islands, Banana Scab in

Scabby Bananas, destruction of

Sclerotinia fructigena (Monilia).

Seasons and the spraying for Black-spot of the Apple 124 ary spores of the Glocosporium of the Passion Fruit

of the Gloeosporium of the Passion Vine Foliage Seed potatoes, disease in.

Wet-rot in

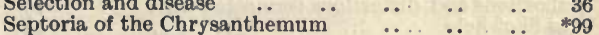

Series of inoculations illustrated $\quad . . \quad \ldots \quad \ldots * 16, * 17$

Shops and stores, use of Formalin in .. $\quad \ldots \quad \ldots 23$

$\begin{array}{lllll}\text { Shops, care of fruit in } & \ldots & \cdots & & \\ \text { Shot-hole, absence of vegetable parasite in some } & & \end{array}$ cases

artificially produced..

caused by fungi

fungi $\quad \ldots \ldots$.. $\quad \cdots \quad * 43$

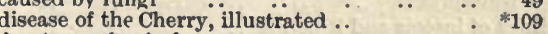

due to mechanical causes .. $\quad \ldots \quad$. . $\quad \ldots \quad 43$

function of the Prunus leaf

function of the stone-fruit leat 
Shot-hole, growth of, illustrated

fungus of the Passion Vine.

$\begin{array}{lll}2 & 43-4 \\ \cdots & * & * 79\end{array}$

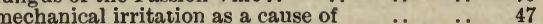

Peach

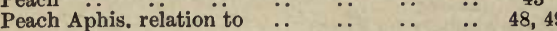

produced without the intervention of fungi ... 49

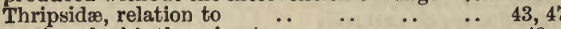

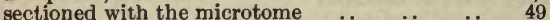

stationary in growth late in the season $\ldots$.. $\quad . .49$

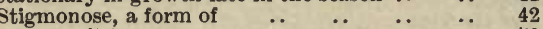

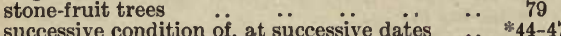

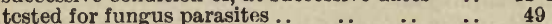

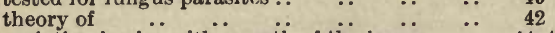

variation in size with growth of the lcaves $\quad \begin{array}{ccc} & \text {.. } & 44-47\end{array}$ without fungi.

Skin of fruit as related to Ripe-rot $\quad \cdots \quad \cdots \quad \quad \cdots, 16,22$ ripening fruit, punctures in, cause of $\quad$. $\quad \ldots \quad 24$

Smut of Brome grass $\ldots * 119$ of Maize compared with that of Prairie Grass .. 119

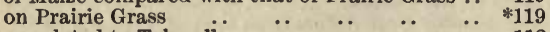

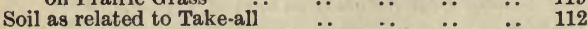

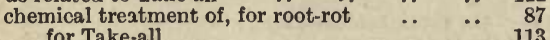

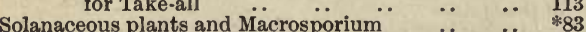

Solvent effect of fungi on tissues $\quad \begin{array}{llll} & \ldots & \ldots & 7\end{array}$

Sonchus oleraceus, rust of (see final plates).

Sorghum attacked by Take-all .. $\quad$.. $\quad$.. $\quad$.. 113

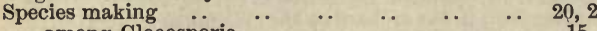

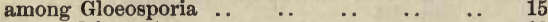

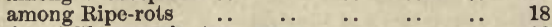

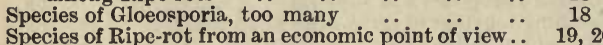

Spores, growth of, as related to the skin of the host,

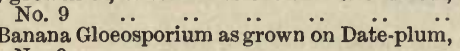

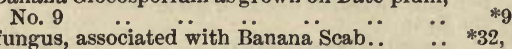
of fungus, associated with Banana Scab.. $\quad . . \quad * 32,33$ $\begin{array}{ll}\text { of Gloeosporium germinating in masses.. } & 12 \\ \text { of plant diseases, illustration of the abundance } & 61,115\end{array}$ of Ripe-rot, colour of

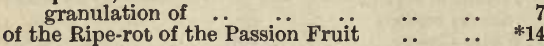

of Ripe-rot, omnipresence of $\quad \begin{array}{lllll}* & \ldots & \cdots & 22\end{array}$

variation in form on same fruit, Figs. $1 \dot{1}$ and $i 2$ and the wind

"Spouting" pustules

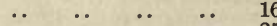
$\begin{array}{lllll}\text { effect of, on a fungus disease } & \ldots & \text {.. } & \text {.. } & 25 \\ & & & \end{array}$

$\begin{array}{lllllll}\text { Spraying, for Ripe-rot } & \ldots & \ldots & \ldots & \ldots & \ldots & 23\end{array}$

Hawthorne hedges 102

$\begin{array}{lrr}\text { in an improper manner as related to Ripe-rot... } & 24\end{array}$

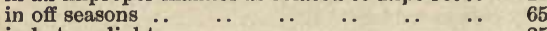

in hot sunlight

object of

of the Quince

proper time of day for

rapidly.

veather, as related to

with whitewash

Spray, how to cause foliage to retain should be fine... .. $\quad \ldots \quad \ldots \quad \ldots 25$

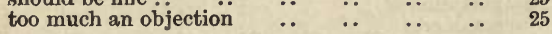

Spread of Ripe-rot through the agency of mites .. 27

Squash and Ripe-rot diseases of

Stage of ripeness and variation of the Gloeosporium

Starch as an adulterant of Sulphur as used for Oidium of the Vine

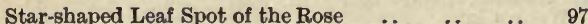

Stigmonose .. $\quad \ldots \quad$. abortions and distortions connected with $\quad \because \quad * 40$

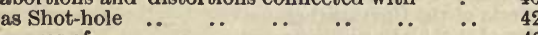

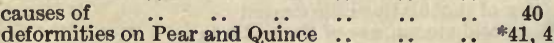
$\begin{array}{lllllr}\text { deformities on Pear and Quince } & \ldots & \ldots & \ldots & * 41,42 \\ \text { on Apples, illustrated } & . . & \ldots & \ldots & \ldots & 38,39\end{array}$

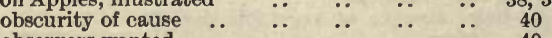

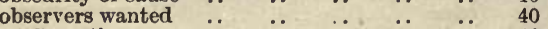

on Carnations ... ...

possibility of a micro-parasite connected with.. widespread

Stings of insects and Ripe-rot .. $\quad$. $\quad$.

Stomata and fungi.

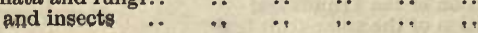

Stone-fruit Shot-hole, a function of the leaves trees, Leaf-curl of

Stone Pippin apple

Stora

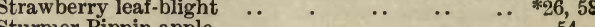

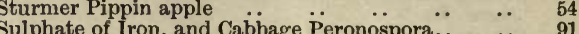

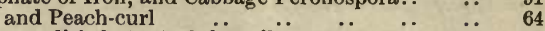

as a disinfectant of the soil..

for Root-rots

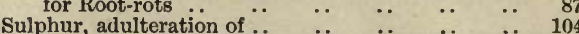

Sulphur and Lime for Peach Curl $\quad \ldots \quad \ldots \quad \ldots 65,66$

Summer

Sun as related to apple

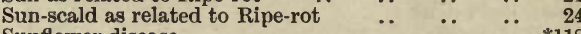

Sunflower disease .. $\quad \begin{array}{lllll}0 & \ldots & \ldots & \ldots & \end{array}$

Sunlight, strong, as related to spraying $\quad \ldots \quad$.. 24,25

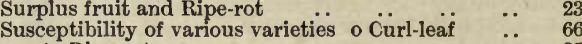
to Ripe-rot

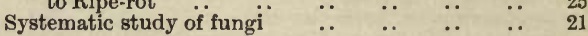

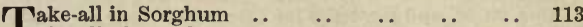

Tardy growth of the Gloeosporium due to unripeness of the host

Tar for the underground parts of fence-posts

Teleutospores of Puccinia coronata $\quad . \quad$. $\quad$.. $* 115$

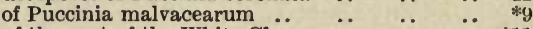

of the rust of the White Clover $\quad \ldots \quad$.. $\quad$.. $* 114$

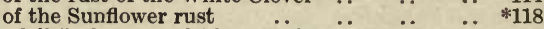

"Tendrils" of spores of Gloeosporium... $\quad$.. $\quad$.. 16

Terminology adopted in the case of the Ripe-rots ... 5

Testing Shot-holes for fungus parasites $\quad$.. $\quad$.. 49

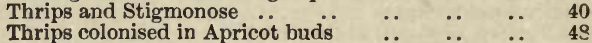

Thrips colonised in Apricot buds $\quad \ldots \quad$.. $\quad$.

$\begin{array}{lllllll}\text { in odd situations } & \cdots & \ldots & \ldots & \ldots & \ldots & 50\end{array}$

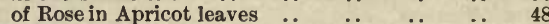

$\begin{array}{cccccc}\text { Thripsidae and Shot-hole } & \cdots & \cdots & \cdots & \cdots & 48 \\ \text { larval form associated with } & \text { Shot-hole, } & \ddot{\text { descrip- }} & 43,47\end{array}$ tion of

Timber-rots.

Toadstools and root disease of Larkspur and rot of timber and roots $\quad \ldots \quad \ldots \quad \ldots \quad 85$ $\begin{array}{llllll}\text { attacking fence-posts } & \text {.. } & \ldots & \ldots & \ldots & 85\end{array}$ $\begin{array}{ccccc}\text { Tomato, and Ripe-rot } & \cdots & \cdots & \cdots & 2,3, * 12,14 \\ \text { and Ripe-rot of Passion Fruit } & \cdots & \cdots & \cdots & 14\end{array}$ inoculated with Gloeosporium of $\ddot{A}$ pple that had passed through Plum No. 23 .. $\quad$.. $\quad$.. 12

$\begin{array}{lllllll}\text { Macrosporium } & \ldots & \ldots & \ldots & \ldots & \ldots & * 67 \\ \text { Rosette } & & & & & \ldots & 120\end{array}$

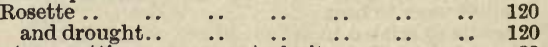

$\begin{array}{llll}\text { Tomatoes, rotting, a menace to fruit } \ldots & \cdots & \cdots & 23 \\ \text { Toughness of internal tissues as related to form of } & \end{array}$ spores, \&c.

of the skin of fruit as related to Ripe-rot

Treatment of Peach Curl from season to season

Trees going to decay through the attacks of toadstools

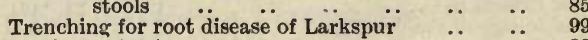

for root-rots $\quad \ldots \quad$.

Trifolium, rust of ...

$\begin{array}{lllll}\text { Triphragmium ulmariae (see final plates). } & & & \\ \text { Tufted Leaf-blight of the Vine .. } & \ldots & \ldots & \ldots & 86\end{array}$

$\begin{array}{llllll}\text { Turnips and Peronospora } & \ldots & \ldots & \ldots & \ldots & 91\end{array}$

T nited States, Banana Scab in . $\quad \ldots \quad \ldots 27$

Yedineae, illustrations of (see final plates).
Uredospore of the Sunflower rust $\ldots$$\quad \ldots \quad \ldots 118$

of Puccinia coronata.. $\quad . . \quad \ldots . \quad \ldots \quad \ldots * 115$

of the rust of White Clover... $\quad \ldots \quad$.. $\quad \cdots \quad$ *114

Uredo suaveolens (see final plates).

Uromyces appendiculatus (see final plates). caryophyllorum fabae (see final plates).

trifolii..

Ustilago bromivora

7

(1)


Wariability of the spores of Ripe-rot

ariation among Gloeosporia..

among Ripe-rots

of colour of spores in connection with change of host, No. 6 .. .. .. .. .

in spores of Gloeosporium, Figs. 22,23 , and 24 . in the form of spores of Gloeosporium, No. 6 .. in the size of spores of Gloeosporium due to variety of host $\quad . . \quad \ldots \quad$.. $\quad$.. $\quad$..

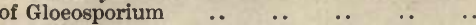
of Gloeosporium spores $\quad . \quad \ldots \quad \ldots \quad \ldots$
of the form of Ripe-rot spores, due to mechanical causes

Varieties of Apple and variation of the Gloeosporium of Peach and their relation to Peach Curl .. 66

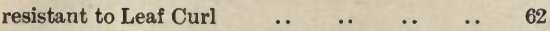

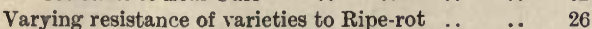
$\begin{array}{lllllll}\text { susceptibility of Roses } & \ldots & \ldots & \ldots & \ldots & 97\end{array}$

Vegetables, rotting, as related to Ripe-rot .. .. 23

Vehicles, special, use in connection with Ripe-rot .. 22

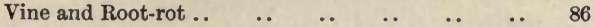

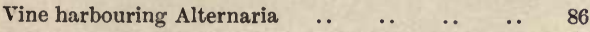

Vineyard posts attacked by toadstool fungi .. $\quad . . \quad 85$

W agga, Apples from, investigated.. PAGE.

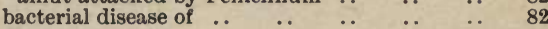
$\begin{array}{llllllll}\text { disease of } & \ldots & \ldots & \ldots & \ldots & \ldots & \ldots & 81\end{array}$ Phoma on

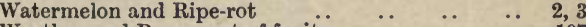

Weather and Brown-rot of fruit .. ..

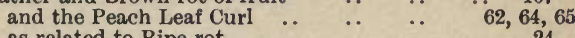
as related to Ripe-rot $\quad \ldots \quad$.. $\quad$.. $\quad \ldots \quad 24$

West Indies, Banana Scab in... $\quad \ldots \quad \ldots \quad \ldots 27$

Wet regions and Bordeaux Mixture $\quad \ldots \quad \ldots \quad \ldots \quad \ldots \quad 66$

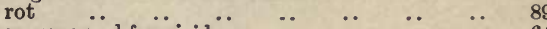
.. 646

White lead for disease of the bark $\quad \ldots \quad$.. $\quad$.. 6

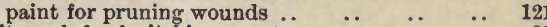

Whitewash for fruit bins..

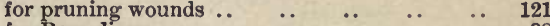
for Rose disease $\quad . . \quad \ldots \quad \ldots 98$

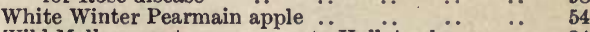

Wild Mallow, rust on, menace to Hollyhocks $\quad \ldots .94$

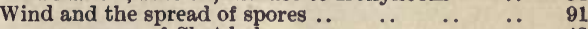
as a cause of Shot-hole ..

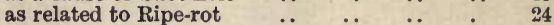

$\begin{array}{llllll}\text { Winter Peach apple } & \ldots & \ldots & \ldots & \ldots & \\ \end{array}$

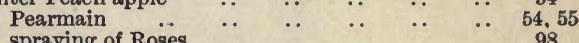
spraying of Roses $\quad \begin{array}{lllllll} & \ldots & \ldots & \ldots & \ldots & \ldots & 98\end{array}$

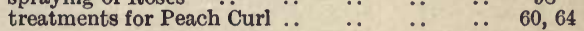

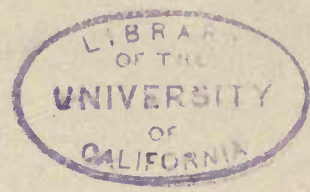

Sydney : William Applegate Gullick, Government Printer.-1904. 


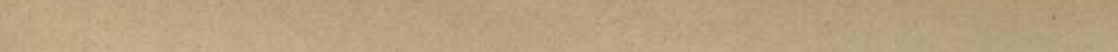

2015

Cingitis

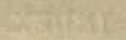

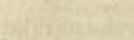


50. Gumming of Sugar cane Preliminary Report. Annual Report of th Department of Mines and Agriculture, Sydney, 1893.

51. Bulletin of the Royal Gardens, Kew, 1894. Contains a reprint of the above.

52. Revue Agricole et Journal de la Chambre d'Agriculture, Maurice, 1894.

Also contains a reprint of the above.

53. Nematodes, mostly Australian and Fijian. 59 pages, with 24 original illustrations in the text, and 125 orignal figures on seven lithographic plates. Macleay Memorial Volume, Linnæan Society of New South Wales, Sydney, 1893.

54. Host and Habitat Index of the Anstralian Fungi. 44 pages. Department of Agriculture, Sydney, 1893.

55. New Australian Fungi.

12 original illustrations in the text-Cyathus dimorphus, Tolyposyorium anthistivia. Agricultural Gazette, Sydney, 1893.

56. Reprint of the above.

Department of Agriculture, Sydney, 1893.

57. Tricoma and other new Nematode Genera.

33 pages, with 50 original illustrations in the text. Linnæan Society of New South Wales, Sydney, 1893.

58. Plant Diseases and their Remedies: Diseases of the Sugar-cane.

56 pages, with over 70 original illustrations in the text. Agricultural Gazette, Sydney, 1893.

59. Reprint of the above.

Department of Agriculture, Sydney, 1893.

Revie Agricole, Manrice, 1894.

60. Diseases of the Sugar-cane.

Special edition for the Queensland Department of Agriculture. Department of Agriculture, Brisbane, 1893.

Nematodes, mostly Australian and Fijian.

59 pages, with 24 original illustrations in the text, and 125 original tigures on seven lithographic plates, as reprinted by Agricultural Department, Sydney, 1893.

62. A new Australian Fungus.

Single page, with 2 original illustrations. Peziza lyonsia. Agricultural Gazette, 1894.

63. Reprint of the same.

Department of Agriculture, Sydney, 1894.

64. Notes on the Diseases of Plants.

11 pages, with 14 original illustrations in the text. Diseases of the bean, tomato, peach, and mango. Agricultural Gazette, Sydney, 1894.

65. Reprint of the same.

Department of Agriculture, Sydney, 1894.

66. Improving Wheats by Selection.

18 pages, 5 illustrations. Department of Agriculture, Sydner, 1894.

67. The Cause of Gumming in Sugar-cane.

7 pages, with 2 illustrations in the text. Agricultural Gazette, Sydney, 1895.

68. Reprint of the same.

Department of Agriculture, Sydney, 1895.

69. Notes on the Form and Size of the Grains in Different Varieties of Wheat.

7 pages. Agricultural Gazette, Sydney, 1895.

70. Reprint of the same.

Department of Agriculture, Sydney, 1895.

71. The Hot-air Treatment of Bunt or Stinking Smut.

2 pages. Agricultural Gazette, Sydney, 1896.

72. Diseases of Plants and their Remedies.

10 pages, with 13 illustrations in the text. Diseases of the squash, lemon, apple, coffee-plant. Agricultural Gazette, Sydney, 1896.

73. Reprint of the same.

Department of Agriculture, Sydney, 1896.

74. Notes on the Threshing of Wheat.

5 pages, no illustrations. Agricultural Gazette, Sydney, 1896.

75. Reprint of the same.

Department of Agriculture, Sydney, 1896.
76. The Hardness of the Grain in the principal varieties of Wheat.

22 pages, with 28 illustrations. Agricultural Gazette, Sydney, 1896.

77. Reprint of the same.

Department of Agriculture, Sydney, 1896.

78. The relative Hardness of Anstralian and American Fife Wheats.

8 pages, and 23 original illustrations in the text. Agricultural Gazette, Sydney, 1896.

79. Notes on the colour of the Grain in different Varieties of Wheat.

4 pages, no illustrations. Agricultural Gazette, Sydney, 1896.

80. Reprint of the same.

Department of Agriculture, Sydney, 1896.

81. The Common Crow.

14 pages, with 1 original illustration in the text. Agricultural Gazette, Sydney, 1896.

82. Reprint of the same.

Department of Agriculture, Sydney, 1896.

83. Experiment Work in Agriculture.

25 pages, with 49 original illustrations in the text. Agricultural Gazette, Sydney, 1896.

84. Reprint of the same.

Department of Agriculture, Sydney, 1896.

85. Cause of an important Apple Disease.

2 pagès, with one original figure in the text, and one original plate. Agricultural Gazette, Sydney, 1897.

86. Reprint of the same.

Department of Agriculture, Sydney, 1897.

87. Some useful Observations on Germinating Wheat.

3 pages, with one original coloured plate. Agricultural Gazette, Sydney, 1897.

88. Reprint of the same.

Department of Agriculture, Sydney, 1897.

89. A Method of Using the Microscope.

5 pages, with three original illustrations in the text. Agricultural Gazette, Sydney, 1897.

90 Reprint of the same.

Department of Agriculture, Sydney, 1897.

91. Letters on the Diseases of Plants.

54 pages, with nearly 100 orginal illustrations in the text, and one original plate. Disease of wheat, maize, plum, apple, potato, citrus fruits, peach, neetarine, grape, onion, timber, with an account of rootgall, and an im proved method of preparing Bordeaux mixture. Agricultural Gazette, Sydney, 1897.

92 Reprint of the same.

Department of Agriculture, Sydney, 1897.

93. Abandoned Orchards of Cumberland County.

7 pages, with about 40 original illustrations. Agricul. tural Gazette, Sydney, 1897.

34. Reprint of the same.

Department of Agriculture, 1897.

95. The Sheep-fluke.

40 pages, with 1 plate and about 30 original illustrations in the text. Agricultural Gazette, Sydney, 1897.

96. Reprint of the same.

Department of Agriculture, Sydney, 1897.

97. The Grading of Wheats.

8 pages, with about 50 illustrations in the text. Agricultural Gazette, Sydney, 1897.

98. Reprint of the same.

Department of Agriculture, Sydney, 1897.

99. The Brush of Wheat-grains.

4 pages, with 20 original illustrations in the text. Agricultural Gazette, Sydney, 1897.

100. Notes on Pests and Crops.

5 pages with 3 original illustrations in the text, and one plate. Agricultural Gazette, Sydney, 1898.

101. Reprint of the same.

Department of Agriculture, Syduey, 1898.

102. Some Tools nseful in Crop Experiment Work.

2 pages, with 7 original illustrations in the text. Agricultural Gazette, Sydney, 1898.

103. Reprint of the same.

Department of Agriv ulture, Sydney, 1898. 
104. Extract from MS. Report on the Parasites of Stock.

62 rages, with about 250 original inlustrations in the text. Agricalliend Gasatte, Syduey, 1898.

105. Reprint of the same.

Department of Arrieulture, Sydney, 1898.

106. Weight per Bushel of Australian Wheats. 6 pages and 1 illnstration. Agroultural Gasette, Sydney, 188.

107. Reprint of the same.

Department of Agricutare, 1898

108, Rattling Jack Wheat.

2 pases aud 1 coloured plate. Agrienllural Guzette, Sydner, 1898.

109. Reprint of the same.

Department of Agriculture, 1598

110. Grain Elevators.

8 pages thi 28 illustrations on 3 plates. Agneulturul Gazette, Syilney, 1900.

111. Reprint of the same. Depurtment of Agriculture, 1900.

112. Grain Elevators.

46 pages, with over 50 illustrations, mostly in the text. Agricultural Gazette, Sydney, 1901.

113. Reprint of the same.

Department of Agriculture, 1900. Also reprinted in Queensland Agrioultual Jowinal, Brisbane, 1 (12.

114. Woodiness of the Passion Fruit.

12 pages, with 18 illustrations in the text, and one plate: Agriculinal Giazcte, Syaney, 1c01.

115. Reprint of the same.

Department of Agriculture, 1901.

116. A Method of Using the Microscope.

Journil of the Royal Microscopieal Soclety, London, 1897.

117. Australian Free-living Marine Nematodes. 24 pages, no illustrations. Proclamations, Limman Suciety of N.S.W. Sydney, 1898.

118. Reprint of the same. F. Cunninghame \& Co., Sydney, 1898.

119. The Californian Wheat Industry. 32 pages, with 46 original illustrations in the text. Agricultural Gazette, Sydney, 1901.

120. Reprint of the same.

Department of Agriculture, Sydney, 1901.

121. New Eel-worm infesting the Roots of Passion vine.

3 pages, with 1 original illustration in the text. Agricuitural Gazette of New Sonth Wales, 1901.

122. Reprint of the same. Department of Agriculture, Sydney, 1901.

123. Foliage Areas of different varieties of Wheat. 1 page, no illustrations. Ayricultural Gazette, Sydney, 1501 .

124. Reprint of the same.

Department of Agriculture, Sydney, 1901.

125. Universal Nomenclatnre for Wheat.

75 pages, with 250 orighial illustrations, including 16 plutes. Agricultural Gazette, Sydney, 1901 to 1904.

126. Tomato Blights.

5 pages, with 3 original illustrations in the text. Agricultural Gazette, Sydney, 1902.

127. Reprint of the same.

Department of Agriculture, Sydney, 1902.

128. Comparative observations on the Brush of about fifty varieties of Wheat.

Agricultural Gazett, Sydney, 1902.

129. Reprint of the sane.

Department of Agriculture, Sydney, 1902.

130. Probable occurrence of Taenia ovilla in Australian Sheep.

1 pare, no illustrations. Agricultiral Gazette, Sydney, 1002 .
131. The Nematode Formula

8 pages, with 5 illustrations in the text. Agvicultion Gasette, Syaney, 1902.

132. Reprint of the same.

Department of Agriculture, Sydney, 1902.

133. Internal Strncture of the Gall-worm. 3 pages, with 4 original illustrations in the text Agricultural Gazdte, Sydney, 1902.

134. Reprint of the same. Department of Agriculture.

135. Rattling Tom Wheat. 1 page, with one original colonred plate. Agricultum Gazotte, Syaney, 1502.

136. Reprint of same. Depurtment of A griculture, Sydney, N.S.W

137. Seed Wheat: An investigation and discussion o the relative value as seed of large plump anc small shrivelled grains.

60 yages, with 32 original illustrations. Agricultura Gazette, Sydney, 1903.

138. Reprint of the same.

Department of Agriculture, Sydney.

139. Effect of Engine-boiler Steam on the Vitality Seeds and Spores.

4 pases, with 2 original illustrations. Avriculthen Gazette, Sydney, 1803.

140. Reprint of the same.

Department of Agriculture, Sydney, 1903.

141. A Handy Horse-power.

1 pase, with 1 original illnstration. Agrieultura Gazette, Sydney, 1:03.

142. Reprint of the same.

Department of Agriculture, Sydney, 150\%.

143. Letters on the Diseases of Plants, Second Series 135 pages, with over 150 original illustrattions; coloured plates : and 4 plates copied from variou authors. Agricultural Guzette, Sydney, 1903-4.

144. Reprint of the same. Department of Agriculture, Sydney, 1904.

145. Free-living Fresh-water New Zealand Nematodes 12 pages, with 7 original illustrations in the text Proceedings of the Cambridge Philosophiea Society, Vol. XII, Pt. V, Cambirige, 1؛04.

146. Quantitative Estimation of Disease Spores.

11 pages, with 5 original illustrations in the text Agricultuial Gazette, Sydney, $1: 04$.

147. Reprint of the same.

Department of Agriculture, Sydney, New South Wales.

148. The Sheep Fluke: Fluke Eggs as an Aid tc Quantitative Diagncsis in the Distomiasis of the Sheep.

12 pages, with 1 original illustration. Agricultura Gazelte, Sydney, $1: 04$.

149. Reprint of the same.

Department of Agriculture, Sydney, 1904.

TO APPEAR

150. Parasites as an Aid in Determining Organic Relationships.

5 pages. Agricultural Gazctte, Sydney, 1304.

151. Reprint of the same.

Department of Agriculture, Sydney, New South Wales, 1904.

152. Tape-Worms of Australia; a preliminary descrip tive notice.

30 pages, with 75 original illustrations. Agricultira Gazette, Sydney, 1904.

153. Reprint of the same.

Department of Agriculture, Sydney, 1904.

In preparation.

The Prevention and Cure of the Blights of Crops. With eereral bumdred origianl illustrations in the text, and numerout coloured plates.

Parasites of Sheep and other Domestic Animals (and incidentally of the Australian Land-fauna).

MOST OF THE ABOVE PUBLICATIONS CAN BE HAD FROM THE DEPARTMENT OF AGRICULTURE, SYDNEY NEW SOUTH WALES, EITHER FREE ON APPLICATION, OR AT PRICES FROM SIXPENCE UPWARDS. 


.

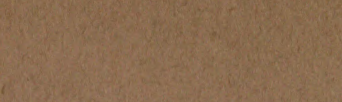
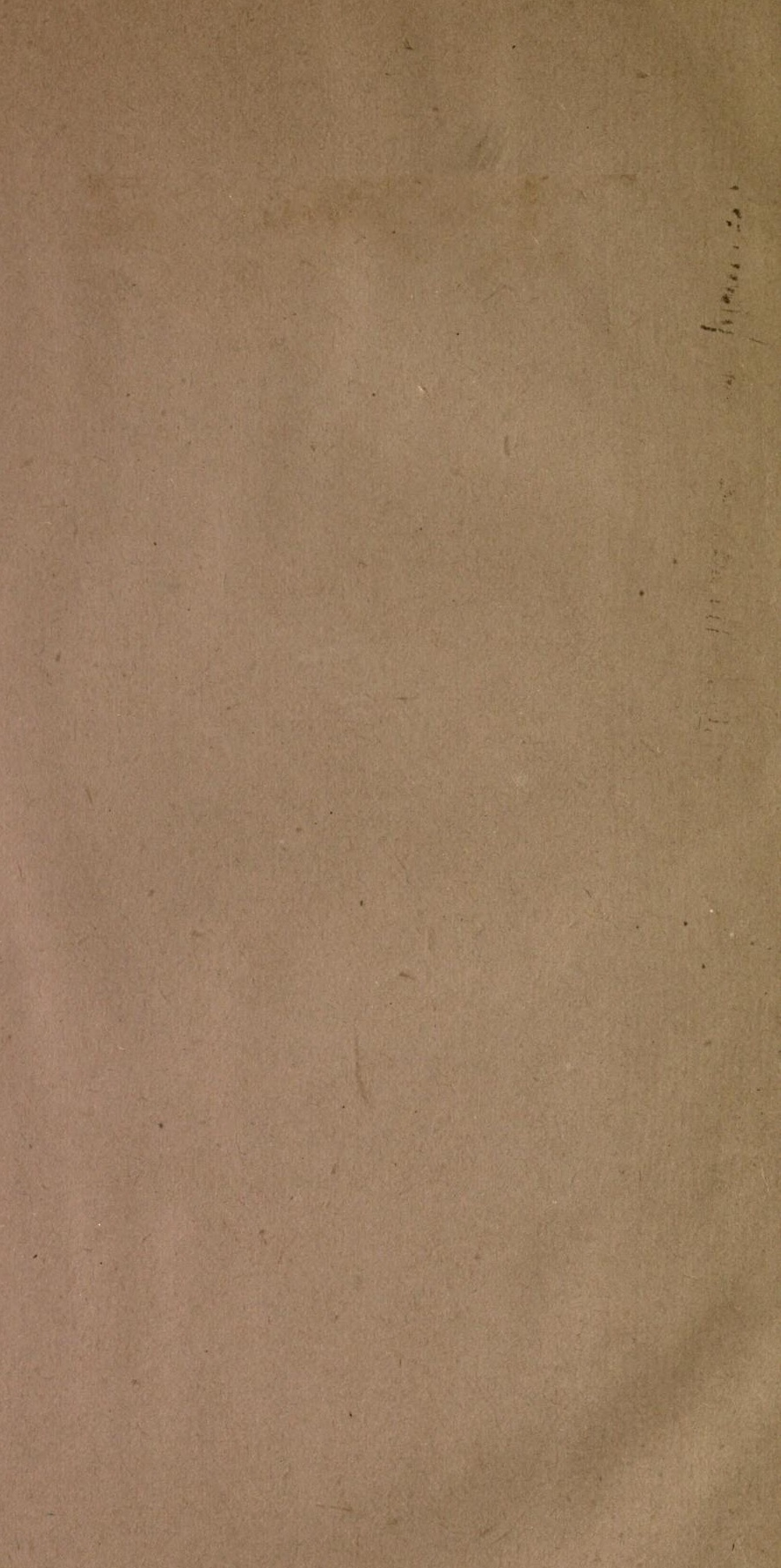
U.C. BERKELEY LIBRARIES

iniminininili

CO27366640
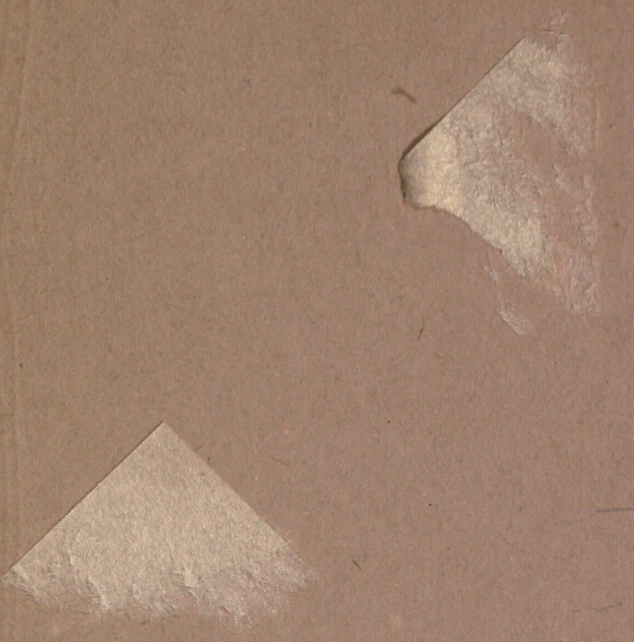
